\title{
Shocks Cambiarios y Competitivos en Países en Desarrollo
}

\author{
Andrés M. César* \\ Tesis para obtener el grado de Doctor en Economía \\ Doctorado en Economía \\ Facultad de Ciencias Económicas \\ Universidad Nacional de La Plata
}

Directora: Irene Brambilla ${ }^{\dagger}$

La Plata, Buenos Aires, Argentina

Agosto de 2018

*Becario Doctoral CONICET - CEDLAS - UNLP. E-mail: andresmcesar@gmail.com

${ }^{\dagger}$ CONICET - UNLP. E-mail: irene.brambilla@econo.unlp.edu 


\section{Resumen}

Esta tesis doctoral pretende contribuir fundamentalmente a la literatura de economía internacional desde la perspectiva de países en desarrollo. Los temas tratados se relacionan estrechamente con aquellas ramas de la literatura dedicadas a estudiar: (i) las grandes recesiones económicas; (ii) el traspaso a precios de las variaciones del tipo de cambio; y (iii) los vínculos entre el mercado laboral y el comercio internacional.

La tesis se divide en dos bloques sostenidos sobre un mismo modelo teórico. La primera parte se titula: "Ajustes de precio y calidad en respuesta a un shock en el tipo de cambio", y está dedicada a estudiar el comportamiento del mercado de bienes durante una etapa de contracción económica caracterizada por una reducción en el ingreso real de los consumidores (ocasionada por una depreciación real de la moneda) que altera la valoración relativa del precio y la calidad de los bienes. La contribución principal de esta parte consiste en identificar y cuantificar el canal composicional como una explicación adicional relevante para entender el traspaso incompleto de las devaluaciones hacia los precios internos. La segunda parte se titula: "Respuesta heterogénea de las firmas frente a un shock competitivo", y está orientada a estudiar el efecto que provoca un aumento en la intensidad competitiva proveniente del comercio internacional en distintos márgenes de ajuste de las firmas domésticas. La contribución más importante de esta parte de la tesis consiste en cuantificar la magnitud de este fenómeno. Se desprenden implicancias para comprender la dinámica del mercado laboral en el corto plazo y la evolución de la productividad agregada de la economía.

Específicamente, en la primera parte se estudia la respuesta de una firma que vende un producto diferenciado frente a un shock negativo en el ingreso real de los consumidores. Una caída en el ingreso real hace que los consumidores valoren más el dinero disponible (y por tanto el precio) y se preocupen menos por la calidad del producto que consumen. Esto genera un aumento en la demanda de aquellos productos de menor precio y calidad relativa. Al mismo tiempo, la respuesta óptima de la firma combina una reducción del margen de ganancia con una disminución en la calidad del producto ofrecido.

Para evaluar la validez empírica de esta proposición teórica se estudian doce episodios de crisis cambiarias en países en desarrollo. Dichas crisis se materializan en una depreciación real de la moneda de magnitud considerable seguida por una fuerte contracción del volumen de importaciones. La devaluación sirve como un experimento que ocasiona una disminución plausiblemente exógena en el ingreso real promedio (medido en 
moneda extranjera) de los consumidores domésticos. Los hallazgos empíricos confirman la intuición económica. Todos los episodios estudiados se caracterizan por un notable efecto composicional en la canasta de importables en los años que siguen a la devaluación. Los resultados muestran una reducción significativa en los precios (medidos en dólares en aduana) y en la calidad estimada de los productos importados. A su vez, aumenta la participación de las variedades de menor precio/calidad relativa en el valor total importado de cada producto.

Estos hechos estilizados motivan el desarrollo de un modelo estructural con el objetivo de cuantificar el ajuste del mark-up y la calidad de los productos importados en respuesta a un shock negativo en el ingreso real. Se asume que las firmas internacionales venden un producto diferenciado en un régimen de competencia monopolística, eligiendo el precio y la calidad en pos de maximizar sus beneficios. El costo marginal es estrictamente creciente y convexo en calidad. Los consumidores eligen aquel producto que les provee la mayor utilidad, están dispuestos a pagar más por una variedad de mayor calidad y esta disposición a pagar es creciente en el nivel de ingresos (hay un trade-off entre precio y calidad). A partir de este modelo, se estiman los parámetros de la ecuación de demanda y de la función de costos de las firmas utilizando microdatos correspondientes al universo de productos importados por Argentina durante el período 1999-2004.

El modelo permite cuantificar la importancia relativa de los distintos canales de ajuste en respuesta a un cambio en alguno de los parámetros estimados. La notable caída del ingreso real (medido en dólares) derivada de la depreciación real del peso argentino reduce la disposición a pagar de los consumidores domésticos. El cambio en este parámetro tiene dos efectos en términos de la estática comparada del modelo: un ajuste de mark-up y una reducción de calidad por parte de la firma. A partir de las ecuaciones del modelo se simulan precios, calidades y niveles de demanda contrafactuales en los dos equilibrios (pre y post reducción del ingreso real) manteniendo constantes el resto de los parámetros (e.g. costos de la firma). Se calcula un índice de precios a nivel producto que se puede descomponer en tres canales: (i) ajuste de mark-ups, (ii) ajuste de calidad, y (iii) efectos composicionales. El modelo hace un buen trabajo en la predicción de la distribución de los cambios de precio. Los resultados sugieren que en promedio, el ajuste de la calidad de cada variedad da cuenta de un 50-57\% de la reducción de precios a nivel producto, el cambio composicional explica un 31-41\%, y la reducción de mark-ups explica un 10-17\%.

Estos resultados sugieren que el ajuste en la calidad de los bienes es el canal más importante para explicar el traslado incompleto de la devaluación hacia el precio de los 
bienes importados medidos en aduana (exchange-rate pass-through). Este canal de ajuste comercial ha sido poco explorado en la literatura. Si bien la intuición microeconómica es sencilla, las implicancias son relevantes para entender algunos fenómenos macroeconómicos que la literatura ha denominado como enigmas, asociados al efecto de las devaluaciones en la economía real o al traslado incompleto de las devaluaciones hacia los precios domésticos.

La segunda parte de la tesis está orientada a estudiar el comportamiento de las firmas y del mercado laboral durante una etapa en la cual se produce un shock exógeno asociado al mercado de bienes (e.g. gran aumento en la productividad de una firma, cambio tecnológico, aparición de nuevos productos que sustituyen anteriores, aumento en la participación de mercado de firmas extranjeras, etc.). El modelo desarrollado en la primera parte predice que un shock competitivo de esta índole afecta de manera diferencial la participación de mercado de las firmas domésticas en función de sus capacidades (e.g. productividad, calidad). La intuición es simple. Una mayor participación de mercado satisfecha por determinadas firmas (e.g. extranjeras) implica una menor participación cubierta por otras firmas (e.g. domésticas), ceteris paribus. La pérdida de mercado experimentada por una firma doméstica es decreciente en su nivel de productividad/calidad. Las firmas afectadas enfrentan una reducción de sus ingresos por ventas, disminuyen la demanda laboral, y eventualmente salen del mercado. De esta predicción se derivan dos implicancias importantes, cuya evaluación empírica se encuentra al margen del presente trabajo. Primero, se produce cierta reasignación de factores productivos que altera el equilibrio de mercado, genera ganadores y perdedores, y afecta la distribución del ingreso de la economía. Por su parte, el hecho de que las firmas menos productivas salgan del mercado aumenta la productividad agregada de la economía.

Las predicciones teóricas se ponen a prueba empíricamente utilizando (i) microdatos de comercio internacional y (ii) microdatos provenientes de un censo industrial de manufacturas que permite observar a las mismas firmas a lo largo del tiempo. El objetivo es identificar y estimar el efecto causal de un shock competitivo sobre los resultados antes mencionados, en pos de cuantificar la magnitud económica de dicho shock. La estrategia de identificación utiliza el crecimiento de las importaciones de manufacturas provenientes de un país de salarios bajos (China) que ha experimentado un notable crecimiento de la productividad total de los factores durante las últimas décadas. La idea es estudiar la respuesta (heterogénea) de corto plazo de las firmas domésticas de un país en desarrollo (en este caso Chile) frente a este shock de competencia internacional.

Los resultados sugieren que las firmas más expuestas al crecimiento de la penetración 
de importaciones de China disminuyen las ventas de productos manufacturados, reducen la cantidad de trabajadores, y enfrentan una mayor probabilidad de salir del mercado, en relación a firmas comparables en otras industrias del mismo sector menos expuestas a este shock. Los efectos estimados son significativamente más pronunciados para aquellas firmas inicialmente menos productivas (2-3 veces mayores). La magnitud económica de los resultados sugiere que este canal explica buena parte de la dinámica de las firmas y de la respuesta del mercado laboral a corto plazo. Si bien hay una incipiente literatura dedicada a estudiar estos fenómenos en países desarrollados, la evidencia para economías en desarrollo es escasa. Los resultados están en línea con la literatura que muestra que los costos de ajuste se distribuyen de manera desigual a través de distintas industrias, regiones, firmas y trabajadores. 


\section{Agradecimientos}

Quiero agradecer especialmente a Irene, por iniciarme en el camino de la investigación científica, por sus valiosas ideas, consejos, recomendaciones y aliento a lo largo de todo este fructífero proceso de tesis. A las autoridades del Comité de Doctorado de la Universidad Nacional de La Plata, por sus importantes aportes y sugerencias durante los seminarios del Doctorado. A mis compañeros de Maestría/Doctorado, colegas y amigos del Centro de Estudios Distributivos, Laborales y Sociales, por acompañarme, orientarme y ayudarme a lo largo de todos estos años. Quiero agradecer el apoyo económico-financiero recibido a través de una beca doctoral otorgada por el Consejo Nacional de Investigaciones Científicas y Técnicas. Agradezco todas las sugerencias y comentarios recibidos por distintos colegas en congresos y reuniones científicas donde expuse distintos fragmentos de esta tesis. A los alumnos y profesores del Departamento de Economía de Brown University, a quienes conocí durante mi estadía en Providence, por sus enseñanzas, el interés que mostraron en mi trabajo y la motivación que despertaron en mi. A mi familia, por apoyarme en todo momento, especialmente cuando dejé de formar parte de nuestro hogar juninense allá por dos mil siete, momento en que comenzaba la maravillosa etapa de estudiante universitario platense. A María Cruz, por su cariño y apoyo incondicional. 


\section{Contents}

I PRIMERA PARTE:

Ajustes de precio y calidad en respuesta a un shock en el tipo de cambio

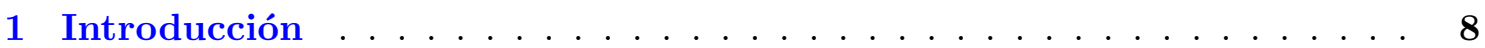

2 Antecedentes y literatura relacionada . . . . . . . . . . . . 16

2.1 Teoría de la Paridad de Poder Adquisitivo . . . . . . . . . . . . . . . 18

2.2 Pass-through . . . . . . . . . . . . . . . . . 20

2.3 Estado actual de la discusión . . . . . . . . . . . . . . 26

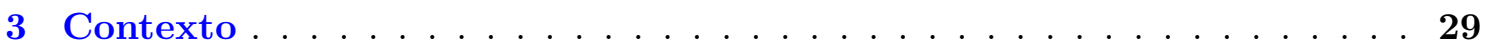

3.1 Crisis cambiarias . . . . . . . . . . . . . . . . . . . . 29

3.2 Crisis Argentina . . . . . . . . . . . . . . . . . 34

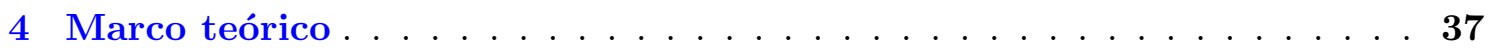

4.1 Consumidores . . . . . . . . . . . . . . . . . . . . 38

4.2 Firmas . . . . . . . . . . . . . . . . . . . 41

4.3 Shock en el tipo de cambio real . . . . . . . . . . . . . . . . . 43

4.4 Índices de precios contrafácticos . . . . . . . . . . . . . . . . . . 43

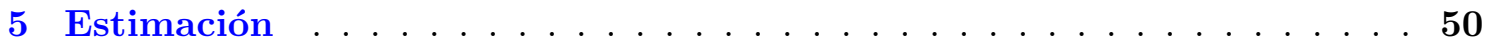

5.1 Fuentes de información . . . . . . . . . . . . . . . . . . 50

5.2 Parámetros de demanda . . . . . . . . . . . . . . . . . . . 52

5.3 Parámetros de costos . . . . . . . . . . . . . . . . 58

6 Resultados . . . . . . . . . . . . . . . . . . . . . . . . 60

6.1 Estadísticas descriptivas . . . . . . . . . . . . . . . . 61

6.2 Disminución de precios . . . . . . . . . . . . . . . . . . . . 64

6.3 Estimación de demanda . . . . . . . . . . . . . . . . . . 68

6.4 Reducción de calidad . . . . . . . . . . . . . . . . . . . . . . 74

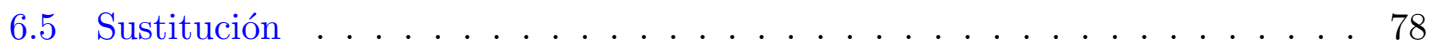

6.6 Calidad y PBI per cápita . . . . . . . . . . . . . . . . . . . 81

6.7 Estimación de costos . . . . . . . . . . . . . . . . . . . 84

6.8 Costos y PBI per cápita . . . . . . . . . . . . . . . . . . 86

6.9 Descomposición del índice de precios . . . . . . . . . . . . . . . 87

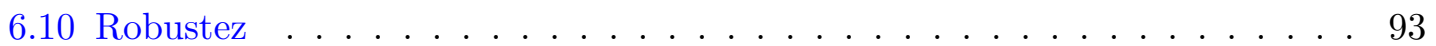

7 Comentarios finales . . . . . . . . . . . . . . . . . 101

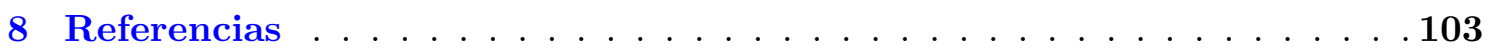

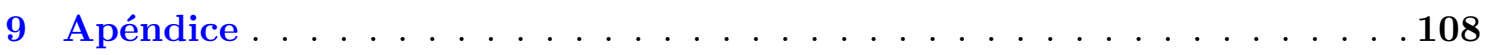


9.1 Demostraciones . . . . . . . . . . . . . . . . . . . . . . . . 108

9.1.1 Solución del modelo . . . . . . . . . . . . . . . . . . 108

9.1.2 Derivación de la ecuación de demanda . . . . . . . . . . . . . . . 109

9.2 Cuadros . . . . . . . . . . . . . . . . . . . . . . 111

9.3 Figuras . . . . . . . . . . . . . . . . . . . 116

9.4 Sesgo de sustitución . . . . . . . . . . . . . . . . . . . . . 123

\section{SEGUNDA PARTE:}

Respuesta heterogénea de las firmas frente a un shock competitivo $\mathbf{1 2 5}$

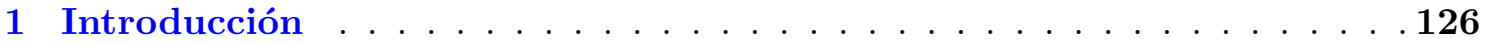

2 Antecedentes y literatura relacionada . . . . . . . . . . . . . . 135

2.1 Efectos del comercio, la globalización y el progreso tecnológico . . . . . . 135

2.1.1 Productividad y estructura organizacional . . . . . . . . . . . . 137

2.1.2 Salarios y distribución del ingreso . . . . . . . . . . . . . . . . . . 144

2.1.3 Empleo y transiciones laborales . . . . . . . . . . . . . . . . . . . 149

2.1.4 Costo de vida y bienestar . . . . . . . . . . . . . . . 155

2.2 Estimación de funciones de producción . . . . . . . . . . . . . . . 158

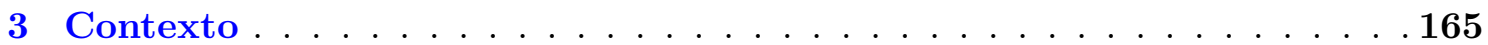

3.1 Chile . . . . . . . . . . . . . . . . . . . . . 165

3.2 China . . . . . . . . . . . . . . . . . . 166

3.3 Crecimiento en la PI China como un shock competitivo . . . . . . . . . 167

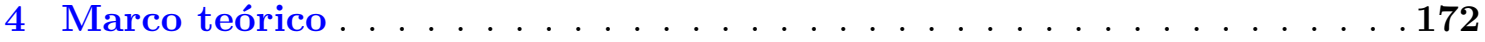

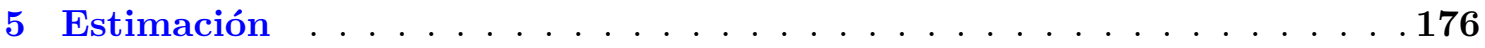

5.1 Fuentes de información . . . . . . . . . . . . . . . . . . 176

5.2 Estadísticas descriptivas . . . . . . . . . . . . . . . . 178

5.3 Estrategia empírica . . . . . . . . . . . . . . . . . . . . 180

6 Resultados . . . . . . . . . . . . . . . . . . . . . . . . 190

6.1 Estimación base . . . . . . . . . . . . . . . . . . . . . 190

6.2 Efectos heterogéneos . . . . . . . . . . . . . . . . . . . 195

6.3 Magnitud económica . . . . . . . . . . . . . . . . . . . 200

6.4 Pruebas de robustez . . . . . . . . . . . . . . . . . . . . 202

7 Comentarios finales . . . . . . . . . . . . . . . . . . . 204

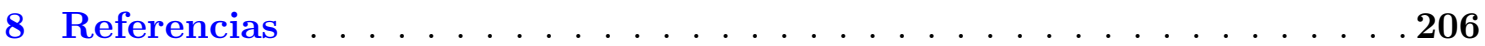

9 Apéndice . . . . . . . . . . . . . . . . . . . . . . . 214

9.1 Cuadros . . . . . . . . . . . . . . . . . . . . . . . . 214

9.2 Figuras . . . . . . . . . . . . . . . . . . . . . . . 222 


\title{
PRIMERA PARTE
}

\author{
Ajustes de precio y calidad en respuesta \\ a un shock en el tipo de cambio
}




\section{Introducción}

Las crisis económicas son fenómenos recurrentes en la historia moderna. Si bien la probabilidad de enfrentar una crisis suele ser mayor en países en vías de desarrollo, la reciente crisis financiera internacional deja en evidencia que las economías desarrolladas no están exentas de tales eventos. La literatura de macroeconomía internacional realizó considerables avances que permitieron tipificar y comprender buena parte de las causas y consecuencias de los distintos episodios. En general, las crisis que afectan a países en desarrollo se caracterizan por grandes contracciones de los ingresos reales, reducciones significativas de la productividad total de los factores, depreciaciones del tipo de cambio real y colapsos de las importaciones. Este trabajo muestra que el ajuste en la calidad de los bienes es un mecanismo que está presente en todos los episodios de este tipo. La intuición es simple: los ingresos reales disminuyen durante la crisis y los consumidores/productores reducen la demanda/oferta de calidad. El mecanismo de ajuste en la calidad no solo tiene implicaciones en términos de bienestar sino que es relevante para el entendimiento de fenómenos macroeconómicos muy estudiados en la literatura, como el efecto de las devaluaciones en la economía real o el traslado incompleto de las devaluaciones hacia los precios domésticos.

Si bien existen explicaciones complementarias para el fenómeno de pass-through incompleto, no existe un claro consenso respecto a la importancia relativa de los distintos mecanismos. El argumento más intuitivo se relaciona con la presencia de bienes y servicios no transables que forman parte del costo final de los bienes importados (e.g. costos de transporte, almacenamiento, financiación, seguros, marketing, venta al por mayor y por menor, etc), cuyo precio en moneda local no debería cambiar en respuesta a una devaluación (Burstein, Neves y Rebelo (2003); Campa y Goldberg (2005, 2010)). La segunda explicación parte de suponer una estructura de competencia imperfecta en el mercado local y/o internacional, donde las firmas eligen óptimamente diferentes precios para un mismo producto en función de las condiciones específicas de cada mercado/región. Este fenómeno se conoce como pricing-to-market (Krugman (1987); Dornbusch (1987)). El poder de mercado de las firmas les permite ajustar estratégicamente sus márgenes de ganancia frente a variaciones de costos/ingresos para mantener o aumentar su participación en determinado mercado, y por tanto amortiguar el traslado a precios de las variaciones del tipo de cambio (Knetter (1993); Bergin y Feenstra (2001); Atkeson y Burstein (2008)). Una tercera explicación se relaciona con la existencia de costos de ajuste o rigideces 
nominales de precios que se hayan expresados en moneda doméstica (Devereux y Engel (2002); Bachetta y van Wincoop (2003); Gopinath y Itskhoki (2010)).

Esta tesis desarrolla una explicación complementaria a las que ha propuesto la literatura, situando a la calidad en el centro de la escena. Se estudia el comportamiento del mercado de bienes durante una etapa de contracción económica caracterizada por una reducción del ingreso real de los consumidores (ocasionada por una depreciación real de la moneda) que altera la valoración relativa del precio y la calidad de los bienes. Se analiza la respuesta de una firma que vende un producto diferenciado y por tanto opera en un entorno de competencia imperfecta. Una caída en el ingreso real de los consumidores hace que estos valoren más el dinero disponible (y por tanto el precio) y se preocupen menos por la calidad del producto que consumen. Ello genera un aumento en la demanda relativa de aquellos productos de menor precio y menor calidad. Al mismo tiempo, la respuesta óptima de la firma combina una reducción del márgen de ganancia con una disminución en la calidad del producto ofrecido. La contribución principal de este trabajo se sustenta en la identificación y cuantificación del canal composicional como una explicación adicional relevante para entender el traspaso incompleto de las devaluaciones hacia los precios internos.

En los últimos años, el fenómeno calidad recibió muchísima atención por parte de literatura. La idea original de Linder (1961) de que países de mayores ingresos consumen y exportan bienes de mayor calidad es avalada por trabajos recientes (Schott (2004); Hummels y Klenow (2005); Hallak (2006)). La calidad se incorporó en modelos teóricos de crecimiento (Grossman y Helpman (1991); Kremer (1993)), en el estudio de fenómenos distributivos asociados al comercio internacional (Goldberg y Pavcnik (2007); Verhoogen (2008)), en el estudio de los efectos del comercio con países de salario bajo sobre los mercados domésticos (Khandelwal (2010)), y más recientemente, en fenómenos asociados a la discriminación de calidad en firmas multi-producto (Manova y Zhang (2012)). Existen diversos trabajos en la literatura que al igual que esta tesis, utilizan modelos de estimación estructural para cuantificar la importancia relativa de las distintas explicaciones del fenómeno de pass-through incompleto (e.g. Hellerstein (2008); Nakamura y Zerom (2010); Hellerstein y Villas-Boas (2010); Goldberg y Hellerstein (2013)), pero ninguno de ellos incorporó la calidad como un canal o factor de ajuste relevante. El objetivo principal de esta tesis es rellenar esta brecha en la literatura.

Para evaluar la validez empírica de la hipótesis teórica planteada se examinan doce episodios asociados a crisis económicas en países en desarrollo, caracterizados por una depreciación real de la moneda y una contracción en el volumen de importaciones. 
La devaluación se utiliza como un cuasi-experimento que ocasiona una disminución (plausiblemente exógena) en el ingreso real promedio de los consumidores domésticos (medido en moneda extranjera). ${ }^{1} \quad$ Los hallazgos empíricos confirman la intuición económica. Todos los episodios estudiados se caracterizan por un notable efecto composicional en la canasta de importables. El precio de los productos importados (medidos en dólares en aduana) se reduce en los años que siguen a la depreciación real de la moneda ( $21 \%$ en promedio), y también disminuye la calidad estimada de los productos importados $(0,10$ desvíos estándar con respecto a la calidad promedio inicial en la industria a la que pertenece cada variedad). ${ }^{2}$ Asimismo, aumenta (disminuye) la participación de las variedades de menor (mayor) precio/calidad relativa en el valor total importado de cada producto.

Estos hechos estilizados motivan el desarrollo de un modelo estructural que tiene fundamentalmente dos objetivos. Primero, ilustrar simplificadamente la hipótesis de este trabajo. Segundo, servir de base para la estimación econométrica. Se propone un modelo de equilibrio parcial donde cada producto está compuesto por un conjunto de variedades verticalmente diferenciadas. Por el lado de la oferta, cada firma internacional produce sólo una de las variedades de un producto diferenciado, en un mercado caracterizado por competencia monopolística. Por el lado de la demanda, cada consumidor elige aquella variedad que le provee una mayor utilidad indirecta. Se asume que las variedades importadas se venden directamente a los consumidores. Se asume la existencia de un equilibrio en estrategias puras Bertrand-Nash donde cada firma elige un precio y una calidad en equilibrio. En este modelo se presenta un trade-off entre precio y calidad. Cuando se produce una caída del ingreso real de los consumidores disminuye la disposición a pagar, pues aumenta la valoración marginal del ingreso disponible (lo que equivale a valorar relativamente menos la calidad). Como consecuencia, las firmas tienen el incentivo de ajustar a la baja sus márgenes de ganancia y la calidad del producto que ofrecen. ${ }^{3}$ El cambio en ingresos, precios y calidades afecta la demanda relativa de cada firma produciéndose además un efecto composicional: para un mismo producto se sustituyen

\footnotetext{
${ }^{1}$ Varios trabajos utilizan episodios devaluatorios como experimentos que permiten identificar variaciones exógenas en la oferta/demanda de las firmas (e.g. Abowd y Lemieux (1993); Verhoogen (2008)). A su vez, el tipo de cambio real se utiliza como variable instrumental en un amplio rango de trabajos empíricos que justifican su validez en la exogeneidad de dicho precio para el conjunto de firmas y/o consumidores (e.g. Revenga (1992); Brambilla, Lederman y Porto (2012)).

${ }^{2}$ Las medidas de calidad utilizadas en este trabajo se obtienen a partir de la estimación de un sistema de demanda de elección discreta. En este contexto, la calidad es entendida como un fenómeno puramente subjetivo y se vincula directamente con las elecciones que hacen los consumidores.

${ }^{3}$ Es probable que las firmas internacionales ofrezcan una amplia gama de variedades de un mismo producto, de manera que la traducción al mundo real de una caída en la calidad podría vincularse, por ejemplo, con un aumento en la participación de segundas marcas y/o modelos de menor calidad relativa.
} 
variedades de precio/calidad alto por variedades de precio/calidad bajo. El resultado final es una reducción en el precio de los productos importados medido en dólares, que actúa como un atenuante adicional de la suba de precios de estos mismos productos expresados en moneda local. La estimación de los parámetros estructurales del modelo permite cuantificar la importancia relativa de los distintos mecanismos. A partir de las ecuaciones del modelo se simulan precios, calidades y niveles de demanda contrafactuales en los dos equilibrios (pre y post reducción del ingreso real) manteniendo constantes el resto de los parámetros (e.g. costos de la firma). Luego es posible calcular un índice de precios a nivel producto y descomponer la variación que experimenta en respuesta a un shock negativo en el ingreso real en tres canales: (i) ajuste de mark-ups, (ii) ajuste de calidad, y (iii) efectos composicionales.

Los parámetros de la ecuación de demanda y de la función de costos de las firmas internacionales se estiman utilizando microdatos correspondientes al universo de productos importados por Argentina durante el período 1999-2004. Las características excepcionales de la crisis Argentina de 2001-2002 la transforman en un cuasi-experimento histórico y económico significativo, lo que aumenta la credibilidad del ejercicio realizado. La estrategia de identificación parte de suponer la exogeneidad de este shock devaluatorio para el conjunto de firmas internacionales que exportan a la Argentina.

El principal set de datos utilizado para realizar estas estimaciones proviene del Departamento de Pedidos Especiales del Instituto Nacional de Estadísticas y Censos (INDEC) de Argentina. Consiste en un panel de datos de aduana del universo de productos importados durante el período 1999-2004. Actualmente, este tipo de datos está disponible para un amplio conjunto de países. Los datos incluyen información anual del valor libre a bordo (Free-On-Board o FOB) y del valor costo-seguro-flete (Cost-Insurance-Freight o CIF), cantidades, países de origen y códigos de producto desagregados a 8 dígitos según la clasificación internacional del Sistema Armonizado (SA). Siguiendo la práctica estándar en la literatura se utiliza el valor unitario (valor CIF dividido por la cantidad) como proxy del precio. La segunda fuente de información proviene de la base de datos COMTRADE (recopilada por Naciones Unidas). Esta base contiene flujos bilaterales de comercio internacional para un amplio conjunto de países con un nivel de desagregación de 6 dígitos del SA. Los datos de COMTRADE se utilizan para (i) describir el ajuste de precios, calidad y cambio composicional presente en los doce episodios devaluatorios estudiados, y (ii) construir variables instrumentales para el precio en la ecuación de demanda.

Para estimar los parámetros de la demanda y la calidad se utiliza un sistema de 
demanda multinomial nested logit, siguiendo la contribución seminal de Berry (1994) a la literatura de estimación de demanda en modelos de elección discreta. En este enfoque, la calidad se define como el componente vertical del modelo y tiene una definición estructural asociada a la valoración promedio que asignan los consumidores a cada variedad. Intuitivamente, la calidad de una variedad es la fracción de su participación de mercado (en la industria correspondiente) que no es explicada por su precio. La ventaja principal de este enfoque es que las medidas estimadas de calidad son comparables entre países y a través del tiempo. Sin embargo, es importante mencionar que esta manera de inferir calidad no permite separar la tecnología incorporada en un producto de la valoración heterogénea que tienen los consumidores por este u otros atributos asociados a la calidad. Dado que el set de datos principal (INDEC) no incluye características observables de los productos importados, se explota la dimensionalidad del panel especificando un componente de calidad invariante en el tiempo con efectos fijos a nivel producto, al cual se suma el desvío temporal respecto a este promedio a partir de un efecto fijo año-país de origen. Dado que los precios están potencialmente correlacionados con el componente no observado de la calidad, se utilizan variables instrumentales para identificar los parámetros del modelo. ${ }^{4}$

Para estimar los parámetros de costos se supone cierta forma funcional para el costo marginal de las firmas exportadoras. Se asume que los costos marginales son crecientes y convexos en calidad, y que las firmas operan en un mercado caracterizado por competencia monopolística, de modo que son lo suficientemente pequeñas tal que sus decisiones de precio y calidad no afectan las elecciones de otras firmas. Se asume una función de costos derivada de una tecnología de producción de coeficientes fijos que combina una cantidad fija de determinados insumos (e.g. trabajo) con una tecnología dada para producir calidad (e.g. capital). Luego se resuelve el problema de optimización de la firma y se obtiene el precio y la calidad de equilibrio. Dado que las condiciones de primer orden dependen del precio, los parámetros de la demanda y la calidad estimada, es posible invertir estas funciones en pos de calibrar dos parámetros de la función de costos de cada firma (y el modelo está exactamente identificado). Una vez obtenidos los parámetros de la ecuación de demanda y los parámetros de la función de costos de cada firma es posible realizar el ejercicio contrafactual. Se simula el precio, la calidad y la demanda de cada variedad importada y se construye un índice de precios a nivel producto. La devaluación provoca un shock negativo en los ingresos reales medidos en dólares y reduce de la disposición a

\footnotetext{
${ }^{4}$ Khandelwal (2010) y Amiti y Khandelwal (2013) utilizan un enfoque similar para estimar la calidad de los productos importados por Estados Unidos.
} 
pagar de los consumidores. Este cambio se estima paramétricamente en la ecuación de demanda. Luego se computan distintos índices de precios ajustando (secuencialmente) el precio, la calidad y la demanda de cada variedad, a partir de los nuevos parámetros de la ecuación de demanda. Ello permite cuantificar la magnitud de cada mecanismo para explicar la reducción total en el precio de un producto.

Los resultados de la estimación de la demanda muestran que la utilidad marginal del ingreso de un consumidor representativo aumenta en promedio 5,5-5,9\% en los años que siguen a la devaluación del peso argentino. El modelo hace un buen trabajo en la predicción del cambio en el precio promedio de los productos importados. Los resultados de este ejercicio sugieren que el ajuste en la calidad de cada variedad explica (en promedio) alrededor del 50-57\% de la reducción total del precio de un producto, el efecto sustitución explica alrededor de $31-41 \%$ y el ajuste del mark-up explica un 10-17\%.

La existencia de shocks de costos/tecnológicos al interior de las firmas podría incomodar a la estrategia de identificación porque los parámetros de la función de costos son obtenidos a partir de una calibración que depende de los precios observados. En la sección de robustez se presenta una estrategia de identificación alternativa que utiliza el método de diferencias en diferencias con el objetivo de confirmar la reducción de precios de los productos importados por Argentina post devaluación, controlando por la posible existencia de shocks de costos/tecnología en la firma/país de origen. Para realizar este ejercicio se utilizan datos transaccionales de las aduanas de Argentina y Chile, que incluyen todas las transacciones de importación de un set limitado de productos (electrodomésticos y automóviles) durante el período 1999-2004. Esta data contiene información más detallada sobre las características de los bienes, con mayor grado de detalle en el caso de los automóviles importados (e.g. marca, modelo, motor, cantidad de puertas, aire acondicionado, etc.). Además de utilizarse como prueba de robustez, este ejercicio permite ilustrar más precisamente los mecanismos que resalta esta tesis. Además, dispara preguntas relacionadas con el poder de mercado y la política comercial que podrían extender esta línea de investigación en el futuro.

Antes de pasar a una revisión detallada de la literatura es importante mencionar algunos trabajos asociados con la hipótesis de esta tesis. Burstein, Eichembaum y Rebelo (2005) destacan que el ajuste rezagado y parcial en el precio de los bienes y servicios no transables es la explicación principal de las bajas tasas de inflación que se observan luego de los grandes episodios de devaluación. ${ }^{5}$ Realizan una serie de ejercicios para simular la

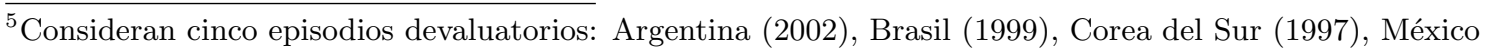


inflación real y obtienen resultados bastante acertados, pero no idénticos. Atribuyen las causas del desvío a dos factores: (i) un error de especificación por suponer que el sector de distribución es perfectamente competitivo; y (ii) "fly-from-quality", entendido como la sustitución hacia bienes locales de menor calidad que llevan a cabo los consumidores en la etapa posterior a las grandes devaluaciones. Para documentar este canal utilizan una encuesta de precios realizada en Buenos Aires y datos de scanner de supermercados recolectados por una empresa de investigación de mercado de Argentina. McKenzie y Schargrodsky (2005) encuentran resultados similares utilizando datos de consumo de alta frecuencia recolectados por LatinPanel, basados en un panel de 3.000 hogares argentinos. Los autores documentan un aumento de $7 \%$ en la frecuencia de shopping, en un proceso de búsqueda de precios para suavizar la crisis económica, y una disminución de 5 p.p. de la participación de las marcas de primera línea en el gasto total de los hogares. Esta tesis demuestra que el canal de ajuste en la calidad también opera al nivel de manufacturas importadas. Gopinath y Neiman (2014) sostienen que la reducción en el uso de insumos intermedios importados producido luego de la devaluación argentina del año 2002 es la explicación principal del colapso inmediato en la productividad de las firmas. En sus resultados descriptivos muestran que el cambio en el mix de insumos importados (variedades y países de origen) al interior de las firmas explica dos tercios de la reducción del valor importado entre 2000 y 2002; y que las grandes firmas ajustaron principalmente reduciendo, pero sin dejar de importar, los productos habitualmente traídos desde el exterior. ${ }^{6}$ En lugar de modelar las decisiones de utilización de insumos por parte de las firmas domésticas, esta tesis enfatiza una explicación por el lado de la demanda, siguiendo las contribuciones seminales a la literatura de estimación de demanda en modelos de elección discreta (Mc Fadden (1973); Berry (1994); Berry, Levisohn y Pakes (1995)). Este enfoque permite racionalizar el ajuste de calidad que se observa en las estimaciones y complementar las contribuciones previas asociadas a los grandes episodios devaluatorios, con hallazgos especialmente relevantes para la literatura de exchange-rate pass-through.

Esta parte de la tesis se estructura de la siguiente manera. El capítulo dos describe la evolución de las distintas ramas de la literatura relacionadas con este trabajo. El

\footnotetext{
(1994) y Tailandia (1997).

${ }^{6}$ Según los datos de Gopinath y Neiman (2014) (obtenidos de Datamyne), el número de firmas importadoras pasó de 15.000 a menos de 7.000 entre 2001 y 2002. Sin embargo, la contribución neta del proceso de entrada y salida de firmas explica menos de $12 \%$ de la caída de importaciones entre 2000 y 2002, con un patrón similar para el número de variedades importadas. Ello se debe al alto grado de concentración que exhibe el comercio internacional entre un pequeño número de firmas y sectores claves. La mayor parte del ajuste comercial (65\%) se explica por cambios en el mix de variedades importadas al interior de las firmas.
} 
capítulo tres se concentra en las crisis cambiarias, repasa algunas ideas de la literatura de macroeconomía internacional y presenta estadísticas descriptivas de los episodios estudiados. El capítulo cuatro desarrolla el marco teórico, eje fundamental de la tesis doctoral. Los datos y la estrategia de estimación se presentan en el capítulo cinco. Todos los resultados se presentan en el capítulo seis. El capítulo siete concluye con algunas ideas generales y plantea preguntas relevantes en la agenda de investigación. 


\section{Antecedentes y literatura relacionada}

El estudio de la relación entre precios y tipos de cambio tiene larga data en economía y es un clásico en la literatura de economía internacional. La manera de abordar el tema evolucionó considerablemente a lo largo del tiempo. La literatura pasó de un análisis macroeconómico, cuyo objetivo era evaluar los fundamentos de la teoría de monetarismo global, hacia el estudio de los ajustes externos, sobre todo a partir de la ruptura del sistema de Bretton Woods en 1971. Años más tarde, el debate se desplazó hacia el estudio de la validez de la Ley de Precio Único y de la Teoría de la Paridad de Poder Adquisitivo. A partir de las contribuciones seminales de Krugman (1987) y Dornbusch (1987), la literatura comenzó a enfatizar cuestiones de organización industrial relacionadas con la segmentación de mercados y la discriminación de precios entre regiones geográficamente distantes ("pricing-to-market"). Otras discusiones más recientes adoptan un enfoque de equilibrio general y analizan la influencia del fenómeno en la determinación de la política monetaria y los regímenes de tipo de cambio óptimos en pos de contribuir a la estabilización macroeconómica, teniendo en cuenta fenómenos globales como la transmisión internacional de shocks y la volatilidad de los flujos de capital y comercio.

Estudiar el vínculo entre ambas variables es de vital importancia para entender el comportamiento de la economía global y comprender con mayor exactitud situaciones económicas frecuentes que conectan y afectan el bienestar de distintos individuos a lo largo y ancho del planeta. ¿Qué impacto provoca una devaluación en la economía real? ¿Cuál es la respuesta de las firmas internacionales frente a shocks de costos/demanda vinculados a variaciones en los tipos de cambio? ¿Los shocks monetarios y cambiarios se propagan internacionalmente? ¿Cuáles son las consecuencias distributivas de estos episodios? son solo algunas de las tantas preguntas que se ha planteado la profesión y que se hayan íntimamente vinculadas al estudio de la relación entre precios y tipos de cambio.

El volumen de trabajos dedicados a estudiar la relación entre precios y tipos de cambio aumentó sostenidamente a lo largo del tiempo. ${ }^{7}$ La manera de abordar el tema evolucionó considerablemente dando lugar a distintos enfoques que abordan el tema desde distintas perspectivas. Conviene entonces distinguir las diferentes vertientes de la literatura para luego describir más detalladamante el estado actual de la discusión en

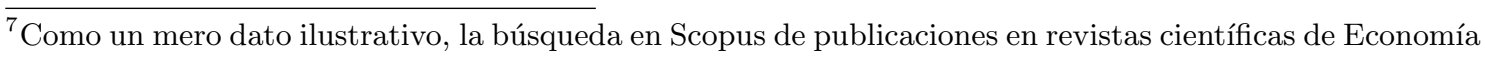
que contengan en el abstract al menos una de las siguientes combinaciones: "exchange-rate pass-through", "purchasing power parity" o "law of one price" muestra una tendencia creciente desde fines de los 70' y se acelera marcadamente a partir de los 90'. En el año 2010 se alcanza un máximo de 213 publicaciones.
} 
la cual se enmarca este trabajo.

Goldberg y Knetter (1997) destacan que la evolución de la literatura tiene que ver en parte con los cambios institucionales derivados del traspaso de un sistema de tipos de cambio fijo a uno flotante. En 1971 se produjo la ruptura del sistema de Bretton Woods, basado en la libre conversión a tasa fija de dólares por oro y en la obligación del resto de los países miembros a mantener sus tipos de cambio con el dólar dentro de una banda de fluctuación del 1\%. La consecuencia de esta ruptura fue el abandono del patrón oro por parte de las principales potencias económicas, quienes adoptaron un sistema de tipos de cambios fluctuantes. Por tal motivo, el volumen de trabajos empíricos dedicados a estudiar fenómenos asociados al tipo de cambio crece exponencialmente a partir de la década del 70'.8 La evolución de la literatura también se asocia con la emergencia de desarrollos teóricos vinculados a modelos de competencia imperfecta en economía internacional (Krugman (1987) y Dornbusch (1987)) que vinculan a esta literatura con aquella en organización industrial. Es posible añadir un tercer factor que tiene mayor relevancia a medida que pasa el tiempo. La creciente disponibilidad de microdatos permite analizar con mayor precisión y grado de detalle los patrones de comercio internacional, la estructura de competencia subyacente a los mercados locales e internacionales, las decisiones al interior de las unidades productivas y la heterogeneidad en los perfiles de demanda que enfrentan las firmas (específicos a cada país y contexto económico).

Este trabajo se enmarca fundamentalmente dentro de la literatura avocada al estudio del traslado a precios de las variaciones en el tipo de cambio (exchange-rate pass-through) para un país determinado. Esta vertiente de la literatura puede desglosarse a grosso modo en dos niveles de análisis. El primero se concentra en el traslado de variaciones del tipo de cambio hacia los precios de importación medidos en aduana, estudia el fenómeno de frontera (y es aquí donde se ubica el trabajo). El segundo estudia el grado de traslación de estas variaciones de precios de frontera hacia el conjunto de precios enfrentados por productores y consumidores. Naturalmente, las estimaciones del coeficiente de pass-through para este segundo nivel resultan siempre menores a las correspondientes para el primer nivel, pues las últimas incluyen cierto componente no transable expresado en moneda doméstica que a priori, no debería verse afectado por las variaciones del tipo de cambio. También es importante advertir que la magnitud del

\footnotetext{
${ }^{8}$ Las primeras contribuciones para Estados Unidos abordaron el tema del pass-through más bien de manera indirecta, pues su principal objetivo consistía en evaluar los efectos de las variaciones del tipo de cambio sobre la balanza comercial (Branson (1972); Magee (1974); Krugman y Baldwin (1987); entre muchos otros).
} 
coeficiente estimado depende crucialmente del período de tiempo en el cual se miden los precios. El consenso es que a corto plazo, el pass-through es rezagado e incompleto, y varía considerablemente entre países e industrias. A largo plazo, la magnitud de las estimaciones aumenta pero en general, no lo suficiente como para alcanzar el valor de la unidad. ${ }^{9}$

\subsection{Teoría de la Paridad de Poder Adquisitivo}

La hipótesis básica que fundamenta la correspondencia entre precios y tipos de cambio subyace en la Teoría de la Paridad de Poder Adquisitivo (PPA). Sus orígenes se remontan a David Ricardo (1810), quien sostenía que un aumento persistente de los precios se trasladaría en algún momento al tipo de cambio. ${ }^{10}$ Sin embargo, la teoría de la PPA como tal, adquirió formalmente su terminología en los años que siguieron a la primera guerra mundial, cuando la necesidad de financiar el esfuerzo bélico por parte de las principales potencias beligerantes provocó el abandono del patrón oro (Cassel, 1922). La emisión descontrolada se tradujo en contextos altamente inflacionarios y en un debate político internacional acerca de los niveles apropiados de los tipos de cambio nominales. La propuesta de Cassel (1922) consistía en actualizar los tipos de cambio a partir de la inflación acumulada desde 1914 con el objetivo de mantener la PPA de las distintas monedas involucradas. Actualmente, dos aplicaciones importantes de la teoría de la PPA consisten en obtener estimaciones o pronósticos para el tipo de cambio real de largo plazo, y en el ajuste por diferenciales de precio para las comparaciones internacionales de ingreso y producto.

La versión absoluta de la teoría de la PPA sostiene que el tipo de cambio nominal entre dos monedas debería ser igual al cociente de los niveles agregados de precios de ambos países, de modo que la moneda de un país tenga la misma capacidad de compra en el país extranjero. Este marco teórico emerge de la generalización para un conjunto de bienes de la Ley de Precio Único (LPU), que expresa que en mercados competitivos (sin costos de transporte ni barreras al comercio) los bienes idénticos deberían venderse al mismo precio en distintos países, pues cualquier diferencial de precios sería eliminado mediante operaciones de arbitraje internacional. Numerosos factores limitan el cumplimiento de la PPA en la práctica. Los costos de transporte y las barreras comerciales entre países crean el primer diferencial de precios. La brecha se acentúa si las firmas pueden discriminar

\footnotetext{
${ }^{9}$ Se recomienda al lector interesado recurrir a las excelentes revisiones de la literatura realizadas por Goldberg y Knetter (1997) y Burstein y Gopinath (2014).

${ }^{10}$ La PPA también fue discutida por otros economistas clásicos muy influyentes como John Stuart Mill, Alfred Marshall y Ludwig Von Mises.
} 
precios entre distintos mercados alterando sus márgenes de ganancia. La heterogeneidad de preferencias, ingresos y disposición a pagar de los consumidores en distintos países altera la elasticidad de la demanda percibida por las firmas internacionales. Además, el precio final de un producto suele contener una fracción no menor de bienes y servicios no transables (e.g. costos de distribución, marketing, venta al por mayor/menor, etc.) cuya magnitud depende de la estructura de los distintos mercados domésticos y agentes económicos involucrados. Si se asume que los niveles absolutos de precios no se igualan, sobrevive una variante suavizada de la PPA que se concentra en las variaciones de precios. En su versión relativa, la ley expresa que las tasas de cambio de los precios deberían igualarse una vez expresadas en una moneda común. De ser válida la PPA relativa, un corolario sería la existencia de un traslado a precios completo de toda variación en el tipo de cambio en cualquier momento del tiempo (exchange-rate pass-through perfecto/completo).

Las primeras discusiones comenzaron a cuestionar la validez empírica de la LPU. Incluso los estudios que se concentraron en categorías de bienes relativamente homogéneas y altamente transables encontraron grandes diferenciales de precios (desvíos de la PPA) con una elevada volatilidad de corto plazo (Giovaninni (1988); Knetter (1989, 1993); Engel (1993)). Rápidamente se formó un consenso acerca del incumplimiento de la LPU y de la PPA en el corto plazo. En el largo plazo, los tipos de cambio reales parecían converger lentamente hacia la PPA. En una excelente revisión de la teoría y la evidencia acerca de la PPA, Rogoff (1996) concluye que la duración media estimada para los desvíos de la PPA se haya en torno de los 3 a 5 años, la cual resulta demasiado elevada para ser explicada únicamente por rigideces nominales, y denomina a este fenómeno como el enigma de la PPA o "purchasing power parity puzzle". Los shocks reales (a los gustos o a la tecnología) tampoco parecieran explicar la elevada persistencia de los desvíos en la PPA, por lo que el autor apunta a la segmentación existente en los mercados internacionales, que presentan fricciones comerciales significativas para un amplio conjunto de bienes transables. Obstfeld y Rogoff (2001) discuten seis preguntas inconclusas en la profesión, y entre ellas incluyen el enigma de la PPA y la desconexión entre las variaciones del tipo de cambio y las variables reales ("exchange-rate disconnect").

En la mayor parte de los trabajos empíricos pioneros se comparan series de precios para países desarrollados con cierta desagregación a nivel industria (e.g. Isard (1977); Richardson (1978)). Algunos trabajos se concentran en un conjunto acotado de bienes transables cuyos precios estaban disponibles al menos para un par de países en distintos momentos del tiempo (Giovaninni (1988); Knetter (1989, 1993); Engel (1993)). En general, 
esta literatura trabaja con datos agregados de series de tiempo, utilizando mayormente metodologías de vectores autorregresivos, técnicas de cointegración y modelos de corrección al equilibrio. La falta de datos históricos armonizados entre países y desagregados por industria o por bienes específicos ha sido una de las principales falencias de los estudios pioneros. A su vez, muchas de las medidas empleadas no tuvieron en cuenta los rápidos cambios que ocurren en el entorno competitivo, el desarrollo de nuevos productos y el aprendizaje de los consumidores, factores que alejan a los mercados de un estado de equilibrio de largo plazo (Goldberg y Knetter, 1997).

Las primeras contribuciones que incorporaron varios de estos aspectos fueron aquellas realizadas por Goldberg y Verboven $(2001,2005)$ para la industria automovilística europea. Los autores explotan un detallado panel de datos de precios y características de 150 modelos de automóviles para 5 países de Europa durante el período 1970-2000, para estudiar si el proceso de integración europeo (intensificado sobre todo en 1999 con la creación del euro) redujo la dispersión de precios entre países y aceleró la convergencia hacia la LPU. Encuentran fuerte evidencia a favor de la LPU relativa, con una duración media estimada de los shocks de 1,3 a 1,6 años. También encuentran diferencias significativas en los precios del mismo automóvil en diferentes países, que atribuyen a factores estructurales específicos de cada país (e.g. elasticidad precio de la demanda, política comercial y costos locales de distribución). Sin embargo, estas brechas se reducen cuando se profundiza la integración europea, lo que resulta ser evidencia parcial a favor del fenómeno de convergencia absoluta.

\subsection{Pass-through}

Buena parte de los trabajos de esta rama de la literatura se concentra en modelar y estimar la respuesta de mark-ups y costos marginales de las firmas frente a variaciones del tipo de cambio, con un enfoque de equilibrio parcial en el cual se asume la exogeneidad del tipo de cambio. Estos trabajos se nutren de la literatura de organización industrial. Este es el enfoque que se adopta en esta tesis doctoral. El supuesto de que los shocks al tipo de cambio son exógenos a la firma es aceptado y comunmente utilizado en la literatura empírica. Los datos de tipos de cambio están disponibles públicamente para casi todos los países del mundo y presentan mucha variabilidad temporal. Esto se transforma en una ventaja comparativa de los datos de comercio internacional por sobre aquellos típicamente utilizados en la literatura de organización industrial. 
Las primeras contribuciones para Estados Unidos datan de principios de la década del 70', a partir de que las principales potencias económicas comienzan a utilizar sistemas de tipos de cambio fluctuantes. En la literatura se formó un consenso en torno a la idea de que el pass-through es rezagado e incompleto, y varía considerablemente entre países, industrias y a lo largo del tiempo. A partir de entonces, el eje de la discusión se desplaza hacia el estudio de los determinantes de dicha heterogeneidad. Goldberg y Knetter (1997) revisan extensamente el estado de la literatura hasta ese momento. Lo propio hace el reciente capítulo de Burstein y Gopinath (2014) en el Handbook de Economía Internacional. En el conjunto de trabajos relevados por Goldberg y Knetter (1997), la distribución de las estimaciones de pass-through para Estados Unidos presenta una varianza elevada, con una mediana en torno al $50 \%$.

Como se mencionó previamente, la literatura de exchange-rate pass-through se desglosa en dos niveles de análisis que se hayan íntimamente relacionados. Por un lado, es posible estudiar el traspaso de variaciones del tipo de cambio hacia los precios de importación medidos en aduana (este es el nivel de análisis de este trabajo). Por otro lado, es posible estudiar el traspaso hacia todo el conjunto de precios domésticos (incluyendo bienes transables exportables y bienes no transables). Este último caso es más intensivo en la utilización de microdatos y requiere una mayor cantidad de supuestos sobre el funcionamiento de los mercados domésticos (producción, distribución, y venta al por mayor/menor).

El argumento más intuitivo que explica buena parte del fenómeno de pass-through incompleto hacia el nivel general de precios de una economía se relaciona con la presencia de bienes y servicios no transables (que no cuentan con insumos importados en su función de producción) en la canasta de consumo, cuyo precio en moneda local no se ve afectado frente a una devaluación de la moneda. Para el caso de los productos exportables, los precios se fijan en el mercado internacional. Luego, es de suponer que en respuesta a una devaluación los exportadores exigirán un precio mayor para vender los mismos productos que exportan en el mercado local. ${ }^{11}$ Dado que el precio de los bienes importables también se fija en el mercado internacional, es esperable que su precio en moneda doméstica aumente luego de una devaluación. El grueso de los trabajos encuentra que el pass-through es rezagado e

\footnotetext{
${ }^{11}$ Campos (2010) analiza este fenómeno utilizando microdatos de exportaciones de Brasil, enfatizando los cambios que ocurren en el set firmas-productos en los mercados de exportación como posible explicación adicional al fenómeno de pass-through incompleto. Sin embargo, los resultados empíricos de este trabajo muestran que este fenómeno no tiene demasiada influencia en la determinación del nivel de pass-through agregado. En la sección 2.3 se discuten varios trabajos recientes que estudian el fenómeno de pass-through desde la perspectiva de las firmas exportadoras (e.g. Berman, Martin y Mayer (2012); Chatterjee, Dix-Carneiro y Vichyanond (2013); Amiti, Itskhoki y Konings (2014); entre otros).
} 
incompleto para el conjunto de bienes importados. En cuánto a los determinantes, se han presentado diversas explicaciones tanto teóricas como empíricas.

La primera explicación se relaciona con el poder de mercado de las firmas, y se desarrolla fundamentalmente a partir de las contribuciones seminales de Krugman (1987) y Dornbusch (1987). La idea detrás de este argumento es que buena parte del comercio internacional se enmarca en una estructura de competencia imperfecta, y la segmentación de mercados entre regiones geógraficamente distantes posibilita a las firmas desarrollar prácticas de discriminación de precios de tercer grado, cobrando distintos precios por el mismo producto a consumidores de diferentes países. A su vez, fluctuaciones inesperadas del tipo de cambio que originan modificaciones en la estructura de costos/demanda afectan la determinación óptima del márgen de ganancia elegido por las firmas. Este argumento se encuentra presente en la mayor parte de esta literatura. A pesar de la multiplicidad de explicaciones, la causa más consensuada es justamente la existencia de discriminación de precios de tercer grado, pues la mayor parte de las variaciones en el tipo de cambio parecen ser compensadas por ajustes en los márgenes de ganancia de las firmas, que varían según el país destino de sus productos. Sin embargo, el hecho de que prácticamente ninguno de estos trabajos incorpora la dimensión de calidad en el análisis podría sesgar considerablemente los resultados obtenidos. En un trabajo influyente, Hummels y Skiba (2004) argumentan que la explicación asociada al PTM está sobreestimada en aquellos trabajos que suponen costos de transporte tipo iceberg, pues este supuesto da cuenta de buena parte del fenómeno de pricing por calidad. Por su parte, trabajos recientes muestran que el fenómeno de discriminación de calidad es un hecho estilizado del comercio internacional (Manova y Zhang, 2012).

La segunda explicación se relaciona con la existencia de costos locales de distribución (e.g. transporte, almacenamiento, financiación, seguros, venta al por mayor y por menor, marketing, etc.) que agregan valor agregado local al precio final de los bienes importados. Dado que estos costos suelen expresarse en moneda doméstica, en principio no deberían cambiar sustancialmente frente a variaciones en el tipo de cambio y por lo tanto, deberían reducir el pass-through hacia el precio final de los productos importados. Esta explicación también se encuentra presente en gran parte de esta literatura (e.g. Burstein, Neves y Rebelo (2003); Corsetti y Dedola (2004); Campa y Goldberg (2005, 2010); Burstein, Eichembaum y Rebelo (2005); entre otros).

La tercera explicación se relaciona con el fenómeno de rigidez nominal de precios, vinculado a la existencia de costos de ajuste. Este fenómeno también ha sido explorado 
por diversos trabajos teóricos y empíricos (Devereux y Engel (2002); Bachetta y van Wincoop (2003); Engel (2006); Gopinath y Itskhoki (2010); Goldberg y Hellerstein (2013)). Utilizando datos de aduana de productos importados por Estados Unidos, Gopinath e Itskhoki (2010) estiman un coeficiente de pass-through significativamente mayor para los productos que ajustan con alta frecuencia (44\%) en relación a los que ajustan con baja frecuencia (21\%). Muestran que un modelo de pricing dinámico con costos de menú y mark-ups variables permite matchear los resultados empíricos. Engel (2002) identifica y discute estas tres fuentes de pass-through incompleto para explicar la rigidez de precios en moneda local que se observa en la práctica, y denomina a este fenómeno "local-currency pricing", término que la literatura siguió utilizando con bastante frecuencia.

Hay un conjunto de trabajos que tratan de descomponer y cuantificar empíricamente la importancia relativa de los distintos factores que explican el pass-through incompleto, mediante la estimación de modelos estructurales que permiten evaluar las distintas hipótesis a través de experimentos contrafácticos (e.g. Hellerstein (2008); Nakamura y Zerom (2010); Hellerstein y Villas-Boas (2010); Goldberg y Hellerstein (2013); entre otros). La metodología utilizada en este trabajo es muy cercana en espíritu a la que utiliza esta rama de la literatura. Naturalmente, la evidencia es mixta debido a que se estudian distintas industrias, países y períodos de tiempo; pero además porque muchas de las variables fundamentales (como mark-ups y costos marginales) no son directamente observables y requieren de supuestos importantes para ser identificadas.

Hellerstein (2008) intenta responder quién soporta (acapara) el costo (beneficio) de las variaciones grandes e imprevistas del tipo de cambio: ¿las firmas internacionales, las domésticas o los consumidores?. Para responder esta pregunta desarrolla y estima un modelo estructural aplicado a un panel de datos mensuales de la industria de cerveza en el área metropolitana de Chicago, que le permite cuantificar el pass-through hacia productores y distribuidores sin observar directamente los costos marginales de las firmas. El fenómeno de "doble marginalización" nace de suponer una estructura de competencia imperfecta no solo en el mercado internacional sino también en el sector de distribución doméstico. La atención se centra en el rol que juegan los mayoristas y minoristas de la cadena de distribución (particularmente en la determinación estratégica de los mark-ups). El modelo permite cuantificar la importancia relativa del componente local de costos y del ajuste de los mark-ups. El pass-through incompleto se explica en partes iguales por el ajuste estratégico del mark-up por parte de productores internacionales y distribuidores locales (sobre todo los primeros) y por los componentes locales del costo final del producto. 
El efecto en términos de bienestar sobre los consumidores domésticos es en general modesto debido a que los precios finales de venta al por menor responden muy parcialmente frente a las variaciones del tipo de cambio (11\%), en línea con los hallazgos de Engel (2002). En un trabajo relacionado, Hellerstein y Villas-Boas (2010) estudian la organización internacional de las actividades de producción de las firmas multinacionales (relaciones verticales entre ensambladores y distribuidores de insumos) y su vínculo con los ajustes de mark-ups y el pass-through. Estiman un modelo estructural para la industria automotriz de Estados Unidos utilizando datos en panel mensuales para los 24 modelos de automóviles más vendidos por seis productores multinacionales. El principal resultado es que un aumento de un desvío estándar en la externalización de los insumos (outsorcing) se asocia con una reducción promedio del pass-through hacia los precios internos del 12\%. Los distintos experimentos confirman que el pass-through es mucho mayor en cadenas de producción verticalmente integradas (multinacionales) en relación a aquellas más externalizadas, debido a que estas últimas experimentan una mayor cantidad de ajustes de mark-up en los distintos eslabones de producción en respuesta a los shocks de costos ocasionados por las variaciones inesperadas del tipo de cambio.

Goldberg y Hellerstein (2013) utilizan microdatos semanales de venta al por mayor y menor de distintas líneas de cerveza de la segunda cadena de supermercados más grande de Chicago. La alta frecuencia de los datos (muy inusual en esta literatura) les permite identificar el rol que juegan las rigideces nominales debido a que observan un buen número de períodos donde los precios no cambian, seguidos por cambios discretos hacia nuevos niveles. Estiman un modelo estándar de oligopolio, en el que permiten que las firmas se desvíen de las CPO cuando enfrentan costos fijos de remarcar precios (costos de menú). Los autores muestran que los ajustes de precios son bastante infrecuentes y que los cambios de precio al por menor siempre son antecedidos por cambios de precios de venta al por mayor, de modo que serían los distribuidores o productores locales quienes enfrentan los mayores costos de ajustar precios. El resultado de la descomposición del pass-through incompleto atribuye, en promedio, un $60 \%$ al componente local de costos, un $8,3 \%$ al ajuste de mark-up, un 30,4\% a los costos de ajuste específicos a cada marca y un 1,3\% al efecto indirecto/estratégico de dichos costos, con resultados que varían considerablemente entre las distintas marcas de acuerdo a su participación en el mercado: más market share se asocia con una mayor importancia del costo de ajustar precios.

Nakamura y Zerom (2010) utilizan microdatos de ventas y precios para la industria del café en el contexto de un modelo de oligopolio estructural con el objetivo de determinar 
la importancia relativa de los distintos determinantes del pass-through. Estiman un coeficiente de largo plazo (año y medio) de 33\% y documentan un rezago importante en los ajustes de precios que ocurre fundamentalmente a nivel mayorista. Encuentran que los costos locales son el principal factor explicativo del pass-through incompleto (59\%), seguido por el ajuste del mark-up (33\%) y un efecto prácticamente nulo de los costos de ajuste $(0,33 \%)$.

Linda Goldberg y José Manuel Campa han realizado varias contribuciones a esta literatura. En general, utilizan un enfoque cross-country y hacen hincapié en la relación que existe entre la utilización de insumos importados y el traslado a precios de las variaciones en el tipo de cambio. Utilizando datos trimestrales para 23 economías de la OECD en el período 1975-2003, Campa y Goldberg (2005) estiman coeficientes de pass-through de $46 \%$ para el corto plazo (un trimestre) y de $64 \%$ para el largo plazo. Encuentran que el pass-through es mayor en países que presentan mayor variabilidad del tipo de cambio y de inflación. La contribución más interesante del trabajo es analizar la relevancia que tienen los cambios en la participación de las distintas industrias (toman cinco) en el set de importaciones de cada país, a la hora de explicar la evolución del pass-through agregado de dichas economías, además de tener en cuenta la posibilidad de que ocurran cambios en las elasticidades asociados a cada industria, sea porque cambian las condiciones competitivas o las macroeconómicas.

Campa y Goldberg (2006) documentan que la industria predice mejor el pass-throgh hacia el precio de un producto importado que el país. La excepción de Estados Unidos, que presenta niveles inusualmente bajos de pass-through. Los costos locales de distribución son sobre todo específicos a cada industria y no presentan gran variabilidad en el tiempo. El hecho de que haya aumentado en el tiempo el uso de insumos importados para la mayor parte de industrias y países, explica que los precios al por menor de los bienes de consumo importados y otros transables, muestren una mayor sensibilidad respecto a las variaciones en el tipo de cambio.

Campa y Goldberg (2010) se basan en un modelo simple de dos países con rigidez salarial para explicar la influencia que tienen los cambios de precios de los bienes importados originados por variaciones del tipo de cambio en el nivel de precios agregado de la economía, utilizando datos agregados para 29 sectores de 21 economías desarrolladas de la OECD. El canal de transmisión son los bienes transables directamente consumidos o aquellos utilizados en la producción de otros bienes (transables y no transables). Los insumos importados (canal de costos) dan cuenta de entre 10\% y $48 \%$ del precio final de 
los bienes transables, y son el canal más importante para explicar la sensibilidad de los precios al consumidor. Los valores oscilan entre $3 \%$ y $22 \%$ en los sectores no transables. Los costos de distribución comprenden, en promedio, desde un $30 \%$ hasta un $50 \%$ del costo total de los bienes de consumo en los países estudiados. El otro hallazgo de este trabajo es la evidencia a favor de la existencia del proceso de "doble marginalización".

\subsection{Estado actual de la discusión}

Buena parte de los trabajos más recientes estudia el fenómeno de pass-through desde la perspectiva de las firmas exportadoras (e.g. Berman, Martin y Mayer (2012); Chatterjee, Dix-Carneiro y Vichyanond (2013); Amiti, Itskhoki y Konings (2014)). Varios de estos trabajos incorporan el componente de diferenciación por calidad (Manova y Zhang (2012); Bernini y Tomassi (2015); Chen y Juvenal (2016, 2018)). Manova y Zhang (2012) utilizan datos de aduana de firmas y productos de China durante el período 2003-2005 para establecer algunos hechos estilizados vinculados a la variación de precios de productos exportados y a la utilización de insumos importados entre firmas, productos y socios comerciales. Dos de estos hechos se hayan especialmente vinculados con la hipótesis fundamental de esta tesis: (i) los exportadores más exitosos utilizan insumos de mayor calidad para producir bienes de mayor calidad; y (ii) las firmas ajustan la calidad de sus productos en los distintos mercados que sirven, mediante la utilización de insumos de diferente calidad, en función del ingreso, tamaño del mercado y distancia de cada destino. En este sentido, el hecho de que un mercado sufra un shock de magnitud (sea una crisis, una devaluación, la firma de un tratado comercial, etc.), naturalmente debería afectar las elecciones de las firmas internacionales que exportan a dicho mercado.

Utilizando un panel de datos de firmas francesas para el período 1995-2005, Berman, Martin y Mayer (2012) analizan la reacción de las firmas exportadoras frente a variaciones del tipo de cambio real. Las firmas más grandes y más productivas tienden a absorber una mayor proporción de las variaciones del TCR en sus mark-ups (que aumentan en el evento de una devaluación) mientras que ajustan mucho menos sus volúmenes de comercio. Además, encuentran evidencia de mayor pricing-to-market para bienes de consumo que para bienes intermedios, y para sectores con mayores costos de distribución (en línea con los hallazgos de doble marginalización en Hellerstein (2008), Campa y Goldberg (2010), y Goldberg y Hellerstein (2013)).

Utilizando datos en panel para firmas de Bélgica durante el período 2000-2008, 
Amiti, Itskhoki y Konings (2014) muestran la importancia de tener en cuenta el hecho de que los grandes exportadores son simultáneamente grandes importadores, para explicar los bajos niveles de pass-through agregado que usualmente muestran los datos, y para comprender la heterogeneidad que existe entre las distintas firmas involucradas en el comercio internacional. Los grandes exportadores utilizan una mayor proporción de insumos importados y por tanto tienen menores niveles de pass-through, dado que compensan las variaciones del tipo de cambio en sus costos marginales. A su vez, tienen una mayor participación en el mercado de exportación y mayores márgenes de ganancia, que ajustan activamente en respuesta a las variaciones de costos que enfrentan. En un trabajo relacionado, Bernini y Tomassi (2015) muestran que el efecto que proviene de la utilización de insumos importados (canal de costos) es mucho más débil para reducir el pass-through hacia el precio de exportables cuando se trata de variedades de calidad alta, puesto que estas se producen con insumos importados de alta calidad cuyo precio es menos sensible a variaciones del tipo de cambio. En este sentido, el poder de mercado de los proveedores de este tipo de insumos debilita el canal de costos. Los autores desarrollan un modelo de competencia monopolística, donde la producción de bienes exportables de alta calidad requiere de insumos importados de alta calidad, y ponen a prueba las predicciones del modelo utilizando un panel de datos de firmas italianas durante el período 2000-2006.

Chatterjee, Dix-Carneiro y Vichyanond (2013) estudian los efectos que tienen las variaciones del tipo de cambio sobre las exportaciones de manufacturas de firmas multi-producto, utilizando datos de aduana (producto-firma) de Brasil para el período 1997-2006. Sus principales hallazgos muestran que en respuesta a una devaluación las firmas exportadoras aumentan sus mark-ups, y lo hacen en mayor proporción para sus productos principales (menores costos marginales). Además, expanden el rango de productos exportados hacia productos menos eficientes, ya que que aumenta la importancia de segundas marcas/productos en el set de exportaciones en relación a los productos principales, de modo que se produce una reasignación de recursos al interior de la firma hacia un uso menos eficiente. Verhoogen (2008) encuentra evidencia en otra dirección, asociada al quality upgrading que realizan las firmas exportadoras mexicanas en los años que siguen a la devaluación. Ambas explicaciones pueden reconciliarse si el análisis incorpora el destino de las exportaciones como una variable relevante (Brambilla, Lederman y Porto (2012), Bastos, Silva y Verhoogen (2018)). También puede mencionarse la complementariedad entre la utilización de insumos importados, insumos domésticos y la respuesta de la inversión en tecnología (e.g. mejoras de plantas productivas domésticas) 
en los años que siguen a la devaluación.

Chen y Juvenal (2016) utilizan un novedoso set de datos de la industria del vino, que incluye precios, cantidades y destinos de los vinos exportados por 209 firmas multi-producto argentinas entre 2002 y 2009. La información disponible incluye nombre, cosecha, cepa y tipo de vino, que combinan con un ranking de vinos realizado por catadores expertos, variable que utilizan como medida directa y observable de la calidad. ${ }^{12}$ El modelo que utilizan predice que la elasticidad de la demanda percibida por las firmas disminuye con una depreciación real y con la calidad. Entonces frente a una variación del TCR, cambian más los precios que fijan los exportadores (en moneda doméstica) que sus cantidades exportadas, y más acentuadamente para productos de alta calidad (el pass-through decrece con la calidad). Este es el mismo resultado que presentan Bernini y Tomassi (2015). El trabajo de Chen y Juvenal (2018) está estrechamente relacionado con la idea de esta parte de la tesis. Los autores encuentran una caída significativa en la calidad de los vinos exportados por Argentina durante el período de la crisis financiera internacional. Argumentan que este "fly-from-quality" fue disparado fundamentalmente por la caída de la demanda agregada, y muestran que la caída en la calidad fue más pronunciada para aquellos hogares que tenían la posibilidad de sustituir los vinos importados con alguna alternativa doméstica, y para aquellas firmas de menor tamaño. Este canal es similar en espíritu a la idea de esta tesis. Sin embargo, la forma de modelar el comportamiento de firmas y consumidores es totalmente diferente. Más aún, la aplicación empírica realizada en esta tesis se extiende al conjunto de manufacturas importadas, en lugar de concentrarse en una industria específica. ${ }^{13}$

\footnotetext{
${ }^{12}$ Crozet, Head y Mayer (2012) utilizan un enfoque muy similar para las exportaciones de Champagne de firmas francesas para estudiar la relación entre comercio internacional y calidad de los bienes.

${ }^{13}$ Otros trabajos que se concentran en determinadas industrias son Goldberg y Verboven (2001) y Auer, Chaney y Sauré (2018) para automóviles, Hellerstein (2008) para cerveza, y Nakamura y Zerom (2010) para café.
} 


\section{Contexto}

\subsection{Crisis cambiarias}

Las crisis cambiarias devienen generalmente de desequilibrios persistentes en la cuenta corriente de la balanza de pagos. La interacción de determinados eventos internos y externos socava las expectativas y desencadena una salida de capitales que reduce bruscamente las reservas internacionales. La crisis cambiaria se materializa en la depreciación real de la moneda doméstica. La depreciación genera rupturas en el sistema de pagos, reduce la inversión productiva, retroalimenta la recesión económica y produce efectos negativos sobre la distribución del ingreso. ${ }^{14}$ La modificación de precios relativos ocasionada por la depreciación suele ser el factor que permite equilibrar los desbalances externos. La principal variable de ajuste suelen ser las importaciones, que disminuyen marcadamente a partir de la reducción del ingreso real de los consumidores domésticos (medido en dólares) como consecuencia de la devaluación. La depreciación también aumenta el costo de los insumos importados y disminuye su utilización, lo que reduce significativamente la productividad de las firmas domésticas (Gopinath y Neiman, 2013). Ello retroalimenta la reducción del producto real derivada del contexto recesivo per se.

La elección de los episodios estudiados en este trabajo está limitada por la disponibilidad de microdatos de comercio internacional (COMTRADE-Naciones Unidas). Cinco episodios ocurren en la década del noventa en América Latina: México (1995), Colombia (1998), Brasil (1999), Argentina y Uruguay (2002). Otros cinco corresponden a la crisis asiática, cuyo comienzo se asocia con la devaluación de la moneda tailandesa en Julio de 1997, y continúa con devaluaciones de Indonesia, Malasia, Filipinas, y Corea del Sur durante 1997 y 1998. También se incorporan la crisis de Rusia en 1998 y la crisis de Turquía en 2001.

El Cuadro 1 presenta la evolución anual de las principales variables macroeconómicas durante los años que circunscriben las crisis cambiarias estudiadas. El año T es aquel donde se produce el grueso de la devaluación nominal de la moneda doméstica de cada país. La Figura A1 (en el apéndice) presenta la evolución mensual del tipo de cambio

\footnotetext{
${ }^{14} \mathrm{Al}$ menos dos canales contribuyen a empeorar la distribución del ingreso. El primero se relaciona con un efecto patrimonial derivado del ahorro. Los individuos de mayores ingresos tienen mayor capacidad de dolarizar sus ahorros. El segundo se relaciona con el costo de vida. La devaluación se traslada al precio doméstico de los bienes transables (e.g. alimentos) y estos representan una mayor proporción del gasto de los hogares de menores ingresos, que por tanto sufren un mayor aumento del costo de vida (Cravino y Levchenko, 2017).
} 
real bilateral (TCRB) con respecto al dólar estadounidense en cada uno de los países durante el mismo período. La mayoría de las crisis cambiarias estudiadas ocurrieron en el contexto de regímenes de tipos de cambio fijos o cuasi-fijos y elevada liberalización financiera (libre movilidad internacional de capitales). Estas crisis económicas ponen de manifiesto las dificultades de mantener esquemas de tipo de cambio fijo, libre movilidad de capitales, y autonomía monetaria (Fleming, 1962; Mundell, 1963). Si bien las restricciones teóricas eran conocidas, muchos de estos países tenían serios problemas inflacionarios y aplicaron planes de estabilización utilizando al tipo de cambio como ancla nominal. En estos regímenes, la autonomía de los bancos centrales se encuentra limitada por las necesidades de esterilización de la política monetaria, cuyo objetivo es mantener el nivel del tipo de cambio. En general, el buen desempeño económico de los primeros años de estos regímenes fomenta la entrada de capitales, lo que genera una tendencia a la apreciación de la moneda doméstica. Los bancos centrales intervienen absorbiendo estos excedentes, aumentando las reservas, y esterilizando sus intervenciones con operaciones de mercado abierto (deuda). Ello puede aumentar el nivel de fragilidad económica frente a perturbaciones internas (e.g. aumento del déficit fiscal y/o comercial), o derivadas del contexto económico global (e.g. reducción del precio internacional de las materias primas, aumento en la tasa de interés internacional, recesión económica de socios comerciales, entre otras). Si bien estos regímenes fueron efectivos para contener la inflación y reactivar la economía, no planificaron adecuadamente una estrategia de salida que permita anticipar la salida de capitales y suavizar el ciclo económico. ${ }^{15}$

En todos los casos, la crisis cambiaria es antecedida por una fuerte reducción de las reservas internacionales. La reducción promedio de las reservas internacionales en el año previo a la devaluación es de 2,6 puntos del producto bruto. La devaluación nominal promedio es de $91 \%$. Sobresalen las devaluaciones del peso Argentino durante 2001-2002 (206\%) y de la rupia Indonesia durante 1997-1998 (244\%). En la mayoría de los casos, los primeros meses se caracterizan por un escenario de volatilidad cambiaria que incluye una sobrerreacción del tipo de cambio nominal (Figura A1). La variación anual promedio del índice de precios al consumidor es de $27 \%$ durante el año de la devaluación. Las tasas de inflación más altas se registran en Rusia (86\%), Indonesia (58\%) y Turquía (54\%). El traslado a precios de la devaluación es notablemente bajo en los casos de Argentina, Brasil, Malasia y Corea del Sur. Todas las devaluaciones ocurren en un contexto recesivo. La caída promedio del producto per cápita es cercana al 7\%. Se destacan los casos de

\footnotetext{
${ }^{15}$ Naturalmente, las crisis estudiadas difieren en su severidad, duración y en las respuestas de política llevadas a cabo por los gobiernos de turno.
} 
Indonesia (-14,3\%), Argentina (-11,9\%) y Tailandia (-8,7\%). La producción se recupera en la mayoría de los países en el año que sigue a la devaluación, con la excepción de Colombia (-5,6\% en 1999) e Indonesia (-0,6\% en 1999). El producto per cápita aumenta en todos los países dos años después de la devaluación ( $5 \%$ en promedio).

En todos los casos, las importaciones disminuyen marcadamente en el año de la devaluación (20\% en promedio). La reducción de las importaciones es particularmente notable en el caso Argentino (-50\%). Las importaciones comienzan a recuperarse entre uno y dos años después de la devaluación (6,6\% y $22 \%$ anual en promedio, respectivamente). Por su parte, las exportaciones aumentan en promedio 4,7\% durante el año de la devaluación y 6,4\% en el año siguiente. Algunos de los países experimentan un aumento importante de sus exportaciones durante el año de la devaluación (México, Corea, Tailandia e Indonesia) y otros presentan caídas significativas (Filipinas y Uruguay). En general, el determinante principal de la mejora del saldo del balance comercial es la reducción de las importaciones. A su vez, la mejora del balance comercial (7,9 p.p. del PBI en promedio) es el factor más importante detrás de la mejora del saldo del balance de cuenta corriente (8,2 p.p. del PBI en promedio).

La literatura de macroeconomía internacional dedicada a estudiar las causas de las crisis monetarias se divide usualmente en tres "generaciones" de modelos. Los modelos de primera generación muestran que en un sistema de tipo de cambio fijo, un nivel de reservas internacionales por debajo de determinado umbral/valor crítico provoca una corrida bancaria (o ataque especulativo) que termina por agotar las reservas (Salant y Henderson (1978); Krugman (1979); Flood y Garber (1984)). Sin embargo, estos modelos no pueden explicar las crisis que ocurren sin que se agoten las reservas internacionales. En estos casos, los bancos centrales logran mantener el nivel del tipo de cambio mediante el aumento en la tasa de interés. Naturalmente, ello afecta el nivel de inversión real, el crecimiento del producto y del empleo. Los modelos de segunda generación incorporan el lado real de la economía, y sugieren la posible existencia de equilibrios múltiples. En este caso, países que se encuentren en un estado de vulnerabilidad pueden experimentar una crisis cuando los inversores consideren que dicha crisis es inminente y se genere un estado de contagio (Obstfeld (1994); Eichengreen, Rose y Wyplosz (1995)). Sin embargo, estos modelos sugieren que después de la corrida bancaria y la consecuente depreciación de la moneda, los niveles de actividad y de empleo deberían recuperarse en el corto plazo. Sin embargo, en muchos de estos episodios la recuperación económica no se produce sino algunos años después de la crisis cambiaria. De hecho, la depreciación real es seguida por 
una fuerte contracción de la economía real. Los modelos de tercera generación sugieren que la persistencia de la recesión se explica por un efecto hoja de balance del sector privado (Krugman (1999); Chang y Velasco (1999); Aghion, Bachetta y Banerjee (2001)). Si los agentes económicos (consumidores, firmas, bancos y/o gobierno) tienen deuda expresada en moneda extranjera, el valor de la deuda expresado en moneda doméstica se incrementa después de la depreciación. Dado que los ingresos no aumentan en la misma proporción, aumenta la participación de estos pasivos en el ingreso total y ello puede reducir la inversión y el producto total de la economía, e incluso puede desembocar en un default de la deuda externa, tal como sucede en muchos de los episodios estudiados (Tailandia, Rusia y Argentina).

Si bien estos modelos son útiles para comprender la génesis de las crisis monetarias, cada contexto tiene sus particularidades y merece ser estudiado con mayor grado de detalle. Diversos factores pueden ayudar a comprender la profundidad y la duración de los distintos episodios. Es importante tener en cuenta las condiciones micro y macroeconómicas que circunscriben a cada contexto. Algunos de los factores explicativos importantes se relacionan con la magnitud y la evolución de: (i) la distorsión de precios relativos (e.g. inflación persistente, apreciación del tipo de cambio real), (ii) el saldo de la cuenta corriente, (iii) la volatilidad de los flujos internacionales de capital, (iv) el saldo de las cuentas públicas (e.g. un déficit persistente financiado en moneda extranjera), (v) las respuestas de política económica de los gobiernos de turno, etc. El estudio de los aspectos fiscales, comerciales y financieros que forman parte de la génesis y de la superación de estos episodios, y su interdependencia, se encuentra al margen del presente trabajo. 
CUADRO 1

Evolución de variables macroeconómicas

\begin{tabular}{|c|c|c|c|c|c|c|c|c|c|c|c|c|}
\hline & $\begin{array}{c}\text { MEX } \\
1995 \\
\end{array}$ & $\begin{array}{l}\text { BRA } \\
1999 \\
\end{array}$ & $\begin{array}{l}\text { ARG } \\
2002 \\
\end{array}$ & $\begin{array}{l}\text { URU } \\
2002 \\
\end{array}$ & $\begin{array}{l}\mathrm{COL} \\
1998 \\
\end{array}$ & $\begin{array}{c}\text { TAI } \\
1998 \\
\end{array}$ & $\begin{array}{l}\text { IND } \\
1998 \\
\end{array}$ & $\begin{array}{c}\text { MAL } \\
1998 \\
\end{array}$ & $\begin{array}{c}\text { FIL } \\
1998 \\
\end{array}$ & $\begin{array}{l}\text { COR } \\
1998 \\
\end{array}$ & $\begin{array}{l}\text { RUS } \\
1999 \\
\end{array}$ & $\begin{array}{l}\text { TUR } \\
2001 \\
\end{array}$ \\
\hline \multicolumn{13}{|c|}{ Indice de tipo de cambio nominal bilateral (respecto al dólar) } \\
\hline T-3 & 92 & 87 & 100 & 85 & 80 & 79 & 77 & 89 & 87 & 81 & 53 & 42 \\
\hline $\mathrm{T}-2$ & 92 & 93 & 100 & 91 & 91 & 81 & 81 & 89 & 89 & 85 & 60 & 67 \\
\hline $\mathrm{T}-1$ & 100 & 100 & 100 & 100 & 100 & 100 & 100 & 100 & 100 & 100 & 100 & 100 \\
\hline $\mathrm{T}$ & 190 & 156 & 306 & 160 & 125 & 132 & 344 & 139 & 139 & 147 & 254 & 196 \\
\hline $\mathrm{T}+1$ & 225 & 158 & 290 & 212 & 154 & 121 & 270 & 135 & 133 & 125 & 290 & 241 \\
\hline $\mathrm{T}+2$ & 235 & 202 & 292 & 216 & 183 & 128 & 289 & 135 & 150 & 119 & 301 & 240 \\
\hline \multicolumn{13}{|c|}{ Indice de precios al consumidor } \\
\hline $\mathrm{T}-3$ & 85 & 91 & 102 & 91 & 70 & 89 & 87 & 94 & 88 & 91 & 68 & 39 \\
\hline T-2 & 93 & 97 & 102 & 96 & 84 & 95 & 94 & 97 & 95 & 96 & 78 & 65 \\
\hline $\mathrm{T}-1$ & 100 & 100 & 100 & 100 & 100 & 100 & 100 & 100 & 100 & 100 & 100 & 100 \\
\hline $\mathrm{T}$ & 135 & 105 & 141 & 114 & 119 & 108 & 158 & 105 & 109 & 108 & 186 & 154 \\
\hline $\mathrm{T}+1$ & 181 & 112 & 146 & 136 & 132 & 108 & 191 & 108 & 116 & 108 & 224 & 224 \\
\hline $\mathrm{T}+2$ & 219 & 120 & 155 & 149 & 144 & 110 & 198 & 110 & 120 & 111 & 272 & 280 \\
\hline \multicolumn{13}{|c|}{ PBI per cápita (miles de dólares constantes a PPA) } \\
\hline $\mathrm{T}-3$ & 13.1 & 11.1 & 15.2 & 13.2 & 8.4 & 8.8 & 6.0 & 14.6 & 4.0 & 16.6 & 12.8 & 13.9 \\
\hline $\mathrm{T}-2$ & 13.3 & 11.3 & 14.9 & 12.9 & 8.5 & 9.4 & 6.4 & 15.7 & 4.1 & 17.7 & 12.4 & 13.2 \\
\hline $\mathrm{T}-1$ & 13.7 & 11.2 & 14.1 & 12.4 & 8.6 & 9.8 & 6.6 & 16.4 & 4.2 & 18.5 & 12.6 & 13.9 \\
\hline $\mathrm{T}$ & 12.7 & 11.1 & 12.4 & 11.4 & 8.6 & 9.4 & 5.6 & 14.8 & 4.1 & 17.4 & 11.9 & 12.8 \\
\hline $\mathrm{T}+1$ & 13.2 & 11.4 & 13.4 & 11.5 & 8.1 & 8.6 & 5.6 & 15.3 & 4.1 & 19.2 & 12.7 & 13.5 \\
\hline $\mathrm{T}+2$ & 13.9 & 11.4 & 14.4 & 12.1 & 8.3 & 8.9 & 5.8 & 16.3 & 4.2 & 20.8 & 14.1 & 14.0 \\
\hline \multicolumn{13}{|c|}{ Indice del valor de importaciones (dólares constantes) } \\
\hline $\mathrm{T}-3$ & 83 & 87 & 116 & 108 & 92 & 113 & 82 & 90 & 75 & 85 & 121 & 85 \\
\hline $\mathrm{T}-2$ & 85 & 100 & 116 & 108 & 94 & 110 & 87 & 94 & 88 & 98 & 121 & 82 \\
\hline $\mathrm{T}-1$ & 100 & 100 & 100 & 100 & 100 & 100 & 100 & 100 & 100 & 100 & 100 & 100 \\
\hline $\mathrm{T}$ & 80 & 85 & 50 & 72 & 96 & 80 & 95 & 81 & 85 & 76 & 83 & 76 \\
\hline $\mathrm{T}+1$ & 111 & 94 & 69 & 76 & 72 & 90 & 56 & 90 & 87 & 95 & 110 & 92 \\
\hline $\mathrm{T}+2$ & 128 & 97 & 96 & 97 & 81 & 113 & 71 & 112 & 97 & 116 & 130 & 113 \\
\hline \multicolumn{13}{|c|}{ Indice del valor de exportaciones (dólares constantes) } \\
\hline $\mathrm{T}-3$ & 60 & 86 & 95 & 103 & 88 & 96 & 86 & 87 & 74 & 76 & 99 & 95 \\
\hline $\mathrm{T}-2$ & 88 & 95 & 97 & 110 & 97 & 92 & 93 & 95 & 85 & 84 & 98 & 85 \\
\hline $\mathrm{T}-1$ & 100 & 100 & 100 & 100 & 100 & 100 & 100 & 100 & 100 & 100 & 100 & 100 \\
\hline $\mathrm{T}$ & 119 & 106 & 103 & 90 & 107 & 111 & 111 & 100 & 79 & 114 & 111 & 105 \\
\hline $\mathrm{T}+1$ & 141 & 119 & 109 & 93 & 114 & 120 & 76 & 114 & 87 & 129 & 122 & 113 \\
\hline $\mathrm{T}+2$ & 153 & 130 & 118 & 122 & 113 & 139 & 96 & 132 & 99 & 151 & 127 & 120 \\
\hline \multicolumn{13}{|c|}{ Balance comercial (\% PBI) } \\
\hline $\mathrm{T}-3$ & -5.0 & -2.2 & -1.7 & -3.2 & -6.4 & -6.7 & -1.3 & -3.9 & -7.8 & -0.9 & 4.2 & 0.9 \\
\hline $\mathrm{T}-2$ & -1.7 & -2.6 & -0.6 & -3.3 & -5.6 & -6.2 & -0.6 & 1.4 & -8.8 & -2.9 & 2.2 & -0.2 \\
\hline $\mathrm{T}-1$ & -2.6 & -2.4 & 1.3 & -2.7 & -5.9 & 1.4 & -0.3 & 0.9 & -10.3 & -0.7 & 6.7 & -3.1 \\
\hline $\mathrm{T}$ & 4.2 & -1.9 & 15.0 & 1.2 & -5.9 & 15.6 & 9.8 & 22.0 & -9.1 & 10.8 & 17.0 & 3.8 \\
\hline $\mathrm{T}+1$ & 2.7 & -2.3 & 11.2 & 3.1 & 0.5 & 12.2 & 8.1 & 25.1 & -3.9 & 5.7 & 20.0 & 1.5 \\
\hline $\mathrm{T}+2$ & 1.1 & -2.2 & 7.0 & 2.7 & -0.8 & 8.4 & 10.5 & 19.2 & -2.0 & 2.1 & 12.7 & -1.1 \\
\hline \multicolumn{13}{|c|}{ Balance de cuenta corriente $(\% \mathrm{PBI})$} \\
\hline $\mathrm{T}-3$ & -6.7 & -2.7 & -4.2 & -2.1 & -4.9 & -8.0 & -3.0 & -9.7 & -2.7 & -1.8 & 2.6 & 0.7 \\
\hline T-2 & -4.6 & -3.5 & -3.2 & -2.5 & -4.8 & -8.0 & -3.2 & -4.4 & -4.8 & -4.0 & -0.2 & -0.4 \\
\hline $\mathrm{T}-1$ & -5.6 & -3.9 & -1.4 & -2.4 & -5.4 & -2.0 & -2.1 & -5.9 & -5.3 & -1.8 & 0.0 & -3.6 \\
\hline $\mathrm{T}$ & -0.5 & -4.2 & 9.0 & 2.8 & -4.9 & 12.5 & 4.0 & 13.2 & 2.1 & 10.7 & 11.7 & 1.9 \\
\hline $\mathrm{T}+1$ & -0.6 & -3.7 & 6.4 & -0.7 & 0.8 & 9.8 & 3.9 & 15.9 & -3.5 & 4.5 & 17.5 & -0.3 \\
\hline $\mathrm{T}+2$ & -1.6 & -4.2 & 2.0 & 0.0 & 0.8 & 7.4 & 4.5 & 9.0 & -2.7 & 1.9 & 10.5 & -2.4 \\
\hline \multicolumn{13}{|c|}{ Variación de reservas internacionales (\% PBI) } \\
\hline $\mathrm{T}-3$ & 0.3 & 0.6 & 0.7 & -0.4 & 0.0 & 3.4 & 0.4 & -1.4 & 1.2 & 1.3 & -0.7 & 0.1 \\
\hline T-2 & 1.0 & -0.6 & -0.4 & 0.8 & 0.9 & 1.0 & 1.0 & 1.8 & 3.9 & 0.2 & 0.0 & 1.1 \\
\hline $\mathrm{T}-1$ & -2.4 & -1.1 & -7.4 & 1.0 & 0.1 & -8.5 & -1.6 & -2.6 & -2.6 & -3.7 & -1.3 & -0.8 \\
\hline $\mathrm{T}$ & -2.4 & -1.1 & -5.2 & -14.7 & -0.7 & -1.4 & -0.8 & 7.1 & 1.1 & 4.4 & 0.6 & -2.6 \\
\hline $\mathrm{T}+1$ & 1.5 & 0.5 & -3.2 & 3.6 & -0.2 & 0.7 & 0.4 & 3.2 & 3.1 & 5.1 & 2.0 & 0.0 \\
\hline $\mathrm{T}+2$ & 2.5 & -0.2 & -2.3 & 1.1 & 0.4 & -0.8 & 0.9 & -0.6 & -0.4 & 3.4 & 1.2 & 0.7 \\
\hline
\end{tabular}

Notas. T es el año donde se produce el grueso de la devaluación nominal en cada país. Fuentes. World Development Indicators (Banco Mundial) y Exchange Rates Archives (Fondo Monetario Internacional). 


\subsection{Crisis Argentina}

Después de ocho años de crecimiento promedio cercano al 6\%, Argentina se sumergió en una profunda y prolongada recesión a partir de 1999. Distintos factores coadyuvaron en esta etapa crítica de la economía Argentina, siendo los más significativos: (i) la crisis financiera y cambiaria de Brasil en $1999,{ }^{16}$ (ii) una moneda doméstica altamente sobrevaluada en el contexto de un sistema de tipo de cambio fijo con el dólar (convertibilidad) en efecto desde 1991, y (iii) una deuda externa creciente que aumentó 134\% en términos reales durante 1991-2001. La situación se agravó considerablemente cuando el gobierno realizó una serie de negociaciones de reestructuración de deuda que culminaron con el default de deuda más grande de la historia Argentina en Diciembre de 2001. La crisis de balanza de pagos se conjugó con una aguda crisis monetaria y bancaria, y una brusca salida de capitales que derivó en el colapso del régimen de convertibilidad. Argentina adoptó un régimen de tipo de cambio flexible que se hizo efectivo a partir de Enero de 2002. Durante el primer trimestre de 2002 el peso se devaluó cerca de $200 \%$ (llegando incluso a $265 \%$ en el mes de Junio), para terminar el año con un tipo de cambio nominal en torno a los 3,37 pesos por dólar. El nivel de traslado a precios de la devaluación fue notablemente bajo, pues la inflación medida por el índice de precios al consumidor (IPC) acumuló un 41\% interanual a Diciembre de 2002 (de modo que el pass-through para este lapso fue de 18,44\%). El tipo de cambio real aumentó $144 \%$ durante 2002. Ello se tradujo en una enorme reducción del poder de compra de los hogares argentinos, sobre todo en términos de bienes y servicios transables (precios en dólares). El incremento en el costo de vida probablemente haya sido mayor para los primeros deciles de la distribución del ingreso porque estos hogares destinan una mayor fracción del ingreso a bienes transables y porque tienen menores posibilidades de sustitución dado que consumen variedades de menor calidad (Cravino y Levchenko, 2017).

La actividad económica colapsó dramáticamente y el producto bruto interno cayó $5,7 \%$ en el último trimestre de 2001 y 10,9\% durante 2002, con una recuperación que comienza a partir del año 2003. El desempleo presentaba niveles elevados desde 1999 $(14,1 \%)$ y tocó techo durante 2002 alcanzando al $18 \%$ de la fuerza laboral. La inversión entendida como formación bruta de capital pasó de representar 18\% del PBI en 1999 a menos de $12 \%$ en 2002 . En este contexto, las importaciones cayeron abruptamente $(62 \%$ en términos reales entre 2000 y 2002). No solo ajustaron considerablemente las cantidades

\footnotetext{
${ }^{16}$ Brasil es el principal socio comercial de Argentina. Los flujos de comercio bilaterales con Brasil representan cerca de un cuarto $(23,4 \%)$ del comercio total argentino durante 1999-2004.
} 
importadas, sino también los precios de los productos importados. La Figura 1 ilustra dos hechos importantes: (i) el precio promedio de los productos importados (medido en dólares en aduana) disminuye significativamente en los años que siguen a la devaluación en la mayoría de las industrias, y (ii) se advierte una considerable variabilidad temporal de precios tanto al interior como a través de las distintas industrias de manufacturas importadas.

En la sección de resultados se muestra que este hallazgo está presente en todos los episodios estudiados, lo que lo transforma en un hecho estilizado fuertemente robusto. A su vez, se muestra que la calidad de los productos importados también disminuye significativamente en la gran mayoría de las industrias de todos los países estudiados. Las medidas de calidad se estiman separadamente para cada país a partir de un sistema de demanda multinomial nested logit. También se muestra que en todos los casos se produce un cambio composicional a nivel producto caracterizado por un aumento en la participación de las variedades de menor precio/calidad relativa. En la siguiente sección se desarrolla un modelo de comercio internacional en equilibrio parcial que permite racionalizar estos hechos estilizados. La estimación estructural del modelo permite elaborar un conjunto de índices de precios que sirven para descomponer y cuantificar los distintos canales que explican la reducción total del precio promedio de los productos importados (mark-ups, calidad y sustitución). 
FIGURA 1

Cambio en el precio de variedades importadas por industria

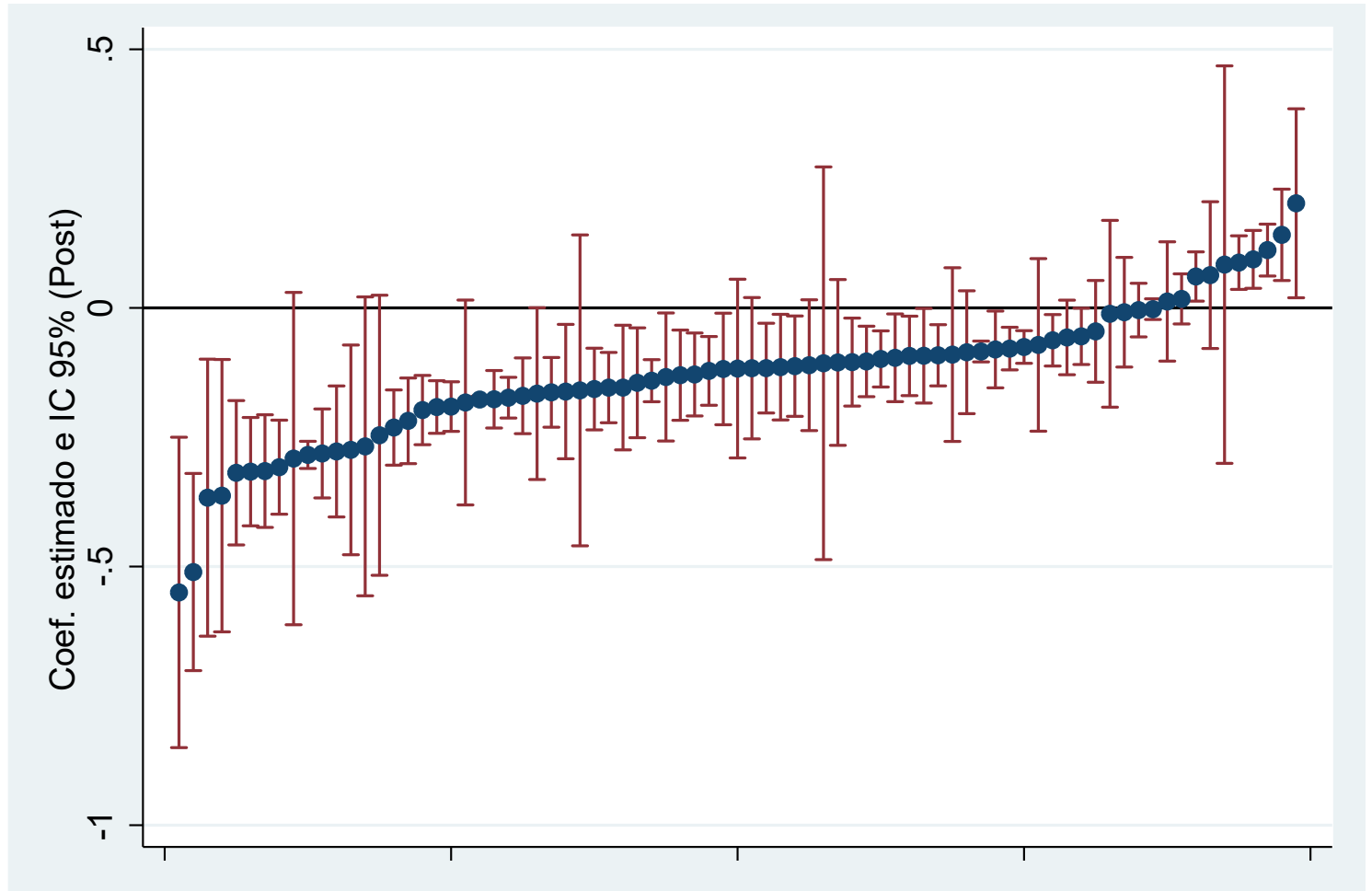

Notas. La figura presenta coeficientes estimados junto a intervalos de confianza (95\%) de 80 regresiones descriptivas (una para cada industria de manufacturas). La variable dependiente es el $\log (p)$ de las variedades importadas (en dólares en aduana) en función de la variable binaria Post (=0 en 1999-2001, =1 en 2002-2004). Las industrias se definen por los primeros dos dígitos (hs2) de la clasificación internacional del Sistema Armonizado. Las regresiones incluyen efectos fijos a nivel variedad, donde las variedades se definen como una combinación de productos ( 8 dígitos) y países de origen. Los errores estándar son robustos y se clusterizan a 4 dígitos. Se utiliza el valor unitario (valor FOB dividido cantidad) como proxy del precio. Se pondera por la participación de cada variedad en las importaciones anuales de la industria correspondiente. Los resultados no cambian al utilizar valor CIF en lugar de FOB, otros ponderadores, y otros grupos de clusters. Fuente. Datos de aduana del INDEC (Argentina). 


\section{Marco teórico}

Sea $P_{j t}$ el precio de un producto importado $j$ en el momento $t$ denominado en moneda extranjera (medido en dólares estadounidenses en la aduana). ${ }^{17}$ El precio final que paga un consumidor en moneda local $\left(P_{j t}^{D}\right)$ puede expresarse como el precio en dólares multiplicado por el tipo de cambio del período $e_{t}$, más un componente aditivo que representa los costos locales $T_{j t}$ (e.g. costos de transporte, marketing, o cualquier otro costo asociado a la producción/venta) y cierto margen de ganancia al por mayor y/o por menor $R_{j t}>1$ :

$$
P_{j t}^{D}=\left(P_{j t} e_{t}+T_{j t}\right) R_{j t}
$$

Un aumento en el tipo de cambio $e_{t}$ provoca un aumento en el precio expresado en moneda doméstica $P_{j t}^{D}$. Si el aumento en $P^{D}$ es menos que proporcional al aumento en $e_{t}$ se dice que el traslado a precios de la devaluación (exchange-rate pass-through) es imperfecto o incompleto. Recordar las tres explicaciones estándar de la literatura: (i) los costos locales $T_{j t}$ (mayormente no transables) suelen expresarse en moneda doméstica y en principio, no deberían verse afectados por variaciones del tipo de cambio; (ii) en un contexto de competencia imperfecta, las firmas (domésticas o internacionales) pueden reducir sus márgenes de ganancia $\left(R_{j t}\right.$ o $\left.P_{j t}\right)$ frente a variaciones del tipo de cambio para mantener/ampliar su participación de mercado, lo que reduce el impacto en los precios finales; y (iii) las firmas enfrentan algún costo a la hora de ajustar sus precios de venta $\left(P^{D}\right)$.

En este trabajo se discute una explicación alternativa para el pass-through incompleto. El hecho estilizado que origina la hipótesis de trabajo es la marcada reducción en el precio de los bienes importados $P_{j t}$ (medidos en dólares en aduana) en los años que siguen a la depreciación real de la moneda doméstica. Este hallazgo está presente en todos los episodios devaluatorios estudiados. El argumento teórico propuesto es simple. La devaluación reduce ingreso real (medido en dólares) y ello disminuye la disposición a pagar por calidad de los consumidores. Ello provoca un proceso de sustitución hacia variedades de menor precio y menor calidad, e incentiva a las firmas a reducir tanto la calidad como los márgenes de ganancia de las variedades que ofrecen en este mercado. ${ }^{18} \mathrm{El}$

\footnotetext{
${ }^{17}$ Sin pérdida de generalidad, a lo largo de toda la discusión teórica se omite el subíndice $i$ correspondiente a la industria de cada producto $j$.

${ }^{18}$ Como ya se mencionó, existe un enorme volumen de literatura que muestra que las firmas cobran distintos precios para un mismo producto en distintos mercados (PTM), o ajustan sus mark-ups en respuesta a
} 
modelo pretende ilustrar estos mecanismos y sirve de base para la estimación estructural que permite cuantificarlos.

Se trabaja con un modelo estructural en equilibrio parcial que consta de tres elementos: la demanda de los consumidores, los costos de las firmas internacionales, y las condiciones de equilibrio. ${ }^{19}$ Por el lado de la demanda, se utiliza un modelo de elección discreta para productos diferenciados. Por el lado de la oferta, es necesario realizar ciertos supuestos sobre la forma funcional de la función de costos de los productores internacionales, y sobre la estructura de competencia inherente al mercado internacional. Siguiendo un supuesto estándar en la literatura, se asume una estructura de mercado de competencia monopolística. Luego se resuelve el problema de optimización de la firma y se deriva un conjunto de condiciones de primer orden (CPO). De estas CPO se desprenden dos resultados de estática comparada en respuesta a un shock en el tipo de cambio. La devaluación reduce el ingreso real (medido en dólares) de los consumidores domésticos y disminuye la disposición a pagar por calidad (pues aumenta la utilidad marginal del ingreso disponible). Entonces, las firmas (i) reducen sus mark-ups de equilibrio, y (ii) reducen la calidad óptima de los productos que ofrecen. Es importante notar que el supuesto fundamental detrás de este enfoque es que las firmas se encuentran siempre en equilibrio, debido a que las CPO se cumplen en todo momento. El modelo no permite que las firmas se encuentren temporalmente fuera del equilibrio. Si hay un shock de oferta o de demanda, las firmas ajustan automáticamente hacia un nuevo equilibrio, de modo que no se contempla la posibilidad de que existan costos de ajuste de precios (rigideces nominales). Al tratarse de un modelo estático, tampoco se tienen en cuenta factores dinámicos que podrían afectar las estimaciones de los parámetros de demanda o la calibración de los parámetros de costos. Por ejemplo, se ignora el hecho de que los importadores puedan mantener inventarios en respuesta a disminuciones de precios temporales.

\subsection{Consumidores}

Los consumidores tienen preferencias de elección discretas. Esto significa que eligen aquella variedad que les provee el mayor nivel de utilidad indirecta. La utilidad que el

shocks de demanda/costos. Dado que es probable que las firmas exporten una amplia gama de variedades de un mismo producto, una caída en la calidad podría explicarse, por ejemplo, por un aumento de la participación de segundas marcas y/o modelos de menor calidad relativa.

${ }^{19} \mathrm{La}$ aplicación de este tipo de modelos no es una novedad en la literatura de economía internacional. Existen varios trabajos dedicados a estudiar el fenómeno de pass-through basados en la estimación de modelos estructurales (Hellerstein (2008); Nakamura y Zerom (2010); Hellerstein y Villas-Boas (2010); Goldberg y Hellerstein (2013)). Es importante que al leer el modelo, el lector tenga presente que los parámetros se estiman utilizando datos en panel de precios y cantidades de productos importados. 
individuo $h$ deriva de elegir el producto $j$ que proviene del país $s$ en el momento $t$ está dada por la siguiente función de utilidad indirecta:

$$
U_{h j s t}=\theta_{j s t}-\alpha\left(y_{h t}\right) \log \left(p_{j s t}\right)+\mu_{h j}(\sigma)+(1-\sigma) \epsilon_{h j s t}
$$

con $\epsilon_{\text {hjst }} \stackrel{\text { iid }}{\sim}$ valor extremo tipo I (McFadden (1981), Cardell (1991)). Este componente captura aquellos atributos cuya valoración depende de cada consumidor (e.g. el color de una prenda de vestir), y por lo tanto se supone que en promedio proveen una utilidad igual a cero. Todos los productos se agrupan de manera predeterminada en conjuntos exhaustivos y mutuamente excluyentes, de modo que el término de error del modelo se descompone en un shock aleatorio i.i.d. $\left(\epsilon_{h j s t}\right)$ más un componente específico a cada grupo de productos $\left(\mu_{h j}\right) .{ }^{20}$ Este último término es el que genera la estructura anidada (nested) pues permite que las preferencias de un consumidor $h$ estén más correlacionadas para las distintas variedades de un mismo producto $j$ (within nest) que para las variedades de productos distintos (across nests). Empíricamente, estos grupos/categorías de producto (nests) surgen naturalmente de la estructura de clasificación de los datos de comercio internacional. El parámetro $\sigma$ captura el grado de correlación entre las distintas variedades $s$ de un mismo producto $j$. A medida que $\sigma$ se aproxima a cero este modelo converge al tradicional modelo logit. Este parámetro también puede asociarse con la elasticidad Armington utilizada en modelos tradicionales de teoría del consumidor y comercio internacional, que representa la elasticidad de sustitución entre productos transables elaborados por distintos países (Armington, 1969).

$\theta_{j s t}$ es la calidad y $p_{j s t}$ es el precio. El coeficiente $\alpha\left(y_{h t}\right)$ que acompaña al precio es la utilidad marginal del ingreso, o la inversa de la disposición a pagar, que se supone depende negativamente del ingreso del consumidor $\left(y_{h t}\right)$. Por lo tanto, un cambio en el ingreso real altera la utilidad relativa del precio y la calidad. Se supone que tanto los precios como el ingreso están expresados en moneda extranjera (dólares estadounidenses). Cuando hay una caída en el ingreso real, el coeficiente $\alpha\left(y_{h t}\right)$ aumenta, reflejando que los consumidores valoran más el ingreso disponible, lo que equivale a valorar relativamente menos la calidad. En este modelo, el componente vertical de la diferenciación de producto $\left(\theta_{j s t}\right)$ puede interpretarse como un atributo observable o inobservable (e.g. calidad percibida) que aumenta la valoración por parte de los consumidores y que los induce

\footnotetext{
${ }^{20}$ Cardell $(1991)$ demostró que si $\epsilon \stackrel{i i d}{\sim} E V$, luego $\mu+(1-\sigma) \epsilon \stackrel{i i d}{\sim} E V$ es la única distribución que satisface esta propiedad distributiva.
} 
a pagar más por determinada variedad. Manteniendo el precio constante, todos los consumidores preferirían un producto de mayor calidad y por tanto la demanda aumentaría si se incrementase la calidad.

Es importante notar que en la especificación de utilidad elegida se asume una forma funcional no lineal para el precio. Este supuesto se realiza debido a que el modelo logit tradicional (lineal en $p$ ) genera predicciones contraintuitivas con respecto a los precios elegidos por las firmas en contextos de competencia imperfecta, dado que los mark-ups dependen negativamente de la calidad del producto. Sin embargo, lo esperable es que ocurra lo contrario. ${ }^{21}$ Esta situación se resuelve asumiendo una forma funcional del tipo $\log (p)$, que resulta en un modelo de elasticidad de demanda constante (dado el supuesto de competencia monopolística), tal como se muestra en la siguiente subsección.

En este modelo, cada consumidor escoge aquella variedad que le provee un mayor nivel de utilidad indirecta. Asumiendo la existencia de un consumidor representativo $h \mathrm{y}$ agregando a través de las demandas individuales (aplicando Ley de Grandes Números) es posible derivar la conocida fórmula para la participación de mercado (o market share) de cada variedad $j s$ en un modelo del tipo nested logit:

$$
w_{j s t}\left(p_{j s t}, \theta_{j s t}, D_{j t}, y_{t}\right)=\frac{\exp \left(\frac{\theta_{j s t}-\alpha\left(y_{t}\right) \log \left(p_{j s t}\right)}{1-\sigma}\right)}{D_{j t}^{\sigma} \sum_{j^{\prime}=0}^{J_{t}} D_{j^{\prime} t}^{1-\sigma}}
$$

donde $J$ es el número de productos disponibles en el mercado, y $D_{j t}$ es un índice a nivel producto (inclusive-value term) que resume las características (precio y calidad) de las diferentes variedades de un mismo producto. El índice $D$ tiene la siguiente expresión:

$$
D_{j t}=\sum_{s \in S} \exp \left(\frac{\theta_{j s t}-\alpha\left(y_{t}\right) \log \left(p_{j s t}\right)}{1-\sigma}\right)
$$

donde $S$ es el set de variedades disponibles (países de origen) para el producto $j$. Sin pérdida de generalidad, se asume que $D_{0 t}=1$. Ello significa que existe un bien externo (outside good) que en promedio provee cero utilidad y es el único producto que compone el grupo 0. Este bien complementa el sistema de demanda pues permite racionalizar la posibilidad de que los consumidores elijan no consumir, o bien comprar determinado

\footnotetext{
${ }^{21}$ Evidencia empírica a favor de una relación positiva entre mark-ups y calidad puede encontrarse en Berry, Levinsohn y Pakes (1995), Chatterjee, Dix-Carneiro y Vichyanond (2013), y Caselli, Chatterjee y Woodland (2017), entre otros. Estos hallazgos son consistentes con modelos donde la elasticidad de demanda percibida disminuye con la performance de la firma, como en Melitz y Ottaviano (2008) o Atkeson y Burstein (2008).
} 
producto que se encuentra al margen del sistema de demanda.

\subsection{Firmas}

Las firmas internacionales ofrecen una variedad $s$ del producto diferenciado $j$. Eligen precio y calidad en pos de maximizar beneficios (ingreso total neto del costo total). Se asume una estructura de mercado de competencia monopolística, de modo que las firmas son lo suficientemente pequeñas como para que sus elecciones de precio y calidad no afecten el índice $D$. Por simplicidad, se asumen rendimientos constantes a escala. El costo marginal $c\left(\theta_{j s t}\right)$ depende únicamente de la calidad del producto final. ${ }^{22}$ Se supone que el costo marginal $c($.$) es estrictamente creciente y convexo en calidad (derivadas primera \mathrm{y}$ segunda estrictamente mayores a cero). El problema de la firma es el siguiente:

$$
\max _{\left(p_{j s t}, \theta_{j s t}\right)} \Pi_{j s t}=\left[p_{j s t}-c\left(\theta_{j s t}\right)\right] w_{j s t}\left(p_{j s t}, \theta_{j s t}, \mathbf{D}_{j t}, y_{t}\right)
$$

A partir de la optimización de la firma se obtienen las CPO que determinan el precio y la calidad de equilibrio (ver el Apéndice para una derivación matemática completa):

$$
\begin{array}{ll}
\boldsymbol{p}: & p_{j s t}=\left(\frac{\alpha\left(y_{t}\right)}{\alpha\left(y_{t}\right)-(1-\sigma)}\right) c\left(\theta_{j s t}\right) \\
\boldsymbol{\theta}: & p_{j s t}=\alpha\left(y_{t}\right) \frac{\partial c\left(\theta_{j s t}\right)}{\partial \theta_{j s t}}
\end{array}
$$

La primera ecuación muestra que el precio es creciente en la calidad si y solo si $\alpha\left(y_{t}\right)>(1-\sigma)$, y que los mark-ups son constantes a través de las firmas, dado el supuesto sobre la forma funcional (log) del precio en la ecuación de demanda. La segunda ecuación muestra que la calidad óptima depende positivamente de la valoración por la calidad (disposición marginal a pagar) y negativamente del costo marginal de producir calidad, de modo que las firmas más eficientes eligen óptimamente un mayor nivel de calidad. La representación gráfica del equilibrio se muestra en la Figura 2.

La línea sólida azul representa la primera $\mathrm{CPO}\left(p_{j s t}\right)$ y la curva punteada roja refiere

\footnotetext{
${ }^{22}$ Naturalmente, el costo de la firma también depende del precio de los insumos y de la tecnología utilizada, que probablemente varían a través de las firmas y en el tiempo. Por simplicidad, estos parámetros se dejan fuera del modelo teórico. Para la implementación empírica y estimación estructural se realizan supuestos adicionales sobre la forma de la función de producción en pos de calibrar dos parámetros de la función de costos de las firmas, asociados por ejemplo al precio de los insumos y a la tecnología utilizada para producir calidad.
} 


\section{FIGURA 2}

Precio y calidad de equilibrio

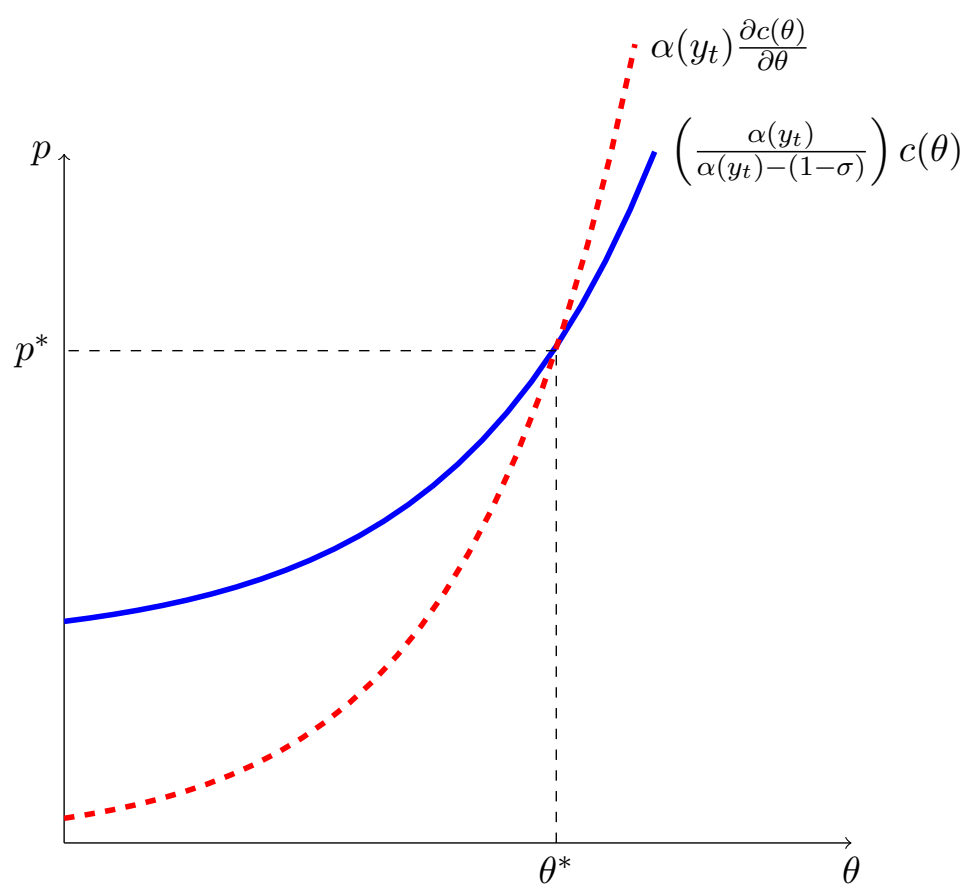

Notas. La curva sólida azul grafica la CPO respecto de $(p)$, mientras que la curva punteada roja ilustra la $\mathrm{CPO}$ de $(\theta)$. Cada firma elige aquella combinación óptima de precio y calidad $\left(\theta^{*}, p^{*}\right)$ donde ambas ecuaciones se cumplen simultáneamente. La existencia de este equilibrio impone una restricción sobre la relación entre el valor del costo marginal y los parámetros de la demanda (pendiente de ambas curvas): $\left(\frac{c^{\prime \prime}(\theta)}{c^{\prime}(\theta)}\right)>\left(\frac{1}{\alpha\left(y_{t}\right)-(1-\sigma)}\right)$.

a la segunda $\mathrm{CPO}\left(\theta_{j s t}\right)$. La primera curva denota al precio como una función creciente la calidad, tal como se muestra en la ecuación (4.6), mientras que la segunda representa al costo marginal (y por tanto al precio) como una función creciente en calidad. La contribución marginal de la calidad a los costos marginales y a la utilidad se igualan en el nivel de calidad óptimo, como sugiere la ecuación (4.7). Cada firma elige la combinación $\left(\theta^{*}, p^{*}\right)$ tal que ambas ecuaciones se cumplen simultáneamente. La existencia de este equilibrio impone una restricción que relaciona el valor del costo marginal y los parámetros de la demanda: $\left(\frac{c^{\prime \prime}(\theta)}{c^{\prime}(\theta)}\right)>\left(\frac{1}{\alpha\left(y_{t}\right)-(1-\sigma)}\right) \cdot 23$

Diferenciando las condiciones de primer orden, se puede mostrar fácilmente que las derivadas del precio y la calidad de equilibrio con respecto al ingreso $\left(y_{t}\right)$ vienen dadas

\footnotetext{
${ }^{23}$ Intuitivamente, esta condición garantiza que ambas curvas se crucen para algún valor positivo del precio y la calidad. La pendiente de la CPO de $(\theta)$ debe ser mayor que la pendiente de la CPO de $(p)$. Notar también que el intercepto en la primer ecuación es mayor que en la segunda. Por último, recordar que $p^{*}$ y $\theta^{*}$ se refieren a el precio y la calidad a nivel variedad (máximo nivel de desagregación posible teórica y empíricamente).
} 
por las siguientes ecuaciones:

$$
\begin{gathered}
\frac{\partial p_{j s t}}{\partial y_{t}}=\frac{-\alpha^{\prime}\left(y_{t}\right)(1-\sigma) c_{j s t}(\theta)}{\left[\alpha\left(y_{t}\right)-(1-\sigma)\right]^{2}}+\frac{\alpha\left(y_{t}\right) c_{j s t}^{\prime}(\theta)}{\left[\alpha\left(y_{t}\right)-(1-\sigma)\right]} \frac{\partial \theta_{j s t}}{\partial y_{t}}>0 \\
\frac{\partial \theta_{j s t}}{\partial y_{t}}=\frac{1}{c_{j s t}^{\prime \prime}(\theta) \alpha\left(y_{t}\right)}\left[\frac{\partial p_{j s t}}{\partial y_{t}} \alpha\left(y_{t}\right)-p_{j s t} \alpha^{\prime}\left(y_{t}\right)\right]>0
\end{gathered}
$$

Tanto el precio como la calidad son crecientes en el ingreso bajo los supuestos previamente realizados de que $\alpha^{\prime}\left(y_{t}\right)<0, c^{\prime \prime}(\theta)>0,\left[\alpha\left(y_{t}\right)-(1-\sigma)\right]>0, \mathrm{y}\left(\frac{c^{\prime \prime}(\theta)}{c^{\prime}(\theta)}\right)>$ $\left(\frac{1}{\alpha\left(y_{t}\right)-(1-\sigma)}\right)$. Esta última condición es necesaria para la existencia de un equilibrio donde el precio y la calidad toman valores positivos. Cuando el ingreso es mayor, los consumidores tienen una mayor disposición a pagar por calidad y ello incrementa la calidad óptima. Los precios también son crecientes en el ingreso, por las dos razones que ilustran ambos componentes de la derivada: mayor calidad implica mayores costos marginales, y mayor disposición a pagar implica mayores mark-ups en equilibrio.

\subsection{Shock en el tipo de cambio real}

La depreciación real de la moneda provoca una disminución del ingreso de los consumidores domésticos (medido en moneda extranjera). Por tanto, el ingreso medido en dólares disminuye de $y_{0}$ a $y_{1}$. Como consecuencia, disminuye la disposición a pagar por calidad de los consumidores. Ello se ve reflejado en un aumento de la utilidad marginal del ingreso de $\alpha\left(y_{0}\right)$ a $\alpha\left(y_{1}\right)$. Las derivadas de las $\mathrm{CPO}$ con respecto al ingreso muestran que las firmas tienen incentivos a reducir sus márgenes de ganancia, y la calidad del producto que ofrecen (ver ecuaciones 4.8 y 4.9). La Figura 3 ilustra este fenómeno.

\section{4 Índices de precios contrafácticos}

En esta sección se desarrolla un procedimiento que permite desagregar el cambio en precios a nivel producto en respuesta a un shock en el tipo de cambio real que provoca la disminución del ingreso medido en dólares. Es importante destacar que estos ejercicios permiten estudiar el pass-through del tipo de cambio hacia los precios de aduana (primer nivel). Esto no es inconsistente con la existencia de los canales habituales de traslado imperfecto (e.g. costos domésticos, márgenes de ganancias domésticos, rigideces de precios). Notar que estos factores son los que explican la diferencia entre los precios de 


\section{FIGURA 3}

Depreciación y reducción del ingreso

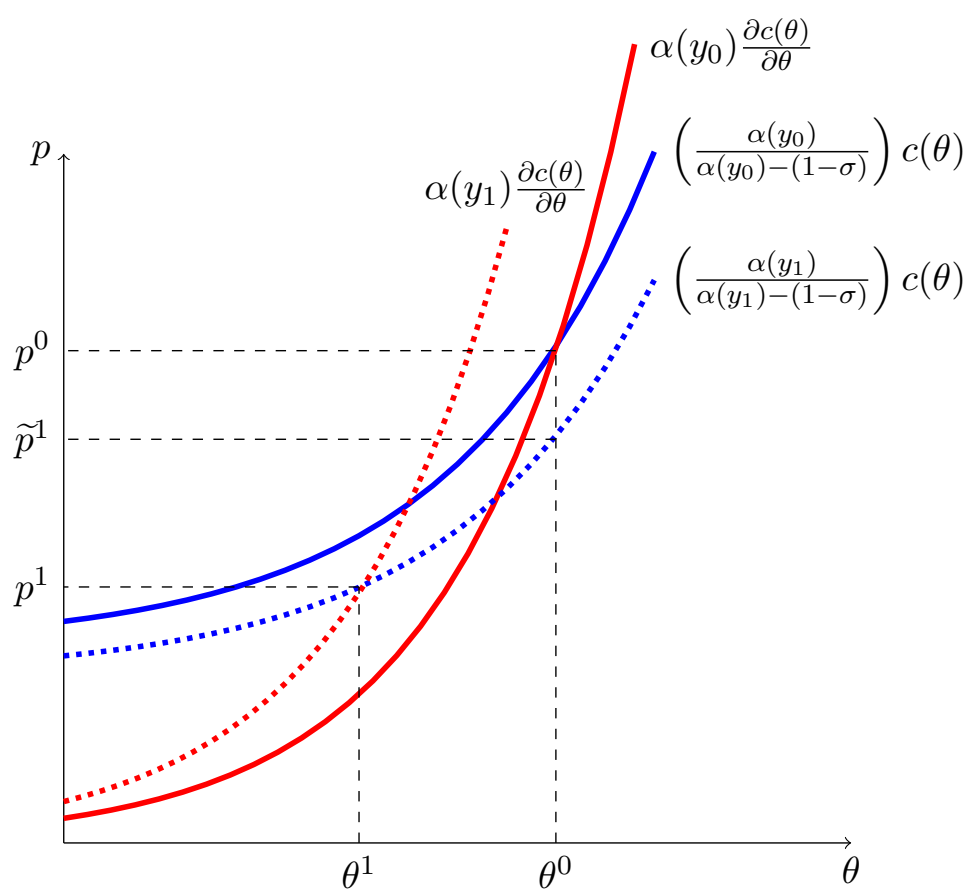

Notas. $\left(\theta^{0}, p^{0}\right)$ y $\left(\theta^{1}, p^{1}\right)$ representan el precio y la calidad de equilibrio en las dos situaciones. Un shock de ingresos negativo aumenta la utilidad marginal del ingreso $\alpha\left(y_{t}\right)$, desplazando ambas curvas. Las firmas tienen un incentivo a ajustar sus márgenes de ganancia como así también la calidad de la variedad que venden. (i) Manteniendo la calidad inicial fija en $\theta_{0}$, el precio óptimo a nivel variedad está dado por $\widetilde{p}^{1}$. (ii) Las firmas también reducen la calidad hasta $\theta_{1}$ porque su valoración relativa ha caído, lo que reduce aún más el precio a nivel variedad debido a la reducción en el costo de producción.

aduana y los precios de venta a los consumidores (segundo nivel).

El primer paso es elaborar un índice de precios a nivel producto. Este índice se construye agregando a través de las variedades (países de origen $s$ ). El precio de un producto $\left(P_{j t}\right)$ se define como el promedio ponderado de los precios de las distintas variedades que lo componen $\left(p_{j s t}\right)$, utilizando como ponderador a la demanda o participación de mercado de cada variedad dentro del ingreso total del producto $j\left(\omega_{j s t}\right)$. Reemplazando el precio de equilibrio en las ecuaciones de demanda (4.3) y (4.4), se obtienen los market shares o ponderadores de equilibrio, que a su vez dependen de la calidad y el resto de las variables exógenas $\left(D_{j t}, y_{t}\right)$. Luego, el precio promedio de un producto $j$ viene dado por:

$$
\bar{P}_{j t}=\sum_{s \in S_{j t}} \omega_{j s t}\left(\theta_{j s t}, D_{j t}, y_{t}\right) p_{j s t}\left(\theta_{j s t}, y_{t}\right)
$$


Una devaluación disminuye los ingresos reales desde $y_{0}$ a $y_{1}$. Dado que el precio de un producto es creciente en el ingreso, la devaluación provoca una caída en los precios de aduana medidos en dólares.

Proposición 1: El índice de precios a nivel producto es creciente en el ingreso. Por lo tanto, una depreciación real que disminuye el ingreso reduce el índice de precios.

Demostración:

Se calcula la derivada del índice de precios con respecto al ingreso:

$$
\frac{\partial P_{j t}}{\partial y_{t}}=\sum_{s \in S_{j t}} \frac{\partial w_{j s t}(.)}{\partial y_{t}} p_{j s t}(.)+\sum_{s \in S_{j t}} w_{j s t}(.) \frac{\partial p_{j s t}(.)}{\partial y_{t}}
$$

Notar que el segundo término es positivo puesto que $\frac{\partial p_{j s t}(.)}{\partial y_{t}}>0$ (ver ecuación (4.8)).

El primer término es positivo si $\frac{\partial w_{j s t}}{\partial y_{t}}>0$ :

$$
\frac{\partial w_{j s t}}{\partial y_{t}}=w_{j s t}(-1) \frac{\log \left(p_{j s t}\right)}{1-\sigma} \alpha^{\prime}\left(y_{t}\right)>0
$$

Dado que, por supuesto, $\alpha^{\prime}\left(y_{t}\right)<0$. Finalmente, se tiene que $\frac{\partial P_{j t}}{\partial y_{t}}>0$.

Por lo tanto, comparando el índice de precios antes de la depreciación real $\left(\bar{P}_{j 0}\right)$ y después de la misma $\left(\bar{P}_{j 1}\right)$, se tiene que:

$$
\begin{aligned}
\Delta_{t} P_{j} & =\bar{P}_{j 1}-\bar{P}_{j 0}<0 \\
\Delta_{t} P_{j} & =\sum_{s} \omega\left(\theta_{j s 1}, D_{j 1}, y_{1}\right) p\left(\theta_{j s 1}, y_{1}\right)-\sum_{s} \omega\left(\theta_{j s 0}, D_{j 0}, y_{0}\right) p\left(\theta_{j s 0}, y_{0}\right)<0
\end{aligned}
$$

Agregando y sustrayendo dos índices de precios que tienen en cuenta el ajuste en la calidad $\left(\widetilde{P}_{j 1}\right)$ y la sustitución entre variedades de distinto precio y calidad $\left(\breve{P}_{j 1}\right)$ es posible descomponer de manera exacta el cambio total en el precio de un producto en los tres componentes que interesa cuantificar: cambio en mark-ups (a nivel variedad); cambio en calidad (a nivel variedad); y efectos sustitución (a nivel producto): 


$$
\begin{aligned}
& \Delta_{t} P_{j}=\bar{P}_{j 1}-\bar{P}_{j 0}<0 \\
& \Delta_{t} P_{j}=\Delta_{j}^{1}+\Delta_{j}^{2}+\Delta_{j}^{3} \\
& \Delta_{t} P_{j}=\underbrace{\left(\widetilde{P}_{j 1}-\bar{P}_{j 0}\right)}_{\text {Mark-ups }}+\underbrace{\left(\breve{P}_{j 1}-\widetilde{P}_{j 1}\right)}_{\text {Calidad }}+\underbrace{\left(\bar{P}_{j 1}-\breve{P}_{j 1}\right)}_{\text {Sustitución }}
\end{aligned}
$$

Los tres términos representan una triple disminución en el precio de un producto. Primero, existe un efecto mark-ups. Debido a que los consumidores están dispuestos a pagar un precio menor por un producto de determinada calidad, las firmas tienen incentivo a reducir el precio de la variedad que ofrecen. Es importante notar que todas las firmas disminuyen el precio en la misma proporción. ${ }^{24}$ Segundo, hay un efecto calidad. Dado que la valoración relativa por la calidad disminuye, las firmas también tienen incentivos a reducir la calidad del producto ofrecido. Ello genera una reducción adicional en el precio de cada variedad debido a la reducción del costo de producción. Tercero, se produce un efecto sustitución. Los cambios en el ingreso, los precios y las calidades afectan la participación de cada variedad dentro del ingreso total de cada producto. Este cambio composicional afecta el precio promedio de cada producto. Los tres componentes tienen signo negativo y contribuyen a explicar la reducción del precio de un producto importado como consecuencia de la caída en la disposición a pagar.

Nuevamente, se parte de una reducción en el ingreso real que incrementa la utilidad marginal del ingreso $\alpha\left(y_{t}\right)$. Condicional en la calidad, los consumidores están dispuestos a pagar menos por cada variedad. Esta disminución en la disposición a pagar incentiva una reducción de precios por parte de las firmas (ajuste de mark-ups a nivel variedad). Manteniendo la calidad fija, los precios óptimos a nivel variedad están dados por $\widetilde{p}^{1}$ (ver Figura 3). Por lo tanto, el índice de precios a nivel producto que incorpora el ajuste de mark-ups es el siguiente:

$$
\widetilde{P}_{j 1}=\sum_{s \in S_{j t}} \omega_{j s 0}\left(\theta_{j s 0}, D_{j 0}, y_{0}\right) \widetilde{p}^{1}\left(\theta_{j s 0}, y_{1}\right)
$$

Luego se tiene que el cambio de precios derivado del ajuste del mark-up a nivel

\footnotetext{
${ }^{24}$ Es probable que exista cierta heterogeneidad en el ajuste de los mark-ups en función del tamaño/productividad de cada firma o la calidad del producto ofrecido. Amiti, Itskhoki y Konings (2018) muestran que las firmas ajustan precios en función de sus propios costos $(60 \%)$ y en función del precio de sus competidores (40\%). La importancia de la complementariedad estratégica en la fijación de precios es creciente en el tamaño de las firmas.
} 
variedad es: $\Delta_{j}^{1}=\widetilde{P}_{j 1}-\bar{P}_{j 0}<0$.

Las firmas también tienen incentivos a ajustar la calidad de la variedad que ofrecen debido a que su valoración relativa ha caído. La reducción de la calidad disminuye el costo de producción y reduce aún más el precio de las variedades (ver Figura 3). Como resultado, el precio a nivel variedad disminuye a $p^{1}$, y el índice de precios a nivel producto queda como sigue:

$$
\breve{P}_{j 1}=\sum_{s \in S_{j t}} \omega_{j s 0}\left(\theta_{j s 0}, D_{j 0}, y_{0}\right) p^{1}\left(\theta_{j s 1}, y_{1}\right)
$$

Luego se tiene que el cambio de precios por ajuste de calidad a nivel variedad es: $\Delta_{j}^{2}=\breve{P}_{j 1}-\widetilde{P}_{j 1}<0$.

Finalmente, el cambio en ingresos, precios y calidades afecta la demanda y por tanto la participación de cada variedad en los ingresos de cada producto $\left(\omega_{j s 1}\right)$. Cambia la composición de las distintas variedades dentro de cada producto. El market share de las variedades de menor precio y menor calidad aumenta en detrimento de la participación de la variedades de mayor precio y mayor calidad. Luego de este proceso de sustitución entre distintas variedades, el índice de precios a nivel producto en la situación final es el siguiente:

$$
\bar{P}_{j 1}=\sum_{s \in S_{j t}} \omega_{j s 1}\left(\theta_{j s 1}, D_{j 1}, y_{1}\right) p^{1}\left(\theta_{j s 1}, y_{1}\right)
$$

Luego se tiene que el cambio de precios por sustitución de variedades a nivel producto es: $\Delta_{j}^{3}=\bar{P}_{j 1}-\breve{P}_{j 1}<0$.

Proposición 2: A nivel variedad, manteniendo la calidad fija en el nivel inicial $\left(\theta_{0}\right)$, el precio es decreciente en $\alpha(y)$. Luego, se tiene que $\Delta_{j}^{1}<0$.

Demostración:

Se calcula la derivada del precio de equilibrio (ecuación (4.6)) con respecto a $\alpha(y)$ :

$$
\frac{\partial p_{j s t}}{\partial \alpha\left(y_{t}\right)}=\frac{-(1-\sigma)}{\alpha(.)-(1-\sigma)} c_{j s t}(.)+\frac{\alpha(.)}{\alpha(.)-(1-\sigma)} c_{j s t}^{\prime}\left(\theta_{j s t}\right) \frac{\partial \theta_{j s t}}{\partial \alpha\left(y_{t}\right)}
$$

Notar que el primer término es negativo porque se supone que $\alpha()>.(1-\sigma)$ (condición necesaria para la existencia del equilibrio). 
El segundo término es igual a cero porque la calidad se mantiene fija $\left(\theta_{0}\right)$, de modo que $\frac{\partial \theta_{j s t}}{\partial \alpha\left(y_{t}\right)}=0$.

Finalmente, se tiene que $\frac{\partial p_{j s t}}{\partial \alpha\left(y_{t}\right)}<0$.

Proposición 3: A nivel variedad, el precio y la calidad de equilibrio son decrecientes en $\alpha(y)$. Luego, el cambio total en el precio es mayor a la reducción producida únicamente por la baja del mark-up $\left(\Delta_{j}^{2}<0\right)$.

Demostración:

Se calcula la derivada de la calidad de equilibrio (ecuación (4.7)) con respecto a $\alpha(y)$ :

$$
\frac{\partial p_{j s t}}{\partial \alpha\left(y_{t}\right)}=\frac{\partial c_{j s t}(.)}{\partial \theta_{j s t}}+\alpha\left(y_{t}\right) c_{j s t}^{\prime}(.) \frac{\partial \theta_{j s t}}{\partial \alpha\left(y_{t}\right)}
$$

Reordenando los términos, se tiene que:

$$
\frac{\partial \theta_{j s t}}{\partial \alpha\left(y_{t}\right)}=\frac{\partial p_{j s t}}{\partial \alpha\left(y_{t}\right)} \frac{1}{\alpha\left(y_{t}\right) c_{j s t}^{\prime}(.)}-\frac{1}{\alpha\left(y_{t}\right)}<0
$$

Puesto que $\frac{\partial p_{j s t}}{\partial \alpha\left(y_{t}\right)}<0$ (Proposición 2) y $\frac{1}{\alpha\left(y_{t}\right) c_{j s t}^{\prime}(.)}>0$.

Proposición 4: La participación de mercado de las variedades cuya calidad es menor a la calidad promedio es creciente en $\alpha(y)$. Luego, se tiene $\left(\Delta_{j}^{3}<0\right)$.

Demostración:

Partiendo de $\theta_{j s t}<\bar{\theta}_{j s t}$, se tiene que $c^{\prime}\left(\theta_{j s t}\right)<c^{\prime}\left(\theta_{j s t}^{-}\right)$.

Utilizando la segunda condición de equilibrio (ecuación (4.7)) se tiene que $\frac{p_{\text {jst }}}{\alpha(y t)}<$ $c^{\prime}\left(\bar{\theta}_{j s t}\right)$.

Luego, reemplazando la primera condición de equilibrio (ecuación (4.6)) en la ecuación anterior, se tiene que $\frac{1}{\alpha(.)-(1-\sigma)} c\left(\theta_{j s t}\right)<c^{\prime}\left(\bar{\theta}_{j s t}\right)$.

Diferenciando con respecto a $\theta_{j s t} \mathrm{y}$ multiplicando ambos lados por $\alpha($.$) se tiene que:$

$$
\frac{\alpha(.)}{\alpha(.)-(1-\sigma)} c^{\prime}\left(\theta_{j s t}\right)<\alpha(.) c^{\prime \prime}\left(\bar{\theta}_{j s t}\right)
$$

Notar que ambos lados representan la pendiente de las dos CPO. Esta última desigualdad se cumple únicamente si $\theta_{j s t}<\bar{\theta}_{j s t}$, que es la condición desde la cual se parte. Intuitivamente, significa que la $\mathrm{CPO}$ respecto de $p$ está por encima de la CPO 
respecto de $\theta$ (a la izquierda del punto de equilibrio en el gráfico).

La demostración es análoga en el otro caso (partiendo de $\theta_{j s t}>\bar{\theta}_{j s t}$ ). 


\section{Estimación}

\subsection{Fuentes de información}

Los microdatos que se utilizan en esta parte de la tesis se obtienen de tres fuentes distintas. Los microdatos de productos importados por Argentina provienen del Instutito Nacional de Estadísticas y Censos (INDEC), que recopila los datos del valor y volumen de importaciones registrados en aduanas, desagregando la información por tipo de producto y país de origen. Estos datos fueron obtenidos a través del Departamento de Pedidos Especiales. Se trata de un panel de datos que abarca el universo de productos importados durante el período 1999-2004. Hoy en día, esta información está disponible para un amplio conjunto de países. Los datos incluyen información anual del valor libre a bordo (Free-On-Board o FOB) y del valor costo-seguro-flete (Cost-Insurance-Freight o CIF), cantidades, países de origen y códigos de producto desagregados a 8 dígitos según la clasificación internacional del Sistema Armonizado. Siguiendo la práctica estándar en la literatura se utiliza el valor unitario (valor CIF dividido por la cantidad) como proxy del precio de cada variedad (8 dígitos-país de origen). Estos datos se utilizan para realizar la estimación estructural del modelo teórico desarrollado en la sección anterior.

La segunda fuente de información es la base de datos COMTRADE (Commodity Trade Statistics Database) elaborada por la Dirección de Estadísticas de Comercio de Naciones Unidas. Esta base también tiene estructura de panel y contiene información detallada sobre valores y cantidades importadas/exportadas por producto a 6 dígitos del Sistema Armonizado, reportadas por institutos de estadística de más de 100 países y regiones. Estos datos son públicos y de libre acceso, ingresando en la sección Get trade data (Comtrade, UNCTAD).$^{25}$ Estos datos se utilizan con dos propósitos. Primero, para describir el ajuste de precio, calidad y sustitución que ocurre en los doce episodios devaluatorios. Y segundo, para construir un "precio de referencia mundial" para cada país exportador, que se utiliza como variable instrumental en la etapa de estimación de la demanda. La idea es que este precio promedio a través de distintos destinos capture variaciones de costos a nivel de cada producto-país de origen.

La aproximación empírica para la definición de variedad utilizada en el modelo teórico está dada por la combinación producto-país de origen. De modo que se tienen tantas variedades de determinado producto como cantidad de países de origen desde los

\footnotetext{
$\overline{{ }^{25} \text { Los datos pueden descargarse en https://www.comtrade.un.org/ }}$
} 
cuales provenga dicho producto. Por ejemplo: se toma el caso de un producto definido a 6 dígitos del SA cuyo código es 841830 y se refiere a "Freezers en forma de cofre con una capacidad menor a los 800 litros". Este producto se importa desde 10 países distintos (Brasil, Estados Unidos, Sudáfrica, Portugal, China, Dinamarca, Italia, Japón, Luxemburgo y Reino Unido), de modo que estas serán las 10 variedades de este producto. El trabajo se concentra en todas las industrias de bienes manufacturados, definidas por los primeros dos dígitos del SA. En total se trabaja con 80 industrias distintas (códigos 16xxxx a 96xxxx). Se excluyen las industrias de productos homogéneos dado que, por definición, son bienes que no presentan demasiada diferenciación por calidad.

Es importante notar que en los datos de aduana no se cuenta con otra información específica de los productos importados más allá del país desde el cual provienen. No se tiene información sobre características de los productos tales como la marca, la antigüedad de la marca (que por ejemplo podríamos asociar con su prestigio), el modelo, o cualquier otro atributo/característica observable que pudiera ser valorada por los consumidores. Otro factor a tener en cuenta se relaciona con el hecho de que estos datos resultan de la agregación de todas las transacciones de importación que se realizan a lo largo del año y que probablemente incluyan productos con distintas características. Por ejemplo, imagine que desde Brasil se importaron tres marcas diferentes de "Freezers en forma de cofre con una capacidad menor a los 800 litros" en el año 1999. Lo que se observa en la data de 1999 es el valor importado total (en dólares) y la cantidad total de unidades importadas en esta categoría de producto (841830). En este ejemplo, el valor unitario (valor CIF sobre cantidad) será una aproximación del precio y reflejará un promedio ponderado por la participación de cada una de las marcas en el total importado desde Brasil dentro de esta categoría de producto en este año determinado. Las medidas de calidad estimadas a partir del sistema de demanda capturan parte de este efecto, tal como se explica más adelante.

Los datos de aduana suelen contener un alto componente de error de medición. Una de las razones es que los datos resultan de la agregación de microdatos aún más desagregados. Es recomendable entonces eliminar valores extremos antes de realizar las estimaciones. En este trabajo, se excluyen las observaciones cuyo valor unitario difiere en más/menos tres desvíos estándar respecto del valor unitario promedio anual de cada producto. Además, la muestra utilizada se restringe a los primeros 50 países exportadores, en función de la participación de mercado de cada exportador en las importaciones totales de cada país. La muestra final representa en promedio el $87 \%$ del valor total importado 
por los países estudiados durante este período.

La tercera fuente de información proviene de datos de registro administrativo de transacciones de importación, provenientes de las aduanas de Argentina y Chile. Estos datos incluyen el universo de transacciones de importación para un set limitado de productos (electrodomésticos y automóviles) durante el período 1999-2004. Los datos contienen información más detallada sobre las características de los bienes, con mayor grado de detalle en el caso de los automóviles importados (e.g. marca, modelo, motor, cantidad de puertas, etc.). El ejercicio que se realiza a partir de estos datos busca comparar la evolución de los precios de los mismos productos en ambos países (utilizando el método de Diferencias en Diferencias). El objetivo es mostrar que efectivamente se produce una reducción en el precio de los bienes importados por Argentina en los años que siguen a la devaluación, utilizando los "mismos" productos importados por Chile como grupo de control. La idea es controlar por la posibilidad de que existan shocks de costos o tecnológicos al interior de las firmas de determinado país de origen. A su vez, estos datos permite ilustrar con mayor precisión los mecanismos que pretende resaltar esta tesis, además de disparar algunas preguntas interesantes que abren posibles líneas de investigación futuras.

\subsection{Parámetros de demanda}

La estimación de los parámetros de la demanda y de la calidad está basada en la ecuación (4.3). Este enfoque sigue la contribución seminal de Berry (1994) a la literatura de estimación de demanda en modelos de elección discreta. Si se toman logaritmos y se normaliza $\omega_{j s t}$ con respecto a una alternativa $\omega_{0 t}$ que se encuentra por fuera del sistema de demanda (outside variety) se obtiene la siguiente ecuación de regresión (ver la derivación matemática en el Apéndice), que puede ser estimada por el método de Mínimos Cuadrados en Dos Etapas (MC2E):

$$
\log \left(\frac{\omega_{j s i t}}{\omega_{0 t}}\right)=\theta_{j s t}-\alpha_{t} \log \left(p_{j s t}\right)+\sigma \log \left(s_{s t \mid j}\right)+\varepsilon_{j s t}
$$

La variable dependiente es el logaritmo de la participación de mercado $\left(\omega_{j s i t}\right)$ de cada variedad $j s$ (medida en cantidades) en su respectiva industria $i$ en el año $t$, normalizada con respecto al market share de la alternativa externa. Recordar que esta normalización se realiza para permitir que el consumidor pueda escoger una variedad que se encuentra 
por fuera del sistema de demanda (o incluso no comprar ninguna variedad). No es necesario contar con una medida específica para la alternativa externa ya que la misma está absorbida por la inclusión de efectos fijos año-industria. Para la definición de una industria, se sigue directamente la estructura de los datos y se trabaja con los primeros dos dígitos de la clasificación internacional del Sistema Armonizado. El precio $p_{j s t}$ se aproxima con el valor unitario (valor CIF sobre la cantidad) y la participación anidada (nested share) $s_{s t \mid j}$ se refiere a la participación de cada variedad $j s$ dentro de la categoría de producto $j$ a la que pertenece (medida en cantidades, al igual que $\left.\omega_{j s i t}\right){ }^{26}$

En general es muy improbable que los datos de comercio internacional cuenten con información sobre atributos tangibles o intangibles que podrían vincularse con distintas dimensiones de la calidad de determinado producto (e.g. marca, diseño, material de fabricación, durabilidad, imagen creada en la mente de los consumidores debido al efecto de la publicidad, etcétera) de modo que no se puede utilizar una estrategia de modelación y estimación de demanda como logit con coeficientes aleatorios o precios hedónicos. Sin embargo, existen atributos que no dependen de los gustos específicos de cada consumidor. Aquellos atributos sobre los cuales existe cierto consenso por parte de los consumidores respecto a su valoración forman parte del componente vertical de la calidad. Mientras que los atributos que dependen de las preferencias de cada persona se asocian con componente horizontal. En la estimación se explota la dimensionalidad de los datos en panel especificando un componente de calidad de producto invariante en el tiempo dado por efectos fijos a nivel producto, al cual se suma el desvío respecto a dicha media dado por el efecto fijo año-país de origen:

$$
\hat{\theta}_{j s t}=\underbrace{\hat{\theta}_{j}+\hat{\theta}_{s t}}_{\text {Comp. Vertical }}+\underbrace{\hat{\varepsilon}_{j s t}}_{\text {Comp. Horizontal }}
$$

En este enfoque, la calidad representa la valoración promedio que los consumidores le asignan a cada variedad importada. Esta es una medida revelada de la calidad que tiene una intuición muy simple: la calidad de una variedad es la parte de su market share que no es explicada por su precio. La calidad de una variedad aumenta (cae) si su precio puede aumentar (disminuir) sin que la variedad pierda (incremente) participación de mercado. La ventaja de utilizar este enfoque estructural para estimar la demanda y la calidad es

\footnotetext{
${ }^{26}$ Recordar que esta variable se incorpora para permitir cierta correlación entre las variedades que pertenecen a una categoría de producto más desagregada (dado que a priori serían sustitutos más cercanos) que aquella que se utiliza para construir la variable dependiente. Permite controlar entonces parte de la correlación que existe en la estructura de preferencias de los consumidores.
} 
que las medidas obtenidas son comparables a través de los países y a lo largo del tiempo. Puede optarse por incluir los residuos estimados en la definición de calidad. Notar que esto es análogo a la literatura que estima productividad total de los factores (TFP) con microdatos de firmas. Sin embargo, si a uno le preocupa la posibilidad de que exista cierto componente de error de medición en la variable dependiente, no debería incorporar dicho error y considerar únicamente el componente vertical del modelo. En este caso, la calidad estimada necesariamente tiene una menor varianza que si se incluyera el error estimado. Los resultados en este trabajo no son sensibles a la inclusión/exclusión de este término residual en la definición de calidad.

Si bien son muchas las variables que pueden afectar a la participación de mercado, varios de estos elementos quedan fuera de la lista después de condicionar por el precio. Por ejemplo, los productos que provenien de Brasil podrían tener más participación de mercado por una cuestión geográfica (distancia) y/o por cuestiones asociadas a la política comercial relacionadas con el acuerdo de libre comercio que rige en la región (MERCOSUR). Sin embargo, el precio CIF incluye tanto los costos de transporte como las tarifas, de modo que la estimación de calidad controla parcialmente por factores geográficos y comerciales. Es importante destacar que la medida de calidad estimada no permite separar factores asociados a la tecnología que tiene incorporada una variedad de la valoración subjetiva que le atribuyen los distintos consumidores a cada uno de estos factores.

Recordar el problema de identificación tradicional de oferta y demanda en mercados con productos homogéneos. En un modelo simple de oferta y demanda el precio de equilibrio depende del término de error del modelo (ecuaciones simultáneas). Este problema también se extiende al caso de productos diferenciados, y se suma el hecho de que es muy probable que los precios estén correlacionados con algún componente no observado de la calidad. Por lo tanto, el precio y el nested share $\left(s_{s t \mid j}\right)$ están potencialmente correlacionados con el término de error del modelo $\left(\varepsilon_{j s t}\right)$. Es por ello que se utilizan variables instrumentales para identificar los parámetros de la ecuación de demanda.

En este trabajo se utilizan dos variables instrumentales para el precio (cost shifters). Estas variables pretenden capturar shocks de costos ocurridos en el país donde se produce cada variedad. Para ser válidas, estas variables deberían afectar el precio de los productos importados por cada país únicamente a través de sus costos. La primera variable es el costo de transporte unitario, que es específico a cada variedad, y se infiere directamente a partir de los datos de aduana provistos por el INDEC. Este costo se mide simplemente como la diferencia entre el precio CIF y FOB de cada variedad. El supuesto de identificación es 
que shocks a los costos de transporte no deberían generar desvíos respecto a la calidad promedio que decida proveer una firma. ${ }^{27}$ Es importante tener en cuenta que esta variable no está disponible en los datos de COMTRADE. Los datos proveen un único valor para cada transacción (presumiblemente el valor CIF) por lo que no es posible inferir el costo de transporte. El costo de transporte se utiliza entonces únicamente en la estimación de la ecuación de demanda de Argentina, a partir de los datos de INDEC. Para estimar la ecuación de demanda en los doce países estudiados se utiliza un único instrumento para el precio. La variable instrumental utilizada es el "precio de referencia mundial", entendido como el precio promedio de cada variedad en todos los mercados donde se vende cada variedad. Esta variable se calcula a partir de los datos de COMTRADE como el valor unitario promedio al cual cada país de origen $s$ exporta determinado producto $j$ a diferentes destinos $n$ :

$$
\bar{P}_{j s}=\frac{1}{N} \sum_{n \in N} V U_{j s n}
$$

Esta variable intenta capturar shocks de costos en el país de origen que afectan dicho precio, pero no están correlacionados con la calidad de los productos exportados a un país en particular. Este instrumento es válido siempre y cuando los shocks de demanda no estén correlacionados entre los distintos países. ${ }^{28}$ Esta variable es estadística y económicamente significativa, y tiene el signo positivo esperado en la primera etapa de la estimación de la ecuación de demanda.

Para instrumentar el nested share se utiliza una variable que pretende aproximar el grado de competencia o las posibilidades de sustitución entre las distintas variedades de cada producto, y por lo tanto posibilidades de subir el precio por encima del costo. Esta variable es simplemente el número de variedades (países de origen) distintas en cada categoría de producto (a 6 dígitos). En este caso, el supuesto de identificación es que la entrada/salida de variedades en cada momento del tiempo está correlacionada con el nested share, pero no con depende de las decisiones de elección de calidad de las firmas. Este supuesto se justifica teóricamente en función del modelo de competencia monopolística elegido, donde todas las firmas son atomísticas, y por tanto las decisiones de calidad que toma cada firma son independientes de las acciones (y el número) de sus competidores.

\footnotetext{
${ }^{27}$ Otros autores han realizado supuestos similares para identificar los parámetros de la ecuación de demanda. Ver por ejemplo las contribuciones de Khandelwal (2010) y Amiti y Khandelwal (2013).

${ }^{28}$ Nevo (2001) realiza un supuesto similar para justificar la validez de este tipo de instrumento en el contexto de distintas ciudades de Estados Unidos. Es probable que en un contexto internacional, la probabilidad de que existan shocks de demanda correlacionados entre distintos países se aún más baja.
} 
Este supuesto podría ser más problemático en industrias caracterizadas por un mayor grado de complementariedad estratégica en las decisiones de las firmas internacionales. Esta variable presenta una correlación negativa y estadísticamente significativa con el nested share (y también con el precio) en la primera etapa de la estimación de la ecuación de demanda.

Una vez estimada la ecuación de demanda (5.1) se obtienen: (i) la disposición a pagar $\frac{1}{\widehat{\alpha}_{t}}$, (ii) el parámetro de sustitución $\widehat{\sigma}$, y (iii) una medida de calidad a nivel variedad $\widehat{\theta}_{j s t}$. Esta medida permite comparar la evolución de la calidad a lo largo del tiempo al interior y a través de las distintas variedades y productos importados por todos los países estudiados.

Recordar que las estimaciones realizadas para el caso de Argentina se utilizan para calibrar los parámetros de costos que se utilizan posteriormente para estimar los precios, calidades y market shares contrafácticos que permiten realizar la descomposición del índice de precios a nivel producto. En este caso entonces, el precio $p_{j s t}$ se interactúa con una variable binaria Post que toma el valor 0 en los tres años del período pre-devaluación (1999-2001), y el valor 1 en los tres años que siguen a la devaluación del peso argentino (2002-2004).

La estrategia de identificación parte de suponer la exogeneidad de la devaluación de la moneda doméstica para el conjunto de firmas internacionales que exportan al país que devalúa su moneda. Hay algunos antecedentes en la literatura que utilizan episodios devaluatorios como experimentos que permiten identificar variaciones exógenas en los costos/demanda de las firmas (e.g. Revenga (1992); Abowd y Lemieux (1993); Verhoogen (2008); Brambilla, Lederman y Porto (2012)). Más aún, el tipo de cambio real frecuentemente se utiliza como variable instrumental en un amplio rango de trabajos empíricos, justificando su validez en la exogeneidad de este precio para el conjunto de firmas y/o consumidores. La modelización de sistemas de demanda en base a un modelo multinomial logit y la inferencia de los costos de producción a partir de supuestos sobre el comportamiento de las firmas son estándar en la literatura de comercio internacional y organización industrial. La descripción estadística y econométrica del problema (por ejemplo, la obtención de la función de demanda agregada, el rol que juegan los errores, los supuestos distributivos sobre los errores, etc.) también es estándar en cualquier libro avanzado de econometría. Ver, por ejemplo, las contribuciones seminales de Berry (1994), Berry, Levinsohn y Pakes (1995), y Goldberg (1995), que modelan calidad en base a características observables de los productos y utilizan los resultados para realizar 
ejercicios de simulación. Khandelwal (2010) se basa en un sistema de demanda con una parameterización similar a la que se utiliza en este trabajo para estimar la calidad de las manufacturas importadas por Estados Unidos.

La razón por la cual no se realizan los ejercicios de simulación en el resto de los episodios devaluatorios es la falta de robustez en la estimación del coeficiente de interacción del precio y en la recuperación de los parámetros calibrados de la ecuación de costos. Hay al menos tres razones que pueden explicar esta situación. En primer lugar, los datos de COMTRADE presentan mayor varianza y mayor error de medición que los datos provenientes de INDEC. Segundo, los datos presentan un mayor nivel de agregación (6 dígitos) en comparación con INDEC (8 dígitos). La cantidad total de variedades y la cantidad de variedades diferentes dentro de cada producto es significativamente menor en los datos de COMTRADE (40.570 y 9,2 en promedio, resp.) en comparación con INDEC (66.485 y 15,5 en promedio, resp.). Y tercero, en los datos de COMTRADE no es posible inferir el costo de transporte. Esta variable tiene un fuerte poder predictivo en la primera etapa de la estimación de la ecuación de demanda de Argentina. Por estas razones empíricas, la descomposición teórica del cambio de precios de los productos importados se realiza únicamente para el episodio devaluatorio de Argentina.

También existe una razón teórica que plantea interrogantes y una potencial línea de investigación a futuro. Se pueden pensar que la devaluación tiene dos efectos diferentes según la orientación internacional de las firmas importadoras. El primero es un efecto doméstico, asociado directamente con la hipótesis de esta tesis. La devaluación reduce el salario en dólares, disminuye la valoración marginal por la calidad, y genera incentivos a reducir la calidad y el precio promedio de los productos importados. Este efecto es muy intuitivo si uno piensa en bienes de consumo importados. El segundo es un efecto más bien internacional. La devaluación puede potenciar las exportaciones de las firmas domésticas. Estas firmas son intensivas en la utilización de insumos importados (Amiti, Itskhoki, y Konings, 2014). Si los insumos intermedios se destinan a elaborar productos que se venden en el mercado doméstico el efecto tiene que ir en la misma dirección que el efecto anterior. Sin embargo, si los insumos importados se utilizan para producir bienes exportables, la dominancia del efecto doméstico ya no es obvia. De hecho, la literatura muestra resultados en las dos direcciones. Verhoogen (2008) muestra evidencia de quality-upgrading en los años que siguen a la devaluación del peso mexicano de 1995. Mientras que Chatterjee, Dix Carneiro y Vichyanond (2013) presentan evidencia de quality-downgrading en la devaluación del real brasileño de 1999. Una cuestión que 
permite racionalizar estos hallazgos aparentemente contradictorios está asociada con la valoración por la calidad que tengan los consumidores que demandan tales exportaciones (Brambilla, Lederman, y Porto, 2012). La mayor parte de las exportaciones de México se destinan a Estados Unidos, y en este caso la devaluación aumentó la calidad promedio de las exportaciones mexicanas. En el caso de Brasil, la mayor parte de sus exportaciones se destinan a sus socios del MERCOSUR, por lo que la devaluación redujo la calidad de sus exportaciones. Naturalmente, ello también depende de factores geográficos y de cuestiones relacionadas con la política comercial. Nuevamente, estos temas forman parte de la agenda de investigación.

\subsection{Parámetros de costos}

La estimación de los parámetros de la función de costos parte de las condiciones de primer orden (4.7) y (4.6) del problema de optimización de las firmas internacionales. Este ejercicio debe entenderse como una calibración de los parámetros a partir de las predicciones del modelo. Es importante tener en mente los supuestos más importantes del modelo: (i) disposición marginal a pagar creciente en el ingreso; (ii) costos marginales crecientes y convexos en calidad; y (iii) competencia monopolística.

Recordar que la motivación principal para recuperar estos parámetros es calcular los índices de precios a nivel producto que permiten realizar la descomposición del cambio en precios. Recordar también que este ejercicio se realiza únicamente para el caso de la devaluación Argentina. Se adopta la siguiente especificación paramétrica para los costos marginales:

$$
c\left(\theta_{j s t}\right)=\phi_{j s t}^{0}+\mathbf{e}^{\phi_{j s t}^{1} \theta_{j s t}}
$$

Esta función representa una tecnología de coeficientes fijos que combina un conjunto de insumos $\left(\phi_{j s t}^{0}\right.$ puede asociarse con el precio/calidad de dichos insumos) con determinada tecnología de producción de calidad. La variable aleatoria $\phi_{j s t}^{1}$ refiere a la eficiencia de cada firma en la producción de calidad. Notar que la función elegida satisface el supuesto de costo marginal creciente y convexo en calidad $\left(c^{\prime}(\theta)>0\right.$ y $\left.c^{\prime \prime}(\theta)>0\right)$. Otro supuesto implícito en esta forma funcional es que el costo marginal no depende de la cantidad producida (rendimientos constantes a escala). Bajo estos supuestos paramétricos, la calidad y el precio de equilibrio que satisfacen las CPO son los siguientes: 


$$
\begin{gathered}
p_{j s t}^{*}=\frac{\alpha_{t} \phi_{j s t}^{0} \phi_{j s t}^{1}}{\phi_{j s t}^{1}\left[\alpha_{t}-(1-\sigma)\right]-1} \\
\theta_{j s t}^{*}=\frac{1}{\phi_{j s t}^{1}} \log \left(\frac{\phi_{j s t}^{0}}{\phi_{j s t}^{1}\left[\alpha_{t}-(1-\sigma)\right]-1}\right)
\end{gathered}
$$

Las firmas más eficientes en la producción de calidad (menor $\phi_{j s t}^{1}$ ) y aquellas que utilizan insumos más costosos (mayor $\phi_{j s t}^{0}$ ) eligen mayor calidad y precio de equilibrio. El sistema formado por estas ecuaciones puede invertirse de manera tal que los parámetros de la función de costos $\left(\phi_{j s t}^{0} \mathrm{y} \phi_{j s t}^{1} 0\right)$ queden expresados en función de los precios observados $\left(p_{j s t}\right)$, la calidad estimada $\left(\theta_{j s t}\right)$ y los parámetros de la ecuación de demanda $\left(\widehat{\alpha}_{t}\right.$ y $\left.\widehat{\sigma}\right)$. Resolviendo para $\phi_{j s t}^{1}$ a partir de la CPO $\left(\theta_{j s t}^{*}\right)$ se obtiene la siguiente ecuación:

$$
\phi_{j s t}^{1} \mathbf{e}^{\phi_{j s t}^{1} \theta_{j s t}}=\frac{p_{j s t}}{\hat{\alpha}_{t}}
$$

Notar que $\phi_{j s t}^{1}$ es independiente del valor de $\phi_{j s t}^{0}$. Esta es la razón principal por la cual se elige esta parametrización. En este caso, el algoritmo empleado para encontrar la solución numérica converge rápidamente. Entonces, para encontrar los valores de $\phi_{j s t}^{1}$ se resuelve numéricamente aplicando un método tradicional de Newton-Raphson:

$$
\phi_{j s t}^{1, n+1}=\phi_{j s t}^{1, n}-\frac{\log \left(\phi_{j s t}^{1, n}\right)+\theta_{j s t} \phi_{j s t}^{1, n}-\log \left(\frac{p_{j s t}}{\alpha_{t}}\right)}{\frac{1}{\phi_{j s t}^{1, n}}+\theta_{j s t}}
$$

Este procedimiento de optimización numérica se resuelve a partir de una normalización de $\theta_{j s t}$. Luego, se obtiene $\phi_{j s t}^{0}$ a partir de la CPO $\left(p_{j s t}^{*}\right)$ :

$$
\phi_{j s t}^{0}=\frac{\alpha_{t}-(1-\sigma)}{\alpha_{t}} p_{j s t}-\mathbf{e}^{\phi_{j s t}^{1} \theta_{j s t}}
$$

Este procedimiento permite recuperar los dos parámetros de la función de costos marginales de cada firma. Luego, es posible calcular el precio y la calidad de equilibrio, y utilizarlos para simular la participación de mercado de cada firma. Finalmente, se calculan los índices de precios tal como se explica en la sección Sección 4.4. 


\section{Resultados}

El objetivo de esta sección es contrastar empíricamente las predicciones teóricas del modelo. En primer lugar, se presentan estadísticas descriptivas asociadas a la evolución de la canasta de productos importados en todos los episodios de crisis cambiarias estudiados. La seccion continúa con un análisis econométrico más detallado, que contiene evidencia sobre la reducción en el precio promedio de los productos importados (medidos en dólares en aduanas) en los años que siguen a la devaluación. Se muestra que la calidad estimada también se reduce post devaluación en todos los episodios estudiados. Además se presenta evidencia sobre el cambio composicional dentro de cada producto. Este fenómeno de sustitución se caracteriza por un aumento (disminución) en la participación de las variedades de menor (mayor) precio y menor (mayor) calidad relativa. Los datos utilizados corresponden al universo de productos importados durante los años que circunscriben la crisis cambiaria en cada país, y provienen de la base de datos COMTRADE (Commodity Trade Statistics Database) elaborada por la Dirección de Estadísticas de Comercio de Naciones Unidas, a partir de microdatos reportados por institutos de estadística de más de 100 países y regiones. ${ }^{29}$

Un segundo bloque de resultados tiene que ver con la cuantificación de los tres mecanismos teóricos que explican la reducción total del precio de un producto importado, utilizando los supuestos del modelo teórico y la metodología para calcular los índices de precios a nivel producto. Recordar que para ello es necesario estimar el sistema de demanda, realizar supuestos sobre la función de costos y la estructura de competencia en el mercado internacional, y a partir del modelo calibrar los parámetros de costos de las firmas internacionales. Luego se construyen distintos índices de precios a nivel producto y se descompone el cambio total en el precio predicho por el modelo (tal como se explica en la sección anterior). Para ello se utilizan datos provenientes del Instituto Nacional de Estadísticas y Censos (INDEC) de Argentina. Como ya se mencionó previamente, estos datos presentan un mayor nivel de desagregación (8 dígitos del SA) que los datos de COMTRADE (6 dígitos), menor error de medición y contienen más información. En particular, es posible construir una variable que aproxima los costos de transporte de cada producto desde cada país de origen. El costo de transporte se utiliza como variable instrumental para el precio en la estimación de la ecuación de demanda. Los resultados

\footnotetext{
${ }^{29}$ Esta base tiene estructura de panel y contiene información detallada sobre valores, cantidades importadas/exportadas y origen/destino de los flujos comerciales por tipo de producto, con un nivel de desagregación de 6 dígitos de la clasificación internacional del Sistema Armonizado.
} 
muestran un elevado poder predictivo en la primera etapa, lo que aumenta la credibilidad de la estrategia de identificación utilizada.

En la última parte de esta sección se realiza un ejercicio de robustez, que intenta controlar por la posible existencia de shocks de oferta que podrían explicar parte del cambio en el precio de los productos importados (e.g. mejoras tecnológicas, precio de insumos, etc). La estrategia de estimación utiliza un método de diferencias en diferencias que permite comparar la evolución del precio de los mismos productos importados por Argentina y Chile durante el período devaluatorio del peso Argentino, utilizando un extenso conjunto de efectos fijos que permiten controlar por diversos factores asociados a la evolución de la oferta. La estimación se realiza con las bases de datos originales de las Aduanas de ambos países, que incluyen todas las transacciones de importación para dos industrias de manufacturas específicas: electrodomésticos y automóviles. Estos datos contienen algunas características observables de los productos, siendo la más importante la marca, que se utiliza como proxy de un conjunto de inobservables inherentes a determinada firma internacional.

\subsection{Estadísticas descriptivas}

Antes de describir los resultados econométricos se presentan algunas estadísticas descriptivas que permiten caracterizar la evolución de las importaciones durante los episodios estudiados. El Cuadro 2 presenta la evolución de la cantidad de variedades importadas, ${ }^{30}$ la cantidad de productos importados, la cantidad promedio de variedades (países de origen) por producto, y la composición agregada de las importaciones (separando insumos intermedios, bienes de capital y bienes de consumo).

En primer lugar, vale la pena recordar que el volumen importaciones disminuye significativamente en todos los países durante el año de la devaluación (20\% en promedio). Argentina está muy por encima de dicho promedio, pues presenta una reducción de importaciones del 50\% en el año 2002. La caída en las importaciones es acompañada por una reducción en el número de variedades importadas. Durante el año de la devaluación se importan en promedio 4 mil variedades menos que durante el año anterior (9 mil en el caso de Argentina). Ello representa una reducción promedio cercana al 11\% de las variedades (24\% en Argentina). También dejan de importarse unos pocos productos (en promedio 47, que representan 1,25\% del total). En el caso de Argentina, dejan de importarse 244

\footnotetext{
${ }^{30}$ Recordar que una variedad se define como la combinación producto-país de origen. Un producto está definido a 6 dígitos de la clasificación internacional del Sistema Armonizado.
} 
productos $(6,5 \%$ del total). Dado que la reducción en el número de variedades es mayor que la caída en el número de productos, se produce entonces una disminución en el número de variedades o países de origen desde los cuales se importa cada producto (1 país menos en promedio, y 2 en Argentina).

En cuanto a la composición de las importaciones, estas se conforman en su mayoría por insumos intermedios (61,7\% en promedio). Los bienes de capital representan en promedio 17,6\% del valor total importado. Los bienes de consumo representan en promedio un 12,4\% del total. ${ }^{31}$ En cuanto a la evolución de dicha composición, se advierten tres tendencias bastante claras. La participación promedio de los insumos intermedios crece sostenidamente a lo largo del período (pasa de un promedio de $56,2 \%$ tres años antes de la devaluación a $67,6 \%$ dos años después). ${ }^{32}$ La participación de los bienes de capital importados presenta la tendencia opuesta (pasan de un promedio de $23,4 \%$ a $10,8 \%$ ). Es probable que esta disminución esté relacionada con la caída de la inversión en contextos de inestabilidad y recesión económica. Por último, la participación de los bienes de consumo en el total importado crece levemente en los años previos a la devaluación, y disminuye alrededor de 2 p.p. en promedio en los años que siguen a la misma. Este último punto es menos claro en los episodios de Colombia y Turquía.

\footnotetext{
${ }^{31}$ Los valores de la tabla no suman 100 porque falta la categoría de otros bienes (8,3\% del total). Estos son productos que a priori podrían clasificarse en cualquiera de las tres categorías. La tabla de conversión utilizada Sistema Armonizado a Categorías Económicas Amplias (HS-BEC, por sus siglas en inglés) presenta valores faltantes en estos productos.

${ }^{32}$ Este es un hecho interesante que merece ser estudiado con mayor profundidad en el futuro. Es probable que una fracción significativa de los insumos importados se destine a elaborar productos exportables. El efecto sobre la calidad de dichos bienes es a priori indeterminado, y la literatura muestra evidencia en ambas direcciones (Verhoogen (2008); Chatterjee et al. (2013)). Sería interesante profundizar sobre estas contribuciones.
} 


\section{CUADRO 2}

Evolución de las importaciones

\begin{tabular}{|c|c|c|c|c|c|c|c|c|c|c|c|c|c|}
\hline & MEX & BRA & ARG & URU & COL & TAI & IND & MAL & FIL & COR & RUS & TUR & Prom. \\
\hline & 1995 & 1999 & 2002 & 2002 & 1998 & 1998 & 1998 & 1998 & 1998 & 1998 & 1999 & 2001 & Simple \\
\hline \multicolumn{14}{|c|}{ Cantidad de variedades (producto-origen) importadas (en miles) } \\
\hline T-3 & 30.5 & 36.3 & 35.7 & 19.5 & 27.1 & 34.7 & 34.3 & 24.5 & . & 36.5 & 55.8 & 41.6 & 34.2 \\
\hline T-2 & 31.5 & 40.1 & 39.6 & 20.5 & 27.0 & 36.0 & 35.0 & 27.7 & 28.8 & 37.7 & 58.7 & 40.3 & 35.2 \\
\hline $\mathrm{T}-1$ & 36.9 & 40.8 & 36.9 & 21.1 & 28.1 & 36.4 & 38.5 & 37.7 & 31.1 & 39.9 & 56.3 & 42.0 & 37.1 \\
\hline $\mathrm{T}$ & 32.2 & 38.1 & 27.9 & 18.3 & 28.1 & 32.8 & 32.8 & 34.6 & 29.3 & 33.0 & 47.5 & 42.5 & 33.1 \\
\hline $\mathrm{T}+1$ & 41.6 & 41.2 & 30.8 & 17.4 & 22.1 & 34.8 & 33.3 & 35.9 & 30.8 & 39.3 & 55.7 & 41.2 & 35.3 \\
\hline $\mathrm{T}+2$ & 45.4 & 41.5 & 32.7 & 18.9 & 30.9 & 43.9 & 37.0 & 39.1 & 29.5 & 39.8 & 54.4 & 43.4 & 38.0 \\
\hline \multicolumn{14}{|c|}{ Cantidad de productos (6 dígitos) importados } \\
\hline $\mathrm{T}-3$ & 4,064 & 3,988 & 3,774 & 3,169 & 3,870 & 3,712 & 3,998 & 2,701 & . & 4,080 & 4,023 & 3,891 & 3,752 \\
\hline $\mathrm{T}-2$ & 4,070 & 4,022 & 3,746 & 2,859 & 3,834 & 3,748 & 3,947 & 2,853 & 3,751 & 4,053 & 3,973 & 3,867 & 3,727 \\
\hline $\mathrm{T}-1$ & 3,901 & 3,986 & 3,746 & 2,954 & 3,831 & 3,739 & 3,985 & 3,632 & 3,811 & 4,072 & 3,967 & 3,379 & 3,750 \\
\hline $\mathrm{T}$ & 3,823 & 3,977 & 3,502 & 2,850 & 3,830 & 3,653 & 3,892 & 3,573 & 3,734 & 3,995 & 3,918 & 3,692 & 3,703 \\
\hline $\mathrm{T}+1$ & 3,812 & 3,940 & 3,629 & 2,828 & 3,432 & 3,641 & 3,957 & 3,619 & 3,770 & 4,056 & 3,917 & 3,663 & 3,689 \\
\hline $\mathrm{T}+2$ & 3,835 & 3,924 & 3,648 & 2,888 & 3,733 & 3,788 & 3,374 & 3,631 & 3,149 & 3,385 & 3,879 & 3,664 & 3,575 \\
\hline \multicolumn{14}{|c|}{ Cantidad de variedades por producto (promedio) } \\
\hline $\mathrm{T}-3$ & 7.5 & 9.1 & 9.5 & 6.1 & 7.0 & 9.3 & 8.6 & 9.1 & . & 8.9 & 13.9 & 10.7 & 9.1 \\
\hline T-2 & 7.7 & 10.0 & 10.6 & 7.2 & 7.0 & 9.6 & 8.9 & 9.7 & 7.7 & 9.3 & 14.8 & 10.4 & 9.4 \\
\hline T-1 & 9.4 & 10.2 & 9.9 & 7.1 & 7.3 & 9.7 & 9.7 & 10.4 & 8.2 & 9.8 & 14.2 & 12.4 & 9.9 \\
\hline $\mathrm{T}$ & 8.4 & 9.6 & 8.0 & 6.4 & 7.3 & 9.0 & 8.4 & 9.7 & 7.8 & 8.3 & 12.1 & 11.5 & 8.9 \\
\hline $\mathrm{T}+1$ & 10.9 & 10.5 & 8.5 & 6.2 & 6.4 & 9.5 & 8.4 & 9.9 & 8.2 & 9.7 & 14.2 & 11.2 & 9.5 \\
\hline $\mathrm{T}+2$ & 11.8 & 10.6 & 9.0 & 6.5 & 8.3 & 11.6 & 11.0 & 10.8 & 9.4 & 11.7 & 14.0 & 11.9 & 10.5 \\
\hline \multicolumn{14}{|c|}{ Insumos intermedios ( $\%$ del total importado) } \\
\hline $\mathrm{T}-3$ & 54.4 & 52.0 & 50.8 & 48.0 & 48.4 & 74.1 & 63.4 & 77.7 & . & 53.3 & 40.5 & 55.6 & 56.2 \\
\hline $\mathrm{T}-2$ & 55.5 & 49.7 & 57.2 & 55.9 & 48.7 & 74.2 & 61.2 & 77.1 & 60.9 & 50.2 & 36.8 & 56.8 & 57.0 \\
\hline $\mathrm{T}-1$ & 63.3 & 51.6 & 59.2 & 55.0 & 47.5 & 73.1 & 62.1 & 78.3 & 64.2 & 53.6 & 39.3 & 63.6 & 59.2 \\
\hline $\mathrm{T}$ & 69.9 & 55.5 & 70.8 & 54.3 & 47.5 & 72.7 & 61.0 & 80.4 & 70.0 & 62.4 & 47.5 & 67.2 & 63.3 \\
\hline $\mathrm{T}+1$ & 64.5 & 66.0 & 67.7 & 58.3 & 61.2 & 75.4 & 63.5 & 80.8 & 69.9 & 60.7 & 58.4 & 67.5 & 66.2 \\
\hline $\mathrm{T}+2$ & 61.3 & 67.6 & 64.1 & 59.9 & 63.4 & 73.3 & 69.3 & 79.2 & 79.2 & 73.3 & 53.8 & 67.2 & 67.6 \\
\hline \multicolumn{14}{|c|}{ Bienes de capital (\% del total importado) } \\
\hline $\mathrm{T}-3$ & 22.0 & 25.5 & 28.4 & 19.2 & 30.1 & 13.1 & 24.5 & 12.5 & & 28.5 & 26.9 & 26.9 & 23.4 \\
\hline T-2 & 21.1 & 28.0 & 18.1 & 6.9 & 29.3 & 13.2 & 26.4 & 12.3 & 23.9 & 30.7 & 28.3 & 26.5 & 22.1 \\
\hline T-1 & 13.3 & 26.9 & 14.6 & 8.1 & 28.1 & 13.7 & 25.1 & 10.8 & 21.9 & 26.5 & 28.4 & 14.9 & 19.4 \\
\hline $\mathrm{T}$ & 11.1 & 25.7 & 8.6 & 7.5 & 28.6 & 14.8 & 26.6 & 10.0 & 16.0 & 21.2 & 27.0 & 10.7 & 17.3 \\
\hline $\mathrm{T}+1$ & 17.5 & 12.3 & 12.3 & 5.7 & 12.8 & 11.1 & 17.2 & 10.4 & 14.5 & 22.7 & 8.7 & 11.1 & 13.0 \\
\hline $\mathrm{T}+2$ & 18.7 & 12.3 & 17.0 & 7.5 & 13.3 & 12.4 & 3.2 & 10.5 & 6.2 & 7.6 & 10.4 & 10.9 & 10.8 \\
\hline \multicolumn{14}{|c|}{ Bienes de consumo (\% del total importado) } \\
\hline $\mathrm{T}-3$ & 16.7 & 10.5 & 17.4 & 27.0 & 9.7 & 7.5 & 3.1 & 4.0 & . & 7.0 & 26.4 & 9.4 & 12.6 \\
\hline $\mathrm{T}-2$ & 17.2 & 10.1 & 20.2 & 29.6 & 11.1 & 7.6 & 3.3 & 4.7 & 6.6 & 8.1 & 24.8 & 10.4 & 12.8 \\
\hline $\mathrm{T}-1$ & 19.3 & 9.6 & 21.9 & 30.0 & 11.8 & 8.0 & 3.5 & 5.7 & 6.7 & 8.9 & 22.6 & 11.0 & 13.3 \\
\hline $\mathrm{T}$ & 15.3 & 8.7 & 14.5 & 25.4 & 12.8 & 7.5 & 2.5 & 4.6 & 7.4 & 7.5 & 16.6 & 11.9 & 11.2 \\
\hline $\mathrm{T}+1$ & 12.8 & 8.6 & 14.4 & 21.4 & 19.1 & 8.0 & 4.2 & 5.8 & 9.2 & 8.3 & 23.6 & 11.9 & 12.3 \\
\hline $\mathrm{T}+2$ & 13.1 & 8.7 & 13.7 & 21.4 & 17.2 & 7.5 & 4.4 & 5.4 & 8.4 & 7.6 & 27.7 & 12.3 & 12.3 \\
\hline
\end{tabular}

Notas. T es el año donde se produce el grueso de la devaluación nominal en cada país. Una variedad se define como una combinación producto-país de origen. Productos desagregados a 6 dígitos del Sistema Armonizado. Fuente. COMTRADE (Naciones Unidas) 


\subsection{Disminución de precios}

En esta sección se presentan los resultados que surgen de estimar un conjunto de regresiones que intentan describir la evolución del precio de los productos importados en cada uno de los países estudiados. Los precios están medidos en dólares y son registrados por la aduana de cada país. El período elegido es de los 6 años que circunscriben a cada una de las crisis cambiarias. La única excepción es Filipinas, donde se trabaja con un período de 5 años porque los datos de COMTRADE para este país están disponibles a partir de 1996. A lo largo de toda esta sección se estiman variantes de la siguiente ecuación de regresión (por el método de mínimos cuadrados ordinarios) separadamente para cada uno de los países estudiados:

$$
\log \left(p_{j s t}\right)=\beta \text { Post }_{t}+\phi_{j s}+\varepsilon_{j s t}
$$

La variable dependiente es el logaritmo del precio (valor unitario) de cada variedad $s$ (país de origen) del producto $j$ en el período $t$. La variable binaria Post $t_{t}$ vale cero en los años previos a la devaluación (entre T-1 y T-3), y vale uno en los años posteriores (entre $\mathrm{T}$ y $\mathrm{T}+2)$. Recordar que el año $\mathrm{T}$ es aquel donde se produce el grueso de la devaluación nominal en cada uno de los países. Las regresiones incluyen efectos fijos a nivel variedad $\left(\phi_{j s}\right)$. Alternativamente, se utilizan efectos fijos a nivel producto $\left(\phi_{j}\right) . \varepsilon_{j s t}$ representa el error de estimación del modelo. En la estimación se calculan errores estándar robustos utilizando clusters a nivel industria (2 dígitos). Los resultados no cambian al utilizar clusters por país de origen o producto (6 dígitos). El coeficiente de interés es $\beta$, que captura la variación promedio en el precio de las variedades importadas en los años que siguen a la crisis cambiaria. En una segunda especificación se reemplaza a la variable Post $_{t}$ por dummies anuales. Esta especificación permite comparar la variación de los precios promedio en cada año respecto al año inicial T-3 (variable binaria omitida en la regresión).

Para facilitar la interpretación, la Figura 4 presenta los coeficientes $\hat{\beta}$ que acompañan a la variable Post $_{t}$, estimados separadamente para cada uno de los países estudiados. Notar que se presentan dos resultados para cada país, según los efectos fijos incorporados como control. Los resultados son muy similares y sugieren que el precio de las variedades importadas se reduce en promedio un $20 \%$ en los años que siguen a la devaluación. Para interpretar los coeficientes en términos porcentuales, dada la forma log-lineal de la 
especificación utilizada, es necesario aplicar la siguiente fórmula: $\Delta_{t} \% p_{j s}=100 .\left(e^{\hat{\beta}}-1\right) .{ }^{33}$ México está por encima del promedio, con una reducción del 36,2\%. Si bien parte de la reducción de precios podría estar explicada por la entrada en vigencia del Tratado de Libre Comercio de América del Norte (NAFTA) en Enero de 1994, los precios disminuyen 22,1\% en 1994, 23,7\% en 1995, y 55,1\% en 1996 (en comparación con 1992). Siendo la caída especialmente pronunciada luego de que ocurre la devaluación del peso mexicano en 1995. Más aún, México reduce considerablemente los aranceles en los años anteriores a la entrada en vigencia del NAFTA. También se destacan la disminución promedio en el precio de las variedades importadas por Indonesia (22,9\%), Brasil $(21,7 \%)$ y Corea del Sur $(18,4 \%)$. Estos resultados se presentan en el Cuadro A1 y en la Figura A3 del apéndice.

\section{FIGURA 4}

Cambio en precios post devaluación

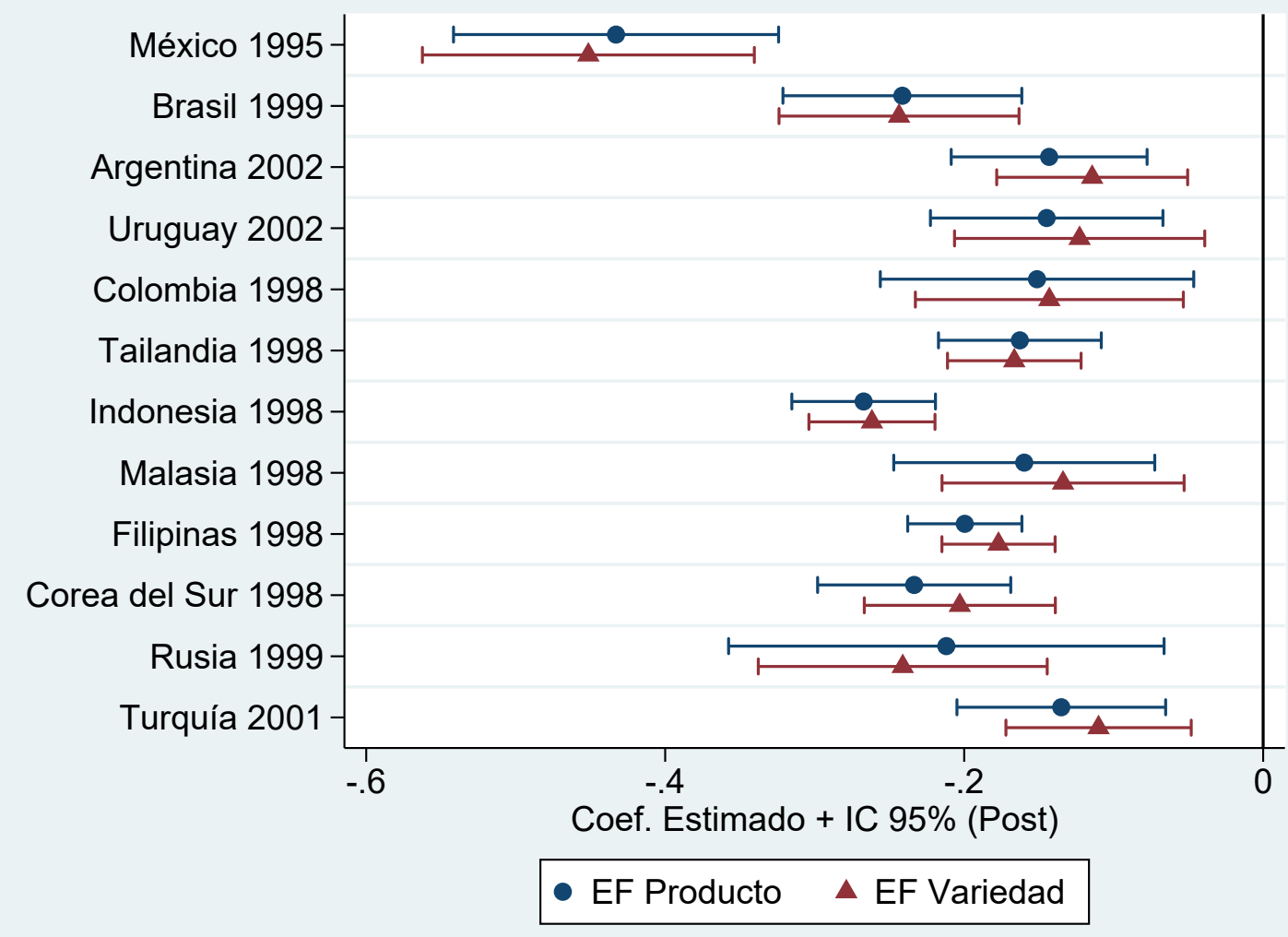

Notas. Coeficientes estimados a partir de 24 regresiones (2 para cada país) del log(precio) en la variable binaria Post ( $=1$ en los tres años que siguen a la devaluación). Una especificación incluye EF a nivel producto (azul) y otra EF a nivel variedad (roja). Cada variedad es ponderada por la participación en el valor total importado de la industria correspondiente. Errores estándar clusterizados a nivel industria. Fuente. COMTRADE (Naciones Unidas).

La ecuación de regresión (6.1) también se estima separadamente para cada una de

\footnotetext{
${ }^{33}$ Tener en cuenta que la regresión que incluye EF a nivel variedad utiliza una menor cantidad de observaciones porque deja por fuera de la estimación combinaciones producto-país que están presentes únicamente en un solo período (singletons).
} 
las 80 industrias de cada país. La Figura 5 presenta los coeficientes estimados para la para la variable Post. Se observa que la mayor parte de las industrias (83\%) presentan una reducción en los precios promedio de las variedades importadas en los años posteriores a la crisis cambiaria. El coeficiente estimado promedio a través de todas las industrias es $-14,2 \%$ y la mediana es de $-16,8 \%$. Notar que en muchas de las industrias los intervalos de confianza son relativamente grandes, teniendo en cuenta que ya se eliminaron valores extremos de la base de datos. ${ }^{34}$ Los datos de COMTRADE presentan mucha variabilidad y probablemente contengan un alto componente de error de medición.

FIGURA 5

Cambio en precios por industrias

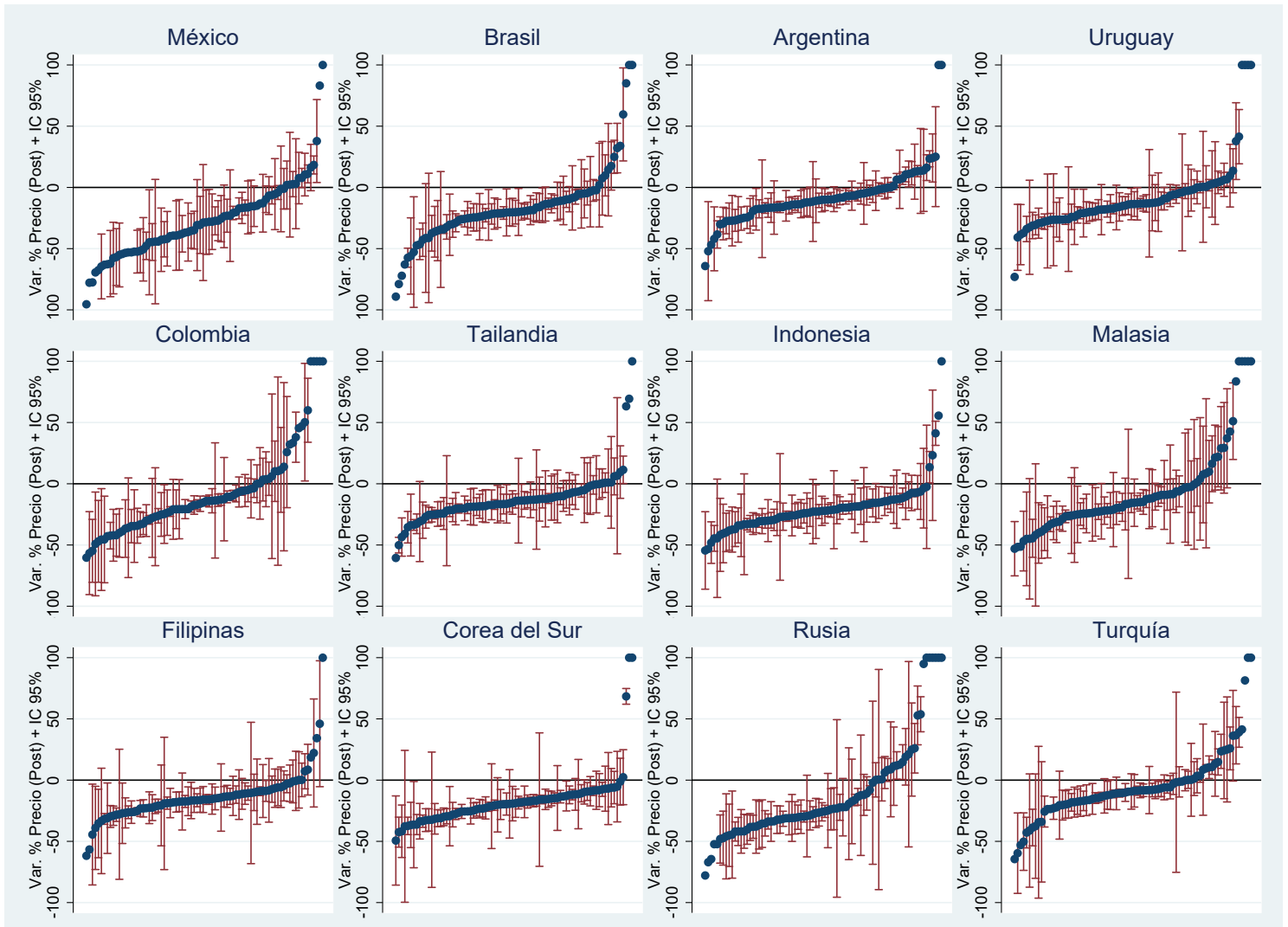

Notas. Coeficientes estimados a partir de regresiones a nivel industria ( 80 regresiones por país) del $\log$ (precio) en la variable binaria Post (=1 en los tres años que siguen a la devaluación). Errores estándar clusterizados a nivel producto. Cada variedad es ponderada por la participación en el valor total importado de la industria correspondiente. Para acotar el rango de valores, los coeficientes superiores a $100 \%$ no incluyen el IC. Fuente. COMTRADE (Naciones Unidas).

En el caso de Argentina también es posible realizar estas mismas estimaciones (como todas las sucesivas) utilizando los datos provenientes del INDEC. Recordar que estos datos tienen un mayor nivel de desagregación (8 dígitos del SA) que los datos de COMTRADE

\footnotetext{
${ }^{34}$ Recordar que se eliminan las observaciones cuyo valor unitario difiere en más/menos tres desvíos estándar respecto del valor unitario promedio anual de cada producto.
} 
(6 dígitos) y presentan menos errores de medición. Los resultamos arrojan coeficientes estimados de manera más precisa (menor error estándar y p-valor más alto). Los resultados de estimar estas mismas regresiones (a nivel variedad y a nivel producto) se presentan en el Cuadro 3. El precio de un producto es calculado como el precio promedio de todas las variedades que lo componen, ponderando a cada variedad por su participación en el valor total importado dentro de cada producto. El precio promedio de las variedades importadas por Argentina (medido en dólares) en los tres años posteriores a la crisis cambiaria resulta ser un $11 \%$ menor que en los tres años previos. La caída en el precio promedio a nivel producto es algo mayor (entre 13\% y 14\%). Esta reducción es mayor porque (como se muestra más adelante) se produce un proceso de sustitución caracterizado por un aumento en la participación de las variedades de precio más bajo en detrimento de la participación de las variedades de precio más alto. Los precios promedio se reducen todos los años del período 2000-2003, y comienzan a recuperarse en el año 2004. La mayor reducción se produce en los años 2002 y 2003, cuando el precio promedio de las variedades resulta ser un $15 \%$ y un $19 \%$ menor que en el año 1999, respectivamente. A nivel producto la tendencia es muy similar. La parte inferior del Cuadro 3 muestra la proporción de variedades y productos que presentan una disminución en su precio en cada uno de los años (en comparación con el precio del año inicial 1999). Se observa que 3 de cada 5 variedades presentan una reducción de precios entre 1999 y 2001. La proporción de variedades cuyo precio se reduce es muy similar en 2002 y 2003 . A nivel producto, más de dos tercios de los productos importados presentan una caída de precios en los años que siguen a la devaluación. 


\section{CUADRO 3}

Reducción de precios en Argentina

\begin{tabular}{lccc}
\hline \hline & $\begin{array}{c}\text { Variedad } \\
(1)\end{array}$ & $\begin{array}{c}\text { Producto-8d } \\
(2)\end{array}$ & $\begin{array}{c}\text { Producto-6d } \\
(3)\end{array}$ \\
\hline Post & $-0.11^{* * *}$ & $-0.13^{* * *}$ & $-0.14^{* * *}$ \\
& $(0.02)$ & $(0.02)$ & $(0.02)$ \\
\hline Año 2000 & $-0.03^{* *}$ & $-0.04^{* *}$ & $-0.04^{*}$ \\
& $(0.02)$ & $(0.02)$ & $(0.02)$ \\
Año 2001 & $-0.09^{* * *}$ & $-0.12^{* * *}$ & $-0.11^{* * *}$ \\
& $(0.02)$ & $(0.02)$ & $(0.03)$ \\
Año 2002 & $-0.15^{* * *}$ & $-0.16^{* * *}$ & $-0.16^{* * *}$ \\
& $(0.02)$ & $(0.02)$ & $(0.02)$ \\
Año 2003 & $-0.19^{* * *}$ & $-0.22^{* * *}$ & $-0.23^{* * *}$ \\
& $(0.02)$ & $(0.02)$ & $(0.03)$ \\
Año 2004 & $-0.14^{* * *}$ & $-0.18^{* * *}$ & $-0.19^{* * *}$ \\
& $(0.03)$ & $(0.03)$ & $(0.03)$ \\
\hline EF Variedad/Producto & $\mathrm{Si}$ & $\mathrm{Si}$ & $\mathrm{Si}$ \\
& & & \\
Observaciones & 323187 & 38392 & 23248 \\
Grupos de EF & 77531 & 7464 & 4318 \\
\hline Proporción $\Delta<0$ & & & \\
1999-2001 & 0.60 & 0.69 & 0.68 \\
1999-2002 & 0.58 & 0.66 & 0.63 \\
1999-2003 & 0.57 & 0.67 & 0.68 \\
1999-2004 & 0.54 & 0.66 & 0.67 \\
\hline
\end{tabular}

Notas. La parte superior del cuadro presenta los coeficientes estimados a partir de distintas regresiones del (log) precio de las variedades/productos importados en variables temporales (Post y dummies anuales). Cada columna presenta un nivel de agregación distinto que incluye los efectos fijos correspondientes. El precio de una variedad importada se aproxima con el valor unitario (valor FOB dividido por cantidad). Las regresiones se estiman ponderando a cada variedad/producto por la participación en el valor total importado de cada industria-año. Errores estándar robustos clusterizados por industria (2 dígitos). Los resultados son robustos a utilizar ponderadores y/o clusters alternativos. La parte inferior presenta la proporción de variedades/productos cuyo precio disminuye en cada año (en comparación con el precio del año inicial 1999). Fuente: INDEC.

\subsection{Estimación de demanda}

En esta subsección se presentan los resultados de la estimación del sistema de demanda a partir de la ecuación de regresión (5.1). Es preciso recordar que en un modelo de oferta y demanda con productos homogéneos, el precio de equilibrio depende del término de error del modelo (ecuaciones simultáneas). Con productos diferenciados, también es probable que los precios estén correlacionados con componentes no observables de la calidad que forman parte del error de estimación del modelo. A su vez, la participación de cada variedad en el producto (nested share) también podría estar correlacionada con el término de error. Por lo tanto, las variables explicativas de la ecuación de demanda 
son endógenas. La estrategia de estimación se basa en la utilización de variables instrumentales que generen variaciones exógenas en la oferta/costos de las firmas (cost shifters) y que no estén correlacionadas con la demanda ni con la calidad. Se utilizan dos variables instrumentales. La primera es un precio de referencia mundial que intenta capturar shocks de costos en los países de origen. La segunda variable es el número de variedades dentro en cada producto, que intenta capturar el grado de competencia entre las distintas variedades y por lo tanto posibilidades de subir el precio por encima del costo.

El método de estimación elegido es Mínimos Cuadrados Ordinarios en Dos Etapas (MC2E). Se incorporan efectos fijos año-industria para controlar por cualquier shock temporal que afecta de manera heterogénea a las distintas industrias. Los errores estándar se clusterizan a nivel industria. Los resultados no se modifican sustancialmente si se utilizan clusters a nivel producto o país de origen. Recordar que una vez estimada la ecuación de demanda es posible recuperar una medida aproximada de la calidad de cada variedad derivada de la suma del efecto fijo a nivel producto y del efecto fijo a nivel variedad-año (ver ecuación (5.2)). Estos efectos fijos representan la valoración promedio que los consumidores tienen por cada variedad. Esta medida revelada de calidad es la participación de mercado de cada variedad una vez que se controla por su precio. La Figura 6 ilustra la intuición detrás de esta metodología. La idea original corresponde a Khandelwal (2011). La figura ilustra la relación entre cantidades, valores unitarios y las calidades estimadas para un producto determinado, en este caso "Aparatos de cocción en base a combustibles gaseosos (hierro o acero)". El gráfico ordena de izquierda a derecha los productos en función de su valor unitario y permite apreciar la correlación positiva que existe entre el precio de cada variedad y su calidad estimada. Esto significa que el consumidor promedio valora más (asigna mayor calidad) en promedio a las variedades de precio más alto. Este es el supuesto que realiza la literatura que utiliza el valor unitario como proxy de la calidad. También es posible advertir que el valor unitario y la calidad estimada se asocian positivamente con el PBI per cápita del país exportador. Este es un hallazgo habitual en la literatura. Como se muestra en la sección 6.6, es un resultado que también se verifica a partir de las estimaciones realizadas en este trabajo.

El Cuadro 4 presenta los resultados de la estimación de los parámetros estructurales del sistema de demanda (ecuación 5.1) por el método de MC2E. El coeficiente ( $\hat{\alpha}$ ) asociado a la elasticidad de la curva de demanda (que acompaña a la variable $\log (\mathrm{p})$ ) es negativo y estadísticamente significativo con un nivel de confianza del $99 \%$ en todos los casos. Por su parte, el parámetro de sustitución $\hat{\sigma}$ también es estadísticamente significativo y 
FIGURA 6

Precio, cantidad y calidad estimada

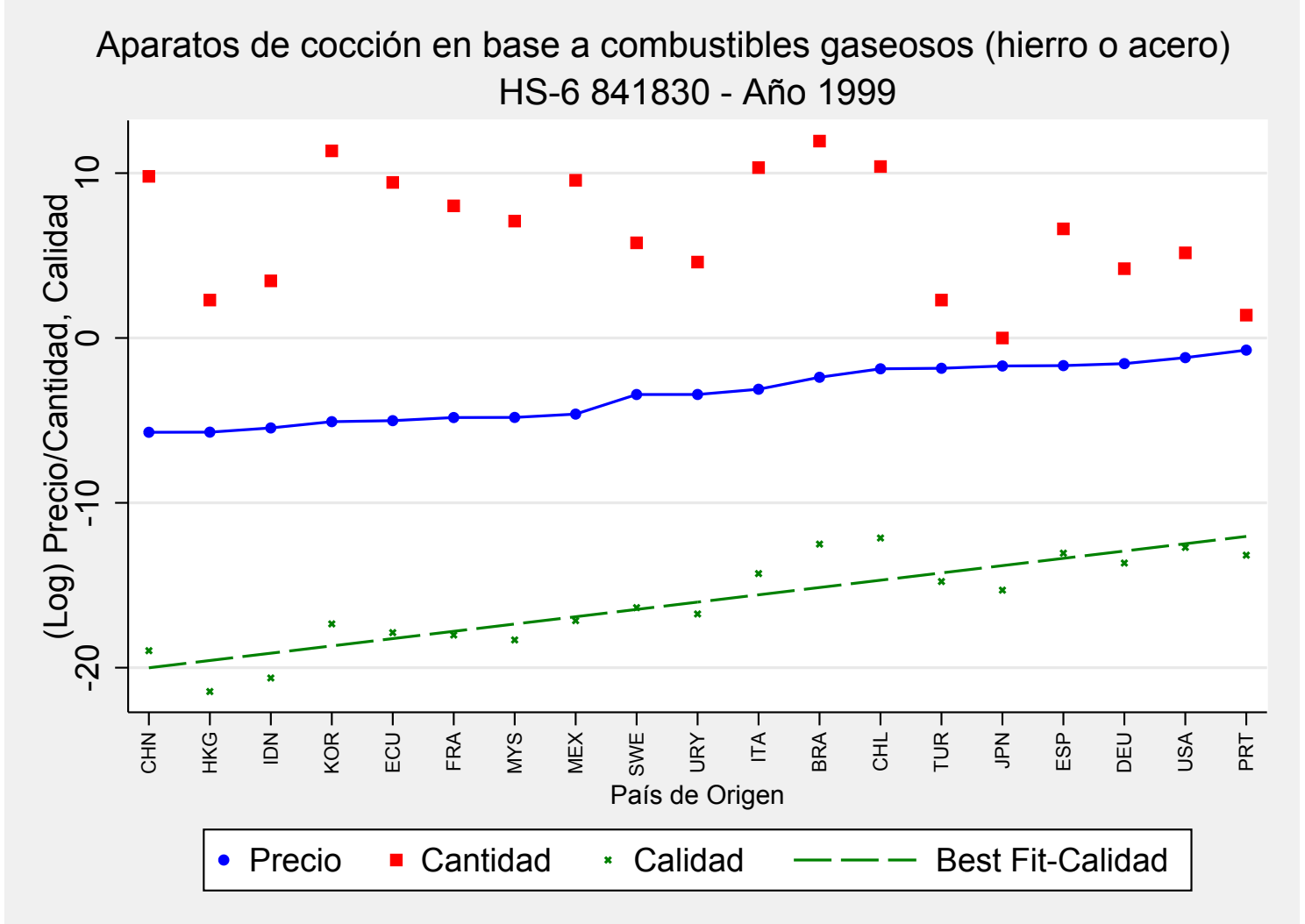

Notas. La figura presenta el precio, la cantidad (ambos en logaritmos) y la calidad estimada de las distintas variedades de cocinas importadas por Argentina en el año 1999. Las variedades se ordenan en función del precio. Fuente. Datos de aduana (INDEC) y COMTRADE (Naciones Unidas).

cae dentro del rango de valores posibles $[0,1)$. Este es un resultado robusto a través de distintas especificaciones que surgen de utilizar distintas combinaciones de efectos fijos y clusterización de los errores estándar. En la segunda parte de la tabla se presentan los resultados de la estimación de las dos regresiones de la primera etapa. Las dos variables instrumentales son relevantes para explicar a las dos variables endógenas. En todos los casos, el precio de referencia mundial está correlacionado positivamente con el precio del producto importado por cada país, y negativamente con la participación anidada (y en ambos casos es estadísticamente significativo con un nivel de confianza del $99 \%$ en la gran mayoría de los casos). Por otro lado, un aumento en el precio promedio de exportación de una variedad se traduce en una pérdida de participación de dicha variedad (país de origen) en el total importado en esa categoría de producto. A su vez, si aumenta (disminuye) la cantidad de países de orígen desde los cuales se importa determinado producto, en promedio disminuye (aumenta) la participación del resto de las variedades de dicho producto, ceteris paribus. En todos los casos, ambos instrumentos sobreviven al test de instrumentos débiles (test F de Sanderson-Windmeijer). 
Las variables instrumentales son relevantes. La validez de la restricción de exclusión no es empíricamente verificable. Los supuestos de identificación que deben cumplirse para que los coeficientes estimados sean válidos son dos: (i) shocks de demanda de los distintos países (destinos) no deberían estar correlacionados con shocks de demanda del país de origen (importador); y (ii) la entrada/salida de distintas variedades de un mismo producto no debería generar desvíos respecto a la calidad promedio que decide proveer una firma. Diversos autores han realizado este tipo de supuestos para justificar la validez de estimaciones relativamente similares (e.g. Nevo (2001), Khandelwal (2010)).

\section{CUADRO 4}

Estimación de la ecuación de demanda

\begin{tabular}{|c|c|c|c|c|c|c|c|c|c|c|c|c|}
\hline & (1) & $\overline{(2)}$ & (3) & (4) & $(5)$ & (6) & (7) & (8) & (9) & (10) & (11) & (12) \\
\hline & MEX & BRA & ARG & URU & $\mathrm{COL}$ & TAI & IND & MAL & FIL & COR & RUS & TUR \\
\hline \multicolumn{13}{|c|}{ Segunda etapa } \\
\hline \multirow[t]{2}{*}{$\log$ (precio) } & $-2.06 * * *$ & $-1.50^{* * *}$ & $-0.77^{* * *}$ & $-0.84^{* * *}$ & $-1.42^{* * *}$ & $-0.86^{* * *}$ & $-1.54^{* * *}$ & $-2.28 * * *$ & $-0.82^{* * *}$ & $-0.85^{* * *}$ & $-1.64^{* * *}$ & $-0.98 * * *$ \\
\hline & $(0.13)$ & $(0.13)$ & $(0.05)$ & $(0.07)$ & $(0.13)$ & $(0.12)$ & $(0.20)$ & $(0.21)$ & $(0.09)$ & $(0.11)$ & $(0.11)$ & $(0.04)$ \\
\hline \multirow[t]{2}{*}{$\log (\mathrm{ns})$} & $0.94^{* * *}$ & $0.84^{* * *}$ & $0.90^{* * *}$ & $0.88^{* * *}$ & $0.84^{* * *}$ & $0.82^{* * *}$ & $0.81^{* * *}$ & $0.66^{* * *}$ & $0.85^{* * *}$ & $0.87^{* * *}$ & $0.79^{* * *}$ & $0.93^{* * *}$ \\
\hline & $(0.02)$ & $(0.02)$ & $(0.01)$ & $(0.02)$ & $(0.02)$ & $(0.02)$ & $(0.02)$ & $(0.03)$ & $(0.02)$ & $(0.01)$ & $(0.01)$ & $(0.01)$ \\
\hline Obs. & 211,274 & 227,888 & 190,712 & 108,322 & 158,971 & 214,593 & 207,785 & 204,083 & 146,787 & 220,429 & 317,109 & 238,743 \\
\hline R-cuadrado & 0.46 & 0.75 & 0.91 & 0.90 & 0.73 & 0.87 & 0.64 & 0.17 & 0.86 & 0.91 & 0.56 & 0.89 \\
\hline
\end{tabular}

\begin{tabular}{|c|c|c|c|c|c|c|c|c|c|c|c|c|}
\hline \multicolumn{13}{|c|}{ Primera etapa } \\
\hline \multicolumn{13}{|c|}{ Variable dependiente: Log(precio) } \\
\hline $\log (p$ ref.) & $\begin{array}{c}0.05^{* * *} \\
(0.01)\end{array}$ & $\begin{array}{c}0.15^{* * *} \\
(0.03)\end{array}$ & $\begin{array}{c}0.25^{* * *} \\
(0.01)\end{array}$ & $\begin{array}{c}0.18^{* * *} \\
(0.01)\end{array}$ & $\begin{array}{c}0.12^{* * *} \\
(0.03)\end{array}$ & $\begin{array}{c}0.10^{* * *} \\
(0.02)\end{array}$ & $\begin{array}{c}0.06^{* * *} \\
(0.02)\end{array}$ & $\begin{array}{c}0.06^{* * *} \\
(0.02)\end{array}$ & $\begin{array}{c}0.08^{* * *} \\
(0.02)\end{array}$ & $\begin{array}{c}0.11^{* * *} \\
(0.02)\end{array}$ & $\begin{array}{c}0.19^{* * *} \\
(0.02)\end{array}$ & $\begin{array}{c}0.23^{* * *} \\
(0.01)\end{array}$ \\
\hline $\mathrm{N}^{\circ}$ orígenes & $\begin{array}{c}-0.05^{* * *} \\
(0.01)\end{array}$ & $\begin{array}{c}-0.04^{* * * *} \\
(0.01)\end{array}$ & $\begin{array}{c}{ }^{*}-0.03^{* * * *} \\
(0.01)\end{array}$ & $\begin{array}{c}-0.03^{* *} \\
(0.01)\end{array}$ & $\begin{array}{c}-0.04^{* * *} \\
(0.01)\end{array}$ & $\begin{array}{c}-0.01^{* *} \\
(0.00)\end{array}$ & $\begin{array}{c}-0.01^{* * *} \\
(0.00)\end{array}$ & $\begin{array}{c}-0.03^{* * * *} \\
(0.01)\end{array}$ & $\begin{array}{l}-0.01 \\
(0.00)\end{array}$ & $\begin{array}{c}-0.01^{*} \\
(0.01)\end{array}$ & $\begin{array}{c}-0.05^{* * *} \\
(0.01)\end{array}$ & $\begin{array}{c}-0.03^{* * * *} \\
(0.01)\end{array}$ \\
\hline R-cuadrado & 0.27 & 0.20 & 0.21 & 0.20 & 0.21 & 0.13 & 0.18 & 0.15 & 0.17 & 0.22 & 0.20 & 0.18 \\
\hline Test F-SW & 184.7 & 22.05 & 333.4 & 315.7 & 56.25 & 103.9 & 11.52 & 81.47 & 27.72 & 19.32 & 135.1 & 333.6 \\
\hline Test F (p) & 0.00 & 0.00 & 0.00 & 0.00 & 0.00 & 0.00 & 0.00 & 0.00 & 0.00 & 0.00 & 0.00 & 0.00 \\
\hline \multicolumn{13}{|c|}{ Variable dependiente: $\log ($ nested share $)$} \\
\hline $\log (p$ ref. $)$ & $\begin{array}{c}-0.07^{* * *} \\
(0.02)\end{array}$ & $\begin{array}{c}-0.08^{* *} \\
(0.04)\end{array}$ & $\begin{array}{c}-0.18^{* * *} \\
(0.04)\end{array}$ & $\begin{array}{c}-0.11^{* * *} \\
(0.04)\end{array}$ & $\begin{array}{l}-0.04 \\
(0.03)\end{array}$ & $\begin{array}{c}-0.13^{* * *} \\
(0.03)\end{array}$ & $\begin{array}{c}*-0.09 * * * \\
(0.03)\end{array}$ & $\begin{array}{c}-0.10^{* * * *} \\
(0.04)\end{array}$ & $\begin{array}{c}-0.10^{* * *} \\
(0.02)\end{array}$ & $\begin{array}{c}-0.10^{* * * *} \\
(0.02)\end{array}$ & $\begin{array}{c}-0.13^{* * *} \\
(0.04)\end{array}$ & $\begin{array}{c}-0.12^{* * *} \\
(0.03)\end{array}$ \\
\hline $\mathrm{N}^{\circ}$ orígenes & $\begin{array}{c}-0.06^{* * *} \\
(0.00)\end{array}$ & $\begin{array}{c}-0.10^{* * *} \\
(0.01)\end{array}$ & $\begin{array}{c}{ }^{*}-0.09^{* * *} \\
(0.01)\end{array}$ & $\begin{array}{c}-0.11^{* * *} \\
(0.01)\end{array}$ & $\begin{array}{c}-0.11^{* * *} \\
(0.01)\end{array}$ & $\begin{array}{c}-0.09 * * * \\
(0.01)\end{array}$ & $\begin{array}{c}{ }^{*}-0.09^{* * *} \\
(0.01)\end{array}$ & $\begin{array}{c}-0.09 * * * \\
(0.01)\end{array}$ & $\begin{array}{c}-0.10^{* * *} \\
(0.01)\end{array}$ & $\begin{array}{c}-0.08^{* * *} \\
(0.01)\end{array}$ & $\begin{array}{c}-0.07^{* * *} \\
(0.00)\end{array}$ & $\begin{array}{c}-0.07^{* * *} \\
(0.00)\end{array}$ \\
\hline R-cuadrado & 0.42 & 0.23 & 0.27 & 0.25 & 0.24 & 0.27 & 0.22 & 0.24 & 0.23 & 0.29 & 0.22 & 0.26 \\
\hline Test F-SW & 633.9 & 1023 & 568.6 & 433.4 & 282.3 & 110 & 568 & 387.4 & 765.8 & 351.2 & 418.3 & 682.7 \\
\hline Test F (p) & 0.00 & 0.00 & 0.00 & 0.00 & 0.00 & 0.00 & 0.00 & 0.00 & 0.00 & 0.00 & 0.00 & 0.00 \\
\hline
\end{tabular}

Notas. La parte superior presenta los coeficientes estimados de doce regresiones (una para cada país) separadas de la ecuación de demanda. La variable dependiente es la participación de mercado de cada variedad en la industria correspondiente, en función del $\log$ (precio) de las variedades importadas y del $\log (\mathrm{ns})$ que es el $\log$ de la participación de cada variedad en el producto a 6 dígitos. Se incluyen efectos fijos a nivel producto, año-origen y año-industria. Errores estándar robustos clusterizados a nivel industria. En la parte inferior se presentan las regresiones de la primera etapa. Los dos instrumentos utilizados son un precio de referencia mundial y la cantidad de variedades en cada categoría de producto. Test de instrumentos débiles corresponde al estadístico F de Sanderson-Windmeijer. Fuente. COMTRADE (Naciones Unidas).

Es importante volver a mencionar que a partir de estas estimaciones se derivan las medidas de calidad que se utilizan en las siguientes secciones. Ellas permiten verificar la 
reducción de calidad a nivel variedad/producto y el proceso de sustitución hacia variedades de menor calidad en los años que siguen a la devaluación de cada país. Tener en cuenta que la calidad estimada está compuesta por un efecto fijo a nivel producto (valoración promedio por dicho producto) más el desvío temporal respecto a este promedio, representado por un efecto fijo año-país de origen.

Estas estimaciones también se realizan separadamente para Argentina utilizando los microdatos de INDEC. En este caso, se incluye a los costos de transporte como variable instrumental adicional (presumiblemente más exógena). Estos costos se calculan como la diferencia entre el precio CIF y el precio FOB, y varían a nivel producto(8-dígitos)-país de origen. Es importante recordar que los parámetros estimados en la ecuación de demanda de los productos importados por Argentina se utilizan para realizar el ejercicio de descomposición de los índices de precios. En este sentido, notar que la ecuación de demanda incluye un término de interacción entre el (log) precio y la variable binaria Post , que pretende capturar el aumento en la utilidad marginal del ingreso del consumidor promedio en los años que siguen a la devaluación.

El Cuadro A2 presenta los coeficientes estimados de las regresiones de la primera etapa de la estimación de la demanda de Argentina. El cuadro presenta dos bloques de tres columnas. En el primer bloque (columnas 1 a 3 ) se presentan los coeficientes estimados para la regresión de $\log ($ precio) en función de las tres variables instrumentales

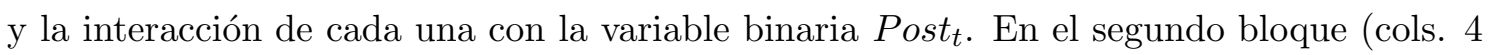
a 6) se presentan los mismos resultados para la variable $\log$ (nestedshare). Las variables dependientes, los costos de importación y los precios de referencia mundiales se expresan en logaritmos. Todas las especificaciones incluyen efectos fijos a nivel producto y a nivel año-país de origen. En la segunda y tercera columna de cada bloque se controla respectivamente por shocks temporales específicos a cada una de las industrias y por inobservables de a nivel industria-origen que no cambian en el tiempo. Estas tres especificaciones se utilizan en la estimación del sistema de demanda. Los coeficientes de ambas variables tienen el signo positivo esperado y son estadísticamente significativas con un nivel de confianza del $99 \%$. Variaciones en el costo de transporte y en el precio de referencia mundial explican parte del cambio en el precio de las variedades importadas por Argentina. La magnitud económica disminuye a partir de la devaluación, siendo más notorio el caso del precio de referencia mundial. Ello significa que, en promedio, disminuye la correlación entre el precio de los productos importados por Argentina y el precio promedio de estos mismos productos vendidos en el resto del mundo. Es probable 
que la hipótesis de este trabajo sea parte de la explicación. La correlación disminuye porque a partir de la devaluación del peso se reduce la calidad y el precio de las variedades importadas por Argentina. La cantidad de variedades (orígenes) de cada producto también tiene el signo esperado (negativo y significativo) y su magnitud económica aumenta a partir de la devaluación. Esta variable también correlaciona negativamente con el precio. La intuición es que un aumento en el número de orígenes de un mismo producto eleva la competencia entre distintas variedades y disminuye tanto la participación como el precio promedio de cada variedad. Todas las variables pasan en test $\mathrm{F}$ de instrumentos débiles de Sanderson-Windmeijer. También pasan el test J de sobreidentificación de Hansen. A los supuestos de identificación realizados anteriormente se suma que (iii) los shocks a los costos de transporte no deberían generar desvíos respecto a la calidad promedio elegida de una firma. En la práctica es un supuesto razonable. Un cambio exógeno en los costos de transporte no debería afectar el modo de producción o la calidad del producto elaborado por la firma. Khandelwal (2010) y Amiti y Khandelwal (2013) realizan un supuesto de identificación similar.

El Cuadro 6 presenta los resultados de la estimación de los parámetros estructurales del sistema de demanda de Argentina por el método de MC2E (ecuación 5.1). Todos los coeficientes estimados son estadísticamente significativos con un nivel de confianza del 99\% y presentan los signos esperados. Los resultados están están en línea con la hipótesis del modelo teórico (motor del argumento de este trabajo): la disposición a pagar se reduce en los años posteriores a la crisis cambiaria (el coeficiente $\hat{\alpha}$ aumenta en valor absoluto). Este resultado es robusto a través de las especificaciones que surgen de incorporar distintas combinaciones de efectos fijos. La devaluación del peso respecto al dólar reduce los ingresos reales medidos en dólares y ello reduce la disposición a pagar por calidad de un consumidor promedio en un 5,5-5,9\%. El parámetro de sustitución $\hat{\sigma}$ también es estadísticamente significativo y está dentro del rango de valores esperado $[0,1)$. 


\section{CUADRO 5}

Estimación de la ecuación de demanda en Argentina

\begin{tabular}{lccc}
\hline \hline & $(1)$ & $(2)$ & $(3)$ \\
\hline $\log (\mathrm{p})$ & $1.45^{* * *}$ & $1.53^{* * *}$ & $1.72^{* * *}$ \\
& $(0.13)$ & $(0.14)$ & $(0.17)$ \\
$\log (p) \times$ Post & $0.08^{* *}$ & $0.09^{* * *}$ & $0.10^{* * *}$ \\
& $(0.037)$ & $(0.030)$ & $(0.031)$ \\
$\log (n s)$ & $0.63^{* * *}$ & $0.64^{* * *}$ & $0.67^{* * *}$ \\
& $(0.04)$ & $(0.04)$ & $(0.05)$ \\
\hline EF producto & $\mathrm{Si}$ & $\mathrm{Si}$ & $\mathrm{Si}$ \\
EF Año $\times$ País & $\mathrm{Si}$ & $\mathrm{Si}$ & $\mathrm{Si}$ \\
EF Año $\times$ Industria & - & $\mathrm{Si}$ & $\mathrm{Si}$ \\
EF País $\times$ Industria & - & - & $\mathrm{Si}$ \\
Observaciones & 347904 & 347904 & 347904 \\
Productos & 8033 & 8033 & 8033 \\
\hline
\end{tabular}

Notas. Regresión estimada por el método de MC2E. La variable dependiente es la participación de mercado de cada variedad en la industria correspondiente, en función del $\log$ (precio) de las variedades importadas y del $\log (\mathrm{ns})$, que es el $\log$ de la participación de cada variedad en el producto a 6 dígitos. Se utilizan como variables instrumentales el costo de transporte, precio de referencia mundial y número de variedades de cada producto (más sus interacciones con la variable Post $t_{t}$ ). Errores estándar robustos clusterizados por industrias. Las regresiones pasan los tests de instrumentos débiles y sobreidentificación. Fuentes. Datos de Aduana (INDEC) y COMTRADE (Naciones Unidas).

\subsection{Reducción de calidad}

En esta sección se presentan los resultados de un conjunto de regresiones que intentan describir la evolución de la calidad de los productos importados por cada uno de los países estudiados durante los episodios devaluatorios. Dado que las medidas de calidad estimadas toman valores positivos y negativos, aplicar logaritmos deja fuera una proporción considerable de las observaciones. Por lo tanto, se utiliza una medida estandarizada de la calidad estimada que permite interpretar los resultados razonablemente. La estandarización es la siguiente:

$$
\hat{\theta}_{j s t}^{e s t a n d .}=\frac{\hat{\theta}_{j s t}-M\left(\hat{\theta}_{j s \in I, t=T-3}\right)}{D\left(\hat{\theta}_{j s \in I, t=T-3}\right)}
$$

A la medida de calidad estimada $\hat{\theta}_{j s t}$ se resta el promedio (M) y se divide por el desvío estándar (S) de la calidad del año inicial $(t=T-3)$ en la industria $(I)$ correspondiente (2 dígitos del SA). El período elegido es de los 6 años que circunscribe a cada crisis 
cambiaria. Se estiman variantes de la siguiente ecuación de regresión (por el método de MCO) separadamente para cada uno de los países estudiados:

$$
\hat{\theta}_{j s t}^{\text {estand. }}=\beta \text { Post }_{t}+\phi_{j s}+\varepsilon_{j s t}
$$

Observar que estas regresiones siguen la misma lógica que las regresiones de precios de la sección 6.2. La variable dependiente es la calidad estimada de cada variedad $s$ (país de origen) del producto $j$ en el período $t$, estimada en la sección anterior a partir de la ecuación de demanda y estandarizada respecto a la calidad promedio inicial en la

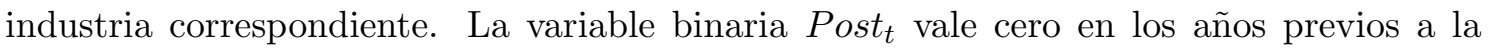
devaluación (entre T-1 y T-3), y vale uno en los años posteriores (entre T y T+2). Igual que antes, las regresiones incluyen efectos fijos a nivel variedad $\left(\phi_{j s}\right)$. Alternativamente, se utilizan efectos fijos a nivel producto $\left(\phi_{j}\right)$. $\varepsilon_{j s t}$ es el error de estimación del modelo. En la estimación se calculan errores estándar robustos utilizando clusters a nivel industria (2 dígitos). Los resultados no cambian significativamente al utilizar clusters por país de origen o producto ( 6 dígitos). El coeficiente de interés $\beta$ captura la variación en la calidad promedio de las variedades importadas en los años que siguen a la crisis cambiaria, medido en desvíos estándar respecto a la calidad promedio inicial en la industria correspondiente. En una segunda especificación se reemplaza a la variable Post $_{t}$ por dummies anuales.

Para facilitar la interpretación, la Figura 7 presenta los coeficientes $\hat{\beta}$ que acompañan a la variable Post $_{t}$ para cada uno de los países estudiados. Notar que se presentan dos resultados para cada país en función de los efectos fijos que se incorporan como control. Los resultados sugieren que calidad promedio de las variedades importadas se reduce significativamente en los años que siguen a la crisis cambiaria (en promedio 0,10 desvíos estándar respecto a la calidad promedio inicial de la industria correspondiente). Se destacan los casos de Malasia (0,19 d.e.), Rusia (0,16 d.e.) y México (0,12 d.e.). Por debajo del promedio aparecen Tailandia e Indonesia. Las regresiones que incluyen dummies anuales muestran que la calidad estimada es significativamente menor en prácticamente todos los años en comparación con el año inicial T-3, siendo marcadamente menor en los años que siguen a la devaluación ( 0,16 d.e. en promedio en $\mathrm{T}+1$, y 0,12 d.e. en promedio en $\mathrm{T}+2$ ). Estos resultados se presentan en el Cuadro A3 y en la Figura A4 del apéndice. 
FIGURA 7

Cambio en calidad post devaluación

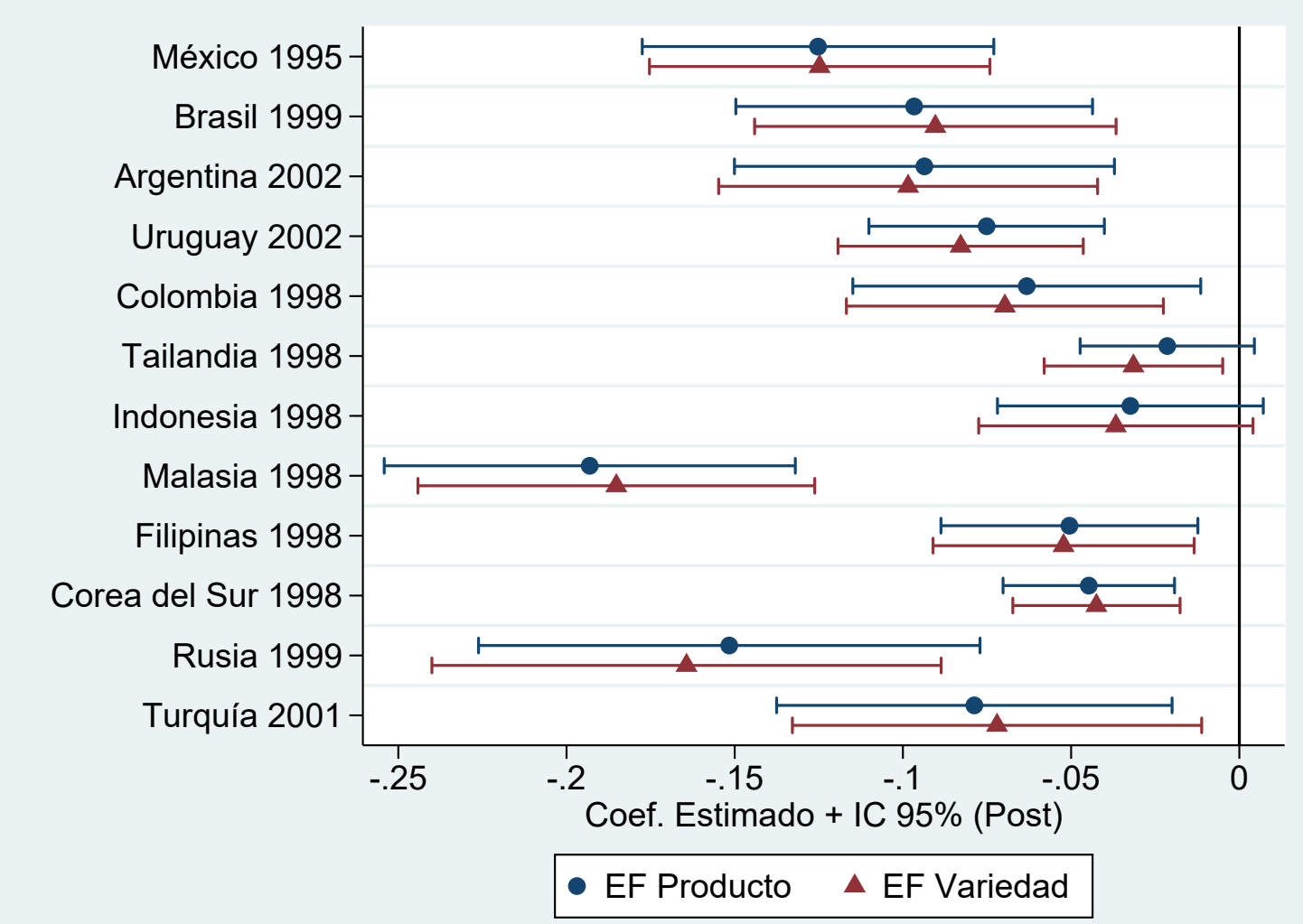

Notas. Coeficientes estimados a partir de 24 regresiones (2 para cada país) de la calidad estimada (estandarizada) en la variable binaria Post ( $=1$ en los tres años que siguen a la devaluación). Una especificación incluye EF a nivel producto (azul) y otra EF a nivel variedad (roja). Cada variedad es ponderada por la participación en el valor total importado de la industria correspondiente. Errores estándar clusterizados a nivel industria. Fuente. COMTRADE (Naciones Unidas).

La ecuación de regresión ((6.3)) también se estima separadamente para cada una de las 80 industrias de cada país. La Figura 8 presenta los coeficientes estimados para la para la variable Post $_{t}$. La gran mayoría de las industrias (77\%) presenta una reducción en la calidad promedio de las variedades importadas en los años posteriores a la crisis cambiaria. El coeficiente estimado promedio es -0,12 y la mediana es de -0,16 desvíos estándar (d.e.) respecto a la calidad promedio de la industria en el año inicial. Los países que presentan mayor caída de calidad promedio a través de sus industrias son México (-0,38 d.e.), Malasia (-0,26 d.e.) e Indonesia (-0,21 d.e.). 


\section{FIGURA 8}

Cambio en calidad por industrias

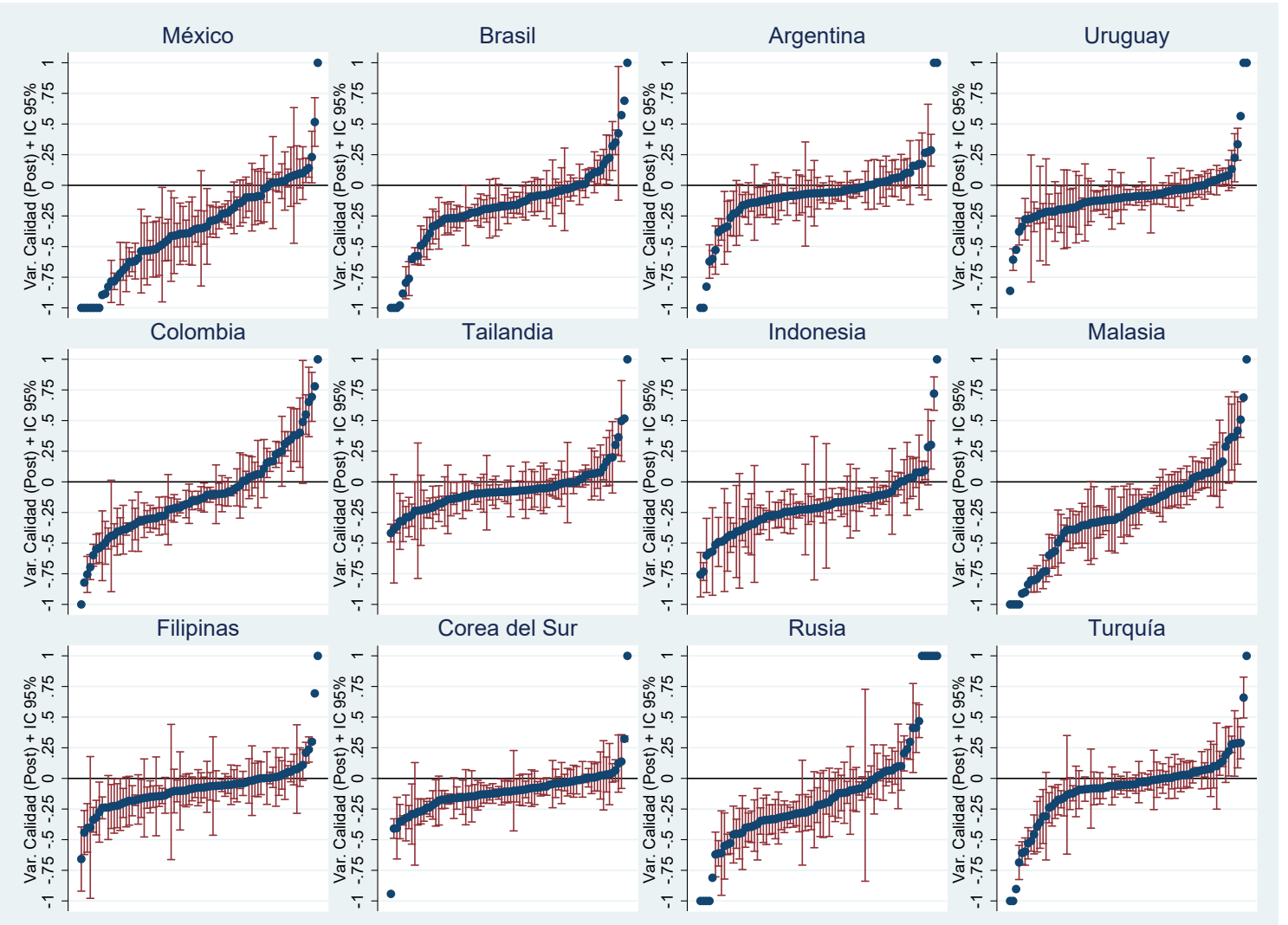

Notas. Coeficientes estimados a partir de regresiones a nivel industria (80 regresiones por país) de la calidad estimada (estandarizada) en la variable binaria Post $(=1$ en los tres años que siguen a la devaluación). Errores estándar clusterizados a nivel producto. Cada variedad es ponderada por la participación en el valor total importado de la industria correspondiente. Para acotar el rango de valores, los coeficientes sup./inf. a 1 error estándar no incluyen el IC. Fuente. COMTRADE (Naciones Unidas).

El Cuadro 6 presenta los resultados para Argentina, utilizando las estimaciones de calidad derivadas de microdatos de Aduanas provenientes de INDEC. En este caso, los coeficientes están estimados con mayor precisión. La calidad promedio de las variedades y los productos importados se reduce significativamente a lo largo de todo el período, mientras que la magnitud de tal reducción aumenta significativamente en los años que siguen a la crisis cambiaria. La calidad promedio en los tres años posteriores a la devaluación resulta ser 0,2 d.e. menor que en los tres años previos. La reducción en la calidad promedio es de 0,25 d.e. en el año 2003 en comparación con 1999. La parte inferior del Cuadro 6 muestra que tres de cada cinco variedades importadas presenta una disminución de calidad en el año 2001. Esta proporción aumenta en los años 2002 y 2003, cuando alrededor del $73 \%$ de las variedades presentan una reducción de calidad. Estos valores son aún más pronunciados en las estimaciones a nivel producto. En este caso, alrededor del 76-78\% de los productos presenta una disminución de calidad en el año 2002, y alrededor del 75-81\% en el año 2003 (siempre respecto a 1999). 


\section{CUADRO 6}

Reducción de calidad en Argentina

\begin{tabular}{lccc}
\hline \hline & $\begin{array}{c}\text { Variedad } \\
(1)\end{array}$ & $\begin{array}{c}\text { Producto-8d } \\
(2)\end{array}$ & $\begin{array}{c}\text { Producto-6d } \\
(3)\end{array}$ \\
\hline Post & $-0.26^{* * *}$ & $-0.26^{* * *}$ & $-0.26^{* * *}$ \\
& $(0.03)$ & $(0.03)$ & $(0.03)$ \\
\hline Año 2000 & $-0.03^{* *}$ & $-0.02^{* *}$ & -0.02 \\
& $(0.01)$ & $(0.01)$ & $(0.01)$ \\
Año 2001 & $-0.05^{* * *}$ & $-0.05^{* *}$ & $-0.04^{*}$ \\
& $(0.02)$ & $(0.02)$ & $(0.02)$ \\
Año 2002 & $-0.28^{* * *}$ & $-0.26^{* * *}$ & $-0.25^{* * *}$ \\
& $(0.03)$ & $(0.03)$ & $(0.03)$ \\
Año 2003 & $-0.33^{* * *}$ & $-0.31^{* * *}$ & $-0.31^{* * *}$ \\
& $(0.03)$ & $(0.03)$ & $(0.03)$ \\
Año 2004 & $-0.27^{* * *}$ & $-0.27^{* * *}$ & $-0.27^{* * *}$ \\
& $(0.03)$ & $(0.03)$ & $(0.03)$ \\
\hline EF Variedad/Producto & $\mathrm{Si}$ & $\mathrm{Si}$ & $\mathrm{Si}$ \\
& & & \\
Observaciones & 323187 & 38392 & 23248 \\
Grupos de EF & 77531 & 7464 & 4318 \\
\hline Proporción $\Delta<0$ & & & \\
1999-2001 & & & 0.67 \\
1999-2002 & 0.60 & 0.65 & 0.83 \\
1999-2003 & 0.73 & 0.80 & 0.80 \\
1999-2004 & 0.72 & 0.77 & 0.77 \\
\hline
\end{tabular}

Notas. La calidad estimada se estandariza en función del promedio y desvío estándar inicial (año 1999) en la industria correspondiente; y se pondera por la participación de cada variedad (producto) en el valor total importado anualmente por cada industria. Errores estándar robustos clusterizados por industria (hs2). Resultados robustos a utilizar ponderadores y/o clusters alternativos.

\subsection{Sustitución}

En esta sección se presenta un conjunto de regresiones que intentan describir el cambio composicional (entre variedades de un mismo producto importado) que ocurre en los años que siguen a la crisis cambiaria. Se muestra que en todos los casos se produce un fenómeno de sustitución de variedades de precio y calidad alta por variedades de precio y calidad bajo. Dicho de otro modo, después de la devaluación aumenta la participación en el valor total importado de cada producto de las variedades de menor precio/calidad relativa, en detrimento de aquellas variedades de mayor precio/calidad. Se estiman (por MCO) variantes de la siguiente ecuación de regresión:

$$
\Delta_{t} s h_{j s}=\beta_{1} \log \left(p_{j s 0}\right)+\beta_{2} \hat{\theta}_{j s 0}+\varepsilon_{j s t}
$$


La variable dependiente $\Delta_{t} s h_{j s}=s h_{j s 1}-s h_{j s 0}$ representa el cambio (entre un período pre y otro post devaluación) en la participación o market share de cada variedad (país de origen) en el valor total importado de la categoría de producto (6 dígitos) a la que pertenece. Los coeficientes de interés son los que acompañan al precio $\left(\beta_{1}\right)$ y a la calidad estimada $\left(\beta_{2}\right)$ de cada variedad en el período inicial. Estos resultados se presentan gráficamente en la Figura 9. Es importante notar que el precio y la calidad están correlacionados por construcción (ver la ecuación 5.1). Por esta razón, también es conveniente realizar esta regresión separadamente para (i) el precio inicial, y (ii) la calidad inicial. En este caso, los resultados son aún más precisos (ver las Figuras A5 y A6 del apéndice). ${ }^{35}$

FIGURA 9

Sustitución de variedades post devaluación

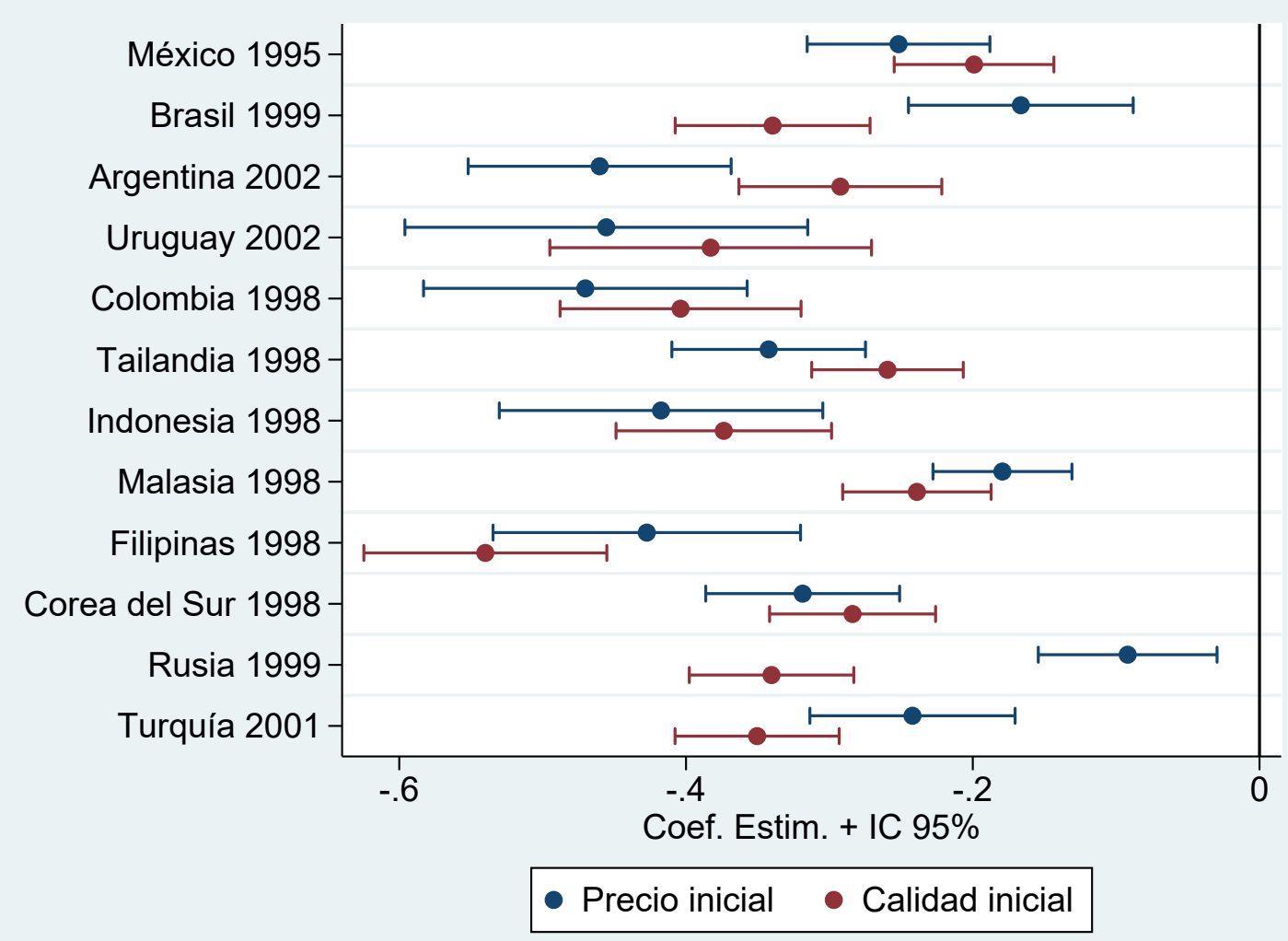

Notas. Coeficientes estimados a partir de (12) regresiones (una para cada país) del cambio promedio en la participación de cada variedad en el total importado entre los dos períodos (pre y post devaluación) en función del precio y la calidad de cada variedad en el período inicial. Errores estándar clusterizados a nivel industria. Fuente. COMTRADE (Naciones Unidas).

Los resultados muestran que en todas las especificaciones, los coeficientes $\hat{\beta}_{1}$ y $\hat{\beta}_{2}$ son negativos y estadísticamente significativos. Ello significa que las variedades de mayor

\footnotetext{
${ }^{35}$ Para agregar robustez al análisis se utilizan dos definiciones de producto para medir el cambio en la participación de mercado (6 y 4 dígitos del SA). Los resultados son robustos. Como es de esperar, la magnitud de los coeficientes estimados disminuye cuando se utiliza una medida más agregada (4 dígitos).
} 
precio y mayor calidad en el período inicial, en promedio pierden participación (en el valor total importado de cada producto). Es decir, se produce un cambio composicional al interior de cada producto a favor de variedades de menor precio y menor calidad relativa. Los resultados son robustos a la inclusión/exclusión de aquellas variedades que entran y salen del set de importaciones. ${ }^{36}$

$\mathrm{Al}$ igual que en las secciones anteriores, estas estimaciones se realizan nuevamente para Argentina utilizando los microdatos de Aduanas provenientes de INDEC. Los resultados se presentan en el Cuadro 7. Las columnas (1) a (6) presentan distintas especificaciones asociadas con distintas combinaciones del precio, la calidad y la participación inicial. La inclusión de la participación inicial de cada variedad es similar a utilizar ponderadores, y se incluye para dotar de robustez al análisis. Se realizan cuatro comparaciones sucesivas (años 2001, 2002, 2003 y 2004) con respecto al año inicial 1999 (paneles A a D). Los resultados van en la misma dirección y muestran que las variedades de mayor (menor) precio/calidad inicial pierden (ganan) participación en los años que siguen al a crisis cambiaria. Los resultados son robustos a utilizar una medida de producto con el máximo nivel de desagregación (8 dígitos del SA). Los resultados también son robustos a la inclusión/exclusión de aquellas variedades que entran y salen del panel.

\footnotetext{
${ }^{36}$ En este caso, se imputa un 0 a la participación de mercado de las variedades que no se importan en determinado período/año. En la sección de estadísticas descriptivas se muestra que en los años que siguen a la devaluación se importan menos variedades en promedio (predomina el efecto salida).
} 


\section{CUADRO 7}

Sustitución de variedades en Argentina

\begin{tabular}{|c|c|c|c|c|c|c|}
\hline & $(1)$ & $(2)$ & $(3)$ & $(4)$ & $(5)$ & $(6)$ \\
\hline \multicolumn{7}{|l|}{ Panel A: 1999-2001 } \\
\hline Precio inicial & $\begin{array}{c}-0.05^{* *} \\
(0.02)\end{array}$ & $\begin{array}{c}-0.14^{* * *} \\
(0.02)\end{array}$ & & . & $\begin{array}{c}-0.28^{* * *} \\
(0.03)\end{array}$ & $\begin{array}{r}-0.25^{* * *} \\
(0.03)\end{array}$ \\
\hline Calidad inicial & 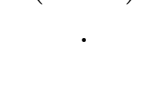 & . & $\begin{array}{c}-0.16^{* * *} \\
(0.02)\end{array}$ & $\begin{array}{c}-0.15^{* * *} \\
(0.02)\end{array}$ & $\begin{array}{c}-0.27^{* * *} \\
(0.03)\end{array}$ & $\begin{array}{r}-0.14^{* * *} \\
(0.03)\end{array}$ \\
\hline Participación inicial & . & $\begin{array}{r}-0.18^{* * *} \\
(0.007)\end{array}$ & & $\begin{array}{r}-0.18^{* * *} \\
(0.007)\end{array}$ & - & $\begin{array}{r}-0.18^{* * *} \\
(0.007)\end{array}$ \\
\hline Observaciones & 48206 & 48206 & 48206 & 48206 & 48206 & 48206 \\
\hline \multicolumn{7}{|l|}{ Panel B: 1999-2002 } \\
\hline Precio inicial & $\begin{array}{c}0.05 \\
(0.03)\end{array}$ & $\begin{array}{c}-0.07^{* *} \\
(0.03)\end{array}$ & & . & $\begin{array}{c}-0.27^{* * *} \\
(0.05)\end{array}$ & $\begin{array}{r}-0.25^{* * *} \\
(0.04)\end{array}$ \\
\hline Calidad inicial & . & $\cdot$ & $\begin{array}{c}-0.16^{* * *} \\
(0.03)\end{array}$ & $\begin{array}{c}-0.15^{* * *} \\
(0.03)\end{array}$ & $\begin{array}{c}-0.39^{* * *} \\
(0.04)\end{array}$ & $\begin{array}{r}-0.22^{* * *} \\
(0.04)\end{array}$ \\
\hline Participación inicial & . & $\begin{array}{r}-0.19^{* * *} \\
(0.009) \\
\end{array}$ & & $\begin{array}{r}-0.19^{* * *} \\
(0.009) \\
\end{array}$ & . & $\begin{array}{r}-0.19^{* * *} \\
(0.009) \\
\end{array}$ \\
\hline Observaciones & 35488 & 35488 & 35488 & 35488 & 35488 & 35488 \\
\hline \multicolumn{7}{|l|}{ Panel C: 1999-2003 } \\
\hline Precio inicial & $\begin{array}{c}-0.04 \\
(0.03)\end{array}$ & $\begin{array}{c}-0.15^{* * *} \\
(0.03)\end{array}$ & & . & $\begin{array}{c}-0.30^{* * *} \\
(0.04)\end{array}$ & $\begin{array}{r}-0.27^{* * *} \\
(0.04)\end{array}$ \\
\hline Calidad inicial & & 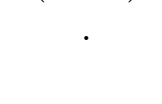 & $\begin{array}{c}-0.18^{* * *} \\
(0.02)\end{array}$ & $\begin{array}{c}-0.15^{* * *} \\
(0.02)\end{array}$ & $\begin{array}{c}-0.32^{* * *} \\
(0.03)\end{array}$ & $\begin{array}{r}-0.14^{* * *} \\
(0.03)\end{array}$ \\
\hline Participación inicial & . & $\begin{array}{r}-0.21^{* * *} \\
(0.009)\end{array}$ & . & $\begin{array}{r}-0.21^{* * *} \\
(0.009)\end{array}$ & . & $\begin{array}{r}-0.21^{* * *} \\
(0.009)\end{array}$ \\
\hline Observaciones & 38648 & 38648 & 38648 & 38648 & 38648 & 38648 \\
\hline \multicolumn{7}{|l|}{ Panel D: 1999-2004 } \\
\hline Precio inicial & $\begin{array}{c}-0.11^{* * *} \\
(0.03)\end{array}$ & $\begin{array}{c}-0.23^{* * *} \\
(0.03)\end{array}$ & & . & $\begin{array}{c}-0.41^{* * *} \\
(0.04)\end{array}$ & $\begin{array}{r}-0.37^{* * *} \\
(0.04)\end{array}$ \\
\hline Calidad inicial & . & . & $\begin{array}{c}-0.24^{* * *} \\
(0.02)\end{array}$ & $\begin{array}{c}-0.21^{* * *} \\
(0.02)\end{array}$ & $\begin{array}{c}-0.36^{* * *} \\
(0.03)\end{array}$ & $\begin{array}{r}-0.17^{* * *} \\
(0.03)\end{array}$ \\
\hline Participación inicial & 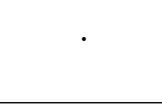 & $\begin{array}{r}-0.23^{* * *} \\
(0.009)\end{array}$ & & $\begin{array}{r}-0.23^{* * *} \\
(0.009)\end{array}$ & . & $\begin{array}{r}-0.23^{* * *} \\
(0.009)\end{array}$ \\
\hline Observaciones & 40273 & 40273 & 40273 & 40273 & 40273 & 40273 \\
\hline
\end{tabular}

Notas. La variable dependiente es el cambio en la participación de cada variedad en el valor importado de cada producto (6 dígitos) entre el año inicial 1999 y los años 2001 a 2004 (paneles A a D). La muestra está restringida a aquellas variedades que se importan en ambos años. Los resultados son robustos a utilizar una definición más desagregada de producto (8 dígitos) y a incluir aquellas variedades que entran y salen del panel. Fuentes. INDEC.

\subsection{Calidad y PBI per cápita}

El objetivo de esta sección es verificar si las medidas de calidad derivadas de la estimación del sistema de demanda multinominal logit son consistentes con el hecho de que los países más ricos tienden a exportar productos de mayor calidad. Este un hallazgo 
habitual en la literatura (e.g. Schott (2004); Hummels y Klenow (2005)). Los fundamentos teóricos de esta literatura comienzan con el trabajo seminal de Linder (1961). El autor plantea que los países más ricos gastan una mayor proporción de su ingreso en bienes de mayor calidad. Y esta demanda por calidad es una fuente de ventaja comparativa en la producción de dichos bienes. ${ }^{37}$ Un corolario de esta premisa es que la similitud de los patrones de producción y consumo generaría un mayor volumen de comercio entre países que presentan niveles de ingreso per cápita similares. Varios trabajos de la literatura encuentran evidencia a favor de esta hipótesis (e.g. Hallak (2006); Baldwin y Harrigan (2007); Verhoogen(2008); Kugler y Verhoogen (2008); Hallak y Sivadasan (2009); Johnson (2009)).

Para estudiar si existe una correlación entre el ingreso per cápita y la calidad promedio de los productos que exportan distintos países, se estiman (por MCO) variantes de la siguiente ecuación de regresión, separadamente para cada uno de los países estudiados:

$$
\hat{\theta}_{j s t}=\beta \log \left(P B I p c_{s t}\right)+\phi_{j t}+\varepsilon_{j s t}
$$

donde $\hat{\theta}_{j s t}$ es la calidad estimada de la variedad $s$ del producto $j$ en el año $t, P B I p c_{s t}$ es el producto per cápita del país de origen $s$ (exportador), $\phi_{j t}$ son efectos fijos a nivel producto-año y $\varepsilon_{j s t}$ es el error de estimación del modelo. El coeficiente de interés es $\beta$, que captura la correlación promedio entre el ingreso per cápita del país de origen y la calidad del producto que exporta. Dado que se incluye un efecto fijo producto-año se explota la variabilidad de la calidad a nivel producto. Es importante notar que no es posible dar una interpretación causal a los coeficientes estimados porque existe doble causalidad. Por un lado, los consumidores de países más ricos demandan bienes de mayor calidad y ello aumenta la probabilidad de producir y exportar este tipo de bienes (Linder, 1961). Por otro lado, mejorar la calidad de los productos ofrecidos permite ganar participación de mercado frente a competidores que se encuentran en el mismo espacio de productos y también permite abrir nuevos mercados. De este modo, mejorar la calidad aumenta el éxito exportador y contribuye al desarrollo económico (Hausmann, Hwang y Rodrik, $2007) .^{38}$

\footnotetext{
${ }^{37}$ La idea de que los países tienden a exportar aquellos bienes que presentan elevada demanda doméstica (en términos relativos) es retomada por Krugman (1980) en su definición de home market effect.

${ }^{38} \mathrm{La}$ mejora de la calidad no sólo tiende a aumentar el ingreso promedio sino que suele incrementar la varianza, porque producir mayor calidad incrementa la demanda relativa de trabajadores más calificados. Verhoogen (2008) y Goldberg y Pavcnik (2007) muestran que la liberalización comercial genera efectos
} 
El Cuadro 9 presenta los resultados. Los coeficientes estimados son positivos y estadísticamente significativos. ${ }^{39}$ En línea con los hallazgos previos de la literatura, los países que poseen mayor producto per cápita, en promedio exportan productos de mayor calidad.

\section{CUADRO 8}

Correlación entre calidad y PBI per cápita

\begin{tabular}{cccccccccccc}
\hline \hline MEX & BRA & ARG & URU & COL & TAI & IND & MAL & FIL & COR & RUS & TUR \\
1995 & 1999 & 2002 & 2002 & 1998 & 1998 & 1998 & 1998 & 1998 & 1998 & 1999 & 2001 \\
\hline
\end{tabular}

$\log (\mathrm{PBIpc}) 0.10^{* * *} 0.17^{* * *} 0.06^{* * *} 0.23^{* * *} 0.05^{* * *} 0.02^{* * *} 0.11^{* *} 0.07^{* * *} \quad 0.07 \quad 0.05^{* * *} 0.20^{* * *} 0.10^{* * *}$ $\begin{array}{lllllllllllll}(0.01) & (0.02) & (0.02) & (0.04) & (0.01) & (0.01) & (0.06) & (0.01) & (0.05) & (0.00) & (0.03) & (0.01)\end{array}$

Obs. $\quad 206,778 \quad 226,499 \quad 189,084 \quad 106,150 \quad 156,050 \quad 213,148 \quad 206,019 \quad 202,933 \quad 145,404 \quad 219,500 \quad 313,074 \quad 234,017$ \begin{tabular}{lllllllllllll} 
EF año-prod. & 20,940 & 21,710 & 18,749 & 14,727 & 19,470 & 20,109 & 21,226 & 19,251 & 16,516 & 22,391 & 21,597 & 20,159 \\
\hline
\end{tabular}

Notas. Coeficientes estimados a partir de (12) regresiones separadas (una para cada país) donde la variable dependiente es la calidad estimada de las variedades importadas en función del (log) PBI per capita del país de origen de cada variedad. Se incluyen efectos fijos a nivel año-producto. Un producto se define a 6 dígitos del Sistema Armonizado. El PBI pc se mide en dólares constantes a paridad de poder adquisitivo. Errores estándar clusterizados a nivel industria. Fuente. COMTRADE (Naciones Unidas) y WDI (Banco Mundial).

También es posible realizar este ejercicio utilizando las medidas de calidad de las variedades importadas por Argentina derivadas de la utilización de los microdatos provenientes de INDEC. Los resultados se presentan en el Cuadro 9. Las tres columnas del Cuadro 9 corresponden a las tres medidas de calidad (que incorporan distintas combinaciones de efectos fijos) derivadas de las especificaciones presentadas en el Cuadro 5. En este caso, la magnitud de los coeficientes estimados aumenta de manera significativa y los coeficientes están estimados con mucha más precisión. Este ejercicio también ilustra la conveniencia de utilizar los microdatos de INDEC por sobre los datos de COMTRADE.

de este tipo que explican buena parte del aumento de la desigualdad de los países en desarrollo durante los 80 s y 90s. En la segunda parte de la tesis se discute buena parte de la literatura dedicada a estudiar el vínculo entre el comercio internacional, los mercados laborales y el bienestar económico.

${ }^{39}$ La única excepción es Filipinas. En este caso, si bien el signo es el esperado, el coeficiente no está estimado con suficiente precisión. 


\section{CUADRO 9}

Correlación entre calidad y PBI per cápita en Argentina

\begin{tabular}{lccc}
\hline \hline & $(1)$ & $(2)$ & $(3)$ \\
\hline Log(PBI pc) & $\begin{array}{l}0.49^{* *} \\
(0.07)\end{array}$ & $\begin{array}{c}0.53^{* * *} \\
(0.07)\end{array}$ & $\begin{array}{c}0.68^{* * *} \\
(0.07)\end{array}$ \\
EF Año $\times$ Producto & $\mathrm{Si}$ & $\mathrm{Si}$ & $\mathrm{Si}$ \\
& & & \\
Observaciones & 354334 & 354334 & 354334 \\
Grupos de EF & 23415 & 23415 & 23415 \\
\hline \hline
\end{tabular}

\subsection{Estimación de costos}

En esta sección se presentan los resultados de la calibración de los parámetros asociados a los costos marginales de las firmas internacionales que exportan a Argentina. Para ello se utilizan los datos provenientes del INDEC. Recordar que para calibrar estos parámetros es necesario realizar supuestos acerca de la forma funcional de los costos (tecnología de coeficientes fijos) y sobre la estructura de competencia inherente al mercado internacional (competencia monopolística). Luego, reemplazando la función de costos en las CPO que resultan de la maximización de beneficios (ecuaciones 4.6 y 4.7) se despejan los dos parámetros de dicha función.

Para obtener los valores del parámetro $\phi_{j s t}^{1}$ se aplica un método de optimización numérica tradicional (Newton-Raphson). Recordar que en la parametrización elegida el valor de $\phi_{j s t}^{1}$ no depende del valor de $\phi_{j s t}^{0}$. Ello permite que el algoritmo empleado converja rápidamente a la solución. Este procedimiento permite recuperar el valor de los dos parámetros de la función de costos marginales para cada una de las firmas. Luego, es posible calcular el precio y la calidad de equilibrio, y utilizarlos para simular la participación de mercado de cada firma. Finalmente, se calculan los índices de precios tal como se explica en la sección Sección 4.4.

El Cuadro 10 expone los resultados de la calibración. Se presenta el valor promedio y los percentiles 10 y 90 para cada uno de los parámetros $\left(\phi_{j s t}^{0} \mathrm{y} \phi_{j s t}^{0}\right)$. Los resultados muestran un rango de valores similar a través de las distintas especificaciones. La última línea del cuadro muestra el porcentaje de observaciones utilizadas para realizar la estimación. Es posible recuperar los parámetros de costos para el $57 \%, 59 \%$ y $65 \%$ de 
las observaciones. Aquellas que se pierden son las que no cumplen con las condiciones que garantizan la existencia de único equilibrio donde la calidad y el precio toman valores positivos (ver los supuestos realizados en la sección 4.2.). Los mark-ups estimados son $35 \%, 32 \%$ y $24 \%$ en cada una de las especificaciones, y disminuyen entre 2 y 3 puntos porcentuales como consecuencia de la reducción en la disposición a pagar de los consumidores.

\section{CUADRO 10}

Calibración de los parámetros de costos en Argentina

\begin{tabular}{lccc}
\hline \hline & $(1)$ & $(2)$ & $(3)$ \\
\hline$\phi_{1}$ Promedio & 2.24 & 2.06 & 1.58 \\
$\phi_{1}$ p10 & 1.08 & 1.01 & 0.83 \\
$\phi_{1}$ p90 & 4.31 & 3.91 & 2.85 \\
& & & \\
$\phi_{0}$ Promedio & 0.015 & 0.016 & 0.021 \\
$\phi_{0}$ p10 & 0.0002 & 0.0002 & 0.0002 \\
$\phi_{0}$ p90 & 0.031 & 0.032 & 0.035 \\
& & & \\
Markup (pre) & 0.35 & 0.32 & 0.24 \\
Markup (post) & 0.32 & 0.30 & 0.22 \\
& & & \\
Observaciones & $57 \%$ & $59 \%$ & $65 \%$ \\
\hline \hline
\end{tabular}

Notas. Las columnas (1)-(3) siguen las tres especificaciones de la ecuación de demanda. $\phi_{j s t}^{1}$ se recupera aplicando el método Newton-Raphson. Por consistencia, es necesario asumir que $\phi_{j s t}^{0}>0 \phi_{j s t}^{1}>0$ y que $\phi_{j s t}^{1}>\frac{1}{\alpha_{t}-(1-\sigma)}$.

Recordar que en un modelo de elección discreta, los supuestos de competencia monopolística más la forma funcional $\log (\mathrm{p})$ (en la ecuación de demanda) generan un modelo con elasticidad de la demanda constante. Por lo tanto, los mark-ups también son constantes para todas las firmas. En este sentido, los valores obtenidos se interpretan como una elasticidad agregada y un mark-up agregado (promedio) para el conjunto de firmas que exportan a Argentina. En la realidad, los mark-ups varían según el tipo de firma, la calidad del producto ofrecido, la disposición a pagar de los consumidores de dicho producto y las decisiones de los competidores. ${ }^{40}$ Sin embargo, los datos disponibles no permiten responder preguntas de este tipo. Esta es otra línea de investigación que interesa profundizar en los próximos años.

\footnotetext{
${ }^{40}$ En un trabajo reciente, Amiti, Itskhoki y Konings (2018) muestran que las firmas ajustan los precios en función de sus propios costos $(60 \%)$ y en función del precio de sus competidores $(40 \%)$, ceteris paribus. La importancia de la complementariedad estratégica en la fijación de precios es creciente en el tamaño de las firmas.
} 


\subsection{Costos y PBI per cápita}

El objetivo de esta sección es evaluar si los parámetros de costos de las firmas internacionales presentan alguna correlación con el nivel de ingreso del país de origen. Recordar que la función de costos elegida se deriva de una tecnología de coeficientes fijos que combina un conjunto de insumos (donde $\phi_{j s t}^{0}$ es el precio de dichos insumos) con determinada tecnología de producción de calidad. La variable aleatoria $\phi_{j s t}^{1}$ refiere a la eficiencia de cada firma en la producción de calidad. Las firmas más eficientes en producir calidad (menor $\left.\phi_{j s t}^{1}\right)$ y aquellas que utilizan insumos más costosos (mayor $\phi_{j s t}^{0}$ ) eligen óptimamente proveer mayor calidad y cobrar un precio más elevado.

Los parámetros de la función de costos varían a nivel variedad (producto-país de origen). En este sentido, es posible evaluar la correlación entre cada uno de estos parámetros y el producto per cápita del país de origen. A priori, se espera que países más ricos sean más eficientes en la producción de calidad (menor $\phi_{j s t}^{1}$ ) y que utilicen insumos de mayor precio/calidad (mayor $\phi_{j s t}^{0}$ ). Ver por ejemplo las contribuciones de Brambilla, Lederman y Porto (2012) y más recientemente Bastos, Silva y Verhoogen (2018). Para evaluar estas correlaciones se estiman variantes de la siguiente ecuación de regresión:

$$
\log \left(\phi_{j s t}^{i}\right)=\beta \log \left(P B I p c_{s t}\right)+\phi_{j t}+\varepsilon_{j s t}
$$

para $i=0,1$. Se estiman dos regresiones separadas para cada uno de los parámetros de $\operatorname{costos}\left(\phi_{j s t}^{0} \mathrm{y} \phi_{j s t}^{1}\right)$, en función del PBI per cápita del país de origen y un conjunto de efectos fijos a nivel año-producto que permiten controlar por shocks temporales distribuidos de manera uniforme entre todas las variedades de un mismo producto. El coeficiente $\beta$ captura la correlación promedio entre el parámetro de costos y el ingreso per cápita del país exportador dentro de cada categoría de producto. Se utilizan errores estándar robustos clusterizados a nivel industria. Los resultados son robustos a clusterizar a nivel producto y a utilizar ponderadores (ponderando a cada variedad por su participación de mercado).

Los resultados se presentan en el Cuadro 11. Los coeficientes estimados son estadísticamente significativos y presentan el signo esperado. Así mismo, son consistentes con la idea de que países más ricos exportan variedades de mayor calidad, utilizan insumos más costosos (presumiblemente de mayor calidad) y son más eficientes en la producción de calidad. Es importante tener en cuenta que los resultados de esta sección (al igual que 
aquellos en la sección 6.6) carecen de una interpretación causal, pero están en línea con la intuición económica y con varios antecedentes de la literatura de comercio internacional.

\section{CUADRO 11}

Correlación entre costos y PBI per cápita

\begin{tabular}{|c|c|c|c|}
\hline & $(1)$ & $(2)$ & $(3)$ \\
\hline \multicolumn{4}{|c|}{ Variable dependiente: $\log (\phi 0)$} \\
\hline $\log (\mathrm{PBI} p \mathrm{c})$ & $\begin{array}{l}0.47^{* *} \\
(0.03)\end{array}$ & $\begin{array}{c}0.48^{* * *} \\
(0.03)\end{array}$ & $\begin{array}{c}0.48^{* * *} \\
(0.02)\end{array}$ \\
\hline \multicolumn{4}{|c|}{ Variable dependiente: $\log (\phi 1)$} \\
\hline $\log (\mathrm{PBI} p \mathrm{p})$ & $\begin{array}{c}-0.07^{* *} \\
(0.04)\end{array}$ & $\begin{array}{c}-0.09 * * * \\
(0.04)\end{array}$ & $\begin{array}{c}-0.06^{* * *} \\
(0.03)\end{array}$ \\
\hline EF Año $\times$ Producto & $\mathrm{Si}$ & $\mathrm{Si}$ & $\mathrm{Si}$ \\
\hline Observaciones & 177062 & 189409 & 213915 \\
\hline Grupos de EF & 19515 & 19854 & 20473 \\
\hline
\end{tabular}

\subsection{Descomposición del índice de precios}

En esta sección se presentan los resultados que surgen de calcular los índices de precios contrafactuales que permiten descomponer el cambio total en el precio de un producto en distintos componentes: (1) mark-ups, (2) calidad, (3) sustitución entre variedades, (4) sustitución entre productos. En pocas palabras, el procedimiento comienza con la estimación de los parámetros de la ecuación de demanda a partir de un modelo de elección discreta (multinomial nested logit). Luego se desarrollan las condiciones de equilibrio de las firmas (CPO). Se asume competencia monopolística y cierta forma funcional para los costos marginales de las firmas (tecnología de coeficientes fijos). Se resuelve para el precio y la calidad de equilibrio y se recuperan los dos parámetros del costo de cada firma a partir de estimar los parámetros de demanda y la calidad. Finalmente, se calcula el precio, la calidad y la demanda teórica de cada firma bajo dos configuraciones de parámetros: antes y después de la caída en la disposición a pagar de los consumidores (es decir, pre y post devaluación).

Recordar que la devaluación y la consecuente caída del ingreso real medido en dólares produce una disminución en la disposición a pagar de los consumidores (aumenta 
$\hat{\alpha}_{t}$ ). Siguiendo las CPO, las firmas tienen incentivos a disminuir tanto sus mark-ups como la calidad del producto ofrecido. La reducción de calidad disminuye los costos y reduce aún más el precio. El cambio en los ingresos, precios y calidades altera la demanda/participación de mercado de las distintas variedades. Este es el efecto sustitución, caracterizado por un cambio en la composición de un producto a favor de variedades de menor precio y calidad relativa.

Los Cuadros 12 a 14 presentan los resultados de la descomposición. La primera columna del Cuadro 12 presenta el promedio y los percentiles 10 y 90 de la distribución del cambio en el precio de las variedades importadas. El modelo predice que en promedio las firmas reducen sus precios un $14 \%$. El $80 \%$ de las firmas reduce el precio en un rango de $3 \%$ a $36 \%$. La segunda columna presenta los mismos estadísticos para la distribución del cambio en la calidad. El modelo predice que en promedio las firmas disminuyen la calidad del producto ofrecido en un 5\%. El $80 \%$ de las firmas reduce la calidad en un rango de $1 \%$ a $10 \%$. Tener en cuenta que el ajuste de calidad reduce los costos de la firma y ello explica parte de la reducción total en el precio del producto ofrecido. Las últimas dos columnas presentan los estadísticos asociados a la descomposición de la reducción total de los precios en sus dos componentes: mark-ups (elasticidad de la demanda) y calidad. En promedio, la mayor parte de la reducción del precio de una firma (83\%) está explicada por la reducción de calidad del producto ofrecido. La reducción del mark-up explica un 17\% de la reducción total del precio.

El Cuadro 13 sigue de manera exacta el procedimiento desarrollado en la Sección 4.4. Se computa el cambio total en el precio de un producto (a 8 dígitos) y se desagrega en los (primeros) tres componentes mencionados en el primer párrafo de esta Sección. El modelo predice que en promedio el índice de precios a nivel producto se reduce en $23 \%$. Nuevamente, la reducción en la calidad de las variedades explica la mayor parte de la reducción del índice de precios (57\%). El aumento en la participación de las variedades de menor precio/calidad en detrimento de las de mayor precio/calidad explica un $31 \%$ de la reducción del precio. Mientras que la caída del mark-up explica en promedio el 11\% restante.

También es posible computar los índices de precios con un mayor nivel de agregación (6 dígitos). En este caso, se agrega un segundo efecto composicional: el cambio en la participación de los productos (a 8 dígitos) que componen cada producto a 6 dígitos. Este efecto sustitución (a nivel producto) explica en promedio un 10\% (2,3 p.p.) de la reducción total del índice de precios. La magnitud del resto de los resultados es similar al 
caso anterior. La reducción en la calidad a nivel variedad explica el $49 \%$ de la reducción del índice de precios, el efecto sustitución a nivel variedad explica un 31\%, y la disminución del mark-up explica en promedio un $10 \%$.

Finalmente, los resultados del Cuadro 11 se presentan gráficamente en las Figuras 10 y 11. Se muestra la distribución del cambio de precios que predice el modelo. En la parte superior de los gráficos se incorporan algunas estadísticas descriptivas. En la Figura 11 se incorporan además diez barras de tres colores (una para cada decil del cambio de precios) que representan la magnitud de los tres efectos. Por ejemplo, en el decil de productos que presentan la mayor caída en el índice de precios a nivel producto 8 dígitos (65\%), la reducción de calidad a nivel variedad y el efecto sustitución entre variedades explican prácticamente la totalidad de dicha caída (61\% y 37\%, respectivamente). En el otro extremo (decil de productos con menor reducción de precio) estos efectos representan un $67 \%$ de la caída ( $53 \%$ y 14\%, resp.) y el tercio restante se explica por la reducción del márgen de ganancia de las firmas. Dado el supuesto de elasticidad de la demanda constante, cuanto menor es el cambio de precios predicho por el modelo, mayor es la importancia del ajuste del mark-up en la reducción del precio a nivel producto. Notar que ello ocurre a expensas de los otros dos efectos, pero sobre todo del efecto sustitución. El ajuste en la calidad a nivel variedad es el factor más relevante y explica una fracción relativamente constante (cercana al 60\%) de la reducción en el precio promedio de los distintos productos que componen cada decil de la distribución del cambio en el índice de precios.

\section{CUADRO 12}

Cambio en precio y calidad contrafactual a nivel variedad

\begin{tabular}{lcccc}
\hline \hline & $\begin{array}{c}\Delta \text { Precio } \\
\text { Variedad }\end{array}$ & $\begin{array}{c}\Delta \text { Calidad } \\
\text { Variedad }\end{array}$ & $\begin{array}{c}\text { Explicado por } \\
\text { Elast. demanda }\end{array}$ & $\begin{array}{c}\text { Explicado por } \\
\text { Calidad } \\
\end{array}$ \\
& $(1)$ & $(2)$ & $(3)$ & $(4)$ \\
\hline Promedio & -0.14 & -0.05 & 0.17 & 0.83 \\
Percentil 10 & -0.36 & -0.10 & 0.03 & 0.63 \\
Percentil 90 & -0.03 & -0.01 & 0.37 & 0.97 \\
\hline \hline
\end{tabular}

Notas. El promedio y los percentiles 10 y 90 corresponden a la distribución de la variable que figura en cada columna. Las columnas (3) y (4) descomponen el cambio en el índice de precios de una variedad (col. 1) en dos componentes: ajuste de mark-up (col. 3) y ajuste de calidad (col. 4). Fuentes. Datos de Aduana (INDEC) y COMTRADE (Naciones Unidas). 


\section{CUADRO 13}

Descomposición del cambio en índice de precios a nivel producto (8d)

\begin{tabular}{lcccc}
\hline \hline & $\begin{array}{c}\Delta \text { Precio } \\
\text { Producto } \\
8 \text { dígitos }\end{array}$ & $\begin{array}{c}\text { Explicado por } \\
\text { Elast. } \\
\text { Demanda }\end{array}$ & $\begin{array}{c}\text { Explicado por } \\
\text { Calidad }\end{array}$ & $\begin{array}{c}\text { Explicado por } \\
\text { Composición } \\
\text { Variedades }\end{array}$ \\
& $(1)$ & $(2)$ & $(3)$ & $(4)$ \\
\hline Promedio & -0.23 & 0.11 & 0.57 & 0.31 \\
Percentil 10 & -0.55 & 0.02 & 0.23 & 0.00 \\
Percentil 90 & -0.05 & 0.26 & 0.92 & 0.71 \\
\hline \hline
\end{tabular}

Notas. El promedio y los percentiles 10 y 90 corresponden a la distribución de la variable que figura en cada columna. Las columnas (2), (3) y (4) descomponen el cambio en el índice de precios de un producto a 8 dígitos (col. 1) en tres componentes: ajuste de mark-up a nivel variedad (col. 2), ajuste de calidad a nivel variedad (col. 3) y sustitución entre variedades (col. 4). Fuentes. Datos de Aduana (INDEC) y COMTRADE (Naciones Unidas).

\section{CUADRO 14}

Descomposición del cambio en índice de precios a nivel producto $(6 \mathrm{~d})$

\begin{tabular}{lccccc}
\hline \hline & $\begin{array}{c}\Delta \text { Precio } \\
\text { Producto } \\
6 \text { dígitos }\end{array}$ & $\begin{array}{c}\text { Explicado por } \\
\text { Elast. } \\
\text { Demanda }\end{array}$ & $\begin{array}{c}\text { Explicado por } \\
\text { Calidad }\end{array}$ & $\begin{array}{c}\text { Explicado por } \\
\text { Composición } \\
\text { Variedades }\end{array}$ & $\begin{array}{c}\text { Explicado por } \\
\text { Composición } \\
\text { Productos }\end{array}$ \\
& $(1)$ & $(2)$ & $(3)$ & $(4)$ & $(5)$ \\
\hline Promedio & -0.23 & 0.10 & 0.49 & 0.31 & 0.10 \\
Percentil 10 & -0.51 & 0.02 & 0.17 & 0.02 & 0.00 \\
Percentil 90 & -0.05 & 0.23 & 0.84 & 0.66 & 0.41 \\
\hline \hline
\end{tabular}

Notas. El promedio y los percentiles 10 y 90 corresponden a la distribución de la variable que figura en cada columna. Las columnas (2), (3), (4) y (5) descomponen el cambio en el índice de precios de un producto a 6 dígitos (col. 1) en cuatro componentes: ajuste de mark-up a nivel variedad (col. 2), ajuste de calidad a nivel variedad (col. 3), sustitución entre variedades (col. 4) y sustitución entre productos (col. 5). Fuentes. Datos de Aduana (INDEC) y COMTRADE (Naciones Unidas). 
FIGURA 10

Cambio en índice de precios a nivel producto

./figuras/grafico_descomp1.pdf

Notas. Estimación no paramétrica de la función de densidad del cambio en el índice de precios a nivel producto (8 dígitos) predicho por el modelo. Fuentes. INDEC (Argentina) y COMTRADE (Naciones Unidas). 


\section{FIGURA 11}

Descomposición del cambio en índice de precios a nivel producto $(8 \mathrm{~d})$

./figuras/grafico_descomp2.pdf

Notas. Estimación no paramétrica de la función de densidad del cambio en el índice de precios a nivel producto ( 8 dígitos) predicho por el modelo. El cambio total en el precio se descompone estructuralmente en sus tres componentes (eje derecho). Se presenta una barra para cada decil del cambio en precios predicho, y cada barra se divide en tres indicando la magnitud de cada uno de los efectos (mark-up, calidad y sustitución). Fuentes. INDEC (Argentina) y COMTRADE (Naciones Unidas). 


\subsection{Robustez}

El hecho estilizado que origina la hipótesis de trabajo es que el precio promedio de los productos importados (medidos en dólares en aduanas) se reduce significativamente en los años que siguen a la devaluación en todos los episodios estudiados. Sin embargo, es preciso notar que las regresiones estimadas son meramente descriptivas y no controlan por la evolución del precio de los insumos utilizados para elaborar los productos importados (mano de obra, capital, insumos intermedios, etc.) ni por variables que permitan dar cuenta de la tecnología utilizada por las firmas internacionales que exportan dichos productos. Es probable que el precio de dichos insumos y/o la tecnología cambien a lo largo del tiempo y que ello afecte los precios internacionales. El objetivo de esta sección es controlar por tales factores, utilizando una base de datos complementaria y una estrategia de identificación alternativa. Además de otorgar robustez al hecho estilizado que dispara la hipótesis de trabajo, esta sección promueve algunas preguntas que forman parte de la agenda de investigación futura.

Es oportuno recordar que los datos de aduana utilizados hasta el momento tienen un nivel de desagregación de 8 dígitos del Sistema Armonizado (INDEC) y de 6 dígitos del SA (COMTRADE) y varían además según el país de origen de cada producto. Los microdatos están computados en términos anuales. Cuando existe más de una transacción por año, el dato anual surge de la agregación de todas las transacciones de importación que suceden en distintos momentos del año. Además, dentro de una misma categoría de producto se incluyen distintas marcas y modelos de un mismo tipo de producto. ${ }^{41}$ Por diversas razones, acceder al universo de datos transaccionales registrados por aduana es prácticamente imposible. Sin embargo, fue posible obtener el registro desagregado para determinadas categorías de bienes de consumo (electrodomésticos y automóviles) provenientes de la Aduanas de Argentina y Chile. Estos microdatos transaccionales permiten construir un nuevo panel de datos de productos importados por ambos países (con el máximo nivel de desagregación posible) durante el período de estudio relevante (1999-2004). A su vez, se cuenta con información sobre la marca de los electrodomésticos y el modelo de los automóviles importados por ambos países. ${ }^{42}$ Estos datos permiten estudiar la evolución del precio de electrodomésticos y automóviles importados por Argentina utilizando a Chile

\footnotetext{
${ }^{41}$ Recordar que las medidas de calidad derivadas de la estimación del sistema de demanda capturan parte de este cambio composicional al interior de cada variedad de producto.

${ }^{42}$ Los microdatos de Argentina contienen además cierto grado de detalle que permite recuperar algunas características observables de los automóviles importados (por ejemplo, el tamaño del motor, la cantidad de puertas, el tipo de carrocería, etc.). A partir de estos datos se realizan algunas regresiones descriptivas.
} 
como grupo de control en pos de controlar por shocks de costos y/o tecnológicos en las firmas internacionales que exportan (a Argentina y a Chile) desde distintos países.

La estrategia de estimación se basa en el método de Diferencias en Diferencias (DID) utilizando las importaciones de Chile como grupo de control. Se estiman por MCO variantes de la siguiente ecuación de regresión:

$$
\log \left(p_{j n t}\right)=\alpha \text { Post }+\gamma \text { Arg }+\beta \text { Post } \times \text { Arg }+\phi_{j t}+\varepsilon_{j n t}
$$

La variable dependiente es el log del precio de las variedades importadas. El precio se aproxima con el valor unitario FOB (libre a bordo) medido en dólares en aduana. Esta regresión se realiza utilizando el universo de transacciones $(n)$ de los productos $j$ en el año t. Para simplificar la exposición, se omiten de los subíndices de las variables marca y país de origen. A cada producto $j$ le corresponde una marca y un país de origen determinado. Se estiman distintas especificaciones que utilizan combinaciones alternativas de efectos fijos que permiten controlar por shocks temporales que afectan a distintas marcas y/o países de manera heterogénea. El coeficiente de interés $(\beta)$ es el que acompaña la interacción de la variable binaria de país ( $\operatorname{Arg}=1$ si la variedad es importada por Argentina, y Arg=0 si es importada por Chile) y la variable que identifica a los años que siguen a la crisis cambiaria (Post=0 durante 1999-2001, y Post=1 durante 2002-2004). Este coeficiente captura la variación promedio del precio de los productos importados por Argentina a partir del año 2002 (en relación a la evolución del precio de los mismos productos importados por Chile).

Los resultados para el caso de los electrodomésticos se presentan en el Cuadro 15. Las columnas (1) a (3) incluyen todas las transacciones de importación de electrodomésticos referidas a combinaciones producto-origen-marca que son importadas por ambos países al menos una vez durante 1999-2004. Dado que hay variedades que entran y salen del set de importaciones, la columna (4) restringe la muestra a combinaciones producto-origen-marca importados por ambos países al menos una vez pre y post devaluación. La columna (5) restringe la muestra a combinaciones que hayan sido importadas por ambos países todos los años del período 2000-2003.

El coeficiente estimado que acompaña a la variable $\mathrm{Arg}$ es positivo y estadísticamente significativo en todas las especificaciones. En promedio, Argentina paga precios más altos que Chile (alrededor de 26-28\%) por electrodomésticos importados relativamente similares. Sin embargo, buena parte de esta brecha (entre 55 y 80\%) se reduce significativamente en los años que siguen a la depreciación del peso Argentino. Los precios 
de los electrodomésticos disminuyen en promedio alrededor de 15-16\% en Argentina en comparación a Chile. El coeficiente $\hat{\beta}$ es negativo, estadísticamente significativo y presenta una magnitud muy similar a través de las distintas especificaciones. ${ }^{43}$ Los resultados son robustos a la inclusión de distintos tipos de ponderadores y al cálculo de los errores estándar con criterios de clusterización diferentes (ver el Cuadro A4 en el apéndice).

\section{CUADRO 15}

Diferencias en Diferencias: Precio electrodomésticos

\begin{tabular}{lccccc}
\hline \hline & \multicolumn{5}{c}{ Log (Precio) } \\
\hline & $(1)$ & $(2)$ & $(3)$ & $(4)$ & $(5)$ \\
\hline \multirow{2}{*}{ Post x Arg } & & & & & \\
& $-0.146^{* * *}$ & $-0.142^{* *}$ & $-0.158^{* * *}$ & $-0.156^{* * *}$ & $-0.156^{* * *}$ \\
Arg & $(0.054)$ & $(0.067)$ & $(0.052)$ & $(0.052)$ & $(0.058)$ \\
& $0.183^{* * *}$ & $0.237^{* * *}$ & $0.263^{* * *}$ & $0.261^{* * *}$ & $0.282^{* * *}$ \\
Observaciones & $(0.050)$ & $(0.066)$ & $(0.066)$ & $(0.098)$ & $(0.098)$ \\
EF Año x Origen & & & & & \\
EF Año x Marca & 46,496 & 46,496 & 46,496 & 22,247 & 8,498 \\
EF Año x Origen x Marca & $\mathrm{Si}$ & $\mathrm{Si}$ & $\mathrm{Si}$ & $\mathrm{Si}$ & $\mathrm{Si}$ \\
\hline \hline
\end{tabular}

Notas. Se estima una regresión del valor unitario FOB (en logs) de electrodomésticos importados, en función de las variables Arg (=1 si Argentina es el importador, =0 si es Chile), Post (=0 en 1999-2001, =1 en 2002-2004) y la interacción Post x Arg. Errores estándar robustos clusterizados por marca-origen. Cols. (1)-(3) incluyen todas las transacciones referidas a combinaciones producto-origen-marca importadas por ambos países al menos una vez durante 1999-2004. Col. 4 (5) restringe la muestra a combinaciones producto-origen-marca importados por ambos países al menos una vez pre y post 2002 (al menos una vez en cada año durante 2000-2003).

En el caso de los automóviles importados, se cuenta con información sobre el origen, la marca, el modelo y en el caso de Argentina sobre algunas características observables como el tamaño del motor, el peso y la cantidad de puertas. Para estudiar la evolución de los precios, se estima la misma ecuación de regresión que en el caso de los electrodomésticos, pero se incorporan efectos fijos más desagregados. La inclusión de efectos fijos por año-origen-modelo permite comparar la evolución temporal de los mismos modelos de automóviles importados por Argentina y Chile.

Los resultados de estimar la ecuación (6.7) por MCO se presentan en el Cuadro 16. Las columnas (1) y (2) incluyen todas las transacciones de importación de automóviles referidas a modelos que son importados por ambos países al menos una vez durante

\footnotetext{
${ }^{43}$ Estos microdatos también permiten estimar la función de demanda, calibrar los costos de las firmas y calcular los índices de precios a nivel producto en pos de descomponer teóricamente la contribución del márgen de ganancia, la calidad y el efecto sustitución (para explicar la reducción del precio de los electrodomésticos). Sin embargo, esto excede el objetivo de este ejercicio y no aporta demasiado a la discusión.
} 
1999-2004. En la columna (3) la muestra se restringe a aquellos modelos importados por ambos países al menos una vez pre y post devaluación. Y en la columna (4) la muestra se restringe a aquellos modelos que hayan sido importadas todos los años del período 2000-2003. Se incluye un extenso conjunto de efectos fijos que intentan controlar por shocks temporales que afectan de manera diferencial a los automóviles importados desde distintos países, a modelos diferentes y a distintas combinaciones modelo-país (unos pocos modelos se importan desde más un país). En todas las especificaciones, el coeficiente $\hat{\beta}$ es negativo y estadísticamente significativo. Los resultados muestran que el precio de los modelos de automóviles importados por Argentina se reduce significativamente (13-15\%) a partir del año 2002 (en relación al precio de los mismos modelos importados por Chile). La magnitud del coeficiente estimado para la variable Arg indica que la brecha de precios entre Argentina y Chile tiende a desaparecer en los años que siguen a la crisis cambiaria Argentina. Los resultados son robustos a utilizar distintos ponderadores o clusters para los errores estándar (ver Cuadro A5 del apéndice).

\section{CUADRO 16}

Diferencias en Diferencias: Precio automóviles

\begin{tabular}{lcccc}
\hline \hline & \multicolumn{4}{c}{ Log (Precio) } \\
\hline & $(1)$ & $(2)$ & $(3)$ & $(4)$ \\
\hline \multirow{2}{*}{ Post x Arg } & & & & \\
& $-0.133^{* * *}$ & $-0.125^{* *}$ & $-0.148^{* * *}$ & $-0.151^{* * *}$ \\
Arg & $(0.045)$ & $(0.049)$ & $(0.049)$ & $(0.051)$ \\
& $0.121^{* *}$ & $0.104^{*}$ & $0.121^{*}$ & $0.161^{* *}$ \\
& $(0.061)$ & $(0.062)$ & $(0.065)$ & $(0.063)$ \\
Observaciones & & & & \\
EF Año x Origen & 47,373 & 47,373 & 23,644 & 15,266 \\
EF Año x Modelo & $\mathrm{Si}$ & $\mathrm{Si}$ & $\mathrm{Si}$ & $\mathrm{Si}$ \\
EF Año x Origen x Modelo & $\mathrm{Si}$ & $\mathrm{Si}$ & $\mathrm{Si}$ & $\mathrm{Si}$ \\
\hline \hline
\end{tabular}

Notas. Se estima una regresión del valor unitario FOB (en logs) de automóviles importados motor a nafta 1500-3000cc, en función de las variables Arg (=1 si Argentina es el importador, $=0$ si es Chile), Post (=0 en 1999-2001, =1 en 2002-2004) y la interacción Post x Arg. Errores estándar robustos clusterizados por marca. Cols. (1)-(3) incluyen todas las transacciones referidas a modelos importados por ambos países al menos una vez durante 1999-2004. Col. 4 (5) restringe la muestra a modelos importados por ambos países al menos una vez pre y post 2002 (al menos una vez en cada año durante 2000-2003).

Dado que se cuenta con información relativamente completa para distintas características observables de los automóviles importados por Argentina, es posible estimar algunas regresiones descriptivas que permitan dar cuenta del tipo de cambio composicional que ocurre en los años que siguen a la devaluación del peso. Se estiman dos tipos de 
ecuaciones de regresión. En primer lugar, se estiman por el método de MCO variantes de la siguiente ecuación de regresión:

$$
\text { Caract }_{j n t}=\alpha \text { Post }_{t}+\phi_{j t}+\varepsilon_{j n t}
$$

La variable dependiente $\left(\right.$ Caract $\left._{j n t}\right)$ corresponde a las distintas características observables de los automóviles: tamaño del motor en cc. (logs), peso en kg. (logs), cantidad de puertas, tipo de automóvil, potencia en caballos (logs) y distintas variables binarias (es convertible, es 4x4, tiene aire acondicionado, tiene motor con inyección, tiene motor con turbo). ${ }^{44}$ Se estiman tres ecuaciones separadas para cada una de estas once características. Las tres especificaciones incluyen efectos fijos a nivel modelo y controlan por distintas tendencias (país de origen, marca y marca-origen). La idea es evaluar si las características observables de un mismo modelo cambian en los años que siguen a la crisis cambiaria. Los resultados muestran que en promedio no existen cambios estadísticamente significativos en las características de los modelos importados por Argentina (ver Figura $12)$.

\footnotetext{
${ }^{44}$ El Cuadro A6 del apéndice presenta estadísticas descriptivas de estas variables.
} 


\section{FIGURA 12}

Cambio en características observables de automóviles

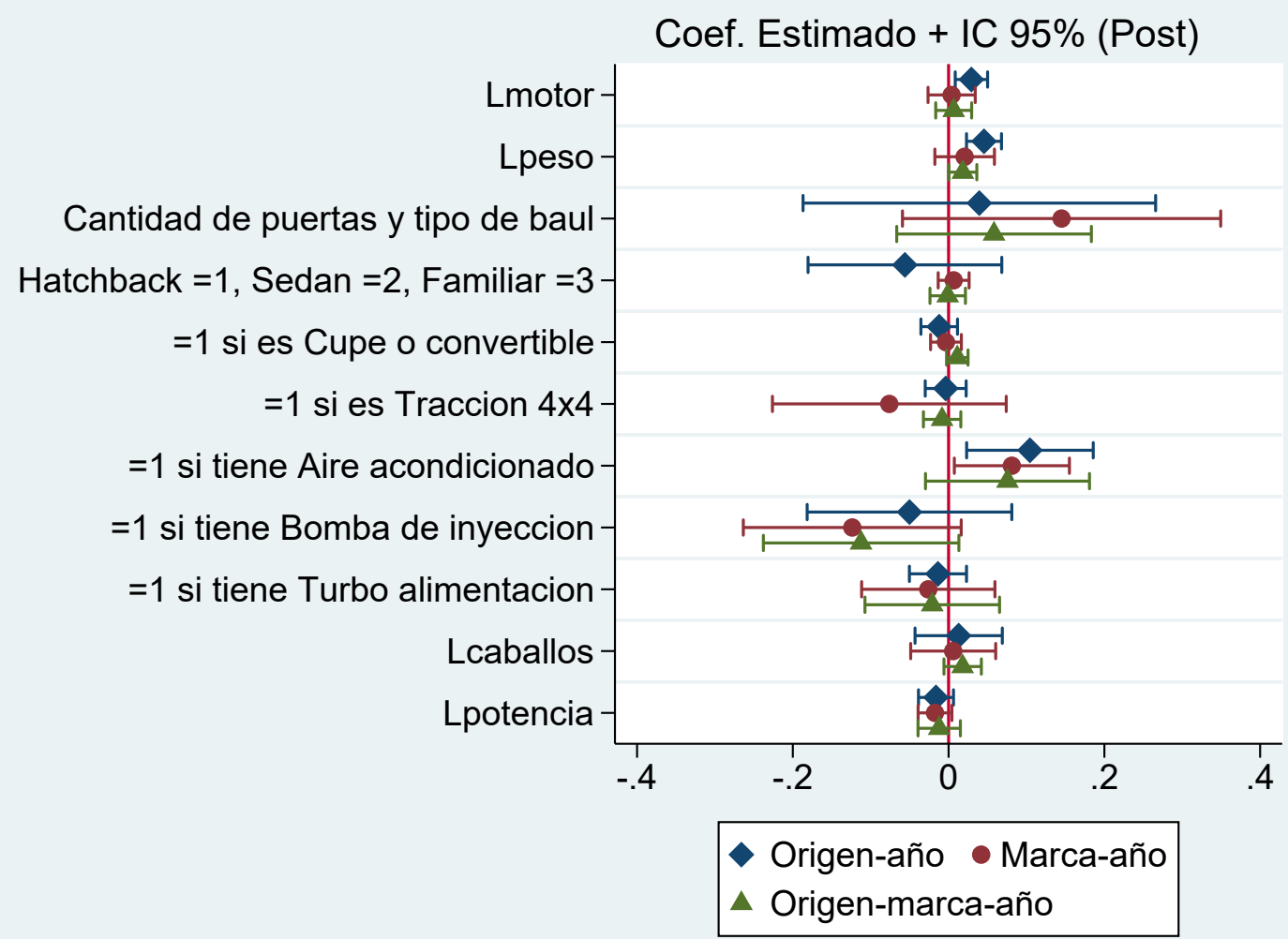

Notas. Se estiman (33) regresiones descriptivas (3 para cada característica) en función de la variable binaria Post (=0 en 1999-2001, =1 en 2002-2004) controlando por distintas combinaciones de efectos fijos. Las tres especificaciones incluyen EF a nivel modelo. Las regresiones incluyen todas las transacciones de modelos importados por Argentina al menos una vez en cada subperiodo. Errores estándar robustos clusterizados por modelo. Fuentes. Transacciones registradas en la Aduana de Argentina.

En segundo lugar, se estima una regresión que intenta capturar la existencia de un cambio composicional dentro del conjunto de automóviles importados por Argentina. En particular, se estima la siguiente ecuación de regresión:

$$
\log \left(\text { share }_{j n t}\right)=\alpha \text { Post }_{t}+\sigma \text { Caract }_{j n t}+\beta \text { Caract }_{j n t} * \text { Post }_{t}+\phi_{j t}+\varepsilon_{j n t}
$$

La variable dependiente es la participación de cada transacción en el total anual importado. El coeficiente de interés $\beta$ es la interacción entre distintas características observables y la variable temporal binaria Post $_{t}$. Se incluyen las mismas combinaciones de efectos fijos que en la estimación anterior. La idea es capturar el cambio en la participación de automóviles que poseen distintas características observables. En línea con la hipótesis de este trabajo, los resultados en la Figura 13 muestran que en promedio aumenta la participación de aquellos modelos de automóviles importados que poseen características 
observables asociadas negativamente con el precio y la calidad. Aumenta la participación de aquellos modelos de menor precio, que tienen motores más pequeños, menor cantidad de puertas, carrocerías más pequeñas, que no son $4 \mathrm{x} 4$, que no tienen aire acondicionado, que no tienen bomba de inyección y que tienen menor potencia.

En términos agregados, las estadísticas muestran que aumenta la participación en las importaciones de aquellas multinacionales que poseen plantas de producción en Argentina en detrimento de aquellas multinacionales que no poseen plantas en Argentina y de otros importadores (Cuadro A7 del apéndice). A su vez, aumenta significativamente la participación de las importaciones provenientes desde el MERCOSUR (principalmente de Brasil) en detrimento de aquellas que provienen de la Eurozona, Norteamérica, Japón y otros países del mundo (Cuadro A8 del apéndice). Es importante destacar el carácter descriptivo de estas estadísticas. La explicación es necesariamente multicausal, puede estar asociada a fenómenos de oferta (e.g. decisiones de relocalización de producción, política comercial) y/o de demanda (e.g. reducción del ingreso real en dólares en Argentina). Es probable que las particularidades de las restricciones que impone la política comercial del MERCOSUR afecten las decisiones de comercio bilateral de las firmas involucradas (Brambilla, 2007). A su vez, dado que muchas de las transacciones se producen entre distintas filiales de una misma empresa multinacional, también es probable que exista un componente no menor vinculado a los precios de transferencia. ${ }^{45}$ Sería interesante estudiar la magnitud y la fuente del poder de mercado (e.g. diferenciación de producto versus colusión) de las automotrices de la región; y evaluar si la restrictividad de la política comercial del MERCOSUR otorga poder de mercado a las empresas multinacionales. Estos temas forman parte de la agenda de investigación futura.

\footnotetext{
${ }^{45}$ Por ejemplo, Cristea y Nguyen (2015) muestran que las multinacionales modifican los precios de sus exportaciones entre filiales en respuesta a cambios en los impuestos corporativos. Brambilla (2007) muestra que las restricciones no arancelarias que forman parte del acuerdo de intercambio automotriz del MERCOSUR pueden incrementar el volumen de comercio estratégico intra-firma.
} 


\section{FIGURA 13}

Cambio en participación de características de automóviles

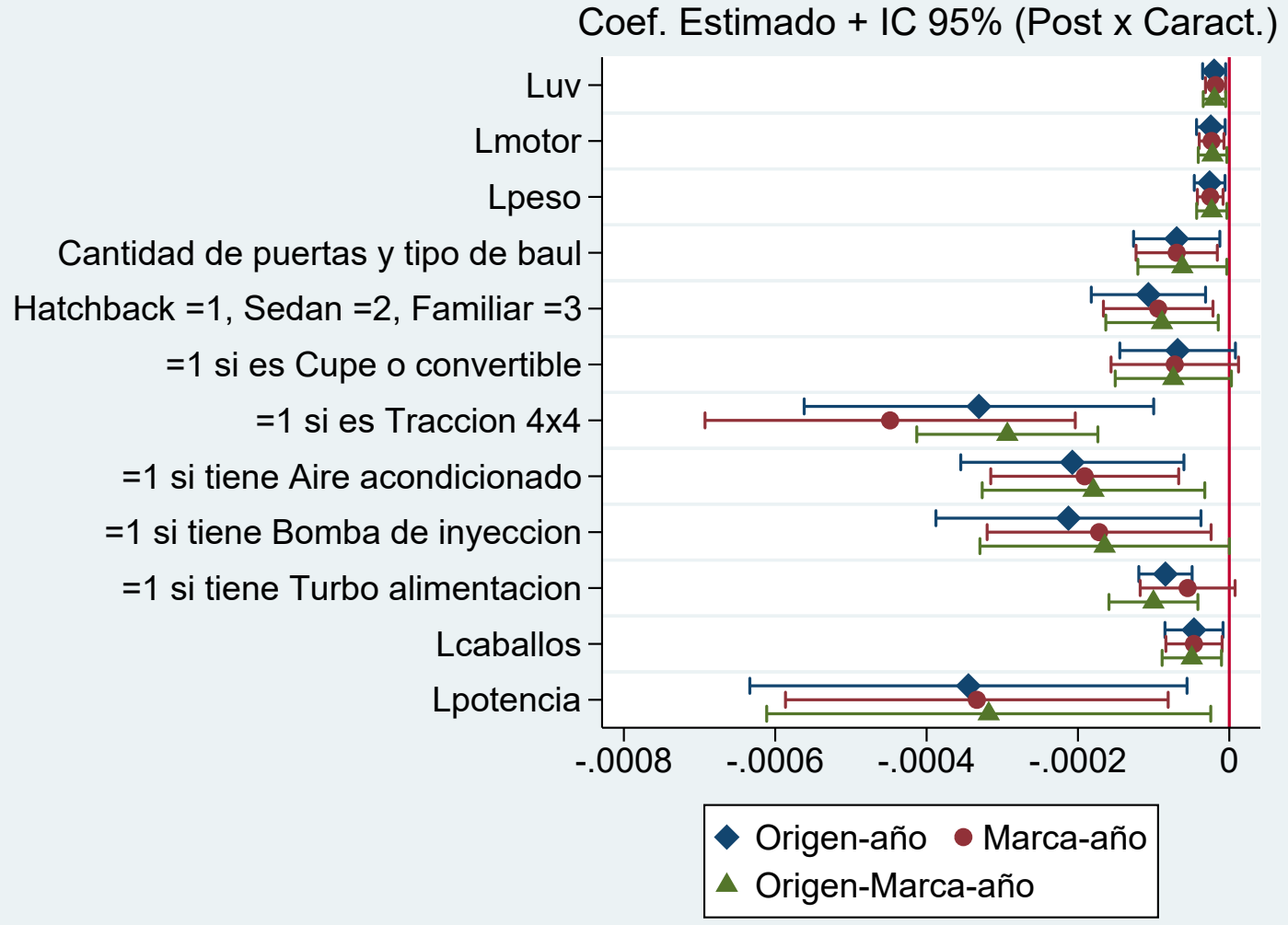

Notas. Se estiman (33) regresiones descriptivas (3 para cada característica) del log de la participación de cada transacción en el total importado anual en función de cada característica, la variable binaria Post (=0 en 1999-2001, =1 en 2002-2004) y la interacción entre ambas (coef. reportado) controlando por distintas combinaciones de efectos fijos. Las tres especificaciones incluyen EF a nivel modelo. Las regresiones incluyen todas las transacciones de modelos importados por Argentina al menos una vez en cada subperiodo. Errores estándar robustos clusterizados por modelo. Fuentes. Transacciones registradas en la Aduana de Argentina. 


\section{Comentarios finales}

Las crisis cambiarias son fenómenos recurrentes en la historia moderna. La mayoría de estas crisis son antecedidas por un déficit persistente en la cuenta corriente de la balanza de pagos. La devaluación permite recomponer el saldo del balance comercial, principalmente través de la reducción del volumen de importaciones. En los años que siguen a la devaluación, se produce un notable efecto composicional en la canasta de importaciones. Todos los episodios estudiados se caracterizan por una reducción en el precio de los productos importados (medidos en dólares en aduana), una disminución en la calidad, y un aumento de la participación de las variedades de menor precio y calidad relativa.

La explicación teórica para estos hechos estilizados es simple e intuitiva. La devaluación reduce el ingreso real (medido en moneda extranjera) y los consumidores/productores reducen la demanda/oferta de calidad. Se propone un modelo de equilibrio parcial que permite racionalizar esta idea y realizar ejercicios de microdescomposición del cambio en el índice de precios a nivel variedad/producto. Por el lado de la oferta, cada firma internacional ofrece una variedad de un producto diferenciado en un mercado caracterizado por competencia monopolística. Los consumidores tienen preferencias de elección discretas, de modo que eligen aquella variedad que les provee la mayor utilidad indirecta. En este modelo, hay un trade-off entre precio y calidad. La depreciación de la moneda reduce el ingreso real de los consumidores domésticos (medido en dólares), aumenta la valoración del ingreso disponible y disminuye la disposición a pagar (ello equivale a valorar relativamente menos la calidad). Esto incentiva a las firmas a reducir sus márgenes de ganancia y la calidad del producto ofrecido. El cambio simultáneo en ingresos, precios y calidades altera la participación de mercado de las distintas variedades. Se produce un fenómeno de sustitución de variedades (o cambio composicional) al interior de cada producto caracterizado por un aumento en la participación de las variedades de menor precio/calidad relativa.

El ejercicio contrafactual de descomposición del cambio en el índice de precios a nivel producto sugiere que el ajuste de calidad a nivel variedad explica en promedio alrededor del 50-57\% de la reducción total del precio a nivel de producto, el efecto sustitución explica en promedio un 31-41\% y el ajuste del márgen de ganancia explica un 10-17\%. Los resultados sugieren que el ajuste en la calidad de los bienes es el canal más importante para explicar el traslado incompleto de la devaluación hacia el precio de los bienes importados medidos 
en aduana (exchange-rate pass-through).

Esta línea de investigación continúa con un trabajo donde se estudian las consecuencias distributivas del traslado a precios de la devaluación del peso en Argentina. Los resultados preliminares sugieren un considerable grado de heterogeneidad en el aumento del costo de vida de los distintos hogares. En un proyecto futuro, se pretende estudiar con mayor profundidad la heterogeneidad en el ajuste de calidad, teniendo en cuenta que muchas firmas internacionales importan insumos intermedios y luego exportan bienes finales a diversos destinos. También interesa estudiar la interacción entre la restrictividad de la política comercial del MERCOSUR (e.g. sector automotriz) y distintos resultados económicos (e.g. poder de mercado de las multinacionales, bienestar de los consumidores). 


\section{Referencias}

Abowd, J. And T. Lemieux (1993). "The Effects of Product Market Competition on Collective Bargaining Agreements: The Case of Foreign Competition in Canada," Quarterly Journal of Economics, 108: 983-1014.

Aghion, P., Bacchetta, P. And A. Banerjee (2001). "Currency Crises and Monetary Policy in an Economy with Credit Constraints," European Economic Review, 45(7): 1121-1150.

Amiti, M. And A. Khandelwal (2013). "Import Competition and Quality Upgrading," Review of Economic Studies, 95(2): 476-90.

Amiti, M., Itskhoki, O. And Konings, J. (2014). "Importers, Exporters, and Exchange Rate Disconnect," American Economic Review, American Economic Association, 104(7): 1942-78.

Amiti, M., Itskhoki, O. And Konings, J. (2018). "International Shocks, Variable Markups and Domestic Price," NBER Working Paper 22119.

Armington, P. (1969). "A Theory of Demand for Products Distinguished by Place of Production," International Monetary Fund Staff Papers, 16: 159-78.

Auer, R., T. Chaney and P. Sauré (2018). "Quality Pricing-to-Market," Journal of International Economics, 110: 87-102.

Atkeson, A. And Burstein, A. (2008). "Pricing-to-Market, Trade Costs, and International Relative Prices," American Economic Review, 98(5): 1998-2031.

Bacchetta, P. And van Wincoop, E. (2003). "Why Do Consumer Prices React Less Than Import Prices to Exchange Rates?," Journal of the European Economic Association, 1(2-3): $662-670$.

Bastos, P., Silva, J. and E. Verhoogen (2018). "Export Destinations and Input Prices" American Economic Review, 108(2): 353-392.

Bergin, P. And Feenstra, R. (2001). "Pricing-to-market, Staggered Contracts, and Real Exchange Rate Persistence," Journal of International Economics, 54(2): 333-359.

Berman, N., Martin, P. And T. Mayer (2012). "How do different exporters react to exchange rate changes?," Quarterly Journal of Economics, 127(1): 437-492.

Bernini, M. And C. Tomasi (2015). "Exchange Rate Pass-through and Product Heterogeneity: Does Quality Matter on the Import Side?," European Economic Review, 77: $117-38$.

Berry, S. (1994). "Estimating Discrete Choice Models of Product Differentiation," RAND Journal of Economics, 25: 242-62.

Berry, S., J. Levinsohn, and A. Pakes (1995). "Automobile Prices in Market Equilibrium," Econometrica, 60(4): 889-917.

Brambilla, I., D. (2007). "A Customs Union with Multinational Firms: the Automobile Market in Argentina and Brazil," NBER Working Paper 11745.

Brambilla, I., D. Lederman And G. Porto (2012). "Exports, Export Destinations and Skills," American Economic Review, 102(7): 3406-38.

Branson, W.L. (1972). "The Trade Effects of the 1971 Currency Realignments," Brookings Papers on Economic Activity, Economic Studies Program, The Brookings Institution, 3(1): 15-70.

Burstein, A., Neves, J. And Rebelo, S. (2003). "Distribution Costs and Real Exchange Rate Dynamics During Exchange-rate-based Stabilizations," Journal of Monetary Economics, Elsevier, 50(6): 1189-1214. 
Burstein, A., Eichenbaum, M. And Rebelo, S. (2005). "Large Devaluations and the Real Exchange Rate," Journal of Political Economy, University of Chicago Press, 113(4): 742-784.

Burstein, A. And Gopinath, R. (2014). "International Prices and Exchange Rates," Handbook of International Economics, 4: 391-451.

Campa, J.M., And GoldBerg, L. (2005). "Exchange Rate pass-through into Import Prices," The Review of Economics and Statistics, MIT Press, 87(4): 679-690.

Campa, J.M., and GoldberG, L. (2006). "Distribution Margins, Imported Inputs, and the Sensitivity of the CPI to Exchange Rates," NBER Working Papers 12121.

Campa, J.M., And Goldberg, L. (2010). "The Sensitivity of the CPI to Exchange Rates: Distribution Margins, Imported Inputs, and Trade Exposure," The Review of Economics and Statistics, 92(2): 392-407.

Campos, C. (2010). "Incomplete Exchange Rate pass-through and Extensive Margin of Adjustment," Department of Economics, Yale University.

Cardell, N. (1991). "Variance Components Structures for the Extreme Value and Logistic Distributions," Mimeo, Washington State University.

CAssel, N. (1922). "Money and Foreign Exchange after 1914".

Caselli, M., A. Chatterjee, and A. Woodland (2017). "Multi-product Exporters, Variable mark-ups and Exchange Rate Fluctuations", Canadian Journal of Economics, 50(4): 1130-1160.

Chang, R. and A. Velasco (1999). "Liquidity Crises in Emerging Markets: Theory and Policy," NBER Macroeconomics Annual, (14): 76-78.

Chatterjee, A., R. Dix-Carneiro, and J. Vichyanond (2013). "Multi-Product Firms and Exchange Rate Fluctuations," American Economic Journal: Economic Policy, 5(2): 77-110.

Chen, N. And L. Juvenal (2016). "Quality, Trade, and Exchange Rate Pass-Through," Journal of International Economics, 100: 61-80.

Chen, N. And L. Juvenal (2018). "Quality and the Great Trade Collapse," Journal of Development Economics, 135: 59-76.

Corsetti, G., and Dedola, L. (2005). "A Macroeconomic Model of International Price Discrimination," Journal of International Economics, 67(1): 129-155.

Cravino, J. And A. Levchenko (2017). "The Distributional Consequences of Large Devaluations," American Economic Review, 107(11): 3477-3509.

Cristea, A. And D. NGuyen (2016). "Transfer Pricing by Multinational Firms: New Evidence from Foreign Firm Ownerships," American Economic Journal: Economic Policy, 8(3): 170-202.

Crozet, M., Head, K. And T. Mayer (2012). "Quality Sorting and Trade: Firm-Level Evidence for French Wine," Review of Economic Studies, 79(2): 609-44.

Devereux, M. B., And Engel . C. (2002). "Exchange Rate Pass-Through, Exchange Rate Volatility, and Exchange Rate Disconnect," Journal of Monetary Economics, 49: 913-940.

Dornbusch, R. (1987). "Exchange Rates and Prices," American Economic Review, 77: 93-106.

Eichengreen, B., Rose, A. K. And C.Wyplosz (1995). "Exchange Market Mayhem: The Antecedents and Aftermath of Speculative Attacks," Economic Policy, 10(21): 249-312.

Engel, C. (1993). "Real Exchange Rates and Relative Prices," Journal of Monetary 
Economics, 32(1): 35-50.

Fleming, J. M. (1962). "Domestic Financial Policies under Fixed and Floating Exchange Rates," IMF Staff Papers, 9: 369-379.

Flood, R. AND P. Garber (1984). "Collapsing Exchange Rate Regimes: Some Linear Examples," Journal of International Economics, 17: 1-13.

Giovannini, A. (1988). "Exchange Rates and Traded Goods Prices," Journal of International Economics, 24(1-2): 45-68.

GoldBerg, P. (1995). "Product Differentiation and Oligopoly in International Markets: The Case of the U.S. Automobile Industry," Econometrica, 63(4): 891-951.

Goldberg, P. And Knetter, M. (1997). "Good Prices and Exchange Rates: What Have We Learned," Journal of Economic Literature, 35(3): 1243-1272.

Goldberg, P. and F. Verboven (2001). "The Evolution of Price Dispersion in the European Car Market," Review of Economic Studies, 68: 811-848.

Goldberg, P. And F. Verboven (2001). "Market Integration and Convergence to the Law of One Price: Evidence from the European Car Market," Journal of International Economics, 65: 49-73.

Goldberg, P. And N. PAVCNiK (2007). "Distributional Effects of Globalization in Developing Countries," Journal of Economic Literature, 45(1): 39-82.

Goldberg, P. And R. Hellerstein (2013). "A Structural Approach to Identifying the Sources of Local-Currency Price Stability," Review of Economic Studies, 80(1): 175-210.

Gopinath, G. And Itskhoki, O. (2010). "Frequency of Price Adjustment and pass-through," The Quarterly Journal of Economics, 125(2): 675-727.

Gopinath, G. And Neiman, B. (2014). "Trade Adjustment and Productivity in Large Crises," American Economic Review, 104(3): 793-831.

Grossman, G. and Helpman, E. (1991). "Quality Ladders and Product Cycles," Quarterly Journal of Economics, 106(2): 557-586.

Hallak, J. C. (2006). "Product Quality and the Direction of Trade," Journal of International Economics, 68(1): 238-265.

Hallak, J. C. And Schott, P. (2011). "Estimating Cross-Country Differences in Product Quality," Quarterly Journal of Economics, 126: 417-474.

Hausmann, R., Hwang. J. And D. Rodrik (2007). "What You Export Matters," Journal of Economic Growth, 12(1): 1-25.

Hellerstein, R. (2004). "Who Bears the Cost of a Change in the Exchange Rate? The Case of Imported Beer," Staff Reports 179, Federal Reserve Bank of New York.

Hellerstein, R. (2008). "Who Bears the Cost of a Change in the Exchange Rate? Pass-through Accounting for the Case of Beer," Journal of International Economics, 76(1): $14-32$.

Hellerstein, R. And S. Villas-Boas (2010). "Outsourcing and pass-through," Journal of International Economics, 81: 170-83.

Hooper, P. And Mann, C. (1989). "Exchange Rate pass-through in the 1980s: The Case of U.S. Imports of Manufactures," Brookings Papers on Economic Activity, Economic Studies Program, The Brookings Institution, 20(1): 297-337.

Hummels, D. And P. Klenow (2005). "The Variety and Quality of a Nation's Exports," American Economic Review, 95: 704-23.

Instituto Nacional de Estadísticas y Censos. "Metodología utilizada en la 
elaboración de los índices de precios y cantidades del comercio exterior." Disponible en página oficial del INDEC: Economía - Índices de Precios - Precios y Cantidades del comercio exterior - Metodología.

Isard, P. (1977). "How Far Can We Push the 'Law of One Price'?," American Economic Review, 67(5): 942-48.

Khandelwal, A. (2010). "The Long and Short (of) Quality Ladders," Review of Economic Studies, 77(4): 1450-1476.

Knetter, M. (1989). "Price Discrimination by U.S. and German Exporters," American Economic Review, 79(1): 198-210.

Knetter, M. (1993). "International Comparisons of Pricing-to-Market Behavior," American Economic Review, 83(3): 473-486.

Kravis, I. And Lipsey, R. (1978). "Price Behavior in the Light of Balance of Payments Theories," Journal of International Economics, Elsevier, 8(2): 193-246.

Kreinin, M. E. (1977). "The Effect of Exchange Rate Changes on the Prices and Volume of Foreign Trade," International Monetary Fund Staff Papers, 24(2): 297-329.

Kremer, M. (1993). "The O-Ring Theory of Economic Development," Quarterly Journal of Economics, 108(3): 551-575.

Krugman, P. and R. Baldwin (1978). "The Persistence of the U.S. Trade Deficit," Brookings Papers on Economic Activity, Economic Studies Program, The Brookings Institution, 18(1): 1-56.

Krugman, P. (1979). "A Model of Balance of Payments Crises," Journal of Money, Credit and Banking, 11: 311-325.

Krugman, P. (1980). "Scale Economies, Product Differentiation, and the Pattern of Trade," American Economic Review, 70(5): 950-59.

Krugman, P. (1987). "Pricing to Market when the Exchange Rate Changes," Real Financial Linkages among Open Economies, pp. 49:70, ed. by Arndt and Richardson. MIT Press, Cambridge.

Krugman, P. (1999). "Balance Sheets, the Transfer Problem, and Financial Crises," International Tax and Public Finance, 6(4): 459-472.

Linder, S. (1961). "An Essay on Trade and Transformation," Uppsala: Almqvist \& Wiksells Bocktryckery Ab.

Marston, R. (1990). "Pricing to market in Japanese manufacturing," Journal of International Economics, 29(3-4): 217-236.

Manova, K. And Z. Zhang (2012). "Export Prices across Firms and Destionations," Quarterly Journal of Economics, 127: 379-436.

Magee, S. P. (1974). "U.S. Import Prices in the Currency-Contract Period," Brookings Papers on Economic Activity, Economic Studies Program, The Brookings Institution, 5(1): $117-168$.

Manova, K. And Z. Zhang (2012). "Export Prices across Firms and Destinations," Quarterly Journal of Economics, 127: 379-436.

Melitz, M. and G. Ottaviano (2008). "Market Size, Trade, and Productivity," Review of Economic Studies, 75: 295-316.

McFadden, D. (1973). "Conditional Logit Analysis of Qualitative Choice Behavior," Frontiers of Econometrics, edited by P. Zarembka. New York Academic Press.

McFadden, D. (1981). "Econometric Models of Probabilistic Choice," Analysis of 
Discrete Data with Econometric Applications, ed. by C.F. Manski and D. McFadden. Cambridge, MIT Press.

McKenzie, D. And E. Schargrodsky (2005). "Buying Less, But Shopping More: Changes In Consumption Patterns During A Crisis," Escuela de Negocios Universidad Torcuato Di Tella, DT 01/2005.

Mundell, R. (1963). "Capital Mobility and Stabilization Policy under Fixed and Flexible Exchange Rates," Canadian Journal of Economic and Political Science, 29(4): 475-485.

Nakamura, E. (2008). "Pass-Through in Retail and Wholesale," American Economic Review, American Economic Association, 98(2): 430-37.

Nakamura, E. And D. Zerom (2010). "Accounting for Incomplete Pass-through," Review of Economic Studies, 77(3): 1192-1230.

Nevo, A. (2001). "Measuring Market Power in the Ready-to-Eat Cereal Industry," Econometrica, 69(2): 307-42.

ObStfeld, M. (1994). "The Logic of Currency Crises," NBER Working Papers 4640.

Obstfeld, M. And K. Rogoff (2001). "The Six Major Puzzles in International Macroeconomics: Is There a Common Cause?," NBER Macroeconomics Annual 2000, (15): $339-412$.

Ohno, K. (1989). "Export Pricing Behavior of Manufacturing: A U.S.-Japan Comparison," IMF Staff Papers, 36(3): 550-79.

Parsley, D. C., And Wei, S-J. (2001). "Explaining the Border Effect: The Role of Exchange Rate Variability, Shipping Costs and Geography," Journal of International Economics, 55: 87-105.

Revenga, A. (1992). "Exporting Jobs? The Impact of Import Competition on Employment and Wages in U.S. Manufacturing," Quarterly Journal of Economics, 107: $255-84$.

Ricardo, D. (1810). "The High Price of Bullion, a Proof of the Depreciation of Bank Notes".

Richardson, J. D. (1978). "Some Empirical Evidence on Commodity Arbitrage and the Law of One Price," Journal of Economic Literature, 8(2): 341-351.

Rogoff, K. (1996). "The Purchasing Power Parity Puzzle?," Journal of Economic Literature, 34(2): 647-668.

Salant, S. And D. Henderson (1978). "Market Anticipations of Government Policies and the Price of Gold," Journal of Political Economy, 86(4): 627-648.

Schотт, P. K. (2004). "Across-Product versus Within-Product Specialization in International Trade," Quarterly Journal of Economics, 119: 647-678.

Verhoogen, E. (2008). "Trade, Quality Upgrading, and Wage Inequality in the Mexican Manufacturing Sector" Quarterly Journal of Economics, 123 (2): 489-530.

Woo, W. T. (1984). "Exchange Rates and the Prices of Nonfood, Nonfuel Products," Brookings Papers on Economic Activity, 2: 511-530. 


\section{Apéndice}

\subsection{Demostraciones}

\subsubsection{Solución del modelo}

Siguiendo el enfoque de elección discreta (modelo multinomial nested logit), la demanda por la variedad de producto $j$ que elabora la firma $s$ está dada por su participación de mercado (market share):

$$
w_{j s t}\left(p_{j s t}, \theta_{j s t} ; \mathbf{D}_{j t}, y_{t}\right)=\frac{\exp \left(\frac{\theta_{j s t}-\alpha\left(y_{t}\right) \log \left(p_{j s t}\right)}{1-\sigma}\right)}{D_{j t}^{\sigma} \sum_{j^{\prime}=0}^{J_{t}} D_{j^{\prime} t}^{1-\sigma}}
$$

donde $\mathbf{D}_{j t}$ es un índice a nivel producto (o inclusive value term), que viene dado por la siguiente expresión:

$$
\mathbf{D}_{j t}=\sum_{s \in S} \exp \left(\frac{\theta_{j s t}-\alpha\left(y_{t}\right) \log \left(p_{j s t}\right)}{1-\sigma}\right)
$$

Cada firma maximiza beneficios de acuerdo al siguiente problema de optimización:

$$
\max _{\left(p_{j s t}, \theta_{j s t}\right)} \Pi_{j s t}=\left[p_{j s t}-c\left(\theta_{j s t}\right)\right] w_{j s t}\left(p_{j s t}, \theta_{j s t}, \mathbf{D}_{j t}, y_{t}\right)
$$

Las condiciones de primer orden son entonces:

$$
\begin{array}{ll}
p_{j s t} \quad: \quad w_{j s t}(.)+\left(p_{j s t}-c(.)\right) \frac{\partial w_{j s t}(.)}{\partial p_{j s t}}=0 \\
\theta_{j s t} \quad: \quad-w_{j s t}(.) \frac{\partial c(.)}{\partial \theta_{j s t}}+\left(p_{j s t}-c(.)\right) \frac{\partial w_{j s t}(.)}{\partial \theta_{j s t}}=0 .
\end{array}
$$

Dado el supuesto de competencia monopolística, las derivadas de la ecuación de demanda vienen dadas por:

$$
\begin{aligned}
\frac{\partial w_{j s t}}{\partial p_{j s t}} & =-\left(\frac{\alpha\left(y_{t}\right)}{1-\sigma}\right) \frac{w_{j s t}(.)}{p_{j s t}} \\
\frac{\partial w_{j s t}}{\partial \theta_{j s t}} & =\left(\frac{1}{1-\sigma}\right) w_{j s t}(.)
\end{aligned}
$$

Notar que la elasticidad de la demanda $\left(\left(\frac{\alpha\left(y_{t}\right)}{1-\sigma}\right)\right)$ es idéntica para todos los 
productos. Resolviendo, se tiene que el precio y la calidad óptimos son los siguientes:

$$
\begin{aligned}
p_{j s t} & =\left(\frac{\alpha\left(y_{t}\right)}{\alpha\left(y_{t}\right)-(1-\sigma)}\right) c(.) \\
\frac{\partial c(.)}{\partial \theta_{j s t}} & =\frac{p_{j s t}}{\alpha\left(y_{t}\right)}
\end{aligned}
$$

\subsubsection{Derivación de la ecuación de demanda}

Al igual que en el apartado anterior, se parte del enfoque de elección discreta, siguiendo la ecuación de demanda de la variedad de cada firma $j s$ representada por su market share:

$$
w_{j s t}\left(p_{j s t}, \theta_{j s t} ; \mathbf{D}_{j t}, y_{t}\right)=\frac{\exp \left(\frac{\theta_{j s t}-\alpha\left(y_{t}\right) \log \left(p_{j s t}\right)}{1-\sigma}\right)}{D_{j t}^{\sigma} \sum_{j^{\prime}=0}^{J_{t}} D_{j^{\prime} t}^{1-\sigma}}
$$

El market share de la variedad externa viene dado por:

$$
w_{0 t}\left(\mathbf{D}_{0 t}, y_{t}\right)=\frac{1}{\sum_{j^{\prime}=0}^{J_{t}} D_{j^{\prime} t}^{1-\sigma}}
$$

Tomando logaritmos y restando estas dos ecuaciones, se obtiene la ecuación de demanda normalizada:

$$
\log \left(w_{j s t}\right)-\log \left(w_{0 t}\right)=\left(\frac{\theta_{j s t}-\alpha\left(y_{t}\right) \log \left(p_{j s t}\right)}{1-\sigma}\right)-\sigma \log \left(D_{j t}\right)
$$

La probabilidad de escoger la variedad $s$, condicional a que el individuo está eligiendo el producto $j$, es equivalente al market share $s$ dentro del producto $j$ :

$$
s_{s t \mid j}=\frac{1}{D_{j t}} \exp \left(\frac{\theta_{j s t}-\alpha\left(y_{t}\right) \log \left(p_{j s t}\right)}{1-\sigma}\right)
$$

Tomando logaritmos:

$$
\log \left(s_{s t \mid j}\right)=\left(\frac{\theta_{j s t}-\alpha\left(y_{t}\right) \log \left(p_{j s t}\right)}{1-\sigma}\right)-\log \left(D_{j t}\right)
$$

Reemplazando esta ecuación en la ecuación de demanda normalizada (9.11):

$$
\log \left(w_{j s t}\right)-\log \left(w_{0 t}\right)=\left(\frac{\theta_{j s t}-\alpha\left(y_{t}\right) \log \left(p_{j s t}\right)}{1-\sigma}\right)+\sigma \log \left(s_{s t \mid j}\right)-\sigma\left(\frac{\theta_{j s t}-\alpha\left(y_{t}\right) \log \left(p_{j s t}\right)}{1-\sigma}\right)
$$


Finalmente, resolviendo y reordenando los términos, se obtiene la siguiente ecuación de demanda lineal en parámetros, que puede ser estimada a partir de los datos disponibles:

$$
\log \left(\frac{\omega_{j s t}}{\omega_{0 t}}\right)=\theta_{j s t}-\alpha_{t} \log \left(p_{j s t}\right)+\sigma \log \left(s_{s t \mid j}\right)
$$




\subsection{Cuadros}

\section{CUADRO A1}

Evolución del precio de las variedades importadas durante los episodios devaluatorios

(1) Efectos fijos a nivel producto-país de origen

\begin{tabular}{|c|c|c|c|c|c|c|c|c|c|c|c|c|}
\hline & $\begin{array}{c}\text { MEX } \\
1995 \\
\end{array}$ & $\begin{array}{l}\text { BRA } \\
1999 \\
\end{array}$ & $\begin{array}{l}\text { ARG } \\
2002 \\
\end{array}$ & $\begin{array}{l}\text { URU } \\
2002 \\
\end{array}$ & $\begin{array}{l}\text { COL } \\
1998 \\
\end{array}$ & $\begin{array}{l}\text { TAI } \\
1998 \\
\end{array}$ & $\begin{array}{l}\text { IND } \\
1998 \\
\end{array}$ & $\begin{array}{c}\text { MAL } \\
1998 \\
\end{array}$ & $\begin{array}{l}\text { FIL } \\
1998 \\
\end{array}$ & $\begin{array}{l}\text { COR } \\
1998 \\
\end{array}$ & $\begin{array}{l}\text { RUS } \\
1999 \\
\end{array}$ & $\begin{array}{l}\text { TUR } \\
2001 \\
\end{array}$ \\
\hline Post & $\begin{array}{c}-0.45^{* * *} \\
(0.06)\end{array}$ & $\begin{array}{c}-0.24^{* * *} \\
(0.04) \\
\end{array}$ & $\begin{array}{c}-0.11^{* * *} \\
(0.03) \\
\end{array}$ & $\begin{array}{c}-0.12^{* * *} \\
(0.04) \\
\end{array}$ & $\begin{array}{c}-0.14^{* * *} \\
(0.05) \\
\end{array}$ & $\begin{array}{c}-0.17^{* * *} \\
(0.02) \\
\end{array}$ & $\begin{array}{c}-0.26^{* * *} \\
(0.02) \\
\end{array}$ & $\begin{array}{c}-0.13^{* * *} \\
(0.04) \\
\end{array}$ & $\begin{array}{c}-0.18^{* * *} \\
(0.02) \\
\end{array}$ & $\begin{array}{c}-0.20^{* * *} \\
(0.03) \\
\end{array}$ & $\begin{array}{c}-0.24^{* * *} \\
(0.05) \\
\end{array}$ & $\begin{array}{c}-0.11^{* * * *} \\
(0.03)\end{array}$ \\
\hline $\mathrm{T}-2$ & $\begin{array}{c}0.01 \\
(0.02)\end{array}$ & $\begin{array}{c}0.02 \\
(0.03)\end{array}$ & $\begin{array}{l}-0.01 \\
(0.09)\end{array}$ & $\begin{array}{c}0.06 \\
(0.12)\end{array}$ & $\begin{array}{c}-0.04^{* *} \\
(0.02)\end{array}$ & $\begin{array}{l}-0.02 \\
(0.03)\end{array}$ & $\begin{array}{c}-0.05^{* * *} \\
(0.02)\end{array}$ & $\begin{array}{l}-0.03 \\
(0.04)\end{array}$ & . & $\begin{array}{c}-0.02^{* *} \\
(0.01)\end{array}$ & $\begin{array}{l}-0.03 \\
(0.09)\end{array}$ & $\begin{array}{c}-0.10^{* * *} \\
(0.02)\end{array}$ \\
\hline $\mathrm{T}-1$ & $\begin{array}{c}-0.25^{* * *} \\
(0.06)\end{array}$ & $\begin{array}{l}-0.03 \\
(0.03)\end{array}$ & $\begin{array}{l}-0.07 \\
(0.08)\end{array}$ & $\begin{array}{l}-0.01 \\
(0.12)\end{array}$ & $\begin{array}{c}-0.09^{* * *} \\
(0.02)\end{array}$ & $\begin{array}{c}-0.15^{* * *} \\
(0.02)\end{array}$ & $\begin{array}{c}-0.21^{* * *} \\
(0.02)\end{array}$ & $\begin{array}{c}0.22 * * * \\
(0.07)\end{array}$ & $\begin{array}{c}-0.06^{* * *} \\
(0.02)\end{array}$ & $\begin{array}{c}-0.09^{* * * *} \\
(0.01)\end{array}$ & $\begin{array}{c}-0.13^{*} \\
(0.07)\end{array}$ & $\begin{array}{c}-0.16^{* * *} \\
(0.05)\end{array}$ \\
\hline $\mathrm{T}$ & $\begin{array}{c}-0.27^{* * *} \\
(0.07)\end{array}$ & $\begin{array}{c}-0.10^{* * *} \\
(0.03)\end{array}$ & $\begin{array}{l}-0.15^{*} \\
(0.09)\end{array}$ & $\begin{array}{l}-0.11 \\
(0.12)\end{array}$ & $\begin{array}{c}-0.11^{* * *} \\
(0.02)\end{array}$ & $\begin{array}{c}-0.20^{* * *} \\
(0.03)\end{array}$ & $\begin{array}{c}-0.30^{* * *} \\
(0.03)\end{array}$ & $\begin{array}{c}0.21^{* *} \\
(0.08)\end{array}$ & $\begin{array}{c}-0.18^{* * *} \\
(0.03)\end{array}$ & $\begin{array}{c}-0.21^{* * * *} \\
(0.02)\end{array}$ & $\begin{array}{c}-0.21^{* * *} \\
(0.07)\end{array}$ & $\begin{array}{c}{ }^{*}-0.21^{* * * *} \\
(0.05)\end{array}$ \\
\hline $\mathrm{T}+1$ & $\begin{array}{c}-0.80^{* * *} \\
(0.09)\end{array}$ & $\begin{array}{c}-0.31^{* * *} \\
(0.07)\end{array}$ & $\begin{array}{c}-0.17^{*} \\
(0.09)\end{array}$ & $\begin{array}{l}-0.13 \\
(0.12)\end{array}$ & $\begin{array}{c}-0.30^{* * *} \\
(0.11)\end{array}$ & $\begin{array}{c}-0.23^{* * *} \\
(0.03)\end{array}$ & $\begin{array}{c}-0.41^{* * *} \\
(0.04)\end{array}$ & $\begin{array}{c}-0.28^{* * *} \\
(0.08)\end{array}$ & $\begin{array}{c}-0.24^{* * *} \\
(0.03)\end{array}$ & $\begin{array}{c}-0.29^{* * *} \\
(0.02)\end{array}$ & $\begin{array}{c}-0.35^{* * *} \\
(0.09)\end{array}$ & $\begin{array}{c}-0.25^{* * *} \\
(0.05)\end{array}$ \\
\hline $\mathrm{T}+2$ & $\begin{array}{c}-0.59^{* * * *} \\
(0.08)\end{array}$ & $\begin{array}{c}-0.36^{* * *} \\
(0.07)\end{array}$ & $\begin{array}{l}-0.11 \\
(0.09)\end{array}$ & $\begin{array}{l}-0.09 \\
(0.13)\end{array}$ & $\begin{array}{l}-0.19^{*} \\
(0.10)\end{array}$ & $\begin{array}{c}-0.25^{* * *} \\
(0.04)\end{array}$ & $\begin{array}{c}-0.37^{* * *} \\
(0.04)\end{array}$ & $\begin{array}{c}-0.13^{* *} \\
(0.06)\end{array}$ & $\begin{array}{c}-0.22^{* * *} \\
(0.05)\end{array}$ & $\begin{array}{c}-0.23^{* *} \\
(0.09)\end{array}$ & $\begin{array}{c}-0.36^{* * *} \\
(0.10)\end{array}$ & $\begin{array}{c}-0.15^{* * *} \\
(0.05)\end{array}$ \\
\hline $\begin{array}{l}\text { Obs. } \\
\text { EF var. }\end{array}$ & $\begin{array}{c}191,431 \\
47,693 \\
\end{array}$ & $\begin{array}{c}209,633 \\
50,226 \\
\end{array}$ & $\begin{array}{c}175,728 \\
40,739 \\
\end{array}$ & $\begin{array}{l}97,165 \\
23,338 \\
\end{array}$ & $\begin{array}{c}141,711 \\
34,780 \\
\end{array}$ & $\begin{array}{c}195,326 \\
45,232 \\
\end{array}$ & $\begin{array}{c}185,888 \\
45,522 \\
\end{array}$ & $\begin{array}{c}185,298 \\
46,623 \\
\end{array}$ & $\begin{array}{c}128,670 \\
35,822 \\
\end{array}$ & $\begin{array}{c}201,334 \\
47,711 \\
\end{array}$ & $\begin{array}{c}292,936 \\
72,547 \\
\end{array}$ & $\begin{array}{c}216,063 \\
52,070 \\
\end{array}$ \\
\hline \multicolumn{13}{|c|}{ (2) Efectos fijos a nivel producto } \\
\hline & $\begin{array}{c}\text { MEX } \\
1995 \\
\end{array}$ & $\begin{array}{l}\text { BRA } \\
1999 \\
\end{array}$ & $\begin{array}{l}\text { ARG } \\
2002 \\
\end{array}$ & $\begin{array}{l}\text { URU } \\
2002 \\
\end{array}$ & $\begin{array}{l}\text { COL } \\
1998 \\
\end{array}$ & $\begin{array}{l}\text { TAI } \\
1998 \\
\end{array}$ & $\begin{array}{l}\text { IND } \\
1998 \\
\end{array}$ & $\begin{array}{l}\text { MAL } \\
1998 \\
\end{array}$ & $\begin{array}{l}\text { FIL } \\
1998 \\
\end{array}$ & $\begin{array}{l}\text { COR } \\
1998 \\
\end{array}$ & $\begin{array}{l}\text { RUS } \\
1999 \\
\end{array}$ & $\begin{array}{l}\text { TUR } \\
2001 \\
\end{array}$ \\
\hline Post & $\begin{array}{c}-0.43^{* * *} \\
(0.06) \\
\end{array}$ & $\begin{array}{c}-0.24^{* * *} \\
(0.04) \\
\end{array}$ & $\begin{array}{c}-0.14^{* * *} \\
(0.03) \\
\end{array}$ & $\begin{array}{c}-0.14^{* * *} \\
(0.04) \\
\end{array}$ & $\begin{array}{c}-0.15^{* * *} \\
(0.05) \\
\end{array}$ & $\begin{array}{c}-0.16^{* * *} \\
(0.03) \\
\end{array}$ & $\begin{array}{c}-0.27^{* * *} \\
(0.02) \\
\end{array}$ & $\begin{array}{c}-0.16^{* * *} \\
(0.04) \\
\end{array}$ & $\begin{array}{c}-0.20^{* * *} \\
(0.02) \\
\end{array}$ & $\begin{array}{c}-0.23^{* * *} \\
(0.03) \\
\end{array}$ & $\begin{array}{c}-0.21^{* * *} \\
(0.07) \\
\end{array}$ & $\begin{array}{c}{ }^{*}-0.14^{* * *} \\
(0.04) \\
\end{array}$ \\
\hline $\mathrm{T}-2$ & $\begin{array}{c}0.03 \\
(0.02)\end{array}$ & $\begin{array}{c}0.03 \\
(0.03)\end{array}$ & $\begin{array}{l}-0.01 \\
(0.08)\end{array}$ & $\begin{array}{c}0.07 \\
(0.12)\end{array}$ & $\begin{array}{c}-0.07^{* *} \\
(0.03)\end{array}$ & $\begin{array}{l}-0.01 \\
(0.04)\end{array}$ & $\begin{array}{l}-0.02 \\
(0.02)\end{array}$ & $\begin{array}{c}-0.04 \\
(0.04)\end{array}$ & . & $\begin{array}{l}-0.02 \\
(0.02)\end{array}$ & $\begin{array}{c}-0.01 \\
(0.11)\end{array}$ & $\begin{array}{c}-0.08^{* * *} \\
(0.03)\end{array}$ \\
\hline $\mathrm{T}-1$ & $\begin{array}{c}-0.20^{* * *} \\
(0.06)\end{array}$ & $\begin{array}{c}0.01 \\
(0.04)\end{array}$ & $\begin{array}{l}-0.09 \\
(0.08)\end{array}$ & $\begin{array}{c}0.01 \\
(0.12)\end{array}$ & $\begin{array}{c}-0.11^{* * *} \\
(0.03)\end{array}$ & $\begin{array}{c}-0.16^{* * * *} \\
(0.02)\end{array}$ & $\begin{array}{c}-0.23^{* * *} \\
(0.03)\end{array}$ & $\begin{array}{c}0.20^{* * *} \\
(0.07)\end{array}$ & $\begin{array}{l}-0.05^{*} \\
(0.03)\end{array}$ & $\begin{array}{c}-0.11^{* * *} \\
(0.02)\end{array}$ & $\begin{array}{l}-0.08 \\
(0.11)\end{array}$ & $\begin{array}{c}-0.17^{* * *} \\
(0.05)\end{array}$ \\
\hline $\mathrm{T}$ & $\begin{array}{c}-0.22^{* * *} \\
(0.06)\end{array}$ & $\begin{array}{c}-0.08^{* *} \\
(0.04)\end{array}$ & $\begin{array}{c}-0.16^{* *} \\
(0.08)\end{array}$ & $\begin{array}{l}-0.11 \\
(0.12)\end{array}$ & $\begin{array}{c}-0.13^{* * *} \\
(0.03)\end{array}$ & $\begin{array}{c}-0.18^{* * *} \\
(0.04)\end{array}$ & $\begin{array}{c}-0.26^{* * *} \\
(0.03)\end{array}$ & $\begin{array}{c}0.19^{* *} \\
(0.09)\end{array}$ & $\begin{array}{c}-0.18^{* * *} \\
(0.03)\end{array}$ & $\begin{array}{c}-0.24^{* * *} \\
(0.02)\end{array}$ & $\begin{array}{l}-0.16 \\
(0.12)\end{array}$ & $\begin{array}{c}-0.20^{* * *} \\
(0.05)\end{array}$ \\
\hline $\mathrm{T}+1$ & $\begin{array}{c}-0.75^{* * *} \\
(0.09)\end{array}$ & $\begin{array}{c}-0.28^{* * *} \\
(0.06)\end{array}$ & $\begin{array}{c}-0.21^{* *} \\
(0.09)\end{array}$ & $\begin{array}{l}-0.14 \\
(0.12)\end{array}$ & $\begin{array}{c}-0.32^{* * *} \\
(0.12)\end{array}$ & $\begin{array}{c}-0.23^{* * *} \\
(0.04)\end{array}$ & $\begin{array}{c}-0.41^{* * *} \\
(0.04)\end{array}$ & $\begin{array}{c}-0.30^{* * * *} \\
(0.08)\end{array}$ & $\begin{array}{c}-0.27^{* * *} \\
(0.03)\end{array}$ & $\begin{array}{c}-0.32^{* * * *} \\
(0.02)\end{array}$ & $\begin{array}{c}-0.29^{* *} \\
(0.14)\end{array}$ & $\begin{array}{c}-0.27^{* * *} \\
(0.05)\end{array}$ \\
\hline $\mathrm{T}+2$ & $\begin{array}{c}-0.53^{* * *} \\
(0.08)\end{array}$ & $\begin{array}{c}-0.33^{* * *} \\
(0.07)\end{array}$ & $\begin{array}{c}-0.16^{*} \\
(0.09)\end{array}$ & $\begin{array}{l}-0.11 \\
(0.12)\end{array}$ & $\begin{array}{c}-0.21^{* *} \\
(0.10)\end{array}$ & $\begin{array}{c}-0.25^{* * * *} \\
(0.06)\end{array}$ & $\begin{array}{c}-0.40^{* * *} \\
(0.05)\end{array}$ & $\begin{array}{c}-0.17^{* * *} \\
(0.07)\end{array}$ & $\begin{array}{c}-0.23^{* * *} \\
(0.05)\end{array}$ & $\begin{array}{c}-0.28^{* * *} \\
(0.09)\end{array}$ & $\begin{array}{l}-0.30^{*} \\
(0.16)\end{array}$ & $\begin{array}{c}-0.19^{* * *} \\
(0.05)\end{array}$ \\
\hline $\begin{array}{l}\text { Obs. } \\
\text { EF prod. }\end{array}$ & $\begin{array}{c}211,464 \\
4,051\end{array}$ & $\begin{array}{c}227,890 \\
4,113\end{array}$ & $\begin{array}{c}190,712 \\
3,686\end{array}$ & $\begin{array}{c}108,324 \\
3,351\end{array}$ & $\begin{array}{c}158,974 \\
3,969\end{array}$ & $\begin{array}{c}214,593 \\
3,846\end{array}$ & $\begin{array}{c}207,785 \\
4,156\end{array}$ & $\begin{array}{c}204,084 \\
3,864\end{array}$ & $\begin{array}{c}146,788 \\
3,929\end{array}$ & $\begin{array}{c}220,429 \\
4,170\end{array}$ & $\begin{array}{c}319,363 \\
4,088\end{array}$ & $\begin{array}{c}238,743 \\
3,877\end{array}$ \\
\hline . & S & 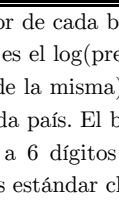 & 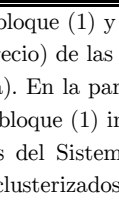 & -1 & 10 & +2 & 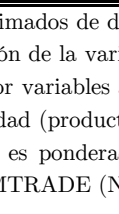 & 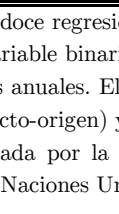 & 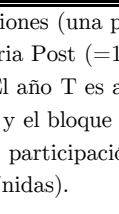 & 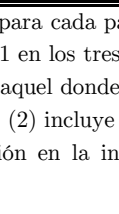 & & 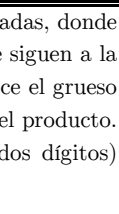 \\
\hline
\end{tabular}


CUADRO A2

Primera etapa de la estimación de la demanda en Argentina

\begin{tabular}{|c|c|c|c|c|c|c|}
\hline & \multicolumn{3}{|c|}{$\log ($ precio $)$} & \multicolumn{3}{|c|}{ Log(nested share) } \\
\hline & (1) & $(2)$ & $(3)$ & (1) & $(2)$ & (3) \\
\hline $\log (\mathrm{CT})$ & $\begin{array}{c}0.79 * * * \\
(0.04)\end{array}$ & $\begin{array}{c}0.79^{* * *} \\
(0.04)\end{array}$ & $\begin{array}{c}0.79 * * * \\
(0.04)\end{array}$ & $\begin{array}{c}-1.02^{* * *} \\
(0.13)\end{array}$ & $\begin{array}{c}-1.02^{* * * *} \\
(0.13)\end{array}$ & $\begin{array}{c}-1.01^{* * *} \\
(0.13)\end{array}$ \\
\hline $\log (\mathrm{CT}) \times$ Post & $\begin{array}{c}-0.01^{* * *} \\
(0.00)\end{array}$ & $\begin{array}{c}-0.01^{* * *} \\
(0.00)\end{array}$ & $\begin{array}{c}-0.01^{* * *} \\
(0.00)\end{array}$ & $\begin{array}{c}0.02^{* *} \\
(0.01)\end{array}$ & $\begin{array}{c}0.02 \\
(0.01)\end{array}$ & $\begin{array}{c}0.01 \\
(0.01)\end{array}$ \\
\hline $\log$ (P Ref.) & $\begin{array}{c}0.06^{* * *} \\
(0.02)\end{array}$ & $\begin{array}{c}0.06^{* * *} \\
(0.02)\end{array}$ & $\begin{array}{c}0.06^{* * *} \\
(0.02)\end{array}$ & $\begin{array}{l}-0.00 \\
(0.03)\end{array}$ & $\begin{array}{l}-0.01 \\
(0.03)\end{array}$ & $\begin{array}{l}-0.02 \\
(0.02)\end{array}$ \\
\hline $\log ($ P Ref. $) \times$ Post & $\begin{array}{c}-0.03^{* * *} \\
(0.01)\end{array}$ & $\begin{array}{c}-0.04^{* * *} \\
(0.01)\end{array}$ & $\begin{array}{c}-0.04^{* * *} \\
(0.01)\end{array}$ & $\begin{array}{c}0.02^{* *} \\
(0.01)\end{array}$ & $\begin{array}{l}0.03^{*} \\
(0.01)\end{array}$ & $\begin{array}{l}0.03^{* *} \\
(0.01)\end{array}$ \\
\hline $\mathrm{N}$ orígenes & $\begin{array}{c}-0.01^{* * *} \\
(0.00)\end{array}$ & $\begin{array}{c}-0.01^{* *} \\
(0.00)\end{array}$ & $\begin{array}{c}-0.01^{* *} \\
(0.00)\end{array}$ & $\begin{array}{c}-0.13^{* * *} \\
(0.01)\end{array}$ & $\begin{array}{c}-0.13^{* * *} \\
(0.01)\end{array}$ & $\begin{array}{c}-0.12^{* * *} \\
(0.01)\end{array}$ \\
\hline $\mathrm{N}$ orígenes $\times$ Post & $\begin{array}{c}0.00 \\
(0.00)\end{array}$ & $\begin{array}{l}-0.00 \\
(0.00)\end{array}$ & $\begin{array}{l}-0.00 \\
(0.00)\end{array}$ & $\begin{array}{c}-0.02^{* * *} \\
(0.00)\end{array}$ & $\begin{array}{c}-0.02^{* * *} \\
(0.00)\end{array}$ & $\begin{array}{c}-0.02^{* * *} \\
(0.00)\end{array}$ \\
\hline EF Producto & $\mathrm{Si}$ & $\mathrm{Si}$ & $\mathrm{Si}$ & $\mathrm{Si}$ & $\mathrm{Si}$ & $\mathrm{Si}$ \\
\hline EF Año $\times$ País & $\mathrm{Si}$ & $\mathrm{Si}$ & $\mathrm{Si}$ & $\mathrm{Si}$ & $\mathrm{Si}$ & $\mathrm{Si}$ \\
\hline EF Año $\times$ Industria & - & $\mathrm{Si}$ & $\mathrm{Si}$ & - & $\mathrm{Si}$ & $\mathrm{Si}$ \\
\hline EF País $\times$ Industria & - & - & $\mathrm{Si}$ & - & - & $\mathrm{Si}$ \\
\hline Test J (p-val) & 0.00 & 0.00 & 0.00 & 0.00 & 0.00 & 0.00 \\
\hline Observaciones & 347,904 & 347,904 & 347,904 & 347,904 & 347,904 & 347,904 \\
\hline
\end{tabular}

Notas. En el primer bloque (columnas 1 a 3) se presentan los coeficientes estimados para la regresión de $\log$ (precio) en función de las tres variables instrumentales y la interacción de cada una con la variable

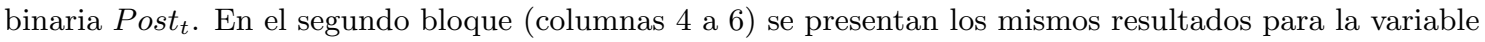
$\log ($ nestedshare). CT se refiere al costo de transporte unitario unitario, y P Ref. es el precio de referencia mundial. Las variables dependientes, los costos de importación y los precios de referencia mundiales se expresan en logaritmos. Todas las especificaciones incluyen efectos fijos a nivel producto y a nivel año-país de origen. Errores estándar robustos clusterizados por industrias (2 dígitos). Se presenta el p-valor del test de sobreidentificación de Hansen. Todas las variables pasan el test $\mathrm{F}$ de instrumentos débiles propuesto por Sanderson-Windmeijer. Fuentes. INDEC (Argentina) y COMTRADE (Naciones Unidas). 


\section{CUADRO A3}

Evolución de la calidad estimada de las variedades importadas durante los episodios devaluatorios

(1) Efectos fijos a nivel producto-país de origen

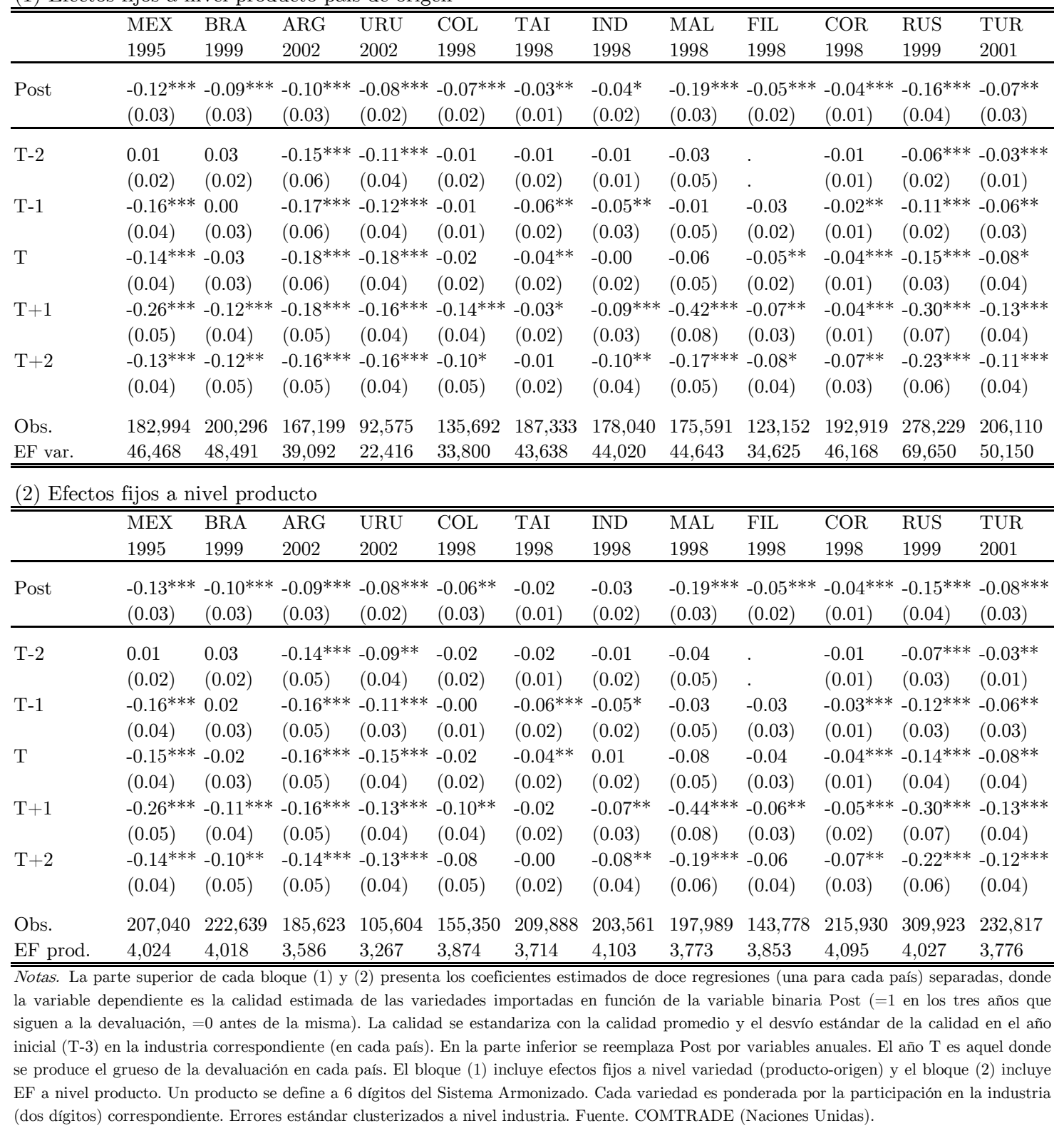


CUADRO A4

Diferencias en Diferencias: Precio (ponderado) electrodomésticos

\begin{tabular}{lccccc}
\hline \hline & \multicolumn{5}{c}{ Log (Precio) } \\
\hline & $(1)$ & $(2)$ & $(3)$ & $(4)$ & $(5)$ \\
\hline \multirow{2}{*}{ Post x Arg } & & & & & \\
& $-0.116^{* *}$ & $-0.129^{* *}$ & $-0.180^{* * *}$ & $-0.180^{* * *}$ & $-0.181^{* * *}$ \\
Arg & $(0.054)$ & $(0.053)$ & $(0.042)$ & $(0.042)$ & $(0.050)$ \\
& $0.103^{*}$ & $0.182^{* * *}$ & $0.261^{* * *}$ & $0.261^{* * *}$ & $0.270^{* * *}$ \\
& $(0.056)$ & $(0.043)$ & $(0.036)$ & $(0.036)$ & $(0.039)$ \\
Observaciones & & & & & \\
EF Año x Origen & 46,496 & 46,496 & 46,496 & 22,247 & 8,498 \\
EF Año x Marca & $\mathrm{Si}$ & $\mathrm{Si}$ & $\mathrm{Si}$ & $\mathrm{Si}$ & $\mathrm{Si}$ \\
EF Año x Origen x Marca & $\mathrm{No}$ & $\mathrm{Si}$ & $\mathrm{Si}$ & $\mathrm{Si}$ & $\mathrm{Si}$ \\
\hline \hline
\end{tabular}

Notas. Se estima una regresión del valor unitario FOB (en logs) de electrodomésticos importados, en función de las variables Arg (=1 si Argentina es el importador, $=0$ si es Chile), Post $(=0$ en 1999-2001, =1 en 2002-2004) y la interacción Post x Arg. Errores estándar robustos clusterizados por marca-origen. Cols. (1)-(3) incluyen todas las transacciones referidas a combinaciones producto-origen-marca importadas por ambos países al menos una vez durante 1999-2004. Col. 4 (5) restringe la muestra a combinaciones producto-origen-marca importados por ambos países al menos una vez pre y post 2002 (al menos una vez en cada año durante 2000-2003). Se utiliza como ponderador la participación de cada producto-marca-origen en el valor anual de las importaciones de cada producto.

\section{CUADRO A5}

Diferencias en Diferencias: Precio (ponderado) automóviles

\begin{tabular}{lcccc}
\hline \hline & \multicolumn{4}{c}{$\log ($ Price $)$} \\
\hline \multirow{3}{*}{ Post x Arg } & $(1)$ & $(2)$ & $(3)$ & $(4)$ \\
\multirow{4}{*}{ Arg } & $-0.181^{* * *}$ & $-0.177^{* *}$ & $-0.202^{* * *}$ & $-0.203^{* * *}$ \\
& $(0.067)$ & $(0.069)$ & $(0.064)$ & $(0.074)$ \\
& $0.173^{* *}$ & $0.169^{* *}$ & $0.178^{* *}$ & $0.197^{* *}$ \\
Observations & $(0.070)$ & $(0.072)$ & $(0.073)$ & $(0.079)$ \\
EF Year x Origin & & & & \\
EF Year x Model & 47,373 & 47,373 & 23,644 & 15,266 \\
EF Year x Model x Origin & Yes & Yes & Yes & Yes \\
\hline \hline
\end{tabular}

Notas. Se estima una regresión del valor unitario FOB (en logs) de automóviles importados motor a nafta 1500-3000cc, en función de las variables Arg (=1 si Argentina es el importador, $=0$ si es Chile), Post (=0 en 1999-2001, =1 en 2002-2004) y la interacción Post x Arg. Errores estándar robustos clusterizados por marca. Cols. (1)-(3) incluyen todas las transacciones referidas a modelos importados por ambos países al menos una vez durante 1999-2004. Col. 4 (5) restringe la muestra a modelos importados por ambos países al menos una vez pre y post 2002 (al menos una vez en cada año durante 2000-2003). Se utiliza como ponderador la participación de cada modelo en el valor anual de las importaciones. 
CUADRO A6

Estadísticas descriptivas de características de automóviles importados por Argentina

\begin{tabular}{lccccc}
\hline \hline & Obs. & Media & DE & Min & Max \\
\cline { 2 - 5 } Caja cambios & 426 & 0.60 & 0.49 & 0 & 1 \\
Motor (cc.) & 19,323 & 1,914 & 405 & 1,124 & 3,000 \\
Peso (kg.) & 18,921 & 1,221 & 214 & 817 & 1,950 \\
Cantidad puertas & 19,206 & 0.86 & 0.36 & 0 & 1 \\
Carrocería & 11,799 & 2.07 & 0.38 & 1 & 3 \\
Cupé & 18,480 & 0.10 & 0.30 & 0 & 1 \\
Tracción & 1,255 & 0.70 & 0.46 & 0 & 1 \\
Aire acondicionado & 19,352 & 0.92 & 0.27 & 0 & 1 \\
Bomba de inyección & 19,352 & 0.81 & 0.40 & 0 & 1 \\
Turbo alimentación & 19,352 & 0.07 & 0.25 & 0 & 1 \\
Caballos de fuerza & 15,128 & 128.70 & 38.96 & 49 & 281 \\
\hline \hline
\end{tabular}

Notas. La variable carrocería se asocia con el tamaño del automóvil y toma 3 valores (Hatchback $=1$, Sedan $=2$, Familiar $=3$ ). Fuentes. Datos de las Aduanas de Argentina.

CUADRO A7

Evolución de participación de importaciones de autos según localización de plantas

\begin{tabular}{lcccccc}
\hline \hline & 1999 & 2000 & 2001 & 2002 & 2003 & 2004 \\
\hline MN sin planta en Arg. & 78.6 & 86.5 & 81.6 & 91.7 & 93.9 & 92.6 \\
MN con planta en Arg. & 10.6 & 8.9 & 13.1 & 7.4 & 5.6 & 6.9 \\
Otros importadores & 10.9 & 4.6 & 5.3 & 0.9 & 0.6 & 0.4 \\
\hline \hline
\end{tabular}

Notas. Participación en el valor total anual importado por Argentina en función de la localización de las plantas y el tipo de empresa importadora. Fuentes. Datos de la Aduana Argentina.

CUADRO A8

Evolución de participación de importaciones de autos según el origen

\begin{tabular}{lcccccc}
\hline \hline & 1999 & 2000 & 2001 & 2002 & 2003 & 2004 \\
\hline Mercosur & 40.1 & 62.5 & 52.6 & 78.1 & 86.5 & 85.0 \\
Eurozona & 37.4 & 21.9 & 23.8 & 11.9 & 9.7 & 7.2 \\
Nafta & 7.4 & 6.8 & 9.3 & 2.7 & 1.7 & 4.6 \\
Japón & 7.6 & 3.6 & 6.4 & 4.3 & 1.4 & 1.9 \\
Resto & 7.5 & 5.2 & 7.9 & 3.1 & 0.7 & 1.3 \\
\hline \hline
\end{tabular}

Notas. Participación en el valor total anual de los automóviles importados por Argentina según el origen de los automóviles. Fuentes. Datos de la Aduana Argentina. 
9.3 $\quad$ Figuras

FIGURA A1

Evolución del tipo de cambio real bilateral

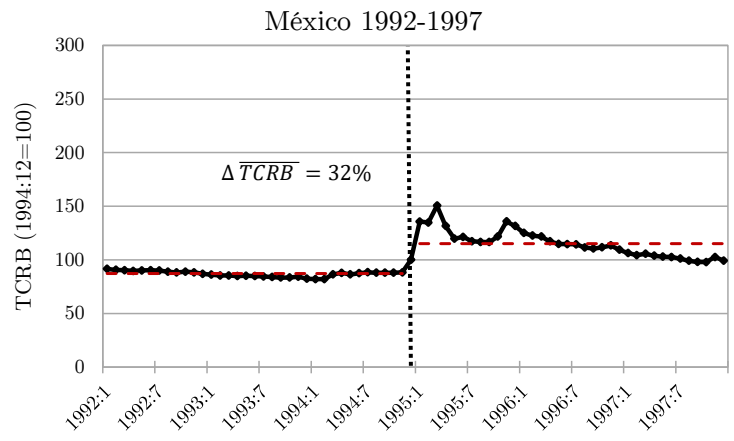

Argentina 1999-2004

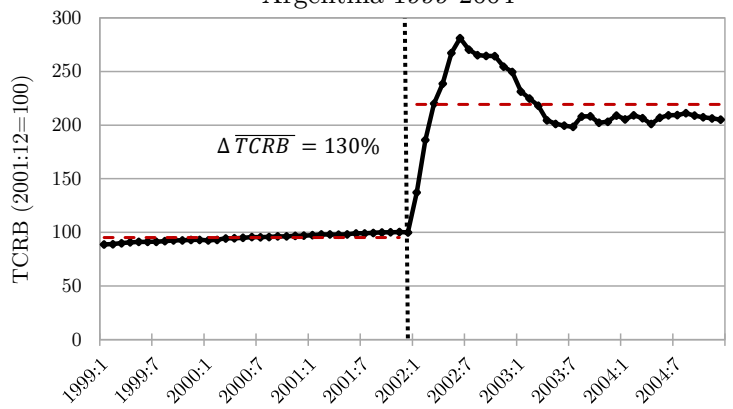

Colombia 1996-2001

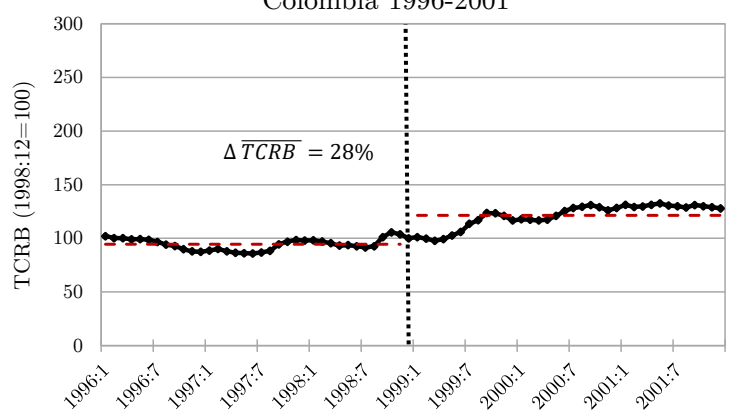

Tailandia 1995-2000

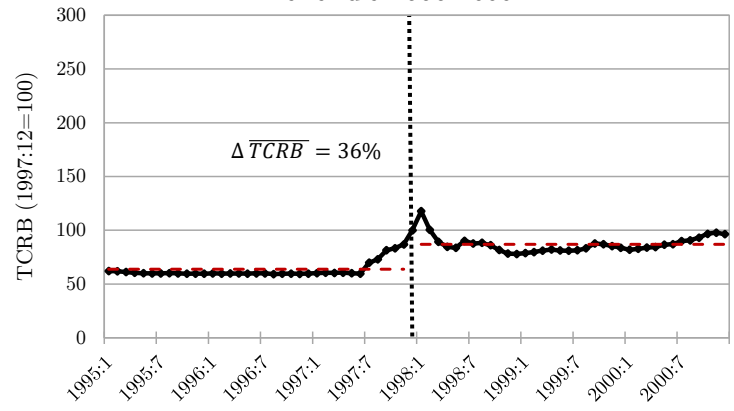

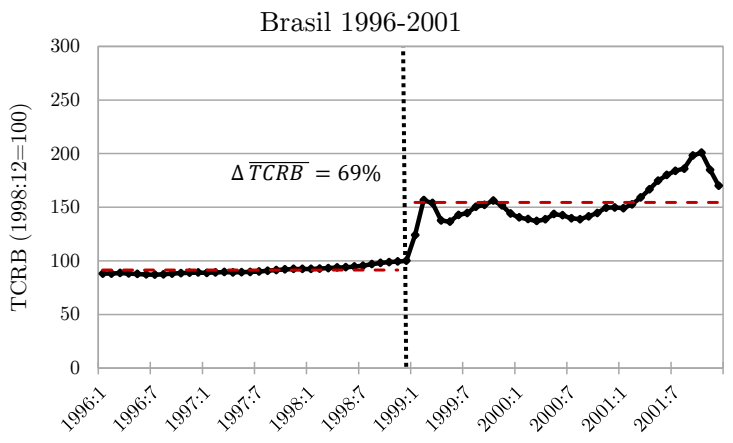

Uruguay 1999-2004

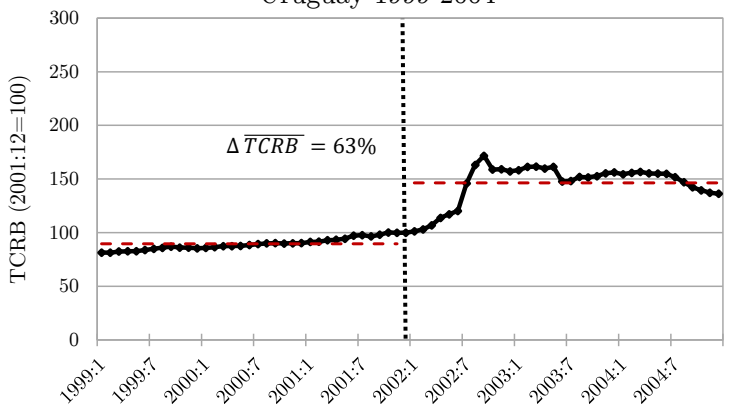

Indonesia 1995-2000

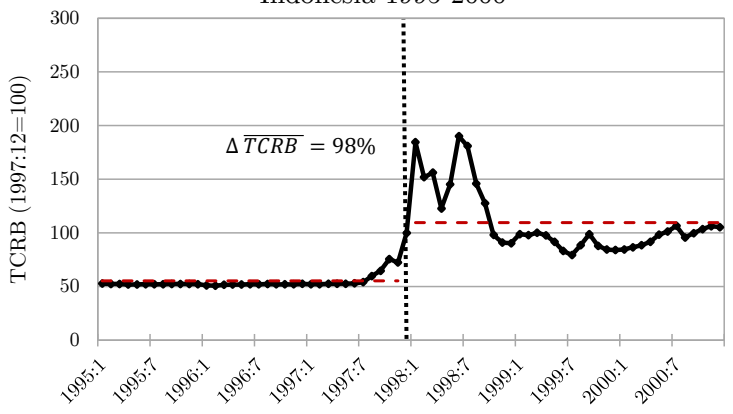

Malasia 1995-2000

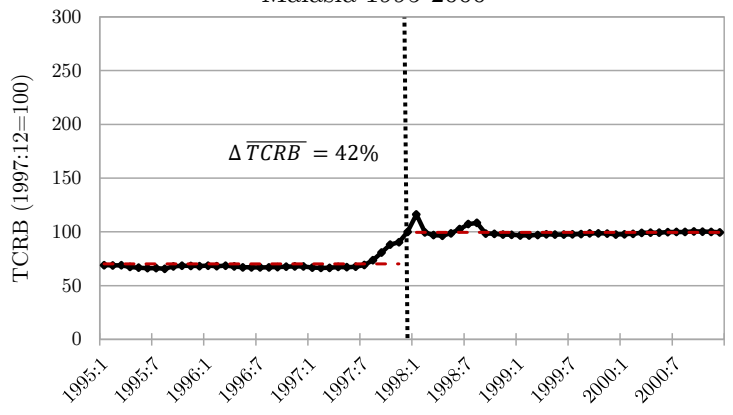

Notas. Continúa en la página siguiente.

117 
FIGURA A1 (cont.)

Evolución del tipo de cambio real bilateral
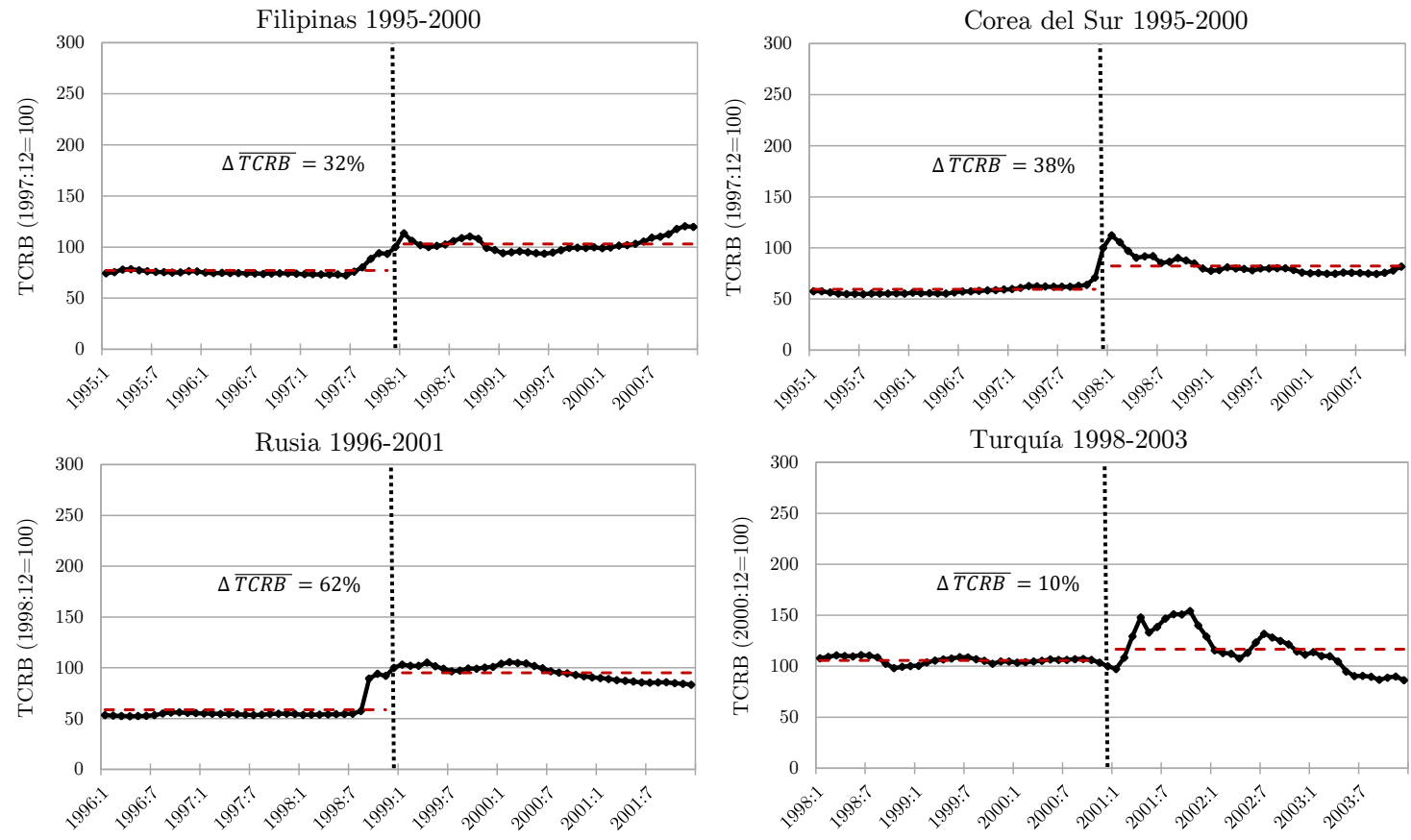

Notas. Evolución del tipo de cambio real bilateral (TCRB) respecto al dólar estadounidense. Se presenta una serie mensual de seis años para cada país, normalizada en 100 en el mes de Diciembre del último año pre-devaluación (línea vertical punteada). A partir de este umbral, se calcula un TCRB promedio para cada subperíodo de tres años (línea horizontal punteada). $\triangle$ TCRB muestra la diferencia porcentual entre ambos promedios. Fuente. Exchange Rates Archives (Fondo Monetario Internacional). 


\section{FIGURA A2}

Evolución del TCN y los precios durante la crisis Argentina

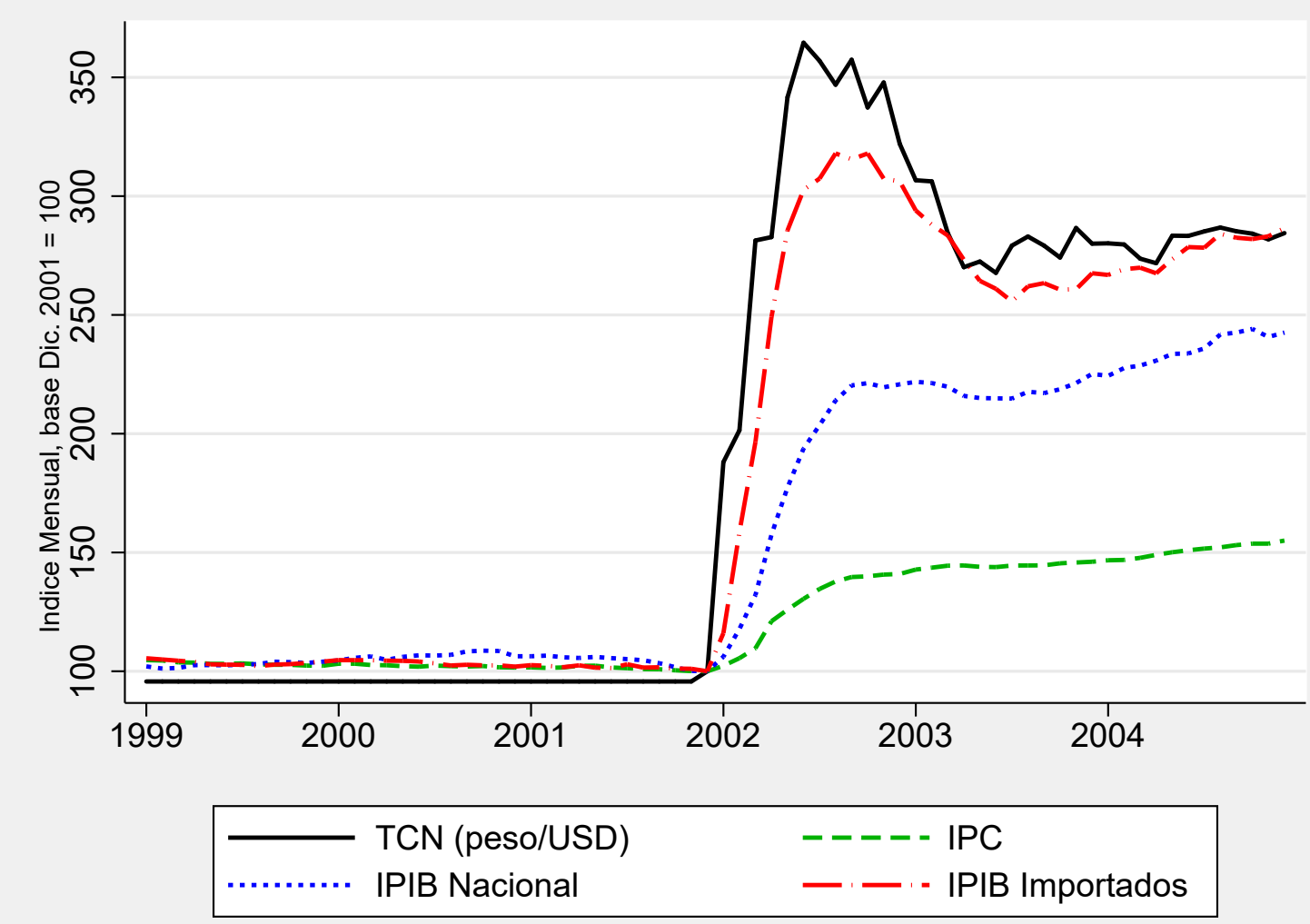

Notas. El tipo de cambio nominal (TCN) y los índices de precio valen 100 en Diciembre de 2001. El índice de precios internos brutos (IPIB) mide los precios promedio a los cuales productores y/o importadores directos venden sus productos en el mercado doméstico. Estos índices presentan un mayor incremento que el IPC puesto que contienen una mayor proporción de bienes transables. IPIB incluye no sólo manufacturas, sino que también asigna una ponderación importante a bienes primarios y energía eléctrica, los cuales $a$ priori deberían presentar un mayor nivel de traslado a precios ya que son bienes relativamente homogéneos (de modo que es más probable que se cumpla la Ley de Precio Único). Es importante mencionar que las prácticas de cuentas nacionales en Argentina (así como en muchos otros países) utilizan índices de precios del tipo matching-model, que siguen a un mismo modelo a través del tiempo y no tienen en cuenta cambios composicionales ni variaciones en la calidad de los productos. En este Anexo se incluye una sección que discute brevemente este tipo de metodologías. Fuente. Instituto Nacional de Estadísticas y Censos (INDEC). 


\section{FIGURA A3}

Cambio anual en el precio de las variedades importadas

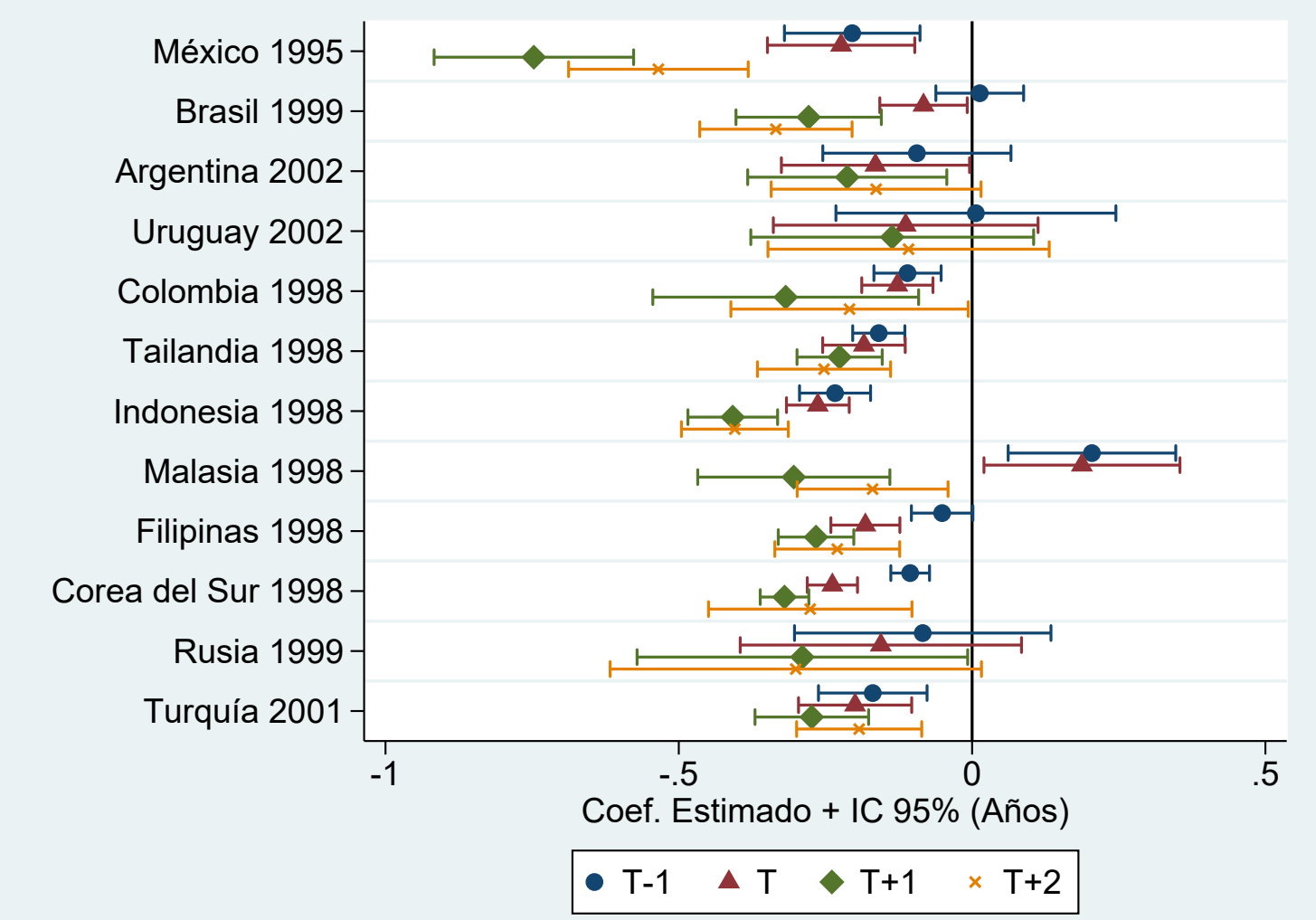

Notas. Coeficientes estimados a partir de 12 regresiones (una para cada país) del log(precio) en las variable binarias anuales (la variable omitida es el año initial T-2). Las regresiones incluyen EF a nivel producto-país de origen. Cada variedad es ponderada por la participación en el valor total importado de la industria correspondiente. Errores estándar clusterizados a nivel industria. Fuente. COMTRADE (Naciones Unidas). 


\section{FIGURA A4}

Cambio anual en la calidad de las variedades importadas

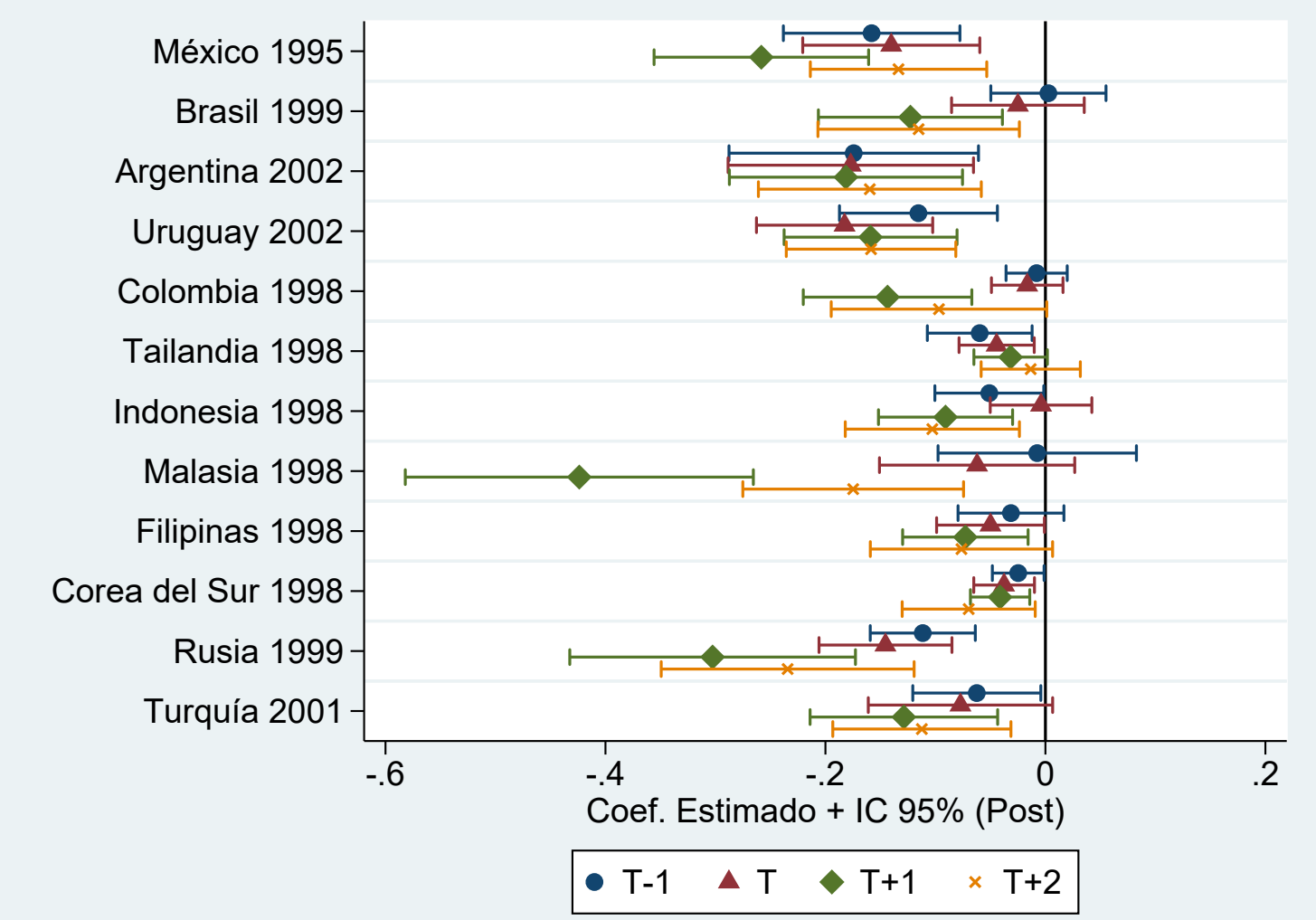

Notas. Coeficientes estimados a partir de 12 regresiones (una para cada país) de la calidad estimada (estandarizada) en las variable binarias anuales (la variable omitida es el año initial T-2). Las regresiones incluyen EF a nivel producto-país de origen. Cada variedad es ponderada por la participación en el valor total importado de la industria correspondiente. Errores estándar clusterizados a nivel industria. Fuente. COMTRADE (Naciones Unidas). 
FIGURA A5

Sustitución de variedades post devaluación (precio)

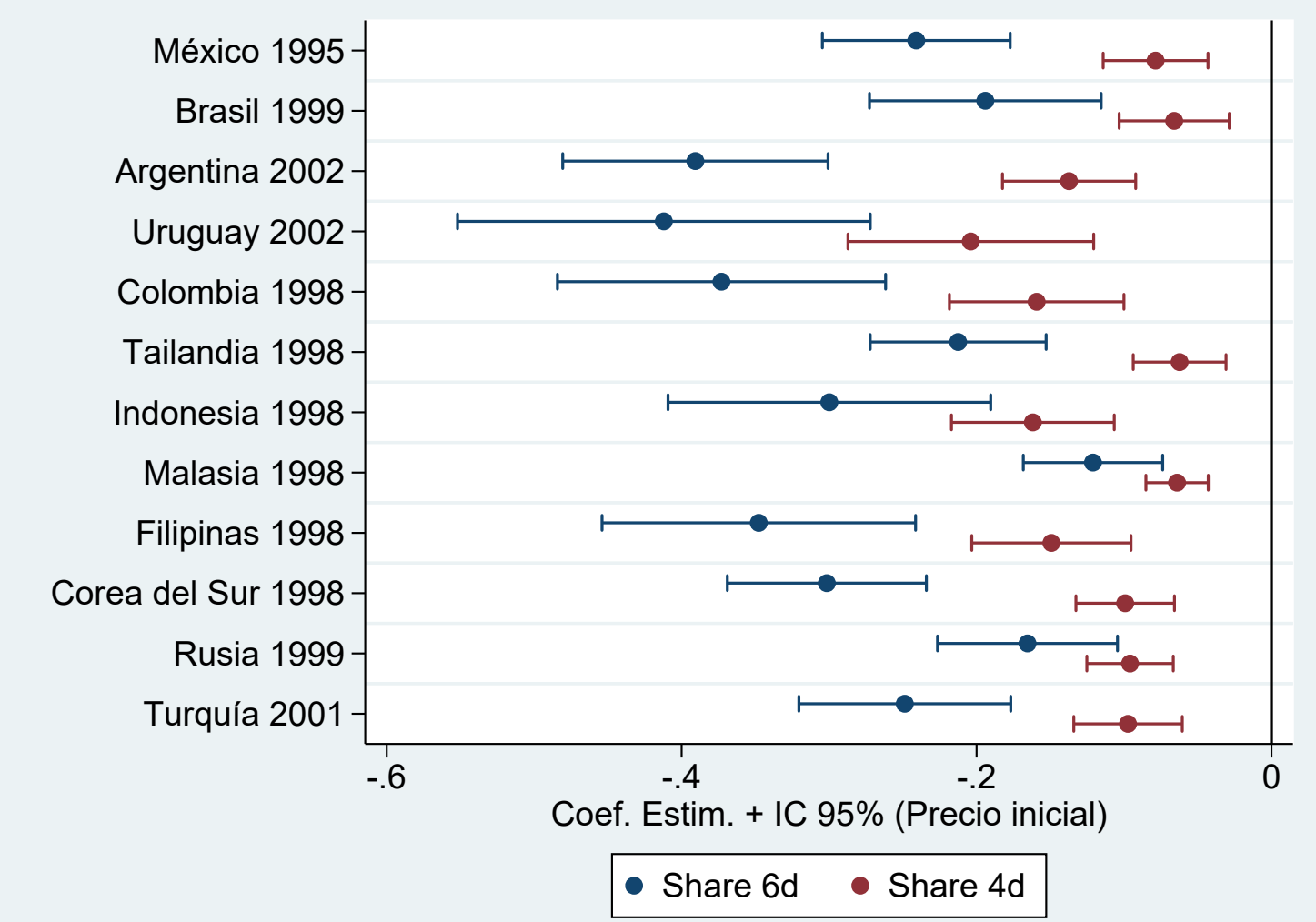

Notas. Coeficientes estimados a partir de (24) regresiones (dos para cada país) del cambio promedio en la participación de cada variedad en el total importado de cada producto entre los dos períodos (pre y post devaluación) en función del precio de cada variedad en el período inicial. Se estiman 12 regresiones utilizando el cambio en la participación de un producto a 6 dígitos (azul) y otras 12 regresiones utilizando la definición a 4 dígitos (rojo). Errores estándar clusterizados a nivel industria. Fuente. COMTRADE (Naciones Unidas). 
FIGURA A6

Sustitución de variedades post devaluación (calidad)

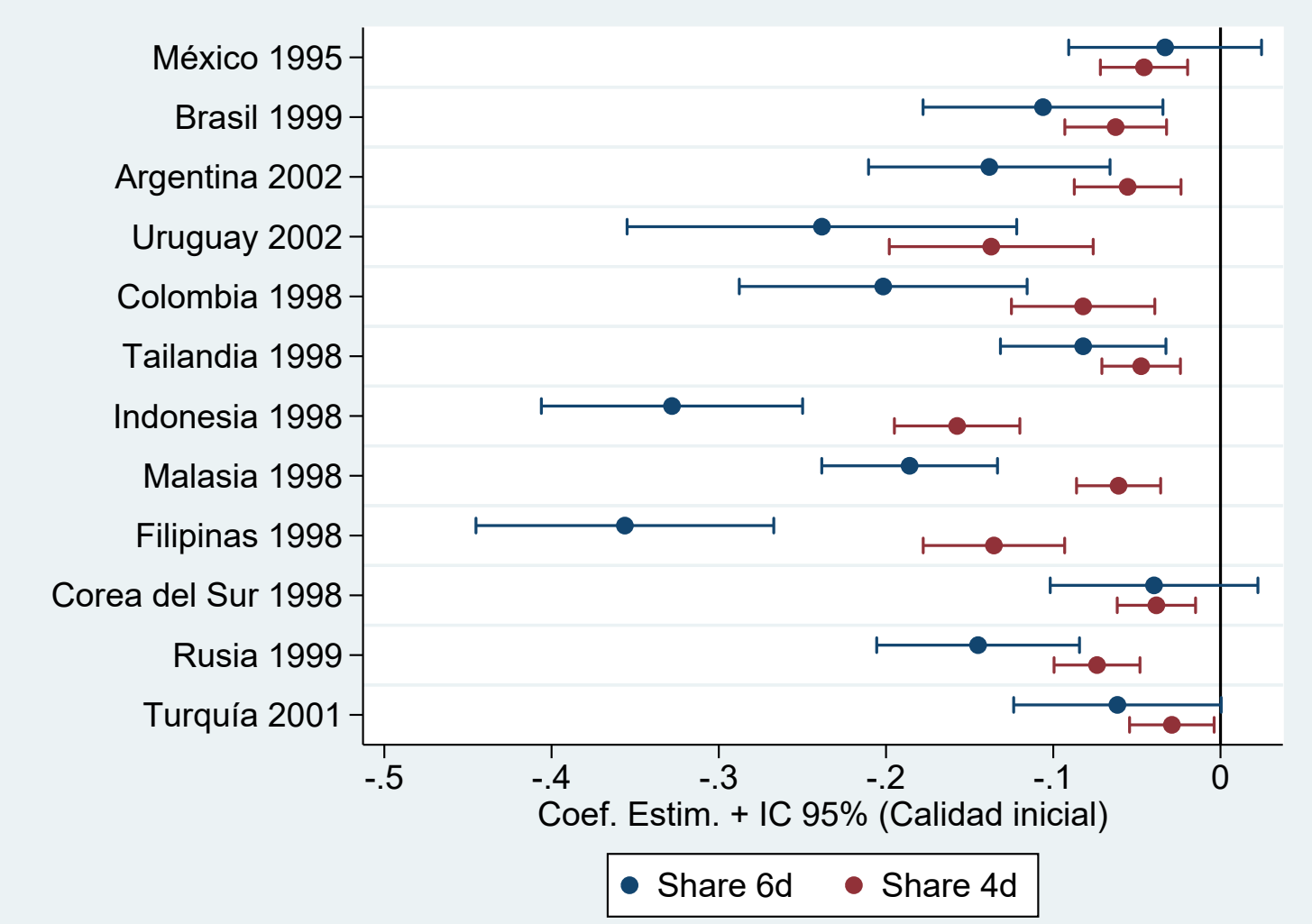

Notas. Coeficientes estimados a partir de (24) regresiones (dos para cada país) del cambio promedio en la participación de cada variedad en el total importado de cada producto entre los dos períodos (pre y post devaluación) en función de la calidad estimada de cada variedad en el período inicial. Se estiman 12 regresiones utilizando el cambio en la participación de un producto a 6 dígitos (azul) y otras 12 regresiones utilizando la definición a 4 dígitos (rojo). Errores estándar clusterizados a nivel industria. Fuente. COMTRADE (Naciones Unidas). 


\subsection{Sesgo de sustitución}

Los índices de precios que no actualizan la canasta de consumo en respuesta a un evento económico de magnitud (e.g. devaluación elevada) contienen cierto sesgo muestral porque los consumidores modifican sus hábitos de consumo (e.g. sustituyen las variedades de precio/calidad alto por variedades de precio/calidad bajo). En particular, los índices de precios de manufacturas importadas que utilizan los mismos modelos de productos están sobreestimados. El índice de precios de importaciones (IPI) elaborado por el INDEC presenta este problema. El IPI es un índice de precios del tipo Paasche con ponderadores móviles, como la gran mayoría de los índices que intentan medir la evolución del precio de una canasta (fija) de productos a través del tiempo. El IPI presenta un nivel general y se desagrega en función del uso económico de las importaciones, a saber: (1) bienes de capital y equipo de transporte industrial; (2) bienes intermedios; (3) combustibles y lubricantes; (4) piezas y accesorios para bienes de capital y equipos de transporte; (5) bienes de consumo. La principal fuente de información es la documentación aduanera en la cual se consignan los valores unitarios a precio CIF. La muestra selecciona las posiciones arancelarias más representativas dentro de cada capítulo con dos criterios: uno de cobertura y permanencia en el tiempo, y otro de homogeneidad de los valores unitarios. ${ }^{46}$ La muestra fija utilizada incluye 222 posiciones arancelarias que representan alrededor del $66 \%$ del valor importado entre 1993 y 1995. Es muy probable que la representatividad de dicha muestra disminuya en el tiempo, más aún para aquellos productos que presentan un alto grado de diferenciación vertical.

La actualización del Sistema de Cuentas Nacionales (que incluye al IPI) tomó como nuevo año base de referencia al año 2004 y fue publicada con un marcado rezago en el año 2014. En el documento metodológico de INDEC se explica que “... más allá de la elección de la fórmula para el cálculo de los índices, existe un común denominador en cuanto a la problemática que presenta el seguimiento de los precios de aquellos bienes que por sus características presentan un alto grado de heterogeneidad... En el caso de los productos manufacturados con alto grado de elaboración (bienes de capital y bienes de consumo durable) es usual que las posiciones arancelarias estén compuestas por productos diversos (aunque del mismo género) o que presenten diversidad de modelos, tamaños, o rendimientos. En consecuencia, para estos bienes, la evolución de los valores unitarios pueden reflejar simultáneamente cambio en los precios y en la composición

\footnotetext{
${ }^{46}$ El INDEC denomina capítulo a los primeros 2 dígitos de la clasificación del Sistema Armonizado, que (recordar) es la definición de industria elegida en este trabajo.
} 
de las posiciones arancelarias, lo que dificulta seriamente la utilización de los valores unitarios en la construcción de índices de precios para esta clase de bienes". En este caso, el INDEC recurre a índices de precio de exportación de los principales líderes en el comercio internacional, ${ }^{47}$ que tienen gravitación en la formación de precios internacionales de productos con alto grado de elaboración, con el objetivo de tener precios de referencia de determinado grupo de productos y evaluar la conveniencia o no de dejar a una categoría de producto en la muestra. Uno de los tantos criterios que se utilizan en la construcción del IPI se refiere a la exclusión de aquellos productos que presentan mucha volatilidad de precios pues se sospecha que existe un cambio de composición al interior de los mismos, lo que afectaría la representatividad de la muestra inicial. Una de las contribuciones de este trabajo es resaltar que la reducción del ingreso real derivada de la devaluación provoca un cambio composicional considerable. En este sentido, la utilización de este tipo de índices en contextos recesivos y/o devaluatorios es ciertamente cuestionable.

\footnotetext{
${ }^{47}$ Se recurre a índices de precios de exportación para un total de 6 capítulos formados por 5 posiciones arancelarias.
} 


\title{
SEGUNDA PARTE
}

\author{
Respuesta heterogénea de las firmas \\ frente a un shock competitivo
}




\section{Introducción}

La idea de que el comercio internacional y la globalización tienden a mejorar el bienestar de largo plazo está fuertemente arraigada en la profesión. Los factores que promueven el incremento del bienestar son la reasignación de factores productivos hacia industrias con ventajas comparativas y firmas con mayor productividad, el acceso a insumos importados y nuevos mercados de exportación por parte de las firmas domésticas, y el incremento en el excedente del consumidor a partir de canastas de consumo más variadas y menos costosas (efectos procompetitivos). Sin embargo, el proceso de reasignación no es automático porque los mercados están plagados de fricciones que dificultan/ralentizan las transiciones. En el camino se producen pérdidas (e.g. capital humano y capital físico) que se distribuyen de manera desigual entre regiones, industrias, firmas y trabajadores con distintas características. En muchas situaciones, el progreso tecnológico genera efectos comparables a los del comercio internacional. En este contexto, cobra relevancia el estudio de los efectos de la globalización y el cambio tecnológico en el mercado laboral, las posibilidades de reasignación de distintas economías, la distribución del ingreso y el bienestar general de la población. ${ }^{48}$

La superación de los costos de ajuste y la materialización de los beneficios de largo plazo depende en última instancia de la velocidad del proceso de ajuste. La efectividad del proceso de reasignación está asociada a la estructura productiva de cada economía (diversificación de la matriz, capacidad de absorción de las industrias/firmas competitivas internacionalmente), las características de la fuerza de trabajo (nivel educativo, edad, ocupación) y la naturaleza de las instituciones (flexibilidad del mercado laboral, redes de protección social, respuestas de política). La intensificación de la globalización podría profundizar la tensión entre trabajadores preocupados por sus resultados laborales de corto plazo y hacedores de política focalizados en el bienestar de largo plazo. En este contexto, estudiar qué firmas/industrias son más sensibles frente a un shock de competitividad permite medir los potenciales efectos de la globalización en los resultados del mercado laboral y analizar la conveniencia de diseñar políticas costo-efectivas que permitan suavizar el proceso de ajuste o compensar a los trabajadores desplazados.

Esta parte de la tesis está orientada a estudiar el comportamiento de las firmas

\footnotetext{
${ }^{48}$ En los últimos años se desarrolló un creciente volumen de literatura dedicada a estudiar los efectos del comercio y el cambio tecnológico en los resultados del mercado laboral (estructura del empleo y distribución del ingreso). La Sección 2 está dedicada a revisar estas contribuciones. Se recomiendan el capítulo 12 del Handbook de Labor Economics escrito por Acemoglu y Autor (2010), el trabajo de Harrison, McLaren y McMillan (2011) y más recientemente la revisión realizada por Muendler (2017).
} 
y del mercado laboral durante una etapa en la cual se produce un shock competitivo en el mercado de bienes (e.g. comercio internacional, progreso tecnológico, cambio en los hábitos de consumo, aparición de nuevos productos). La estrategia de identificación utiliza el incremento en la penetración de importaciones provenientes de un país de salarios bajos que experimentó un notable crecimiento de la productividad durante las últimas décadas como un shock de competitividad (plausiblemente exógeno) para las firmas domésticas. ${ }^{49}$ Se utilizan microdatos correspondientes al universo de firmas de manufacturas de Chile durante el período 1995-2006. La estructura de datos en panel permite controlar por muchos factores inobservables que de otro modo podrían sesgar las estimaciones. Chile es un muy buen escenario para estudiar el efecto causal de un shock competitivo en la respuesta de las firmas domésticas porque es una economía relativamente pequeña en el mercado internacional de manufacturas y se caracteriza por tener elevada apertura comercial (episodios de liberalización comercial temprana hacia fines de 1970 y principios de 1980) y un mercado laboral relativamente flexible.

Para identificar los efectos, se explota el hecho de que la penetración de importaciones Chinas (medida como el valor total de las importaciones provenientes de China dividido la absorción doméstica) creció de manera diferencial a través de las distintas industrias manufactureras de Chile (Figura 1). La PI China promedio pasó de 1,5\% en 1995 a 9,9\% en 2006. Sectores como textiles, juguetes y maquinarias enfrentaron un crecimiento elevado en los niveles de exposición a la competencia China, mientras que sectores como alimentos, papel y productos químicos tuvieron niveles y tasas de exposición considerablemente bajos.

\footnotetext{
${ }^{49}$ Esta estrategia también es utilizada por otros trabajos recientes de esta literatura (Autor, Dorn y Hanson (2013), Autor, Dorn, Hanson y Song (2014), Bloom, Draca y Van Reenen (2015) y Acemoglu, Autor, Dorn, Hanson y Price (2016)).
} 


\section{FIGURA 1}

Evolución de la penetración de importaciones Chinas por sector

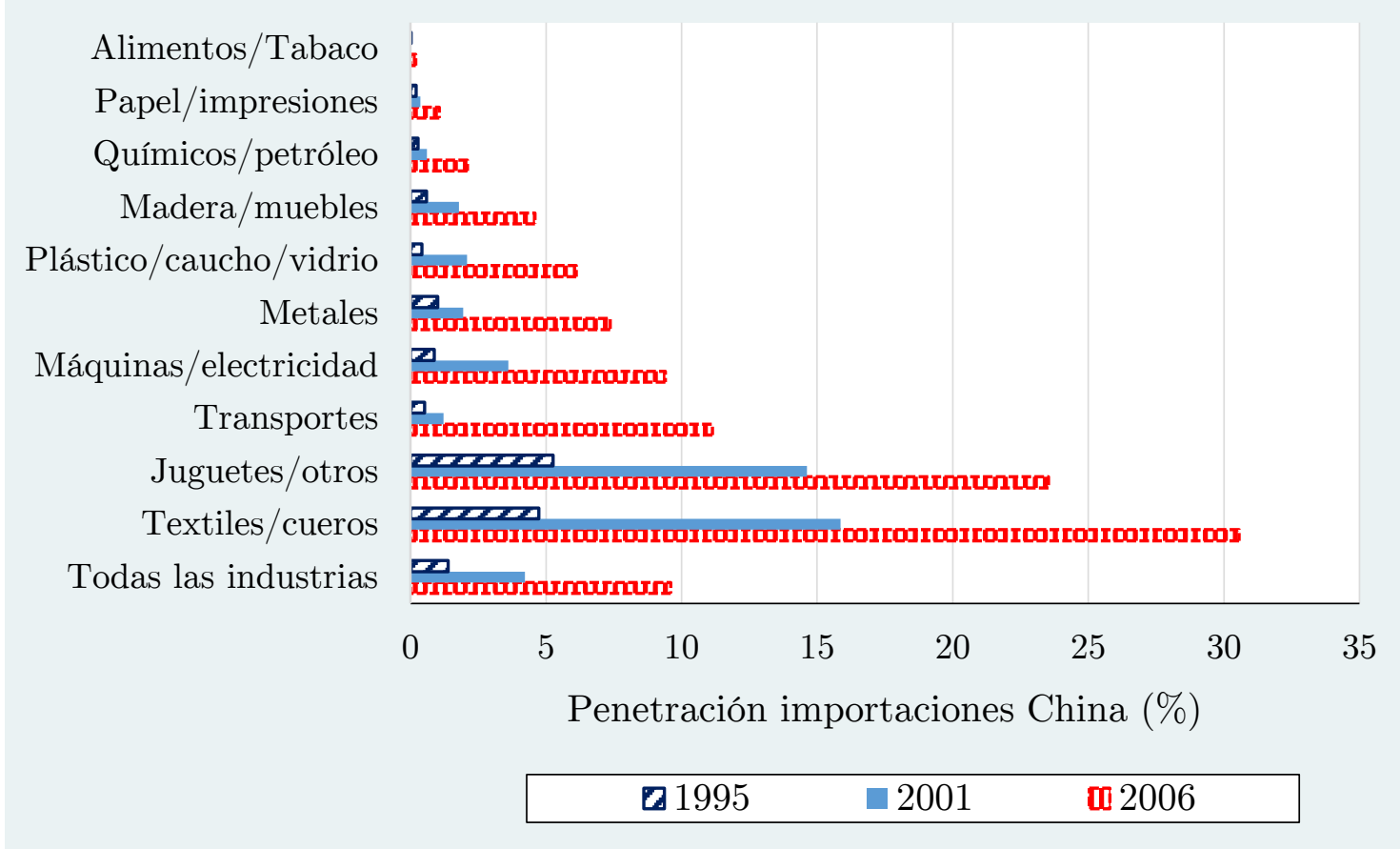

Notas. La penetración de importaciones (PI) China se mide como el valor total de las importaciones provenientes de China dividido por la absorción doméstica (producción menos exportaciones netas) y varía a nivel año-industria. Las industrias se definen a 4 dígitos de la clasificación ISIC Rev. 3 y se agrupan en 10 sectores. Cada sector incluye un subgrupo de industrias relativamente similares: Alimentos/Tabaco (14), Textiles/cueros (10), Madera/muebles (6), Papel/impresiones (7), Químicos/petróleo (6), Plástico/caucho/vidrio (4), Metales (7), Máquinas/electricidad (13), Transportes (3), Juguetes/otros (8). Fuentes: ENIA-INE y COMTRADE-UN.

El modelo desarrollado en la primera parte predice que un shock competitivo de esta índole afecta de manera diferencial la participación de mercado de las firmas domésticas en función de sus capacidades (e.g. productividad, calidad). La intuición es simple. Mayor participación de mercado satisfecha por firmas extranjeras se traduce en menor participación cubierta por firmas domésticas, ceteris paribus. La pérdida de mercado que experimenta una firma doméstica es decreciente en su nivel de productividad/calidad. Las firmas afectadas reducen sus ingresos por ventas, disminuyen la demanda laboral, y eventualmente salen del mercado. ${ }^{50} \mathrm{El}$ objetivo principal de esta parte de la tesis consiste en identificar y cuantificar la magnitud económica de un shock competitivo sobre estos resultados económicos.

La liberalización comercial genera shocks competitivos que repercuten en las firmas, los trabajadores y los resultados del mercado laboral. Sin embargo, la naturaleza endógena

\footnotetext{
${ }^{50}$ Una implicancia importante de esta predicción se relaciona con la reasignación de factores productivos que ocasiona, teniendo en cuenta que los mercados no se ajustan automáticamente. Esto forma parte de un proyecto de investigación más amplio que excede el contenido de este estudio. Idealmente, es deseable trabajar con datos de registro administrativo que permitan seguir las transiciones laborales de los trabajadores.
} 
del comercio dificulta la identificación de efectos causales. Los principales desafíos a los que se enfrenta la literatura son (i) la endogeneidad de la política comercial, y (ii) la necesidad de contar con medidas de restricción comercial que vayan más allá de los aranceles tradicionales. Las barreras no arancelarias son ampliamente utilizadas por los países en desarrollo y (cuando están medidas) suelen ser poco comparables entre países/industrias y en el tiempo. Contribuciones recientes abordan parcialmente estos inconvenientes utilizando medidas de comercio ex-post, como el ratio de penetración de importaciones provenientes de países de salario bajo (Bernard, Jensen y Schott (2006), Khandelwal (2010)). El bajo costo laboral de estos países se traslada al precio de sus bienes exportables, y el crecimiento en la participación de mercado de estas economías en terceros mercados refleja un aumento en la presión competitiva que enfrentan los productores locales. Este trabajo se nutre y pretende contribuir fundamentalmente a esta rama de la literatura. Si bien el volumen de trabajos que estudia fenómenos similares en países de altos ingresos es creciente, la evidencia para países en desarrollo es escasa y está lejos de ser concluyente.

El espectacular crecimiento de China en las últimas décadas brinda una oportunidad única para medir el efecto causal del comercio internacional en distintos resultados económicos relevantes. Buena parte del crecimiento económico de China es explicado por un fenómeno de migración masiva desde zonas rurales hacia aglomerados urbanos, crecimiento notable de la inversión en infraestructura, aumento genuino en la productividad total de los factores, y una estrategia orientada a la promoción de exportaciones que transformó a China en uno de los principales productores de manufacturas del mundo. ${ }^{51} \mathrm{El}$ crecimiento de las exportaciones explicado por estos y muchos otros factores inherentes al cambio institucional y a la transición económica de China proporciona un shock potencialmente exógeno sobre la competitividad de firmas y trabajadores de distintas partes del mundo.

Durante el período estudiado, la cantidad total de trabajadores chilenos empleados en manufacturas disminuye entre los años 1996 y 2001 y comienza a crecer hasta recuperar el nivel del año inicial en 2006. Al dividir a las industrias en dos grupos en función del nivel y/o crecimiento en la PI China a lo largo del período, las tendencias resultan ser marcadamente disímiles. Aquellas industrias más (menos) expuestas a la competencia de China se contraen más (menos) durante la recesión y se recuperan menos (más) durante

\footnotetext{
${ }^{51}$ Muchos de estos factores comienzan a operar a partir de las reformas pro-mercado de los años ochenta. Para obtener evidencia sobre la transición económica de China, consulte Naughton (1996), Hsieh y Klenow (2009), Brandt, Van Biesebroeck y Zhang (2012) y Hsieh y Ossa (2016), entre otros.
} 
la etapa ascendente del ciclo económico. Las industrias con baja exposición eran $18 \%$ más grandes en términos de empleo total en 1995, mientras que esta brecha aumenta a $96 \%$ en 2006 (Figura 2).$^{52}$ Si bien son muchos los factores que pueden explicar la divergencia entre estas industrias (e.g. cambio tecnológico, patrones de consumo, etc.), las estimaciones de este trabajo predicen que el shock competitivo originado en el crecimiento de importaciones provenientes de China explica un 30,3\% de la contracción del empleo total en las industrias expuestas.

FIGURA 2

Evolución del empleo en manufacturas

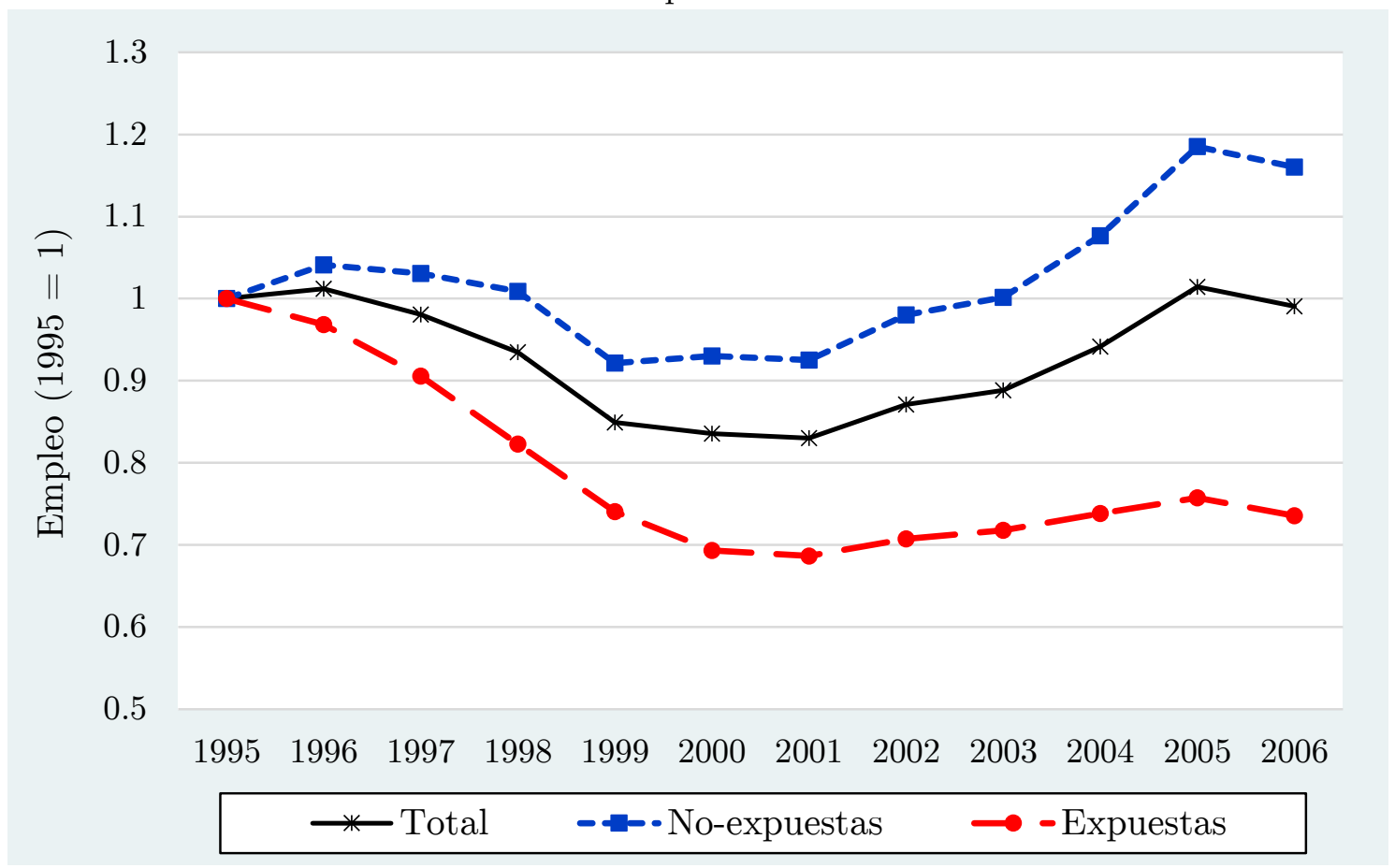

Notas. Industrias expuestas (no-expuestas) tienen penetración de importaciones Chinas por encima (debajo) del percentil 50, que equivale a $0.4 \%$. La PI China se mide como el valor total de las importaciones provenientes de China dividido por la absorción doméstica (producción menos exportaciones netas) y varía a nivel año-industria. Las industrias se definen a 4 dígitos de la clasificación ISIC Rev. 3. Número total de trabajadores normalizado a 1 en 1995. Fuentes: ENIA-INE y COMTRADE-UN.

El principal conjunto de datos utilizado es la Encuesta Nacional Industrial Anual (ENIA) realizada por el Instituto Nacional de Estadísticas de Chile (INE). La encuesta es de tipo censal con frecuencia anual. Incluye al universo de empresas manufactureras con diez o más empleados. Se cuenta con estos datos a partir del año 1995 y se elige

\footnotetext{
${ }^{52} \mathrm{La}$ muestra elegida contempla 78 sobre $u n$ total de 111 industrias, pero los resultados son robustos a trabajar con el total de industrias. La sección 5.1 comenta sobre los criterios utilizados para limpiar la base de datos, y la sección 6.4 explica las pruebas de robustez realizadas. Las industrias expuestas (no expuestas) son aquellas por encima (debajo) de la mediana del crecimiento anual promedio en la PI China a lo largo del período, que equivale a $0,2 \%$. Las industrias expuestas (no expuestas) tenían 132.415 (156.508) trabajadores en 1995 y pasan a tener 100.581 (197.139) en 2006. En total, un $14 \%$ de la fuerza laboral estaba empleada en manufacturas en 1995, fracción que se reduce a 12,7\% en 2006.
} 
limitar el período de estudio al año 2006, con el fin de evitar potenciales factores de confusión derivados del inicio de la crisis financiera global en 2007, que afectó severamente los patrones del comercio internacional en todo el mundo. El módulo principal de la encuesta incluye información sobre características de la empresa tales como el empleo total, los ingresos, la inversión, los insumos intermedios, la industria principal en donde opera, la región en la que se ubica la planta, etc. A partir de estos microdatos se construyen tres variables de resultado: (i) empleo total de la firma, (ii) ingresos por ventas de productos manufacturados, y (iii) probabilidad de salir del mercado. Luego, se estima la productividad total de los factores (TFP) a nivel firma, siguiendo el método propuesto por Ackerberg, Caves y Frazer (2015). Ello permite evaluar la hipótesis teórica de que el efecto del shock competitivo es heterogéno a través de las firmas en función de su nivel de productividad (inicial).

Se emplea un conjunto secundario de datos disponible públicamente en las estadísticas de comercio internacional de Naciones Unidas (UN-COMTRADE). Recordar que estos datos también se utilizan intensivamente en la primera parte de esta tesis. Los mismos contienen información sobre el valor anual de los flujos bilaterales de importaciones/exportaciones (medidos en dólares), cantidades, socios y códigos de producto (a 6 dígitos de la clasificación internacional del Sistema Armonizado) informados por las autoridades de más de 100 países y regiones. Al fusionar este conjunto de datos con la información de las firmas chilenas, es posible construir una medida de PI China (valor total de las importaciones provenientes de China dividido por la producción menos exportaciones netas). Los datos de COMTRADE también se utilizan para construir una variable instrumental para la PI China. Esta variable es la participación promedio de China en las importaciones de un conjunto de países de altos ingresos (como en Autor et al. $(2013,2014)$ y Bloom et al. (2015)). Las dos medidas varían a nivel año-industria (4 dígitos de la CIIU). Estos datos también se utilizan para describir el grado de presión competitiva causada por la PI China, reflejado en la diferencia (mundial) de precios promedio de los productos exportados por China en relación a productos similares exportados por otros países de salario bajo.

Se realizan regresiones a nivel industria y firma. Las estimación preferida regresa las variables de interés (empleo total de la firma, ingreso total por ventas y probabilidad de salir del mercado) en la PI China, incluyendo un amplio conjunto de variables de control a nivel firma (TFP, ratio capital/trabajo, estatus de exportador e importador) más efectos fijos por firma, región-año y sector-año. La inclusión de estos efectos fijos permite 
controlar por muchos factores de confusión inobservables invariantes en el tiempo y por shocks temporales que afectan de manera diferencial a regiones geográficamente distantes o a sectores manufactureros específicos definidos de manera amplia (10 sectores). El coeficiente que acompaña a la PI China captura el efecto de este shock competitivo en las variables de interés. Dado que la PI China es endógena porque los shocks a nivel industria que afectan a las variables de resultado (e.g. precio de los insumos, crisis macroeconómica) están correlacionados con la demanda de importaciones, esta variable se instrumenta con la participación promedio de China en las importaciones de un grupo de países de altos ingresos. El objetivo de esta variable es capturar el shock de oferta de China que le permitió ganar participación de mercado en este conjunto de países a lo largo del tiempo. La regresión de la primera etapa tiene un fuerte poder predictivo, con un coeficiente de 0.79 (0.17) y R-cuadrado de 0.79. Para que el instrumento sea válido, es necesario suponer que (i) el crecimiento de las exportaciones de China es exógeno (impulsado por el crecimiento de la TFP, la inversión en infraestructura, el fenómeno migratorio, etc.) y (ii) los shocks a la demanda de importaciones (a nivel industria) no están correlacionados entre Chile y los países de altos ingresos. La estrategia de identificación para las regresiones realizadas a nivel industria es muy similar. Esta especificación pretende capturar el efecto neto del crecimiento de la PI China en el empleo originado a partir de la variación del empleo a nivel firma (margen intensivo) como también aquel derivado de la apertura/cierre de empresas nuevas/existentes (margen extensivo). Estas regresiones se realizan para motivar la discusión y mostrar de manera más rigurosa la idea que ilustra la Figura 2: las industrias más expuestas al crecimiento en la PI China terminan siendo más pequeñas en términos de empleo total, ingresos y número de empresas activas. ${ }^{53}$

Es importante destacar que esta estrategia de identificación no tiene en cuenta los posibles efectos de equilibrio general derivados de este shock. No es posible capturar efectos indirectos entre distintas firmas que se encuentran en la parte ascendente/descendente de las relaciones comerciales. A su vez, es posible que los trabajadores desplazados de una industria expuesta busquen empleo en industrias no expuestas (efectos de reasignación positivos). También es probable que se produzcan efectos derivados de cambios en la demanda agregada (multiplicador Keynesiano). Varios trabajos recientes exploran preguntas similares en mercados laborales locales (ver por ejemplo Autor et al. (2013), Acemoglu et al. (2016) y Dix-Carneiro y Kovak (2017)). También es muy probable que se produzca un aumento en el excedente del consumidor derivado de la reducción en el

\footnotetext{
${ }^{53} \mathrm{La}$ evolución del ingreso total o el número total de firmas en función del grado de exposición a la competencia China presenta un patrón muy similar al del empleo total expuesto en la Figura 2.
} 
costo de vida y del aumento en la cantidad de variedades de productos disponibles, y que mejore la productividad o disminuyan los costos de firmas domésticas que importen insumos intermedios más baratos desde China. ${ }^{54}$

El segundo conjunto de regresiones a nivel firma tiene como objetivo explorar la existencia de efectos heterogéneos de la PI China en las principales variables de resultado, en función de la productividad de las firmas. La TFP de la firma es inobservable y presenta algunos desafíos de estimación. En primer lugar, la elección de los insumos está correlacionada con la productividad de la firma (no observada por el econometrista) y genera un problema de endogeneidad (sesgo de simultaneidad) al utilizar el estimador clásico de MCO. En segundo lugar, los datos a nivel firma suelen presentar un nivel considerable de atrición. Es probable que la salida de una firma esté correlacionada con su productividad si las firmas tienen alguna noción de su productividad futura antes de salir del mercado (sesgo de selección). ${ }^{55}$ Para estimar la TFP se sigue uno de los avances más recientes de la literatura de estimación de funciones de producción (Ackerberg, Caves y Frazer, 2015). Una vez estimada la TFP de cada firma, en la especificación principal se agrega una interacción entre la PI China y la productividad inicial de cada firma. La productividad se fija en el año inicial para controlar por la endogeneidad de la TFP a la PI China..$^{56}$

Los resultados sugieren que las firmas que operan en industrias más expuestas al crecimiento de la PI China despiden más trabajadores, reducen sus ventas de productos elaborados y enfrentan una mayor probabilidad de salir del mercado, en relación a firmas comparables que se encuentran en industrias menos expuestas del mismo sector productivo. Específicamente, un aumento en 1 p.p. en la PI China, reduce el empleo total de una firma en un $0,89 \%$ en promedio, reduce las ventas totales de la firma en un 1,87\% y aumenta la probabilidad de salir del mercado en 0,65 p.p, ceteris paribus. Las estimaciones también indican que el impacto de la PI China en el empleo, los ingresos y la probabilidad de salida disminuye cuanto mayor es la productividad inicial de la firma doméstica. El efecto marginal de la PI China sobre el empleo/ingresos/salida para una empresa ubicada en el percentil 25 de la distribución sectorial inicial de TFP es 2,69/1,66/2,12 veces mayor

\footnotetext{
${ }^{54}$ Ver por ejemplo Caliendo, Dvorkin y Parro (2018), quienes desarrollan un modelo estructural de comercio que incorpora muchos de estos canales y permite cuantificar una ganancia agregada de bienestar del shock China para EE.UU. de 0,35\%.

${ }^{55}$ Existe una extensa literatura dedicada a la estimación de funciones de producción. Para una excelente exposición sobre estos tópicos se recomienda el capítulo de Ackerberg, Benkard, Berry and Pakes (2007) en el Handkook of Econometrics, y los trabajos seminales de Olley y Pakes (1996), Levinsohn y Petrin (2003) y Ackerberg, Caves and Frazer (2015).

${ }^{56}$ Utilizando la misma estrategia de identificación, no se encuentran efectos de la PI China en la TFP de las firmas. Tampoco parece haber efectos en especificaciones que incluyen rezagos temporales.
} 
que este efecto marginal para una firma situada en el percentil 75. Estos efectos no son estadísticamente significativos para las firmas que pertenecen al quintil de productividad más alto.

En línea con las predicciones teóricas, estos resultados empíricos sugieren que las firmas más productivas están mejor preparadas para soportar un shock competitivo. Ello es consistente con la idea de que las empresas más productivas pueden escapar de la competencia proveniente de países de salario bajo porque elaboran productos de mayor calidad que no compiten directamente con los productos importados desde estos países.

La contribución principal a la literatura es fundamentalmente empírica. La evidencia para países en desarrollo es escasa y está lejos de ser concluyente. La mayor parte de la evidencia para países desarrollados no es extrapolable a países como Chile. El tamaño relativamente pequeño de la economía chilena y su alto grado de apertura comercial aumentan la credibilidad de la estrategia de identificación. La evidencia para EE.UU. no aísla por completo el hecho de que los shocks a la demanda en determinada industria estén correlacionados con la exposición comercial de dicha industria, puesto que la demanda de EE.UU. representa una fracción importante de las exportaciones Chinas (20\% en promedio durante el período estudiado). Otra contribución de este trabajo es mostrar que los shocks competitivos pueden tener efectos heterogéneos en distintas firmas en función de su nivel inicial de productividad. Estos hallazgos son especialmente relevantes para países en desarrollo que tienen problemas visibles de desempleo estructural, fricciones en el mercado laboral que dificultan las transiciones, asignación ineficiente de los factores productivos, y una fracción importante de la fuerza laboral empleada en sectores poco competitivos con muchas empresas de baja productividad.

Esta parte de la tesis se organiza de la siguiente manera. En la Sección 2 se presenta una revisión de la literatura relacionada con este trabajo. En la Sección 3 se presenta una breve discusión del contexto histórico de Chile y China, y se elabora sobre el argumento de shock competitivo. En la Sección 4 se desarrollan las predicciones teóricas en función del modelo desarrollado en la primera parte de la tesis (Sección 4 de la primera parte). Las fuentes de información y la estrategia de estimación se discuten en la Sección 5. Todos los resultados del trabajo se presentan en la Sección 6. La Sección 7 finaliza con comentarios generales y menciona algunos temas que forman parte de la agenda de investigación. Todas las figuras, cuadros y cuestiones metodológicas adicionales se presentan en el Apéndice. 


\section{Antecedentes y literatura relacionada}

Esta sección está dividida en dos partes. En la primera, se presenta una revisión de la literatura dedicada a estudiar los efectos del comercio internacional, la globalización y el progreso tecnológico en el crecimiento económico, la productividad, los resultados del mercado laboral y el bienestar general de los individuos. El objetivo general de esta revisión es abarcar la mayor cantidad de aristas posibles para que el lector se lleve una visión medianamente completa y pueda profundizar en los temas que más le interesen. En la segunda parte, se presentan las contribuciones más importantes de la literatura dedicada a la estimación de funciones de producción. Se discute el problema de identificación y la manera de abordarlo de los métodos de estimación tradicionales y más actuales.

\subsection{Efectos del comercio, la globalización y el progreso tecnológico}

El crecimiento del comercio internacional y el progreso tecnológico generan prosperidad y elevan el nivel general de vida de las sociedades. En el camino se producen grandes cambios económicos que suelen alterar la estructura productiva y los resultados del mercado laboral. Ello genera efectos heterogéneos sobre el bienestar. Si bien se espera que la mayor parte de la sociedad se beneficie, muchos individuos pueden resultar perjudicados. La dimensión distributiva, las posibilidades de reasignación y las pérdidas de capital humano que sufren los individuos desplazados son temas especialmente relevantes en la discusión actual. ${ }^{57}$

Los estudios pioneros se concentraron en estudiar el efecto del comercio internacional sobre el desarrollo económico. Las metodologías que utilizan estos trabajos no lidian correctamente con los problemas de endogeneidad clásicos. La conclusión más sensata que se desprende de esta literatura es que si bien la integración comercial parece afectar positivamente el crecimiento de largo plazo, no es una política que pueda sustituir efectivamente a otras políticas pensadas en el marco de una estrategia global de desarrollo (Rodriguez y Rodrik, 2000). ${ }^{58}$

Hacia fines de siglo, la revolución computacional y la disponibilidad creciente de

\footnotetext{
${ }^{57}$ Para una excelente revisión de la literatura se recomiendan el capítulo 12 del Handbook de Labor Economics escrito por Acemoglu y Autor (2010) y el trabajo de Harrison, McLaren y McMillan (2011). Para revisiones más recientes ver McLaren (2017) y Muendler (2017).

${ }^{58}$ En general, se trata de trabajos relativamente simples que utilizan información agregada para distintos países a lo largo del tiempo, que estudian la correlación entre alguna medida vinculada al desarrollo (e.g. crecimiento del producto per cápita) y distintas medidas de apertura comercial o restricciones comerciales. La mayoría de los trabajos se contextualizan en el marco de modelos tradicionales de comercio caracterizados por marcos teóricos muy simples.
} 
microdatos a nivel firma dieron origen a un conjunto de trabajos dedicados a estudiar los efectos del comercio internacional y del cambio tecnológico en la productividad, los salarios y el empleo de los establecimientos productivos. La literatura también se preocupó por comprender el vínculo entre el comercio internacional y el aumento en los niveles de desigualdad observados fundamentalmente a partir de la década de 1990, tanto en países desarrollados como en países en desarrollo (Goldberg y Pavcnik, 2007). Más recientemente, la literatura se ha dedicado a estudiar las respuestas de empleo asociadas al fenómeno de desindustrialización, la dinámica de las transiciones laborales, los cambios en la naturaleza del trabajo (tareas y ocupaciones) y en la estructura organizacional de las firmas (niveles jerárquicos), las respuestas salariales de trabajadores heterogéneos que se desempeñan en la misma empresa, y el emparejamiento de estos individuos con firmas que también son heterogéneas en diversas dimensiones.

La interacción entre la globalización, el progreso tecnológico y el cambio en los niveles de vida de la población dificultan la identificación de los efectos de cada uno de estos factores en los resultados del mercado laboral. Por ejemplo, el progreso tecnológico derivado de la revolución computacional y el notable crecimiento de países como China e India son eventos prácticamente contemporáneos. En una reciente revisión de la literatura, Muendler (2017) concluye que la integración al comercio internacional explica aproximadamente un cuarto de los cambios observados en el mercado laboral (en cuanto a reducción del empleo en manufacturas y a desigualdad salarial) mientras que el cambio tecnológico explica alrededor de un tercio, con heterogeneidades que dependen de la especificidad de cada contexto económico. Rodrik (2016) argumenta que la globalización y las tecnologías ahorradoras de mano de obra provocaron que muchos países en desarrollo (especialmente de América Latina) abandonasen sus procesos de industrialización con niveles de ingreso considerablemente menores que los países que se industrializaron tempranamente. Esto no ocurrió en los países asiáticos, que continuaron con el proceso industrializador. Si bien los países desarrollados perdieron empleo en manufacturas, la producción industrial mantuvo constante su participación en el producto total.

A lo largo de esta revisión se intenta poner un mayor énfasis en los trabajos de investigación más recientes (a pesar de que aún no hayan sido publicados en revistas científicas) y en los pocos trabajos realizados en el marco de países en desarrollo. Si bien se podrían utilizar distintos criterios para organizar esta revisión (e.g. pregunta de investigación, metodología, unidad de análisis, país/región, etc.), se intenta estructurar la discusión en función de los grandes temas tratados, destacando la metodología general y 
los principales hallazgos de los trabajos más relevantes.

Las metodologías más utilizadas en la literatura son (i) diferencias en diferencias, (ii) variables instrumentales, y (iii) estimaciones estructurales. Las unidades de análisis suelen ser regiones, industrias, firmas o trabajadores. Muchos trabajos explotan la disponibilidad de datos desagregados geográficamente para estudiar el impacto del comercio internacional o del cambio tecnológico en mercados locales que presentan un grado de exposición diferencial frente a dichos shocks. La metodología más extendida en este tipo de trabajos es una combinación de los métodos de diferencias en diferencias y variables instrumentales. Esta es la estrategia utilizada en esta parte de la tesis. La riqueza de este tipo análisis se sustenta en la identificación causal de parámetros estructurales relevantes. Sin embargo, las preguntas que pueden responder estos trabajos son más bien limitadas y la validez externa de los hallazgos debe ser evaluada con mucho criterio. ${ }^{59}$ Por otro lado, varios trabajos utilizan estimaciones de tipo estructural que combinan enfoques teóricos con aplicaciones empíricas. Esta es la estrategia utilizada en la primera parte de la tesis. Esta metodología permite responder preguntas más complejas y cuantificar la magnitud de distintos mecanismos. Sin embargo, la validez de este tipo de trabajos depende de la factibilidad de los supuestos realizados, de la completitud del modelo utilizado y de la correcta estimación de los parámetros relevantes.

\subsubsection{Productividad y estructura organizacional}

La mayor parte de la literatura muestra que la globalización y el comercio internacional generan efectos positivos sobre la productividad. Es importante distinguir el efecto sobre la productividad agregada derivado de la reasignación de factores productivos entre firmas que poseen distintos niveles de eficiencia (between) del efecto productividad que ocurre al interior de las unidades productivas (within). La mayoría de los trabajos estiman productividad utilizando metodologías bastante difundidas en la literatura, otros utilizan distintas variables asociadas a la productividad de la firma y unos pocos realizan innovaciones metodológicas.

Los primeros trabajos que estudian los efectos de la liberalización comercial sobre la productividad se concentran sobre todo en el efecto between (Levinsohn (1993),

\footnotetext{
${ }^{59}$ Es importante destacar que el estimador de DD identifica disparidades entre unidades de análisis (e.g. mercados laborales locales, industrias). Sin hacer supuestos adicionales, el estimador de DD no puede identificar la magnitud de los efectos que son comunes a todas las unidades de análisis (pues estos son absorbidos por los efectos fijos). El estimador de DD requiere de una interpretación cautelosa. En presencia de variables omitidas se corre el riesgo de que el estimador de DD otorgue una contribución exagerada al shock estudiado.
} 
Harrison (1994), Tybout y Westbrook (1995), Krishna y Mitra (1998), Pavcnik (2002)). ${ }^{60}$ La conclusión general de esta literatura es que el comercio internacional mejora la productividad agregada de la economía porque provoca una mejor asignación de los recursos productivos. La liberalización comercial incrementa los niveles de competencia, disminuye los precios domésticos y hace que los productores con costos más altos salgan del mercado. Melitz (2003) formaliza esta idea en un modelo teórico ampliamente utilizado en la literatura de comercio internacional.

Los trabajos más recientes se dedican a explorar los distintos mecanismos que permiten mejorar la productividad al interior de las firmas (within): (i) aprovechamiento de economías de escala; (ii) desarrollo de nuevos productos, procesos productivos y mejoras de calidad de productos existentes (quality-upgrading); (iii) cambios en la composición de la fuerza laboral (skill-upgrading); (iv) utilización de insumos intermedios y bienes de capital importados; (v) incorporación directa de tecnologías avanzadas; (vi) desplazamiento de un conjunto de actividades productivas hacia el exterior (offshoring); (vii) cambios en la composición de productos (en firmas multi-producto); (viii) modificación de la estructura organizacional de la firma (niveles jerárquicos, integración vertical); y (ix) cambios de prácticas organizacionales (supervisión, incentivos). Si bien es probable que muchos de estos factores operen de manera simultánea, la mayor parte de los trabajos suele estudiar estos fenómenos de manera aislada.

El comercio internacional suele ser un catalizador importante de las mejoras de productividad. Un hallazgo empírico ampliamente documentado en la literatura es que las firmas que exportan son más productivas que las no exportadoras. Si bien el modelo de Melitz (2003) predice este resultado, la dirección de la causalidad no está del todo clara empíricamente. Los trabajos pioneros de Bernard y Jensen (1995, 1999) para Estados Unidos, Aw, Chen y Roberts (2001) para Taiwan, y Clerides, Lach y Tybout (2000) para Colombia, México y Marruecos, muestran que las firmas más productivas se autoseleccionan en los mercados de exportación, pero no mejoran la productividad por el mero hecho de exportar. ${ }^{61}$ Esta evidencia sostiene que la causalidad

\footnotetext{
${ }^{60} \mathrm{El}$ espíritu de estos trabajos es similar al de aquellos dedicados a estudiar la relación entre comercio internacional y desarrollo (Grossman y Helpman (1991), Dollar (1992), Lucas (1993), Frankel y Romer (1999)). El grueso de los trabajos empíricos de esta literatura utiliza enfoques tipo cross-country y explora la correlación entre crecimiento económico y alguna medida de comercio internacional (e.g. apertura, barreras comerciales). Estos trabajos suelen estar plagados de insuficiencias metodológicas y empíricas (e.g. problemas de endogeneidad). Esto ha llevado a muchos autores a cuestionar la validez de esta evidencia (Edwards (1993), Rodriguez y Rodrik (2000)). A pesar de la falta de rigurosidad metodológica, esta literatura ejerció considerable influencia tanto en círculos políticos como académicos.

${ }^{61}$ Wagner (2007) llega a la misma conclusión luego de realizar una revisión de 54 trabajos empíricos publicados durante 1995-2006.
} 
va desde productividad hacia exportaciones. En este caso, las políticas de promoción de exportaciones destinadas a lograr mejoras en la productividad podrían no tener el resultado esperado. Por otro lado, trabajos más recientes muestran que las firmas que logran exportar tienden a aumentar sus niveles de productividad (Van Biesebroeck (2005), De Loecker (2007, 2013), Lileeva y Trefler (2010), Bustos (2011)). La idea es que las firmas derivan ganancias de productividad por el solo hecho de comenzar a exportar (learning by exporting) porque adquieren nuevos conocimientos y experiencia que les permite producir de manera más eficiente. Es importante notar que ambas hipótesis no son mutuamente excluyentes sino que más bien son complementarias. Algunas firmas logran exportar por ser altamente productivas y otras se vuelven más eficientes cuando comienzan a vender en otros mercados. La dominancia de una u otra hipótesis depende en última instancia de factores específicos de cada contexto.

Van Biesebroeck (2005) encuentra que los exportadores de nueve países africanos incrementan la productividad luego de entrar en los mercados de exportación, siendo la escala de producción un factor importante para explicar dichas mejoras. En la misma línea, De Loecker (2007) muestra que las firmas Eslovenas que comienzan a exportar mejoran la productividad, siendo mayor el incremento cuando exportan sus productos a países de altos ingresos (Europa Occidental y Norte América). En un trabajo relacionado, Albornoz, Pardo, Corcos y Ornelas (2012) plantean un modelo de experimentación que permite explorar la relación entre los costos fijos de exportar, el aprendizaje obtenido al ingresar en un nuevo destino y la dinámica de entrada/salida/expansión de las firmas. Utilizando datos de Argentina muestran que los nuevos exportadores comienzan siendo pequeños, pero en caso de sobrevivir, crecen y se expanden rápidamente a través de distintos destinos. Bustos (2011) estudia el impacto de un tratado comercial (Mercosur) en la utilización de tecnología de las firmas Argentinas. Los resultados muestran que las firmas en industrias que experimentan una mayor reducción de tarifas por parte de Brasil tienen mayor probabilidad de convertirse en exportadoras, y aquellas firmas que ya exportaban aumentan la inversión en tecnologías a partir del incremento de los ingresos provenientes de las exportaciones, con efectos más pronunciados para las firmas de tamaño y productividad intermedia. El marco teórico utilizado parte del modelo de Yeaple (2005) pero incorpora heterogeneidad entre firmas que difieren según su productividad. Dado que existe un costo fijo de incorporar tecnología, el modelo predice que una reducción en los costos de comercio provoca una reasignación de mercado hacia las firmas exportadoras que puede inducirlas a utilizar tecnologías más avanzadas. 
Lileeva y Trefler (2010) utilizan microdatos firma-producto para estudiar el efecto de un mayor acceso al mercado internacional en las actividades de innovación de las firmas canadienses. Explotan el acuerdo de libre comercio Canadá-Estados Unidos y muestran que las firmas que comenzaron a exportar o aumentaron sus niveles de exportación a partir de la reducción de tarifas incrementaron la productividad laboral, la innovación de productos y la adopción de tecnologías más avanzadas. Los aumentos de productividad son más pronunciados para las firmas menos productivas que comenzaron a exportar a partir del acuerdo. ${ }^{62}$ Los autores explican que esta "selección negativa" se produce por la complementariedad que existe entre exportar y mejorar la productividad, y elaboran un modelo donde existe heterogeneidad no solo en la productividad inicial (a la Melitz 2003) sino también en las ganancias de productividad derivadas de las actividades de innovación de las firmas. Con un enfoque similar, Verhoogen (2008) desarrolla un modelo donde el crecimiento del comercio con países desarrollados aumenta la producción de bienes de alta calidad, porque los consumidores de estos países tienen una valoración más alta de la calidad. El autor muestra que la devaluación del peso mexicano en 1994 generó un aumento exógeno en las exportaciones que ocasionó un aumento en la calidad de los productos exportados (quality-upgrading) y una mejora en la tecnología utilizada, lo que a su vez provocó un aumento en la demanda de trabajo calificado (skill-upgrading) que se trasladó a la prima salarial. ${ }^{63}$

Utilizando datos en panel de firmas de doce países europeos, Bloom, Draca y van Reenen (2015) muestran que las importaciones Chinas aumentaron las tasas de cambio tecnológico a partir de innovaciones/patentes y la adopción de nuevas tecnologías de información que contribuyeron a aumentar la productividad de las firmas expuestas. ${ }^{64}$ Estas firmas también aumentaron el gasto en investigación y desarrollo, la calidad de gerenciamiento, las habilidades de sus trabajadores, redujeron los precios y también la rentabilidad. Por otro lado, la competencia China también reduce el empleo y la probabilidad de supervivencia de las firmas de baja tecnología. Ambos efectos (innovación y selección) provocan una mejora tecnológica en las industrias más afectadas por la

\footnotetext{
${ }^{62}$ Trefler (2004) es uno de los primeros trabajos en estudiar los efectos de un acuerdo de libre comercio en la productividad agregada de la industria, destacando el trade-off entre los costos de ajuste de corto plazo (firmas que se contraen y desplazan trabajadores) y las ganancias de largo plazo (firmas más eficientes que benefician al consumidor).

${ }^{63}$ Varios trabajos muestran que los episodios de liberalización comercial en países en desarrollo provocaron un aumento en la demanda relativa de trabajo calificado que explica parte del aumento de la desigualdad (Goldberg y Pavcnik, 2007).

${ }^{64} \mathrm{La}$ estrategia de identificación utilizada en este trabajo explota la incorporación de China a la Organización Mundial de Comercio en Diciembre de 2001 y la eliminación paulatina de cuotas de importación sobre un conjunto de productos textiles en el marco del acuerdo Multi-Fiber Agreement. El trabajo de Utar (2018), comentado más adelante, utiliza una estrategia de identificación muy similar.
} 
competencia China. Es por ello que en estas industrias también se produce un proceso de reasignación de trabajadores hacia aquellas firmas más avanzadas tecnológicamente. La magnitud de los resultados es tal que el efecto China parecería explicar un $15 \%$ de la mejora tecnológica ocurrida en Europa durante el período 2000-2007. Bernard, Jensen y Schott (2006) muestran resultados muy similares para firmas de EE.UU. en respuesta a un aumento en las importaciones provenientes de países de salario bajo, utilizando distintas variables para aproximar la tecnología de la firma (e.g. intensidad de capital). En otro trabajo relacionado, Utar y Torres-Ruiz (2013) encuentran que las maquiladoras mexicanas que enfrentaron mayor competencia China en sus exportaciones hacia Estados Unidos realizaron mejoras significativas de productividad y la intensidad de uso de trabajo calificado.

También existen algunas contribuciones teóricas que señalan que el efecto del comercio internacional en la innovación es a priori indeterminado. Por ejemplo, Eaton y Kortum (2001) muestran que el efecto neto del comercio en la innovación está indeterminado. El comercio aumenta el tamaño efectivo del mercado y fomenta el proceso innovador, pero a la vez incrementa la competencia por el aumento de las importaciones, lo cual desalienta la innovación. Aghion, Bloom, Blundell, Griffith y Howitt (2005) desarrollan un modelo donde la competencia en el mercado de productos estimula el crecimiento de la productividad y el gasto en investigación y desarrollo si las firmas (y su industria) están cercanas a la frontera productiva mundial, mientras que ocurre lo contrario para firmas e industrias más rezagadas. A su vez, dado que la competencia reduce los márgenes de ganancia y por tanto las cuasirentas derivadas de la innovación, el efecto de la competencia en los incentivos a innovar es inherentemente ambiguo. Los autores muestran evidencia a favor de una relación de U-invertida entre innovación y competencia. ${ }^{65}$

Un factor comunmente asociado a la globalización es el aumento en las actividades de producción coordinadas a través de regiones geográficamente distantes (offshoring). Buena parte del fenómeno se explica por las actividades productivas de corporaciones multinacionales que están insertas en cadenas globales de valor. La literatura teórica también contempla nuevas formas de offshoring vinculadas al comercio de tareas (Grossman y Rossi-Hansberg (2008), Rodriguez-Clare (2010)). La idea es que los

\footnotetext{
${ }^{65} \mathrm{El}$ lector interesado puede recurrir a las contribuciones pioneras de Grossman y Helpman (1991) sobre la relación entre comercio internacional, innovación productiva y crecimiento. También se recomiendan los trabajos de Dani Rodrik sobre competencia imperfecta, economías de escala, comercio internacional e innovación.
} 
insumos intermedios que se comercian internacionalmente contienen un conjunto de tareas asociadas a distintas actividades de producción y de prestación de servicios. En este contexto, las firmas podrían disminuir el costo de producción al asignar un conjunto de actividades más rutinarias y menos intensivas en conocimiento a trabajadores del exterior. En general, las actividades intensivas en conocimiento (e.g. marketing, diseño, innovación) siguen siendo realizadas en las casas matrices. Estos fenómenos no solo afectan los flujos internacionales de bienes y capitales sino que también alteran la demanda relativa de trabajadores con distintos niveles de calificación. Estas explicaciones también aportan a la comprensión del fenómeno de "desindustrialización" ocurrido en las últimas décadas en la mayor parte de los países desarrollados y en buena parte de los países en desarrollo.

De Loecker, Goldberg, Khandelwal y Pavcnik (2016) utilizan datos de firmas multi-producto de la India para estimar el efecto de la liberalización comercial en los costos marginales de las firmas. Asumen que cada firma tiene determinado nivel de eficiencia técnica, pero elabora distintos productos con costos marginales diferentes. La liberalización comercial reduce los costos marginales en mayor medida para los productos que tienen mayor participación en los ingresos de las firmas. Sin embargo, las firmas trasladan una parte menor de la reducción de costos a los precios finales y la mayor parte se destina a aumentar los márgenes de ganancia. El trabajo reciente de Dhyne, Petrin, Smeets y Warzynski (2017) encuentra resultados muy similares, pero introduce alguna innovación metodológica en la estimación de la función de producción de firmas multi-producto. Los autores utilizan microdatos correspondientes al censo de manufacturas de firmas de Bélgica para analizar el efecto del incremento en la competencia China entre 1997 y 2007 en la eficiencia técnica de las firmas domésticas. Los resultados muestran que un aumento de $1 \%$ en la participación China en las importaciones provoca un incremento de 1,05\% en la eficiencia técnica con que se producen los mejores dos productos de la firma y un incremento de 0,65\% para el resto de los productos. En cuanto a la magnitud de estos resultados, el aumento en la competencia China habría generado una ganancia productiva promedio de $2,5 \%$ anual del valor total de producción de manufacturas del período. ${ }^{66}$

Otra rama de la literatura que está creciendo en los últimos años estudia los efectos del comercio internacional sobre la estructura organizacional de las firmas. La organización

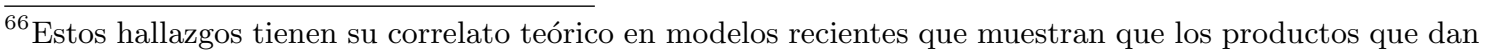
mayor ganancia a las firmas multi-producto son elaborados con mayor eficiencia (Eckel y Neary (2010), Bernard, Redding y Schott (2010, 2011), Mayer, Melitz y Ottaviano (2014)). Extensiones recientes de estos modelos muestran que las firmas responden a la liberalización comercial aumentando el gasto en actividades de investigación y desarrollo que permiten aumentar la eficiencia técnica de los procesos productivos o aumentar la calidad de los productos elaborados (Dhingra (2013), Eckel, Iacovone, Javorcik y Neary (2015)).
} 
de la firma afecta la productividad, el empleo y los salarios de los trabajadores que se desempeñan en distintos niveles jerárquicos. En el modelo de Caliendo y Rossi-Hansberg (2012) la productividad de una firma depende de la forma en que se organiza la producción en función de la demanda que enfrenta por sus productos. Las firmas enfrentan demandas heterogéneas, utilizan trabajo y conocimiento para producir y los empresarios eligen la cantidad de niveles jerárquicos (layers) que determinan el área de control de los distintos agentes (función de su capacidad de resolución de conflictos). A partir de una calibración del modelo para EE.UU. muestran que incorporar endogeneidad en la estructura organizacional de la firma aumenta las ganancias de comercio en $41 \%$ (en comparación al modelo estándar). En un trabajo relacionado, Caliendo, Mion, Opromolla y Rossi-Hansberg (2017) utilizan datos de Portugal para evaluar empíricamente las predicciones del modelo anterior. Los autores muestran que la reorganización de las firmas es una fuente importante para explicar las ganancias agregadas de productividad. La reorganización reduce los costos marginales (y los precios) de la firma, aumentando la productividad física a través de una reducción en el costo variable promedio. Como resultado, la productividad de ingresos se reduce y la productividad física aumenta cuando las firmas agregan niveles jerárquicos. ${ }^{67}$ En un trabajo para Francia, Spanos (2016) muestra que las firmas en mercados más grandes tienen más niveles y son más productivas, y que entre $8 \%$ y $40 \%$ de las diferencias en productividad entre regiones son explicadas por firmas con estructuras organizacionales más complejas.

Por último, es importante destacar una rama de la literatura de organización industrial dedicada a estudiar cuestiones asociadas a la productividad de las firmas y el crecimiento de determinadas industrias (e.g. cambio tecnológico, competencia, integraciones, prácticas organizacionales, etc.). Por ejemplo, en un trabajo seminal en la literatura de estimación de funciones de producción, Olley y Pakes (1996) estudian el efecto de la desregulación en la reestructuración ocurrida en la industria de equipos de telecomunicaciones de EE.UU. La desregulación afectó fuertemente la dinámica de las firmas y provocó una reasignación de capital hacia las firmas más productivas. Más recientemente, Collard-Wexler y De Loecker (2015) analizan el impacto de una nueva tecnología para producir acero en la competencia y en la productividad agregada de este sector. Holmes y Schmitz (2010) revisan la literatura de organización industrial dedicada a estudiar estos temas, y Syverson (2011) realiza una excelente discusión sobre los potenciales

\footnotetext{
${ }^{67}$ Este trabajo parte de las contribuciones teóricas sobre jerarquías basadas en el conocimiento propuestas por Rosen (1982) y Garicano (2000). Los trabajos de Caliendo, Monte y Rossi-Hansberg (2017) para Francia, y Friedrich (2018) para Dinamarca, estudian el efecto del comercio internacional en la estructura organizacional de las firmas y su impacto en la desigualdad salarial al interior de las mismas.
} 
determinantes de la productividad a nivel industria y a nivel firma.

\subsubsection{Salarios y distribución del ingreso}

El comercio, la globalización y el progreso tecnológico afectan la distribución del ingreso porque alteran la oferta/demanda relativa de trabajadores con distintas características, modifican la eficiencia técnica y la estructura organizacional de las firmas y afectan la productividad laboral de los individuos de manera heterogénea. Dado que una parte importante del salario se explica por la productividad marginal del trabajador, los canales por los cuales el comercio y la tecnología afectan la distribución salarial están directamente relacionados con los distintos mecanismos que afectan la productividad (quality/skill upgrading, utilización de nuevas tecnologías, offshoring, cambios en la composición productiva/laboral, modificación de la estructura organizacional de la firma, etc.). En el estudio de estas cuestiones se funden diversas ramas de la literatura.

El aumento generalizado de la desigualdad durante los 1980s y 1990s despertó el interés de la profesión por el fenómeno distributivo. La literatura de economía laboral plantea dos explicaciones tradicionales: (i) el fenómeno de cambio tecnológico sesgado, que aumenta la productividad marginal del trabajo calificado y por tanto la prima salarial; y (ii) la erosión de instituciones laborales que protegían los ingresos de trabajadores de salario medio y bajo (e.g. sindicatos, salario mínimo). ${ }^{68}$ La literatura también señala factores complementarios asociados a la globalización, la transición demográfica, el cambio en la composición de la fuerza laboral y la evolución de la oferta relativa de trabajadores educados. También existen modelos de selección, aprendizaje, capital humano y agencia que arrojan predicciones sobre desigualdad salarial. ${ }^{69}$

La literatura de comercio internacional también se preocupa por comprender este fenómeno. Los primeros trabajos están fuertemente influenciadas por los enfoques teóricos clásicos (Factores Específicos y Heckscher-Ohlin). Estos modelos generan predicciones sobre el salario relativo de trabajadores que pertenecen a distintos grupos en función de sus habilidades, ocupaciones y sectores productivos. El modelo de Heckscher-Ohlin predice que la apertura comercial aumenta el salario relativo del factor relativamente abundante porque

\footnotetext{
${ }^{68}$ Algunos ejemplos de esta fructífera literatura son Katz y Murphy (1992), Berman, Bound y Griliches (1994), Acemoglu (1998), Autor, Krueger y Katz (1998), Card y Lemieux (2001), Autor, Levy y Murnane (2003). Katz y Autor (1999) y Acemoglu (2002) presentan revisiones de esta literatura. Mientras que Berman, Bound y Machin (1998) y Machin y van Reenen (1998) realizan comparaciones internacionales. ${ }^{69}$ Para una revisión de las teorías y modelos tradicionales se recomienda el capítulo de Neal y Rosen en el Handbook of Income Distribution (2000) editado por Atkinson y Bourguignon. Para revisiones más recientes, se recomienda la edición de 2015 de este mismo manual.
} 
el país se especializa en la industria que utiliza intensivamente dicho factor (aumenta su demanda y se incrementa su retribución). ${ }^{70}$ En contra de las predicciones generales de esta teoría, la evidencia muestra que la prima salarial (y la desigualdad en general) aumenta simultáneamente en países desarrollados y en desarrollo (ver las revisiones en Feenstra y Hanson (2003) y Goldberg y Pavcnik (2007)). La falta de soporte empírico de la teoría clásica se explica en parte por la ausencia de heterogeneidad entre firmas.

Muchos trabajos empíricos documentan diferencias significativas y persistentes en la productividad de las firmas que pertenecen a una misma industria. Estas diferencias están correlacionadas con el grado de inserción internacional de las firmas. Las más productivas tienen una mayor probabilidad de ser exportadoras (Clerides, Lach y Tybout (2000); Bernard y Jensen $(1995,1999))$ y el hecho de comenzar a exportar genera ganancias de productividad (Van Biesebroeck (2005); De Loecker (2007, 2013)). Las actividades de importación/exportación se concentran en un pequeño número de firmas que suelen ser más grandes y más productivas, tienden a adoptar tecnologías más avanzadas, están más integradas globalmente, son más intensivas en trabajo calificado y pagan salarios más altos (Bernard, Jensen y Redding (2007), Verhoogen (2008), Bustos (2011)). ${ }^{71}$ A su vez, los países se especializan en distintas etapas de la producción de un bien, lo cual incrementa las actividades de offshoring, el intercambio comercial de bienes intermedios y la demanda relativa (y por ende los salarios) de distintos trabajadores (Hummels, Ishii y Yi (2001); Yi (2003); Feenstra y Hanson (2003)). Estos hechos estilizados provocan un cambio de paradigma en la literatura de comercio internacional, que comienza a plantear sus interrogantes en un marco que tiene en cuenta que las firmas (y los trabajadores) son heterogéneas en diversas dimensiones. Las contribuciones teóricas incorporan algunos de estos hechos estilizados y permiten racionalizar la dispersión de productividad entre firmas de una misma industria y la mayor productividad de las firmas exportadoras (Eaton y Kortum (2002), Bernard, Eaton, Jensen y Kortum (2003), Melitz (2003)). Sin embargo, estos modelos asumen trabajadores homogéneos y competencia perfecta en el mercado laboral, de modo que los salarios pagados por la firma están desconectados de la distribución de productividad.

Algunos trabajos comienzan a explorar la relación entre comercio y desigualdad

\footnotetext{
${ }^{70}$ En la versión más simple del modelo $(2 \times 2 \times 2)$, asumiendo que el factor abundante del país rico (pobre) es el trabajo calificado (no calificado), el comercio entre ambos países debería aumentar la prima salarial por calificación en el país rico y disminuirla en el país pobre.

${ }^{71}$ Verhoogen (2008) estudia las implicancias del mecanismo de mejora en la calidad sobre la desigualdad salarial intra-industrial en México. Un shock devaluatorio hace que las firmas más productivas aumenten sus exportaciones, mejoren la calidad y aumenten los salarios (en relación a las firmas menos productivas de la misma industria).
} 
laboral incorporando variantes a los modelos clásicos de comercio para tener en cuenta la heterogeneidad entre firmas y trabajadores. Por ejemplo, en Yeaple (2005) la heterogeneidad entre firmas surge de la decisión de utilizar tecnologías diferentes y contratar trabajadores con distintas habilidades. Ohnsorge y Trefler (2007) estudian la relación entre comercio y desigualdad en modelos competitivos de asignación, y muestran que las diferencias internacionales en la distribución de "paquetes de habilidades" que ofrecen los trabajadores (e.g. cuantititivas, comunicacionales) tiene implicancias para el comercio internacional, la estructura industrial y la distribución del ingreso. Grossman y Helpman (2007) plantean que la comparación salarial entre trabajadores de una misma firma puede afectar la estructura organizacional, la productividad y las decisiones de desplazar actividades de salario bajo hacia el exterior. Helpman, Itskhoki y Redding (2010) desarrollan un modelo para estudiar los efectos del comercio sobre la distribución salarial y el desempleo, incorporando reasignación de recursos productivos intra-industria, fricciones en el mercado laboral y diferencias en la composición laboral entre firmas. Burstein y Vogel (2017) plantean un modelo cuantitativo de Heckscher-Ohlin multi-país al que incorporan diferencias de productividad entre firmas de un mismo sector (derivadas de la intensidad de uso de habilidades) y diferencias de abundancia de habilidades entre países. Los resultados de parametrizar este modelo para 60 países utilizando firmas, sectores y datos agregados muestran que la reducción de los costos de comercio genera un aumento de salario real para los dos grupos de trabajadores en todos los países y aumenta la prima salarial en la mayoría de los países estudiados. ${ }^{72}$ Los resultados de Dix-Carneiro y Kovak (2017) sobre la liberalización comercial de Brasil contrastan con los anteriores. Los autores muestran que la prima salarial se reduce en las regiones más expuestas a la liberalización. Para racionalizar este resultado desarrollan un modelo de factores específicos con dos tipos de trabajadores que se complementan entre ellos y con los factores específicos, y que son móviles entre industrias de una misma región.

El efecto del desplazamiento de actividades hacia el exterior (offshoring) sobre los salarios es a priori ambiguo en términos teóricos. Por un lado, el hecho de importar un insumo (o contratar un trabajador del exterior) podría reemplazar una tarea previamente realizada por un trabajador doméstico, lo que señala un potencial efecto desplazamiento y un efecto negativo sobre el salario (Feenstra y Hanson $(1996,1997)$ ). Sin embargo, la posibilidad de utilizar insumos importados o contratar trabajadores

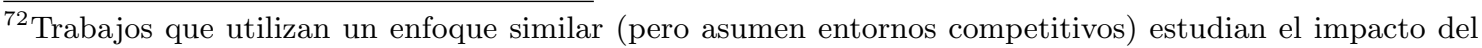
comercio en la prima salarial cuando el capital y el trabajo calificado son complementarios (Burstein, Cravino y Vogel (2013), Parro (2013))
} 
extranjeros podría reducir el costo de la firma o incrementar su productividad, generando aumentos en el producto, el empleo y los salarios (Amiti y Konings (2007), Grossman y Rossi-Hansberg (2008), Costinot y Vogel (2010), Goldberg, Khandelwal, Pavcnik y Topalova (2010)). Utilizando datos administrativos de firmas-trabajadores e información sobre flujos comerciales a nivel firma-producto-país para Dinamarca, Hummels, Jørgensen, Munch y Xiang (2014) encuentran que un incremento en las actividades de offshoring aumenta (disminuye) el salario de los trabajadores de calificación alta (baja), mientras que exportar aumenta el salario de todos los trabajadores. El efecto neto del comercio en los salarios es heterogéneo a pesar de que los trabajadores tengan la misma calificación, pues depende de la exposición al comercio de sus empleadores. ${ }^{73}$ Para trabajadores con calificación similar, el cambio en los salarios varía en función de las características de las tareas desarrolladas. Aquellos que desarrollan tareas rutinarias en sus ocupaciones experimentan las mayores pérdidas salariales en respuesta al offshoring. En cambio, quienes utilizan conocimientos matemáticos, sociales y de lenguaje obtienen aumentos salariales. En línea con estos hallazgos, Ebenstein, Harrison, McMillan y Phillips (2014) encuentran que los trabajadores de EE.UU. que cambian de ocupación como consecuencia de la globalización enfrentan pérdidas salariales del orden del 12-17\%. Amiti y Davis (2011) muestran que el efecto de la liberalización comercial sobre el salario de los trabajadores depende del nivel de globalización de la firma en la cual trabajan. Utilizando datos del censo de firmas manufactureras de Indonesia durante 1991-2000, muestran que la liberalización en bienes finales disminuye los salarios en firmas que compiten con las importaciones pero aumenta los salarios en las firmas exportadoras, mientras que la liberalización en insumos intermedios aumenta los salarios en las firmas que utilizan insumos importados y lo reduce en aquellas firmas que se sólo se abastecen domésticamente.

Trabajos recientes muestran que lo que ocurre al interior de las firmas explica buena parte del aumento en la desigualdad (Song, Price, Guvenen, Bloom y von Watcher (2017), Mueller, Oiumet y Simintzi (2017), Friedrich (2018)). ${ }^{74}$ A su vez, existe un

\footnotetext{
${ }^{73}$ Estos resultados sugieren que las actividades de offshoring tienden a aumentar la prima salarial dentro de una firma, en línea con hallazgos previos a nivel industria (Feenstra y Hanson (1997, 1999)). Y complementan los trabajos teóricos y empíricos que enfatizan un aumento en los niveles de desigualdad intra-grupo en respuesta a la liberalización comercial (Goldberg y Pavcnik (2007), Helpman, Itskhoki y Redding (2010)).

${ }^{74}$ Song, Price, Guvenen, Bloom y von Watcher (2017) utilizan datos de registro administrativo para Estados Unidos durante el período 1978-2013, y señalan que un tercio del aumento en la varianza de los ingresos se explica por lo que ocurre dentro de las firmas. Realizan una descomposición del incremento en la desigualdad al interior de las firmas, cuyo resultado señala que (i) el aumento del emparejamiento de trabajadores-firmas de salario alto, y (ii) el incremento de la segregación entre trabajadores similares entre firmas, tienen una magnitud similar. Friedrich (2018) muestra que las diferencias salariales entre
} 
considerable grado de heterogeneidad entre firmas de un mismo sector y trabajadores que son observacionalmente equivalentes pero trabajan en distintas firmas, incluso dentro de una misma industria (Card, Heining y Kline (2013), Helpman, Itskhoki, Muendler y Redding (2017)).

La literatura sobre jerarquías organizacionales también contribuye a entender la evolución de la estructura salarial que acompaña la expansión de las firmas. Caliendo y Rossi-Hansberg (2012) argumentan que las jerarquías están basadas en el conocimiento, mientras que Chen (2017) sostiene que están basadas en el sistema de incentivos. Ambos modelos sugieren que el número óptimo de niveles (layers) aumenta con la escala de producción. El gerente/director representa un costo fijo que permite reducir el costo marginal de la firma. Los gerentes reciben salarios más altos debido al efecto productividad que generan sobre los trabajadores de menores niveles. Sin embargo, el salario de estos trabajadores disminuye porque los gerentes solucionan problemas que requieren un menor nivel de conocimiento por parte de estos trabajadores, o bien porque las tareas de monitoreo que realizan sustituyen mecanismos de pago por incentivos diseñados para fomentar el esfuerzo de estos trabajadores. Como resultado, ambas teorías predicen un aumento en la desigualdad dentro de la firma a medida que se incorporan nuevos niveles jerárquicos.

Caliendo, Monte y Rossi-Hansberg (2015) es el primer trabajo empírico que realiza un mapeo entre ocupaciones laborales y niveles jerárquicos dentro de la firma. Utilizando datos de registro administrativo empleador-empleado para Francia, muestran que las firmas manufactureras presentan una organización jerárquica consistente con la teoría. La cantidad (el salario) de trabajadores se relaciona negativamente (positivamente) con el nivel jerárquico. A su vez, las firmas que se expanden moderadamente pagan salarios más altos a los trabajadores de todos los niveles, mientras que las firmas que crecen fuertemente agregan jeraquías y pagan salarios más bajos a los trabajadores de niveles preexistentes. Utilizando datos administrativos para Dinamarca entre 1999 y 2008, Friedrich (2018) muestra que distintos shocks de comercio internacional afectan la estructura organizacional al modificar la escala de producción y ello afecta la desigualdad al interior de las firmas. Agregar una jerarquía aumenta en 5,2\% la brecha salarial entre los percentiles 90-50. La riqueza de sus datos le permite evaluar las implicancias de las dos teorías mencionadas previamente (conocimiento versus incentivos). Los resultados muestran que el cambio

niveles jerárquicos al interior de las firmas representa un componente sistemático de la desigualdad global, de magnitud comparable a las diferencias salariales entre firmas. 
en la estructura salarial se explica en partes iguales por el ajuste en los niveles de conocimiento de los trabajadores (cambio composicional) y por cambios en el salario residual que no están asociados a las características de los trabajadores. Caliendo, Monte y Rossi-Hansberg (2017) estudian el efecto de exportar en la estructura organizacional de la firma, utilizando datos administrativos empleador-empleado de Francia. Muestran que las firmas que entran en el mercado de exportación y se expanden considerablemente, se reorganizan agregando niveles jerárquicos, contratando más trabajadores y pagando, en promedio, salarios más bajos a los trabajadores de los niveles jerárquicos preexistentes. En cambio, las firmas que comienzan a exportar pero se expanden poco, no se reorganizan y pagan salarios promedio más altos en todos los niveles.

\subsubsection{Empleo y transiciones laborales}

La liberalización comercial, la globalización y el cambio tecnológico producen modificaciones en la estructura productiva de las economías y catalizan procesos de reasignación de los factores productivos. El estudio de estos fenómenos forma parte de una fructífera y creciente literatura que se dedida a estudiar las fricciones inherentes al entorno del mercado laboral y la dinámica de las transiciones laborales de los trabajadores desplazados hacia otras firmas/sectores o hacia el desempleo.

Una rama tradicional de esta literatura se dedica a estudiar el impacto que provoca la penetración de importaciones provenientes de países de salario bajo en las firmas e industrias expuestas (Revenga (1999), Bernard, Jensen y Schott (2006), Khandelwal (2010), Hummels et al. (2014)). Siguiendo esta línea de investigación, los trabajos de Autor, Dorn y Hanson (2013) y Autor, Dorn, Hanson y Song (2014) utilizan la penetración de importaciones de China como un shock exógeno derivado de mejoras de competitividad inherentes a la transformación productiva experimentada por China en las últimas décadas. Esta economía llevó a cabo un conjunto de reformas institucionales pro-mercado que le permitieron aumentar la productividad total de sus factores de manera notable, y la posicionaron como una de las principales productoras de manufacturas a nivel global (Brandt, Van Biesebrock y Zhang (2012), Hsieh y Ossa (2016)).

Autor, Dorn y Hanson (2013) estudian el efecto del crecimiento en la penetración de importaciones de China entre 1990 y 2007 en los resultados del mercado laboral a través de distintas zonas de conmutación de Estados Unidos que poseen distintos patrones iniciales de especialización industrial. Encuentran que aquellas zonas más expuestas al 
crecimiento en las importaciones de China sufren un aumento del desempleo, reducción de la participación laboral y dismunución del salario promedio (en relación a zonas menos expuestas). ${ }^{75}$ En equilibrio parcial, este efecto explica al menos un cuarto de la reducción agregada del empleo en manufacturas de EE.UU. En un trabajo que utiliza una estrategia de identificación similar, Dauth, Findeisen y Suedekum (2014) estudian el efecto del crecimiento del comercio entre Alemania y los países del Este (China y Europa del Este) entre 1988 y 2008. A diferencia de los hallazgos para EE.UU., la penetración China tiene efectos prácticamente nulos sobre el empleo, porque Alemania ya era intensivo en importaciones en las industrias más penetradas por China (como textiles), por lo que China desplazó importaciones de terceros países (como Italia y Grecia) en lugar de desplazar a productores locales. En cambio, el crecimiento en las importaciones de Europa del Este causó pérdidas de empleo significativas en regiones especializadas en industrias que compiten con dichas importaciones (tanto en manufacturas como en otros sectores). ${ }^{76}$ Sin embargo, en términos agregados, el efecto neto de la integración de Alemania con Europa del Este es positivo, porque los mercados locales especializados en industrias orientadas a las exportaciones experimentaron notables ganancias de producción y un fuerte crecimiento del empleo.

Acemoglu, Autor, Dorn, Hanson y Price (2016) utilizan la matriz insumo-producto para estimar efectos indirectos (sobre proveedores y compradores) del crecimiento en la penetración de importaciones Chinas en EE.UU, explotando la composición industrial inicial (en términos de empleo) de las distintas zonas de conmutación. Sus estimaciones muestran que existe un efecto negativo y significativo de magnitud considerable en las industrias que proveen insumos a las industrias de manufacturas expuestas, mientras que los efectos para las industrias que compran bienes manufacturados a las industrias expuestas son imprecisas e inestables. Los autores enfatizan la posibilidad de que existan efectos de reasignación de los trabajadores desplazados y efectos de demanda agregada (derivados de las pérdidas salariales) al nivel de las distintas zonas de conmutación. Por ejemplo, la decadencia de determinada industria en una región puede ocasionar el crecimiento de una industria similar en otras regiones, de modo que el efecto total podría estar sobrestimado. Sus resultados muestran que el crecimiento en la penetración China entre 1999 y 2001 provocó una reducción del empleo total de 2,4 millones, mayor a la

\footnotetext{
${ }^{75}$ En línea con estos resultados, también encuentran que el crecimiento en la penetración de importaciones Chinas provoca un incremento en el pago de seguros por desempleo, discapacidad, retiro y salud en las zonas con mayor exposición.

${ }^{76}$ Los autores explican que la caída del telón de acero hacia fines de 1980 produce una transformación productiva y notables aumentos de productividad en los países pertenecientes al ex-bloque comunista soviético.
} 
reducción de 2 millones derivada de las estimaciones a nivel industria. Es por ello que los autores concluyen que existen efectos de equilibrio general negativos a nivel de mercados laborales locales. Utilizando un modelo de estimación estructural, un trabajo reciente de Caliendo, Dvorkin y Parro (2018) muestra que las pérdidas de empleo ocasionadas por el crecimiento en la penetración de importaciones Chinas son significativamente menores a las estimadas por Acemoglu et al. (2016).

Caliendo, Dvorkin, and Parro (2018) utilizan el concepto de mercados laborales locales y extienden el modelo de elección discreta de Artuc et al. (2010), combinándolo con un modelo de equilibrio general tipo Eaton y Kortum (2002). En este modelo, la producción y el consumo ocurren en mercados laborales y de producto separados espacialmente. Existen fricciones a la movilidad geográfica de los trabajadores y a los bienes domésticos e internacionales. Los autores estiman un conjunto de parámetros asociados a los costos de movilidad de los trabajadores, el transporte de bienes, factores geográficos (productividad local, fuerzas de aglomeración y amenidades) y relaciones insumo-producto entre las distintas industrias. Al calibrar este modelo para un conjunto de 38 países, 50 estados de EE.UU. y 22 industrias, encuentran que el crecimiento en la penetración de importaciones Chinas explica una contracción del empleo total en manufacturas de 0,8 millones. Alrededor de la mitad la contracción de empleo estaría explicada por una tendencia secular ocasionada por mejoras productivas ahorradoras de mano de obra, la computarización, tecnologías de automatización y una potencial desindustrialización explicada por factores de demanda.

En un trabajo relacionado, Acemoglu y Restrepo (2017) analizan el impacto diferencial de la introducción de robots y tecnologías de automatización entre 1990 y 2007 a través de distintas regiones de EE.UU. Los resultados muestran que la introducción de robots genera un efecto negativo y significativo en los niveles de empleo y salarios de las zonas de conmutación. En un trabajo relacionado, los autores desarrollan un marco teórico para repensar los efectos de la inteligencia artificial y tecnologías de automatización en la demanda de trabajo, los salarios y el empleo. El modelo sugiere que la tecnología genera un efecto desplazamiento que reduce la demanda de trabajo y el salario. A este canal se contrapone un efecto de productividad derivado del ahorro de costos que genera la automatización, que aumenta la demanda de trabajo en tareas no automatizables. Por lo tanto, la automatización se complementa con acumulación de capital humano. En general, el aumento de la productividad por trabajador es mayor que el aumento del salario, lo cual reduce la participación del trabajo en el ingreso nacional. Los autores destacan la 
existencia de restricciones e imperfecciones que retrasan el ajuste de la economía (e.g. desajuste entre oferta y demanda de habilidades requeridas por las nuevas tecnologías) y la posibilidad de que la automatización se esté introduciendo demasiado rápido, a expensas de otras mejoras que podrían elevar la productividad.

Autor, Dorn y Hanson (2015) comparan el efecto del comercio y del cambio tecnológico sobre el empleo de los mercados laborales locales de EE.UU., durante el período 1980-2007. En línea con sus contribuciones previas, ${ }^{77}$ muestran que las zonas más expuestas al crecimiento en la penetración de importaciones Chinas están sujetas a reducciones significativas de los niveles de empleo, en especial en manufacturas y en trabajadores con educación superior incompleta. En cambio, mercados locales más susceptibles al crecimiento de la computarización (especializados en actividades intensivas en tareas rutinarias) experimentaron un fenómeno de polarización ocupacional, tanto en manufacturas como en otros sectores, pero no sufrieron una pérdida neta de empleo. Los efectos del comercio y la tecnología también difieren en la dimensión temporal, siendo que el crecimiento en la penetración de importaciones es relevante sobre todo a partir de los 2000s. En cambio, el efecto del progreso tecnológico en manufacturas adquiere mayor magnitud en la década de 1980, mientras que en otros sectores ocurre a lo largo de todo el período y se va acelerando con el paso del tiempo, de la mano del boom tecnológico derivado de la computarización y la expansión de las tecnologías de la información, especialmente en aquellas industrias intensivas en conocimiento.

Ottaviano, Peri y Wright (2013) estudian el efecto de reducir los costos a la inmigración y al offshoring sobre la estructura, el nivel de empleo y el tipo de tareas realizadas por los trabajadores nativos del sector manufacturero de EE.UU. Siguen el modelo de Grossman y Rossi-Hansberg (2008) y asumen que la complejidad de una tarea es creciente en la intensidad de uso de habilidades cognitivas y comunicacionales, y decreciente en la intensidad de uso de actividades manuales. Cuando la inmigración y el offshoring están disponibles, los productores pueden aumentar su eficiencia reasignando tareas entre trabajadores con distintas ventajas comparativas. Este efecto productividad puede superar al efecto desplazamiento experimentado por los trabajadores nativos. La evidencia está en línea con ello, porque las industrias con mayor exposición a la

\footnotetext{
${ }^{77}$ Los trabajos anteriores refieren a Autor, Dorn y Hanson (2013) comentado más arriba; y Autor y Dorn (2013) que estudia el efecto del cambio tecnológico en la polarización observada en el mercado laboral de EE.UU. Sus hallazgos muestran que las zonas más especializadas en tareas rutinarias adoptaron tecnologías de información más intensivamente, reasignaron más trabajo no calificado hacia servicios (polarización de empleo), experimentaron un mayor crecimiento de los salarios en los extremos de la distribución (polarización salarial) y recibieron un mayor flujo de trabajadores calificados.
} 
globalización (en términos de inmigración y offshoring) presentan mejores resultados en términos de crecimiento del empleo total de trabajadores nativos (en comparación con las menos globalizadas). Ello ocurre porque existe mayor sustituibilidad (o competencia) entre inmigrantes y trabajadores offshore que entre inmigrantes y nativos. Los inmigrantes se especializan en tareas de baja complejidad, los trabajadores offshore en tareas de complejidad media y los nativos en tareas de complejidad alta. Por lo tanto, los inmigrantes no compiten con los nativos porque se especializan en tareas muy diferentes, mientras que los trabajadores offshore se especializan en tareas intermedias y compiten tanto con los inmigrantes como con nativos.

Una nueva generación de trabajos explota la disponibilidad de datos de registro administrativo que permiten vincular a los trabajadores con sus empleadores y estudiar la trayectoria laboral de los individuos (Autor, Dorn, Hanson y Song (2014), Traiberman (2018), Utar (2018)). Autor, Dorn, Hanson y Song (2014) estudian el efecto del crecimiento en la penetración de importaciones de China entre 1992 y 2007 en las trayectorias laborales de los trabajadores industriales de EE.UU. Los resultados muestran que aquellos individuos que en 1991 trabajaban en aquellas industrias que experimentaron mayor competencia de China obtuvieron menores ingresos acumulados, mayor probabilidad de obtener beneficios de seguridad social y pasaron menos tiempo trabajando para los empleadores iniciales y en la industria inicial, y más tiempo en otros sectores. Las pérdidas de ingreso son mayores para aquellos individuos que tenían un salario inicial más bajo, menor nivel educativo y menor apego a la fuerza laboral. Los trabajadores desplazados suelen reinsertarse en manufacturas, donde quedan nuevamente expuestos a los shocks futuros. En cambio, aquellos trabajadores más educados y con salarios iniciales más elevados tienen pérdidas salariales pequeñas y suelen reinsertarse en otros sectores, fundamentalmente servicios. Aún en países muy avanzados que poseen mercados laborales relativamente flexibles como Dinamarca, los trabajadores enfrentan significativos costos de transición entre sectores y especialmente entre ocupaciones (Traiberman (2018), Utar (2018)). La mayor parte de estos costos se asocia con la pérdida de retornos al capital acumulado específico a determinadas ocupaciones.

Traiberman (2018) estima un modelo estructural dinámico del mercado laboral de Dinamarca para evaluar las consecuencias distributivas de importar bienes de bajo precio. Si bien el bienestar aumenta para todos los trabajadores porque las ganancias de consumo (precios bajos e insumos intermedios) superan a los costos estimados de reasignación, existe un notable grado de dispersión en las ganancias experimentadas debido a la existencia de 
grandes fricciones de movilidad ocupacional, tanto en el corto como en el largo plazo. La mediana del costo estimado de moverse a otra ocupación dentro del mismo sector es 1,7 veces mayor que el costo estimado de moverse a otro sector manteniendo la misma ocupación. Una innovación importante de este trabajo tiene que ver con la construcción de funciones de producción al nivel de ocupaciones para distintas industrias, y la utilización de la matriz insumo-producto para capturar el grado de sustitución entre los bienes domésticos y los importados. Los resultados muestran una distinción fundamental entre el corto plazo (que dura hasta 10 años) y el largo plazo. En el corto plazo, el impacto del shock comercial está más disperso a través de las ocupaciones que a través de las industrias, especialmente en el sector transable. Mientras que en largo plazo, las diferencias salariales entre ocupaciones tienden a desaparecer, a la vez que se produce una reducción en el salario por habilidad pagado en manufacturas que es compensado por un aumento de igual magnitud en el sector no transable.

Utar (2018) utiliza el desmantelamiento de las cuotas de importación en determinados productos a partir de la entrada de China a la OMC como un cuasi-experimento que permite identificar un efecto causal de la política comercial en los ingresos y trayectorias laborales de los trabajadores expuestos. ${ }^{78}$ Los trabajadores de firmas expuestas pierden en promedio un $89 \%$ del salario inicial a lo largo de nueve años (sobre todo por la reducción en las horas de trabajo), pasan menos tiempo trabajando en otras empresas y experimentan mayor inestabilidad laboral asociada a momentos de desempleo (alrededor de un año en promedio) en relación a trabajadores comparables en otras firmas menos expuestas de la misma industria. Los trabajadores desplazados suelen reinsertarse en el sector de servicios. Los resultados de largo plazo que obtienen estos trabajadores dependen de la capacidad que tengan para reinsertarse eficazmente en el mercado laboral, en función de la adaptabilidad del tipo de capital humano acumulado (nivel y campo educativo, y especificidad de la ocupación).

La idea de que determinados aspectos específicos del capital humano podrían representar una barrera a la reasignación laboral eficiente está presente desde hace muchos años en la literatura (Becker (1964), Topel (1991), Neal (1995)). Al igual que Poletaev y Robinson (2008), los resultados en Utar (2018) muestran que el capital humano es específico a la combinación de industrias y ocupaciones. Utar (2018) también muestra que los trabajadores de menor nivel educativo que fueron desplazados por este shock

\footnotetext{
${ }^{78}$ Bloom, Draca y van Reenen (2016) utilizan una estrategia de identificación muy similar para evaluar los efectos de este shock en las actividades de innovación de las firmas manufactureras de 12 países europeos.
} 
comienzan a invertir en capital humano a través de la educación, lo que podría aumentar la oferta de trabajadores calificados. Este fenómeno se relaciona con una pregunta más amplia asociada al efecto que tiene el comercio con países de salario bajo en la demanda de habilidades, tanto en países desarrollados como en los países en desarrollo que suelen ser el destino elegido para las actividades de offshoring. También existe evidencia en sentido contrario. Atkin (2016) muestra que la expansión de exportaciones provocada por las reformas comerciales en México ocasionó un aumento en las tasas de abandono escolar, reflejando un potencial efecto negativo del comercio en la oferta de trabajadores calificados.

Por último, es importante mencionar un conjunto de contribuciones teóricas relacionadas con la existencia de fricciones en el mercado laboral, firmas heterogéneas y comercio internacional (e.g. Artuc, Chaudhuri y McLaren (2010); Dix-Carneiro (2014); Coşar, Guner y Tybout(2016); Caliendo, Dvorkin, y Parro (2018)). Por ejemplo, en el contexto de la liberalización comercial de Brasil de la década de 1990, Dix-Carneiro (2014) introduce diferencias en los retornos al capital humano entre sectores, y muestra que existe un considerable grado de heterogeneidad en los costos de ajuste que enfrentan los distintos trabajadores. Otro grupo de trabajos teóricos desarrolla marcos analíticos que permiten estudiar el funcionamiento del mercado laboral y el emparejamiento entre firmas y trabajadores (e.g. Costinot y Vogel (2010), Helpman, Itskhoki y Redding (2010)). También existen contribuciones teóricas recientes que estudian este fenómeno desde el campo de la macroeconomía (e.g. Lise y Robin (2017)).

\subsubsection{Costo de vida y bienestar}

Las secciones anteriores mencionan diversos mecanismos por los cuales el comercio, la globalización y el progreso tecnológico afectan la productividad y los resultados del mercado laboral. Naturalmente, estos fenómenos impactan directamente sobre el nivel de bienestar de los individuos. El comercio y la tecnología alteran los costos de producción y los precios relativos. Dado que individuos con ingresos diferentes consumen canastas distintas, el cambio de precios relativos afecta de manera heterogénea el salario real a través de la distribución del ingreso. Existen muy pocos trabajos que estudian el efecto del comercio en el bienestar teniendo en cuenta el canal del gasto. El trabajo pionero de Porto (2006) desarrolla un método para estudiar el efecto de la política comercial en los precios y salarios domésticos que permite inferir el efecto sobre el bienestar (variación compensatoria) a lo largo de la distribución del ingreso, utilizando datos provenientes de 
la encuesta de gasto de los hogares de Argentina. ${ }^{79}$ Los resultados muestran que el cambio de precios derivado del acuerdo de liberalización regional (Mercosur) beneficia levemente a todos los hogares y proporcionalmente más a los hogares más pobres.

En un trabajo muy preliminar y meramente descriptivo, Broda y Romalis (2008) muestran que la inflación acumulada en EE.UU. entre 1994 y 2005 es 6 p.p. menor para los hogares del primer decil en relación a los del último decil de la distribución del ingreso. Los pobres gastan una mayor fracción de sus ingresos en bienes no durables, y el precio de los bienes no durables consumidos por los pobres aumenta menos que el precio de los no durables consumidos por los ricos, y menos que el precio de los servicios (consumidos mayormente por los ricos). Dado que las importaciones Chinas se concentran en productos no durables de baja calidad, que son fuertemente consumidos por los pobres, las estimaciones sugieren que alrededor de un tercio de la reducción del precio relativo de los pobres se explica por el crecimiento de las importaciones desde China.

Faber (2014) explota la entrada de México en el NAFTA para estudiar el efecto de la reducción de tarifas en los cambios de precios de bienes de diferente calidad y su impacto sobre el costo de vida a lo largo de la distribución del ingreso. Los resultados sugieren que el acceso a importaciones provenientes de EE.UU. reduce el precio relativo de los bienes de mayor calidad, y ello genera un incremento significativo de la desigualdad de ingresos reales. ${ }^{80}$

Atkin, Faber y Gonzalez-Navarro (2016) estudian el efecto de la inversión extranjera en cadenas de comercialización (retail globalization) sobre el bienestar de los hogares. Mediante el desarrollo y la estimación de un modelo estructural en el que incorporan consumidores, trabajadores y empresarios, encuentran que la entrada de supermercados extranjeros en México generó un notable aumento en el bienestar de los hogares (6\% del ingreso inicial del hogar, en promedio) derivado principalmente de la reducción en el costo de vida. Los efectos sobre ingresos y empleo son prácticamente nulos. Los resultados de la descomposición del cambio en el índice de precios revelan que un cuarto de la ganancia de consumo se explica por el efecto pro-competitivo (reducción de precios en comercios existentes), y tres cuartos se explican por las ganancias derivadas de comprar

\footnotetext{
${ }^{79}$ Este trabajo sigue la contribución seminal de Deaton (1989) sobre medición de efectos de cambios de precio (en su caso, productos de agricultura) sobre el costo de vida de los hogares, utilizando encuestas de consumo de los hogares.

${ }^{80}$ La reducción de tarifas promedio entre 1993 y 2002 (12 p.p.) produce un aumento en el costo de vida de 1,4 a 4,4 p.p. mayor para los hogares del primer quintil de ingresos en relación a los hogares del quinto quintil. La magnitud económica de este resultado equivale aproximadamente a un $25-55 \%$ del crecimiento diferencial en los ingresos nominales de ambos quintiles (canal que también contribuye a aumentar la desigualdad en este período).
} 
en los nuevos comercios extranjeros (precios bajos, más variedades y otras comodidades). ${ }^{81}$ En promedio, las ganancias de comercio son positivas para todos los grupos de ingreso, pero regresivas. El decil superior gana alrededor de 50\% más que el decil inferior. Dado que las elasticidades de sustitución son similares para ambos grupos, los resultados sugieren que los hogares ricos valoran significativamente más que los pobres las posibilidades de consumo (e.g. marcas importadas, mayor variedad) y otras comodidades (e.g. estacionamiento, seguridad, higiene) ofrecidas por los supermercados extranjeros.

Otra rama de la literatura se estructura a partir del desarrollo de modelos cuantitativos que utilizan información agregada para medir las ganancias de bienestar derivadas del comercio internacional (Arkolakis, Costinot y Rodriguez-Clare (2012); Melitz y Redding (2014); Fajgelbaum y Khandelwal (2016); Feenstra y Weinstein (2017)). Por ejemplo, Fajgelbaum y Khandelwal (2016) desarrollan una modelo cuantitativo para estudiar los efectos distributivos del comercio internacional, que combina el sistema de demanda AIDS (Almost Ideal Demand System) de Deaton y Malbauer (1980) con un sistema de oferta tipo Armington. Los autores imponen una estructura de demanda no-homotética con curvas de Engel específicas para cada bien. Los parámetros del modelo (e.g. elasticidad precio e ingreso de los shares de gasto por sector y país de origen) pueden estimarse a partir de datos agregados de producción y comercio bilateral, disponibles para un amplio conjunto de países a lo largo del tiempo. Los resultados muestran que el comercio es fuertemente pro-pobre, porque los pobres gastan una mayor fracción de su ingreso en bienes transables y en sectores que presentan una menor elasticidad de sustitución entre países. En promedio, la pérdida de ingreso real derivada de cerrar el comercio es $63 \%$ en el percentil 10 de la distribución del ingreso, contra un $28 \%$ en el percentil 90. En países con una menor elasticidad ingreso de las exportaciones las ganancias de comercio tienden a ser menor pro-pobres, porque la apertura aumenta el precio relativo de los bienes con baja elasticidad ingreso.

De esta revisión se desprende la necesidad de contar con más trabajos dedicados a estudiar la relación entre comercio internacional, globalización y el bienestar de los individuos a lo largo de toda la distribución del ingreso, especialmente en países en desarrollo. Es probable que el desarrollo de esta literatura esté limitado por la carencia de microdatos de buena calidad a disposición de los investigadores. Mejores microdatos permitirán identificar estos efectos, estimar adecuadamente los parámetros relevantes,

\footnotetext{
${ }^{81}$ El efecto variedad ha sido resaltado por otros trabajos importantes en la literatura, que señalan que un aumento en el número de variedades disponibles gracias al comercio y a la innovación incrementa el bienestar del consumidor promedio (e.g. Feenstra (1994), Broda y Weinstein (2006)).
} 
ahondar en la validez de distintos modelos teóricos y evaluar la factibilidad de los supuestos convencionales de la literatura.

\subsection{Estimación de funciones de producción}

Existe una literatura dedicada a estimar funciones de producción. En los distintos trabajos se funden contribuciones correspondientes a la literatura de organización industrial, economía internacional y econometría. Esta sección pretende introducir este tema al lector no especializado. Se discute entonces el problema de identificación y la intuición detrás de los métodos más actuales propuestos en la literatura.

Suponga que se tiene una simple función de producción tipo Cobb-Douglas expresada en logaritmos:

$$
y_{i t}=\beta_{0}+\beta_{l} l_{i t}+\beta_{k} k_{i t}+\omega_{i t}+\varepsilon_{i t}
$$

Donde $y_{i t}$ es el nivel de producción de la firma $i$ en el momento $t$ (en logs), $l_{i t}$ y $k_{i t}$ son los insumos productivos trabajo y capital (también en logs), los parámetros $\beta$ corresponden a la productividad marginal de los distintos insumos, $\omega_{i t}$ son factores observados por la firma pero no por el econometrista (e.g. capacidad empresarial) y $\varepsilon_{i t}$ son factores inobservables, tanto para la firma como para el econometrista (e.g. accidentes, shocks impredecibles, etc.). Es posible entonces pensar en dos tipos de productividad: una sistemática $\left(\omega_{i t}\right)$ y otra totalmente aleatoria $\left(\varepsilon_{i t}\right)$. Si bien las firmas observan $\omega_{i t}$, el econometrista no observa ninguno de los shocks.

Para entender el problema de identificación es útil pensar en el proceso generador de datos: ¿cuál es el modelo económico que debería haber generado estos datos?. Si se suponen firmas que maximizan sus beneficios, la demanda de los distintos insumos depende positivamente de $\omega_{i t}$. Dado que las firmas observan $\omega_{i t}$ al tomar sus decisiones de producción pero el econometrista no lo hace, se genera un problema de endogeneidad (simultaneidad) en la estimación de la función de producción. Las firmas con $\omega_{i t}$ más alto contratan más insumos, y generan un mayor producto por dos razones: porque son más productivas (efecto directo de $\omega_{i t}$ ) y porque contratan más factores productivos. Luego, todo el efecto es atribuído a las variables (factores) observadas. Por lo tanto, los coeficientes que no tienen en cuenta este inconveniente a priori deberían estar sobrestimados. ${ }^{82} \mathrm{Un}$

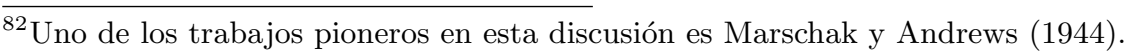


segundo problema de endogeneidad se produce porque las firmas pueden elegir salir del mercado, lo que genera un problema de selección (atrición) ya que podrían tener algún conocimiento sobre su productividad futura antes de salir del mercado. Es probable que firmas con mayor stock de capital puedan soportar shocks negativos más grandes. En este sentido, el problema de selección haría que el coeficiente de $k$ esté subestimado.

Las soluciones tradicionales que propone la literatura (efectos fijos, variables instrumentales) no funcionan bien en la práctica. En general, es difícil que existan instrumentos disponibles que satisfagan la restricción de exclusión. Por ejemplo, algunas encuestas a nivel firma (o las mismas combinadas con datos de comercio internacional provenientes de aduanas) incluyen información sobre el precio de los insumos utilizados por las mismas. Estos deberían afectar la demanda de insumos (relevancia) y afectar a la productividad únicamente por este canal (exclusión). Sin embargo, puede ocurrir que las diferencias de precios estén capturando diferencias en la calidad. Además, dado que la demanda de insumos depende de la productividad, una firma con poder en el mercado de insumos podría afectar el precio de los mismos a través de cambios en su productividad.

Cuando existen datos con estructura de panel es posible utilizar rezagos en los insumos como variables instrumentales. Sin embargo, para que este instrumento sea válido es necesario suponer que los errores $\omega_{i t}$ no están correlacionados serialmente, mientras que los insumos si lo están. Si bien podría pensarse que la utilización de efectos fijos puede resolver algunos problemas de endogeneidad, este método puede ocasionar problemas importantes. Primero, porque no contempla los cambios en $\omega_{i t}$ observados por la firma. Segundo, porque exacerba cualquier error de medición en la utilización de insumos (en general, en el stock de capital).

Olley y Pakes (1996) parten de la presunción de que firmas que reciben un shock alto en $\omega_{i t}$ deciden utilizar más insumos. En particular, deciden invertir más. Luego, utilizan una función no paramétrica de la inversión como proxy para $\omega_{i t}=\omega_{i t}\left(i_{i t}, k_{i t}\right)$. La productividad observada por la firma depende de la inversión $i_{i t}$ y del stock de capital $k_{i t}$.

La estrategia de identificación está basada en un modelo de optimización dinámica de las firmas en tiempo discreto. Se asume que el trabajo no tiene costos de ajuste y se elige óptimamente en cada período. Existen costos de ajuste en el stock de capital que dependen del nivel de inversión contemporáneo. La inversión en $t$ se transforma en capital en el período siguiente $t+1$. La productividad sigue un proceso de Markov. La solución del modelo dinámico corresponde a un nivel de inversión que depende de la productividad 
y del stock de capital: $i_{i t}=i_{i t}\left(\omega_{i t}, k_{i t}\right)$. Si el nivel de inversión es estrictamente positivo, la función $i($.$) es estrictamente creciente en \omega_{i t} \mathrm{y}$ por lo tanto puede ser invertida tal que $\omega_{i t}=\omega_{i t}\left(i_{i t}, k_{i t}\right)$. Luego, es posible utilizar esta función en la estimación de la ecuación de regresión:

$$
\begin{gathered}
y_{i t}=\beta_{0}+\beta_{l} l_{i t}+\beta_{k} k_{i t}+\omega_{i t}\left(i_{i t}, k_{i t}\right)+\varepsilon_{i t} \\
y_{i t}=\beta_{0}+\beta_{l} l_{i t}+\phi_{i t}\left(i_{i t}, k_{i t}\right)+\varepsilon_{i t}
\end{gathered}
$$

Donde $\phi_{i t}$ es una función no paramétrica que puede ser aproximada por un polinomio o por una regresión de Kernel. Esta ecuación se estima en una primera etapa en la cual se recuperan $\hat{\beta}_{l}$ y $\hat{\phi}_{i t}$. Existen dos supuestos importantes detrás de esta estimación. Primero, se asume que $\omega_{i t}$ es unidimensional. Y segundo, la relación entre la inversión y $\omega_{i t}$ es determinística (no hay error).

En una segunda etapa del método de Olley y Pakes (1996) es posible recuperar el parámetro $\hat{\beta}_{k}$. Recordar que el shock $\omega_{i t}$ tiene un componente esperado (dado el supuesto del proceso de Markov) y un componente de innovación: $\omega_{i t}=E\left[\omega_{i t} \mid \omega_{i t-1}\right]+\psi_{i t}$. Luego, reemplazando en la ecuación de regresión y usando el supuesto de Markov, se obtiene:

$$
\begin{gathered}
y_{i t}=\beta_{0}+\beta_{l} l_{i t}+\beta_{k} k_{i t}+\omega_{i t}+\varepsilon_{i t} \\
y_{i t}=\beta_{0}+\beta_{l} l_{i t}+\beta_{k} k_{i t}+E\left[\omega_{i t} \mid \omega_{i t-1}\right]+\psi_{i t}+\varepsilon_{i t} \\
y_{i t}-\beta_{l} l_{i t}=\beta_{k} k_{i t}+\widetilde{g}\left(\omega_{i t-1}\right)+\psi_{i t}+\varepsilon_{i t}
\end{gathered}
$$

Del paso anterior, se tiene que $\phi_{i t}\left(i_{i t}, k_{i t}\right)=\beta_{0}+\beta_{k} k_{i t}+\omega_{i t}\left(i_{i t}, k_{i t}\right)$. Reemplazando en la ecuación anterior:

$$
y_{i t}-\hat{\beta}_{l} l_{i t}=\beta_{k} k_{i t}+\widetilde{g}\left(\omega_{i \hat{t}-1}-\beta_{k} k_{i t-1}\right)+\psi_{i t}+\varepsilon_{i t}
$$

Luego es posible estimar esta regresión utilizando un polinomio o una regresión de Kernel para la función $g($.$) . Dado que \beta_{k}$ aparece dos veces, es necesario imponer la 
restricción de que sea el mismo coeficiente. Intuitivamente, $\beta_{k}$ se estima utilizando la variabilidad en $k_{i t}$ a través de las firmas luego de controlar por $\omega_{i t-1}$.

Finalmente es posible recuperar la productividad como un residuo:

$$
\hat{\omega_{i t}}=\hat{\phi_{i t}}-\hat{\beta_{k}} k_{i t}
$$

Para tratar el problema de selección derivado de la decisión de salir del mercado, Olley y Pakes (1996) muestran que es posible incorporar esta decisión en el modelo de optimización de la firma. Se obtiene la solución de una cota inferior de productividad que depende negativamente del stock de capital. A mayor capital, mayores son los beneficios y por lo tanto se necesita un menor $\omega_{i t}$ para seguir operando.

$\mathrm{Al}$ incorporar esta consideración en la estimación, la primera etapa del método no se modifica. De modo que se obtienen $\hat{\beta}_{l}$ y $\hat{\phi_{i t}}$ igual que antes. En la segunda etapa es necesario condicionar en que la firma se queda en el mercado, porque esta es la muestra que efectivamente se observa en los datos. Es por ello que se incorpora como control en la segunda etapa la probabilidad de supervivencia en $t$, estimada a partir de la información existente en $t-1: \hat{P}_{i t}=p\left(k_{i t-1}, i_{i t-1}\right)$. Nuevamente, $\hat{P}_{i t}$ se estima con un probit utilizando un polinomio o una regresión de Kernel y $g(\hat{g}$.$) se estima como antes. Los resultados$ muestran que controlar por selección no afecta demasiado las estimaciones.

Levinsohn y Petrin (2003) plantean que utilizar como proxy a la inversión deja a todas las firmas con inversión cero por fuera de la muestra. Este problema puede ser más relevante en el caso de países en desarrollo. Los autores trabajan con la misma base de datos que se utiliza en esta parte de la tesis, correspondiente al panel de firmas de la Encuesta Nacional Industrial Anual (ENIA) elaborada por el Instituto Nacional de Estadísticas de Chile. En este caso, un 50\% reportan inversión igual a cero. Si bien esto no genera problemas en términos de consistencia de los estimadores, el tamaño de la muestra puede reducirse significativamente. Este problema no es severo en Olley y Pakes (1996) porque utilizan un único sector (telecomunicaciones) caracterizado por firmas grandes e intensivas en capital. Levinsohn y Petrin (2003) proponen utilizar insumos intermedios en lugar de inversión. La diferencia con el método anterior es que los insumos se ajustan en el mismo período y entran directamente en la función de producción. Se obtiene entonces la siguiente función de producción: 


$$
y_{i t}=\beta_{0}+\beta_{l} l_{i t}+\beta_{k} k_{i t}+\beta_{m} m_{i t}+\omega_{i t}+\varepsilon_{i t}
$$

Donde $m$ representa al gasto en insumos intermedios. Al igual que en el método de Olley y Pakes, en la primera etapa se recuperan $\hat{\beta}_{l}$ y $\hat{\phi_{i t}}$ a partir de estimar la ecuación de regresión: $y_{i t}=\beta_{0}+\beta_{l} l_{i t}+\phi_{i t}\left(i_{i t}, k_{i t}\right)+\varepsilon_{i t}$.

En la segunda etapa se recuperan $\beta_{k}$ y $\beta_{m}$ a partir de la siguiente ecuación:

$$
y_{i t}=\beta_{0}+\beta_{l} l_{i t}+\beta_{k} k_{i t}+\beta_{m} m_{i t}+E\left[\omega_{i t} \mid \omega_{i t-1}\right]+\psi_{i t}+\varepsilon_{i t}
$$

$$
y_{i t}-\hat{\beta}_{l} l_{i t}=\beta_{k} k_{i t}+\beta_{m} m_{i t}+\widetilde{g}\left(\omega_{i t-1}-\beta_{k} k_{i t-1}-\beta_{m} m_{i t-1}\right)+\psi_{i t}+\varepsilon_{i t}
$$

Notar que $m_{i t}$ es endógeno porque depende de $\psi_{i t}$. Levinsohn y Petrin proponen utilizar rezagos como variables instrumentales. $\psi_{i t}$ no está serialmente correlacionado porque es innovación, de modo que los rezagos son exógenos. Suponer que los insumos son exógenos equivale a asumir una función de coeficientes fijos entre insumos y producción que no está afectada por un error.

Un aporte interesante del trabajo de Levinsohn y Petrin (2003) consiste en la comparación de distintos métodos de estimación. Sus resultados muestran que en general MCO tiende a sobrestimar los factores variables (trabajo, insumos intermedios) y a subestimar al capital. Más arriba se explicó que el capital puede subestimarse por el hecho de que existe un sesgo de selección (las firmas menos productivas salen del mercado). Sin embargo, Levinsohn y Petrin no corrigen por el problema de selección, de modo que la explicación parece venir por el hecho de que el capital es un factor relativamente fijo sujeto a costos de ajuste. La correlación de $\omega_{i t}$ con los factores variables es mayor que aquella con el capital. Los autores muestran que el método de OP es relativamente similar a LP, especialmente cuando se usa la muestra con inversión estrictamente positiva. El estimador de efectos fijos no es igual a ningún otro estimador. Tanto LP como OP son distintos al estimador de variables instrumentales. Si se asume que LP y OP son correctos, MCO siempre es preferible a variables instrumentales y a efectos fijos.

En un trabajo más reciente, Ackerberg, Caves y Frazer (2015) plantean que los métodos de OP y LP hacen supuestos sobre colinealidad y timing en la elección de los 
insumos que pueden ser problemáticos. La inversión (o los materiales) se invierte para controlar por $\omega_{i t}$ en la primera etapa: $i_{i t}=f_{1 i t}\left(\omega_{i t}, k_{i t}\right)$. La inversa de esta función es $f_{1 i t}^{-1}=\left(i_{i t}, k_{i t}\right)$. La demanda de trabajo depende de las mismas variables: $l_{i t}=f_{2 i t}\left(\omega_{i t}, k_{i t}\right)$. De modo que $l_{i t}=f_{2 i t}\left(f_{1 i t}^{-1}\left(i_{i t}, k_{i t}\right), k_{i t}\right)$, o $l_{i t}=g_{i t}\left(i_{i t}, k_{i t}\right)$. Dado que $\phi$ es una función no paramétrica, el término $\beta_{l} l_{i t}$ no está identificado en la primera etapa, porque los dos términos son colineales. Es decir, trabajo e inversión están determinados por las mimas variables de estado (capital y productividad). La decisión se toma simultáneamente y no hay término de error en esta decisión. Por lo tanto, para poder estimar la primera etapa se necesita romper con la perfecta colinealidad entre trabajo y las otras variables.

Ackerberg, Caves y Frazer (2015) consideran que es razonable suponer que el trabajo se elige antes que los materiales ya que es semi-fijo. En este caso, OP funcionaría pero LP no. ACF proponen otro método de estimación que permite utilizar materiales. Los autores suponen entonces que el trabajo se elige antes que los materiales: $m_{i t}\left(\omega_{i t}, k_{i t}, l_{i t}\right)$. Luego se obtiene la siguiente función de producción:

$$
\begin{gathered}
y_{i t}=\beta_{l} l_{i t}+\beta_{k} k_{i t}+\omega_{i t}\left(l_{i t}, k_{i t}, m_{i t}\right)+\eta_{i t} \\
y_{i t}=\phi_{i t}\left(l_{i t}, k_{i t}, m_{i t}\right)+\eta_{i t}
\end{gathered}
$$

En la primera etapa se recupera únicamente $\hat{\phi}_{t}, \mathrm{y} \operatorname{los} \beta$ se recuperan en la segunda etapa. Al igual que antes, se obtiene:

$$
\begin{gathered}
y_{i t}=\beta_{l} l_{i t}+\beta_{k} k_{i t}+\omega_{i t}\left(l_{i t}, k_{i t}, m_{i t}\right)+\eta_{i t} \\
y_{i t}=\beta_{l} l_{i t}+\beta_{k} k_{i t}+E\left(\omega_{i t} \mid \omega_{i t-1}\right)+\psi_{i t}+\eta_{i t} \\
y_{i t}=\beta_{l} l_{i t}+\beta_{k} k_{i t}+g\left(\phi_{i t-1}-\beta_{l} l_{i t}-\beta_{k} k_{i t}\right)+\psi_{i t}+\eta_{i t}
\end{gathered}
$$

Notar que la diferencia con el método anterior es que $l$ está del lado derecho. Luego, se estima esta regresión por mínimos cuadrados en dos etapas o por el método generalizado de momentos, utilizando a $l_{i t-1}$ como instrumento para $l_{i t}$. Las condiciones de ortogonalidad utilizadas para identificar los coeficientes en la segunda etapa son: (1) 
$E\left(\psi_{i t} k_{i t}\right)=0 ;$ y $(2) E\left(\psi_{i t} l_{i t-1}\right)=0$.

En la práctica, primero se corre una regresión no paramétrica y se recupera $\hat{\psi}_{i t}$ (dado un valor determinado de $\beta_{l}$ y $\beta_{k}$ ):

$$
\omega_{i t}=g\left(\phi_{i t-1}-\beta_{l} l_{i t-1}-\beta_{k} k_{i t-1}\right)+\eta_{i t}
$$

Luego, se evalúa la función de distancia ${ }^{\wedge} \psi_{i t} Z W Z^{\prime} \hat{\psi_{i t}}$. Se itera y se eligen los valores de $\beta_{l}$ y $\beta_{k}$ que minimizan esta función de distancia, actualizando el valor de $\psi$ en cada iteración.

Una ventaja de este método por sobre LP se relaciona con el hecho de que el supuesto de timing de elección de los insumos funciona, mientras que en LP no. La gran diferencia es que el coeficiente de trabajo se recupera en la segunda etapa de estimación en lugar de la primera. El método propuesto por ACF también tiene otras dos ventajas sobre OP. Por un lado, permite utilizar materiales en lugar de inversión en la primera etapa. Y por otro, permite agregar efectos dinámicos al trabajo (costos de contratación y despido). Por estas razones, este es el método de estimación preferido en este trabajo. 


\section{Contexto}

En esta sección se describe resumidamente el contexto histórico, político y ecónomico de Chile y China en pos de aumentar la credibilidad de la estrategia de identificación utilizada y comprender el marco económico-institucional en el cual se sustentan los hallazgos de este trabajo. La discusión es sumamente breve e introductoria. Para un desarrollo más profundo sobre estas cuestiones, se recomienda la lectura de los trabajos citados.

\subsection{Chile}

Luego de un período de intervención estatal que incluyó la implementación de un régimen de políticas de sustitución de importaciones durante la década de 1960 y principios de la década de 1970, el gobierno militar llevó a cabo un amplio conjunto de reformas económicas pro-mercado durante el período 1974-1979. Como parte del programa de liberalización comercial, Chile eliminó la mayoría de sus barreras no arancelarias (BNA) y redujo significativamente sus barreras arancelarias. Los aranceles sobre algunos productos superaban el 100\% en 1974. Cinco años después, se estableció un arancel ad-valorem del $10 \%$ uniforme a través de todas las industrias. En los años que siguieron a la recesión de 1982-1984 aumentaron los niveles de protección comercial, con un arancel uniforme que se elevó hasta 35\%. Sin embargo, este arancel disminuyó a un valor del $20 \%$ en el año 1985. Las barreras no arancelarias no se aplicaron durante este período transitorio de protección (Levinsohn (1999) y Pavcnik (2002)). Este conjunto de reformas posicionó a Chile como una de las economías de América Latina con mayor grado de apertura comercial hacia comienzos de la década de $1990 .^{83}$

Otro aspecto importante de las reformas se centró en las regulaciones del mercado laboral. El gobierno prohibió sindicatos y reemplazó la negociación colectiva con un plan de fijación salarial. Si bien las leyes laborales no se modificaron per se, se produjo una considerable desregulación laboral de facto, con tribunales que favorecieron a las empresas a la hora de despedir trabajadores. A partir de Junio de 1978, las empresas podían despedir a los trabajadores legalmente alegando necesidades económicas, sin que sea necesario requisito alguno sobre causas justas. A pesar de algunos cambios en el esquema de compensación, esta última reforma aún se mantiene en la práctica. El Código Laboral

\footnotetext{
${ }^{83}$ Según los indicadores de desarrollo del Banco Mundial, el coeficiente de apertura (importaciones más exportaciones sobre producto bruto interno) en Chile era de $61.75 \%$ en 1990, casi el doble del valor promedio de $32.99 \%$ del resto de los países de América Latina.
} 
aprobado en 1979 reemplazó los sindicatos nacionales por uniones sindicales dentro de cada empresa, redujo los derechos de huelga de los trabajadores y disminuyó significativamente los costos de contratación y despido.

Chile experimentó un nuevo cambio institucional con la recuperación de la democracia en 1990. La misma coalición política ocupó el poder durante el período 1990-2010. Estos gobiernos mantuvieron un consenso básico sobre el papel crítico que juega el sector privado y la desregulación de los mercados para lograr la eficiencia, a la vez que tuvieron como objetivos reducir la pobreza y la desigualdad. En 1991 se introdujeron algunas modificaciones en el Código Laboral. Quizás la más relevante fue el aumento en el límite inferior de la remuneración salarial que deben percibir los trabajadores despedidos, que pasó de 5 a 11 meses de salario. Entre 1998 y 2001 Chile experimentó una recesión macroeconómica que desató un intenso debate sobre las regulaciones laborales. En este mismo lapso, se produjo un aumento en el salario mínimo del 30\%. En diciembre de 2001 se implementó una nueva modificación de las leyes laborales. Si bien esta reforma aumentó los derechos de negociación colectiva, también amplió ciertos márgenes de flexibilidad relacionados con las prácticas de contratación, pasantías, trabajos de tiempo parcial y contratos temporales.

El pequeño tamaño de la economía chilena, su elevado nivel de apertura comercial (liberalización comercial temprana en la segunda mitad de la década de 1970) y el hecho de contar con un mercado laboral relativamente flexible proveen un buen escenario para estudiar el impacto causal de un shock competitivo en el comportamiento de las firmas domésticas a corto plazo, utilizando como shock el crecimiento en la penetración de importaciones provenientes de uno de los países en desarrollo más competitivos del mundo.

\subsection{China}

A partir de la década de 1980, China llevó a cabo un amplio conjunto de reformas económicas estructurales que transformaron su estructura agraria en una moderna economía industrializada, que se convirtió en uno de los países líderes en la producción de manufacturas a nivel mundial. Las principales reformas comerciales persiguieron un régimen dual caracterizado por políticas de sustitución de importaciones y promoción de exportaciones (Naughton, 1996). La fracción de exportaciones de China como porcentaje del PBI aumentó de 5,91\% en 1980 a un máximo de 37,18\% en 2006. La crisis financiera global de 2007 afectó severamente los patrones del comercio internacional a nivel mundial, 
y las exportaciones de China como fracción del PBI experimentaron una tendencia a la baja a partir de entonces. ${ }^{84}$

Buena parte del crecimiento de China fue impulsado por un proceso de migración masiva desde zonas rurales hacia centros urbanos, fuerte ola de inversiones en infraestructura, acceso creciente de las firmas Chinas a tecnologías, insumos intermedios y bienes de capital importados, ingreso masivo de flujos de inversión extranjera directa y notable aumento en la productividad total de los factores. Según Brandt, Van Biesebroeck y Zhang (2012), el crecimiento promedio de la TFP de las firmas manufactureras Chinas fue de $8 \%$ anual durante el período 1998-2007. A estas reformas internas que promovieron el crecimiento y el comercio, se sumó la adhesión de China a la Organización Mundial del Comercio en Diciembre de 2001, con estatus permanente de nación más favorecida.

\subsection{Crecimiento en la PI China como un shock competitivo}

El crecimiento de las exportaciones explicado por los factores antes mencionados, inherentes al conjunto de reformas económicas e institucionales ocurridas en China, proporciona un shock potencialmente exógeno para la competitividad de firmas y trabajadores de otros países. En particular, dado que China se caracteriza por elaborar y exportar productos de bajo precio cuya producción es intensiva en la utilización de mano de obra, el crecimiento en la penetración de importaciones de manufacturas Chinas representa un aumento en el grado de presión competitiva al cual se enfrentan las empresas manufactureras domésticas.

Utilizando datos para los 50 países con mayor valor nominal de importaciones provenientes de COMTRADE, se estiman 80 regresiones descriptivas (una por industria) del $(\log )$ precio de las variedades importadas en la variable binaria China (=1 si un producto es importado de China, $\mathrm{y}=0$ si es importado de cualquier otro país) incluyendo efectos fijos país importador-producto-año. La muestra se restringe a aquellas variedades de productos exportados por China y por otros países de salario bajo, para comparar países con costos laborales, tecnología y calidad de producto relativamente similares. ${ }^{85}$ Esta lista incluye a países con menos del 5\% del PBI per cápita de Estados Unidos durante el período 1972-2001 (como en Bernard, Jensen y Schott (2006)). Más precisamente, se estima la

\footnotetext{
${ }^{84}$ Para evitar posibles efectos de confusión derivados de la crisis financiera internacional, los trabajos suelen interrumpir la muestra en el año 2006. Este es el criterio que seguimos en este trabajo.

${ }^{85} \mathrm{Si}$ las regresiones se realizan incluyendo a todos los países exportadores (en lugar de utilizar únicamente al grupo de países de salario bajo) las diferencias de precio de China son aún más pronunciadas, lo cual probablemente se explica por diferencias en la calidad de los bienes.
} 
siguiente ecuación de regresión lineal por el método de MCO:

$$
\log \left(P_{i j s t}\right)=\beta C h i n a_{i j t}+\mu_{i j t}+\varepsilon_{i j s t}
$$

Donde $i$ indexa a los países importadores (50 principales), $j$ son productos (6 dígitos del SA), $s$ son países de origen (China y otros países de salario bajo) y China $a_{i j t}$ es una variable binaria que vale 1 si el producto $j$ se importa desde China y vale 0 si el producto proviene de cualquier otro país de salario bajo. El coeficiente de interés $\beta$ muestra la diferencia promedio en el precio de los (mismos) productos exportados por China versus países de salario bajo.

La Figura 3 presenta los (80) coeficientes estimados para el coeficiente que acompaña a la variable China y los intervalos de confianza de 95\%, reexpresados para mostrar diferencias porcentuales. ${ }^{86}$ Los resultados muestran que los productos importados desde China son, en promedio, significativamente más baratos que sus pares importados desde otros países de salario bajo en la gran mayoría de industrias. Los números que aparecen entre paréntesis muestran la diferencia porcentual de precios (promedio) en cada sector manufacturero. Por ejemplo, las máquinas/productos eléctricos que China vende en el exterior son en promedio un $49 \%$ más baratos que productos similares exportados por el resto de los países de salario bajo. También existen diferencias notables en los sectores de plásticos, caucho y vidrio (34\%), juguetes (31\%) y papel e impresiones (29\%). Por otro lado, la diferencia de precios es muy pequeña en el sector alimenticio.

\footnotetext{
${ }^{86} \operatorname{Los}$ coeficientes estimados $(\hat{\beta})$ se reexpresan para mostrar diferencias porcentuales aplicando $\Delta \% P=$ 100. $\left(e^{\hat{\beta}}-1\right)$.
} 


\section{FIGURA 3}

Diferencia mundial de precios de productos exportados por China vs. Otros países de salario bajo

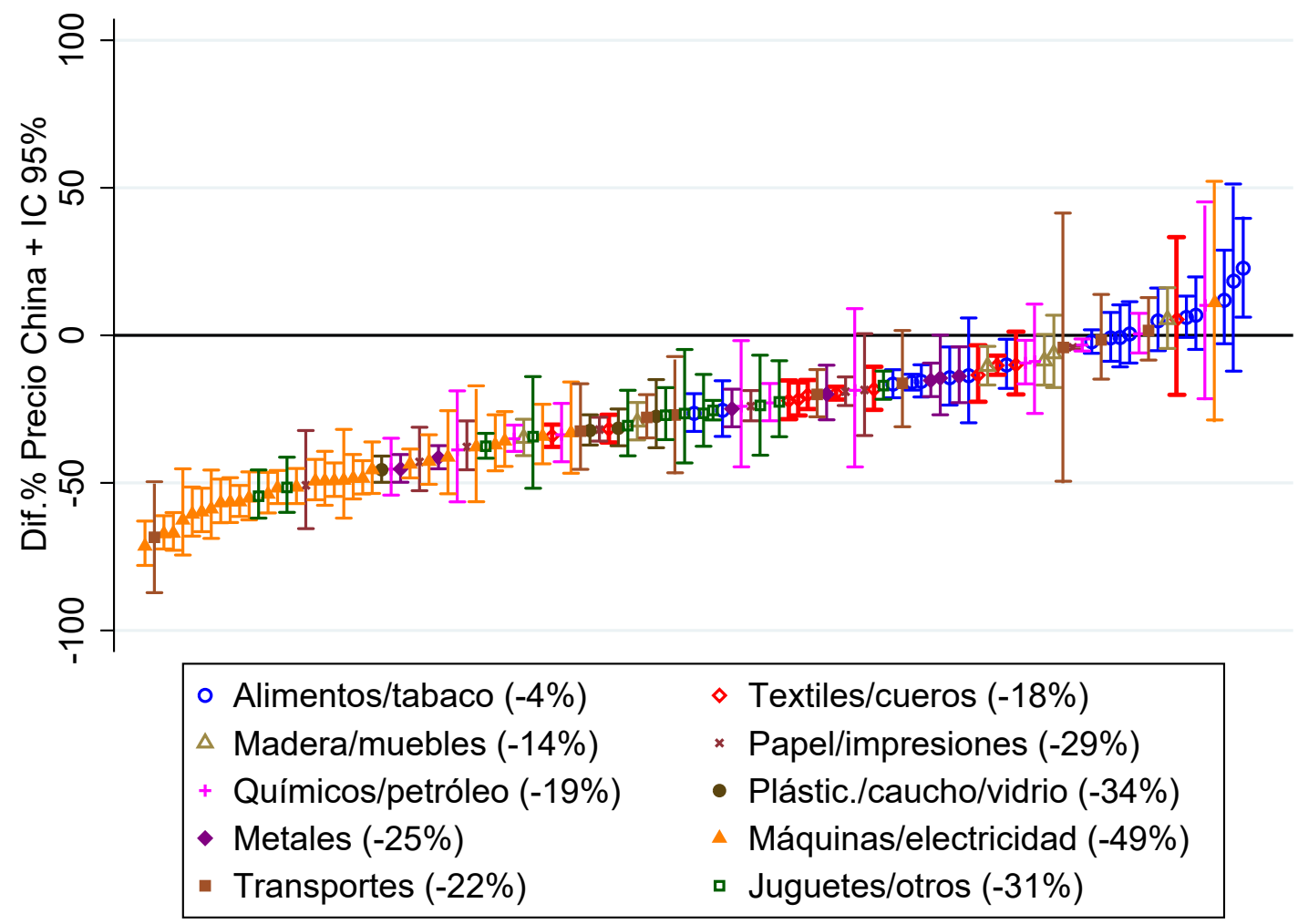

Notas. Coeficientes estimados e IC 95\% de (80) regresiones (por industria) del (log) precio de variedades importadas en una variable binaria China ( $=1$ si el producto es exportado por China, $=0$ si es exportado desde otro país de salario bajo) controlando por efectos fijos país importador-producto-año. Coeficientes reexpresados para mostrar diferencias porcentuales, aplicando $\Delta \% P=100 .\left(e^{\hat{\beta}}-1\right)$. La muestra se restringe a los primeros 50 países importadores del mundo, según el valor total de las importaciones durante 1995-2006. Entre paréntesis se muestra la diferencia de precios promedio de China vs. Otros países de salario bajo para las industrias de cada sector. Los precios se miden en valores unitarios a dólares constantes. Una variedad se define como la combinación producto-país exportador. Un producto se define a 6 dígitos de la clasificación internacional armonizada (HS). Industrias definidas a 4 dígitos de la clasificación ISIC Rev. 3. Errores estándar robustos clusterizados por producto. Fuente. COMTRADE-UN.

Es posible pensar que el crecimiento en la penetración de importaciones no representa un verdadero shock competitivo si las firmas domésticas sustituyen insumos locales de precio alto con insumos de precio más bajo importados desde China. Si bien esta hipótesis puede ser válida para algunas firmas, la Figura 4 muestra que este efecto debería estar dominado por el efecto directo provocado por un aumento en la presión competitiva, ya que la composición de las importaciones chilenas provenientes de China está sesgada hacia bienes manufacturados de consumo final $(70 \%)$ en relación a la composición de importaciones provenientes del resto del mundo, que contiene una mayor proporción de insumos intermedios (48\%) y bienes de capital (29\%). El sesgo hacia bienes de consumo importados desde China también se presenta cuando la comparación se realiza con otros 
países de salario bajo. En la sección de robustez se presenta una especificación que controla por un conjunto de variables adicionales, entre ellas la participación de insumos importados en el total de insumos utilizados por la firma, y los resultados permanecen inalterados.

En el año 2006 China se convirtió en el segundo país de origen más importante de las importaciones de Chile ( $14 \%$ del total importado) después de Estados Unidos $(18,8 \%)$. En el primer año de la muestra (1995) China estaba en la posición siete (3\%). El incremento en la participación China se produjo principalmente a expensas del deterioro de la participación de Estados Unidos, que pasó de 27\% en 1995 a 18,8\% en 2006 (Cuadro $1)$.

Algunas de las publicaciones relacionadas con este trabajo se concentraron en el efecto de las importaciones provenientes de todos los países de salario bajo en el empleo industrial (Bernard et al. (2006); Khandelwal (2010)). En este trabajo se decide utilizar únicamente a China principalmente por dos razones. En primer lugar, la participación de China en el total de importaciones Chilenas que provenien de países de salario bajo es en promedio superior al 90\% durante el período elegido (Cuadro 1). En segundo lugar, como se mostró previamente en la Figura 3, China exporta productos significativamente más baratos que similares exportados por el resto de los países de salario bajo.

FIGURA 4

Composición de las importaciones de Chile por tipo de bien

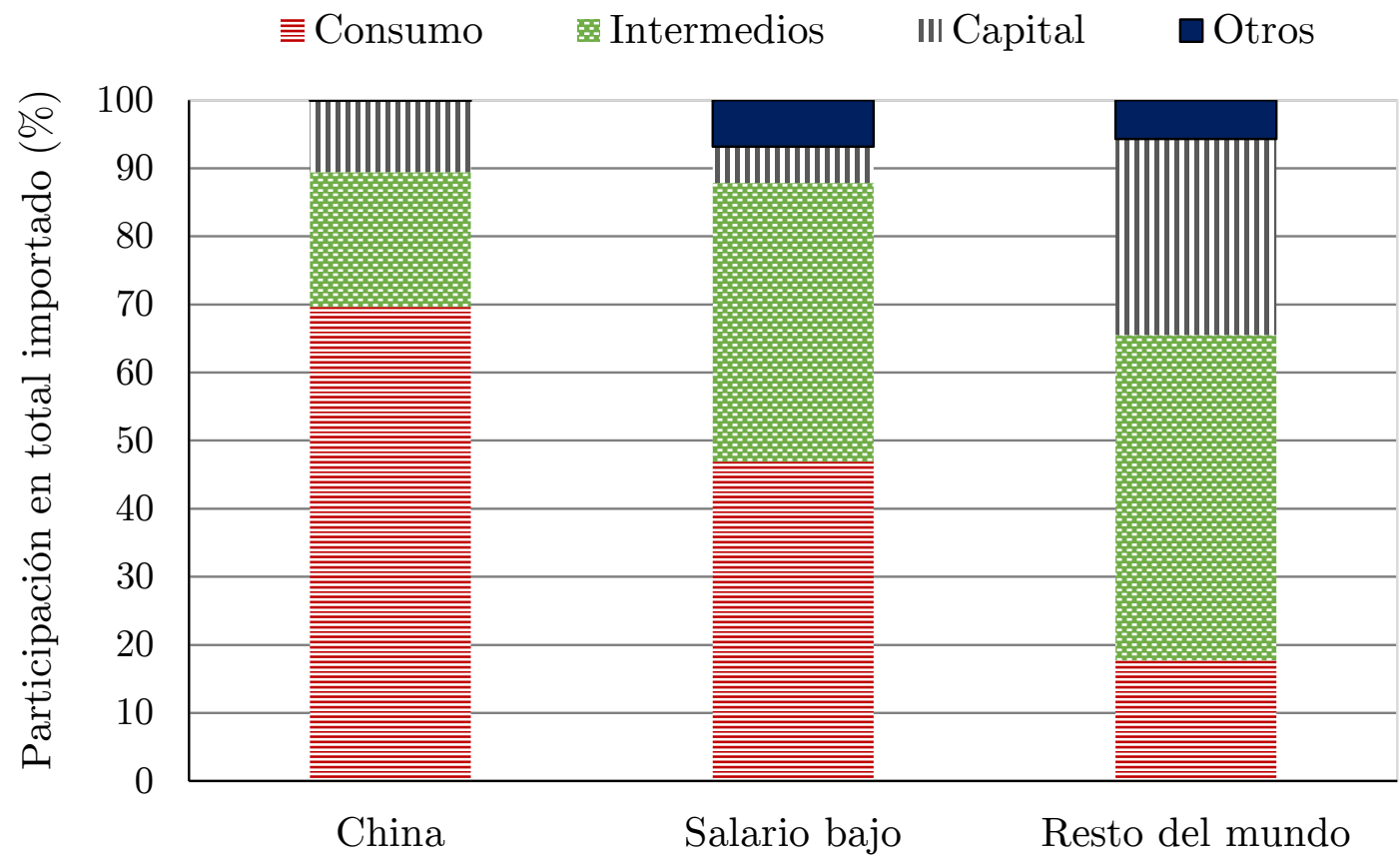

Notas. Composición promedio anual a través del periodo 1995-2006 según el tipo de bien importado y el origen de las importaciones (China versus Resto del Mundo). Para clasificar a los productos importados se utiliza la clasificación amplia de bienes BEC (Broad Economic Categories). Fuente. COMTRADE-UN. 


\section{CUADRO 1}

Evolución de la composición de importaciones de Chile según su origen

\begin{tabular}{cccccccccc}
\hline \hline \multirow{2}{*}{ Año } & \multirow{2}{*}{ China } & EE.UU. & Brasil & $\begin{array}{c}\text { Argen- } \\
\text { tina }\end{array}$ & $\begin{array}{c}\text { Ale- } \\
\text { mania }\end{array}$ & España & Italia & $\begin{array}{c}\text { Salario } \\
\text { bajo }\end{array}$ & Resto \\
\hline 1995 & 3.0 & 27.1 & 9.0 & 6.3 & 6.0 & 3.5 & 3.9 & 0.3 & 40.9 \\
1996 & 3.6 & 26.8 & 7.2 & 6.3 & 5.0 & 3.7 & 3.8 & 0.4 & 43.1 \\
1997 & 4.2 & 25.9 & 7.8 & 6.3 & 5.3 & 4.0 & 4.4 & 0.5 & 41.6 \\
1998 & 5.0 & 25.6 & 7.1 & 6.9 & 5.3 & 4.4 & 4.5 & 0.5 & 40.8 \\
1999 & 5.7 & 24.1 & 8.2 & 7.9 & 5.2 & 3.5 & 4.4 & 0.9 & 40.2 \\
2000 & 7.0 & 23.3 & 9.6 & 8.6 & 4.4 & 3.1 & 3.1 & 1.0 & 39.9 \\
2001 & 7.5 & 21.7 & 10.3 & 8.9 & 5.1 & 3.4 & 3.2 & 1.0 & 38.9 \\
2002 & 8.6 & 19.0 & 11.5 & 10.5 & 5.5 & 3.2 & 2.7 & 1.0 & 37.9 \\
2003 & 10.3 & 16.6 & 12.1 & 10.6 & 4.3 & 2.7 & 2.4 & 0.9 & 40.2 \\
2004 & 12.2 & 17.0 & 12.0 & 10.5 & 4.2 & 2.6 & 2.2 & 0.8 & 38.5 \\
2005 & 12.0 & 18.7 & 12.1 & 9.7 & 4.5 & 2.3 & 1.9 & 0.7 & 37.9 \\
2006 & 14.0 & 18.8 & 9.6 & 9.1 & 4.0 & 2.3 & 2.0 & 0.8 & 39.3 \\
\hline \hline
\end{tabular}

Notas. Se presenta la evolución de la composición de importaciones de Chile para los principales países de origen durante 1995-2006. Los países de salario bajo son aquellos que poseen menos del $5 \%$ del PBI de Estados Unidos durante 1972-2001. Fuente. COMTRADE-UN. 


\section{Marco teórico}

En el enfoque tradicional de Heckscher-Ohlin, los países poseen distintas proporciones de factores productivos y ello se traslada al contenido factorial de los bienes que producen y exportan. Dado que China es un país abundante en mano de obra no calificada, la apertura al comercio internacional por parte de dicho país representa un incremento en la oferta mundial de este tipo de trabajadores. Este modelo predice que aquellas industrias (del resto del mundo) que utilizan intensivamente mano de obra no calificada van a contraerse a medida que crece la penetración de importaciones provenientes desde China. Los modelos tradicionales permiten pensar en intuiciones básicas de este tipo. Guiados por una masa creciente de evidencia empírica, los modelos de comercio más recientes se concentran en el estudio de fenómenos de índole microeconómica que se producen al interior de las distintas unidades productivas. En estos modelos, el impacto de la globalización puede ser heterogéneo a través de distintas firmas incluso si estas pertenecen a una misma industria (finamente desagregada). En el caso de China por ejemplo, podría ocurrir que algunas firmas domésticas no compitan directamente con los productos exportados por China, o que compitan en otra dimensión del espacio que no es afectada por la competencia China (e.g. diferenciación por calidad).

Algunos trabajos son consistentes con la idea de que las firmas pueden escapar de la competencia de países de salario bajo, alterando la composición o mejorando la calidad de los productos que elaboran. Bernard, Jensen y Schott (2006) muestran que la probabilidad de cambiar de industria por parte de una firma aumenta significativamente cuando crece la penetración de importaciones de países de salario bajo. ${ }^{87}$ En la misma línea de investigación, Khandelwal (2010) muestra que el efecto de la penetración de importaciones de países de salario bajo en la producción y el empleo, es mayor en las industrias que poseen una escalera de calidad "más corta", definidas como aquellas industrias donde hay un menor espacio para la diferenciación por calidad. También es esparable que firmas más productivas tengan mayor probabilidad de aumentar la calidad de sus productos o modificar la composición de su plataforma de productos en respuesta a shocks competitivos de distinta índole.

El modelo propuesto por Melitz (2003) muestra que la exposición al comercio induce

\footnotetext{
${ }^{87}$ Utilizan cuatro paneles de firmas de EE.UU. durante 1977-1997. En este período, un total de 25.000 plantas cambian de industria. Estas representan en promedio un $7,8 \%$ de las firmas que sobreviven durante cada período de 5 años. En un trabajo anterior, Bernard y Jensen (2004) encuentran que la probabilidad de convertirse en exportador aumenta para aquellas plantas que se cambian de industria.
} 
únicamente a las firmas más productivas a entrar en el mercado de exportaciones, a la vez que simultáneamente induce a las menos productivas a salir del mercado. De manera inversa, se esperaría que la penetración de importaciones de un país de salarios bajos afecte en mayor medida a las firmas domésticas menos productivas que compiten en segmentos de mercado relativamente similares. Esta es la predicción teórica que se evalúa empíricamente en este trabajo. Como se muestra a continuación, es posible llegar a predicciones similares en el marco de un modelo más simple, como aquel propuesto en la primera parte de esta tesis. Este modelo predice que un aumento en la productividad de determinado grupo de firmas (de China) afecta de manera diferencial la participación de mercado de otro grupo de firmas (de Chile), en función de las capacidades que tengan estas últimas (e.g. productividad, calidad del producto elaborado, etc.).

Recordemos brevemente el modelo. Por el lado lado de la demanda, se asume que los consumidores eligen aquella variedad que les provee un mayor nivel de utilidad indirecta (modelo logit). ${ }^{88}$ Por el lado de la oferta, las firmas internacionales ofrecen determinada variedad $s$ de un producto diferenciado $j$, y eligen precio y calidad en pos de maximizar sus beneficios. Se asume una estructura de mercado de competencia monopolística y rendimientos constantes a escala. Para simplificar la discusión, en el análisis que sigue se decide omitir los subíndices $s$ y $t$, pues no agregan nada en la discusión. Se asume que una firma $j$ está radicada en Chile o en China (que se denotan con los supraíndices CLE y CHN, respectivamente). La tecnología de la firma se resume en el parámetro $\varphi_{j}$ asociado a su nivel de productividad factorial. Por lo tanto, el costo marginal $c\left(\theta_{j}, \varphi_{j}\right)$ depende de la calidad del producto elaborado $\left(\theta_{j}\right)$ y de la productividad de la firma $\left(\varphi_{j}\right)$. Se supone que el costo marginal $c($.$) es estrictamente creciente y convexo en calidad (derivadas primera$ y segunda estrictamente mayores a cero) y decreciente en productividad. El problema de la firma es el siguiente:

$$
\max _{\left(p_{j}, \theta_{j}\right)} \Pi_{j}=\left[p_{j}-c\left(\theta_{j}, \varphi_{j}\right)\right] w_{j}\left(p_{j}, \theta_{j}, \varphi_{j}\right)
$$

Luego, las CPO que determinan el precio y la calidad de equilibrio de cada firma son las siguientes:

\footnotetext{
${ }^{88}$ En la primera parte se asume cierta correlación en la utilidad que proveen las distintas variedades de un mismo producto. Ello da origen a un modelo con estructura anidada (nested logit). En esta parte, se utiliza la versión más simple del modelo (logit). Ello no altera las predicciones y permite simplificar la discusión.
} 


$$
\begin{aligned}
p_{j} & =\alpha(.) c\left(\theta_{j}, \varphi_{j}\right) \\
\frac{\partial c_{j}(.)}{\partial \theta_{j}} & =p_{j}-c\left(\theta_{j}, \varphi_{j}\right)
\end{aligned}
$$

Cada firma elige la combinación óptima de precio y calidad $\left(\theta_{j}^{*}, \varphi_{j}^{*}\right)$ que maximiza sus beneficios. Dado que se asume un modelo tipo logit, la demanda (o market share) que enfrenta cada firma está dada por la siguiente ecuación:

$$
w_{j}^{*}=\frac{\exp \left(\theta_{j}^{*}-\alpha p_{j}^{*}\right)}{\sum_{k \in K} \exp \left(\theta_{k}-\alpha p_{k}\right)}
$$

Notar que la participación de mercado de una firma es creciente en la calidad y decreciente en el precio:

$$
\begin{aligned}
\frac{\partial w_{j}}{\partial \theta_{j}} & =\frac{\exp \left(\theta_{j}^{*}-\alpha p_{j}^{*}\right)}{\sum_{k \in K} \exp \left(\theta_{k}-\alpha p_{k}\right)}=w_{j}>0 \\
\frac{\partial w_{j}}{\partial p_{j}} & =(-\alpha) \frac{\exp \left(\theta_{j}^{*}-\alpha p_{j}^{*}\right)}{\sum_{k \in K} \exp \left(\theta_{k}-\alpha p_{k}\right)}=-\alpha w_{j}<0
\end{aligned}
$$

Es fácil mostrar que el precio es decreciente en el nivel de productividad de la firma. Si se deriva la primera CPO con respecto a $\varphi_{j}$ se tiene que $\frac{\partial p_{j}}{\partial \varphi_{j}}=\alpha \frac{\partial c_{j}(.)}{\partial \varphi_{j}}<0$, pues se supuso que $\frac{\partial c_{j}(.)}{\partial \varphi_{j}}<0$. Por su parte, la calidad es creciente en el nivel de productividad de la firma. Dado $c\left(\theta_{j}, \varphi_{j}\right)$, aplicando teorema de la función implícita, se tiene: $\frac{\partial c_{j}(.)}{\partial \varphi_{j}}+\frac{\partial c_{j}(.)}{\partial \theta_{j}} \frac{\partial \theta_{j}}{\partial \varphi_{j}}=0$. Reordenando los términos se obtiene el resultado deseado $\frac{\partial \theta_{j}}{\partial \varphi_{j}}=-\frac{\frac{\partial c_{j}(.)}{\partial \theta_{j}}}{\frac{\partial c_{j}(\cdot)}{\partial \varphi_{j}}}>0$, dados los supuestos $\frac{\partial c_{j}(.)}{\partial \theta_{j}}>0$ y $\frac{\partial c_{j}(.)}{\partial \varphi_{j}}<0$.

Por lo tanto, se tiene que la participación de mercado de una firma es creciente en su productividad:

$$
\frac{\partial w_{j}}{\partial \varphi_{j}}=\frac{\partial w_{j}}{\partial \theta_{j}} \frac{\partial \theta_{j}}{\partial \varphi_{j}}+\frac{\partial w_{j}}{\partial p_{j}} \frac{\partial p_{j}}{\partial \varphi_{j}}>0
$$

Ya están generadas las condiciones para demostrar el efecto que provoca un aumento en la productividad de las firmas de China sobre la participación de mercado de las firmas de Chile. Dado el supuesto de que solo existen firmas de Chile (CLE) y de China (CHN) que satisfacen el mercado, se tiene que $\sum_{i \in C L E} w_{i}^{C L E}+\sum_{j \in C H N} w_{j}^{C H N}=1$. 
Proposición 1: un aumento en la productividad de las firmas de China aumenta su participación de mercado, en detrimento de la participación de las firmas de Chile.

Demostración:

Se deriva directamente del resultado de la siguientes derivadas:

$$
\begin{aligned}
\frac{\partial w_{j}^{C H N}}{\partial \varphi_{j}^{C H N}} & =w_{j}^{C H N}\left[\frac{\partial \theta_{j}^{C H N}}{\partial \varphi_{j}^{C H N}}-\alpha \frac{\partial p_{j}^{C H N}}{\partial \varphi_{j}^{C H N}}\right]>0 \\
\frac{\partial w_{i}^{C L E}}{\partial \varphi_{j}^{C H N}} & =-w_{i}^{C L E} \sum_{j \in C H N} \exp \left(\theta_{j}-\alpha p_{j}\right)\left[\frac{\partial \theta_{j}^{C H N}}{\partial \varphi_{j}^{C H N}}-\alpha \frac{\partial p_{j}^{C H N}}{\partial \varphi_{j}^{C H N}}\right]<0
\end{aligned}
$$

Proposición 2: la reducción de la participación de mercado de una firma $i$ de Chile en respuesta al aumento de la productividad China es decreciente en el nivel de productividad/calidad de la firma $i$.

\section{Demostración:}

Se deriva directamente del resultado de la siguiente derivada:

$$
\frac{\partial\left(\frac{\partial w_{i}^{C L E}}{\partial \varphi_{j}^{C H N}}\right)}{\partial \varphi_{i}^{C L E}}=-w_{i}^{C L E} \sum_{j \in C H N} \exp \left(\theta_{j}-\alpha p_{j}\right)\left[\frac{\partial \theta_{j}^{C H N}}{\partial \varphi_{j}^{C H N}}-\alpha \frac{\partial p_{j}^{C H N}}{\partial \varphi_{j}^{C H N}}\right]\left[\frac{\partial \theta_{i}^{C L E}}{\partial \varphi_{i}^{C L E}}-\alpha \frac{\partial p_{i}^{C L E}}{\partial \varphi_{i}^{C L E}}\right]<0
$$




\section{Estimación}

\subsection{Fuentes de información}

Los microdatos utilizados en esta parte de la tesis provienen de dos fuentes. Por un lado, se utiliza un censo anual de manufacturas (Encuesta Nacional Industrial Anual, ENIA) que posee estructura de panel. Esta encuesta es realizada por el Instituto Nacional de Estadísticas de Chile (INE). Los datos comprenden el universo de firmas Chilenas con diez o más empleados que elaboran algún tipo de manufactura. Se cuenta con estos datos a partir del año 1995. Se decide detener el período muestral en el año 2006 para evitar posibles factores de confusión derivados del inicio de la crisis financiera global en el año 2007, que afectó severamente los patrones del comercio mundial. ${ }^{89}$ Esta base de datos también ha sido utilizado por trabajos importantes de la literatura, tales como Levinsohn (1999), Pavcnik (2002), y Levinsohn and Petrin (2003), entre muchos otros.

El módulo principal de la encuesta incluye información sobre las características de la firma, siendo las más relevantes el número de empleados, el gasto total en salarios, compra de bienes de inversión, insumos intermedios, ingresos por ventas, valor bruto de producción, afiliación a la industria, región de actividad, etc. Las principales variables de resultado que interesan en este análisis son el empleo total de la firma, los ingresos por ventas de productos finales y la probabilidad de salida del mercado. Es importante destacar que la información disponible permite estimar la productividad total de los factores (TFP) de cada firma, siguiendo uno de los avances más recientes en la literatura dedicada a la estimación funciones de producción. En particular, se sigue el método propuesto por Ackerberg, Caves y Frazer (2015).

En segundo lugar, se utilizan datos de comercio internacional que provienen de las estadísticas de comercio de productos básicos de Naciones Unidas (UN-COMTRADE) ${ }^{90}$ Recordar que estos datos también se utilizan intensivamente en la primera parte de la tesis. Los datos tienen forma de panel de flujos bilaterales de comercio internacional con un nivel de desagregación de productos de 6 dígitos de la clasificación internacional del Sistema Armonizado. Los datos incluyen información sobre el valor de las importaciones/exportaciones (medidos en dólares), las cantidades, los socios comerciales y los códigos de productos. Estos datos son recopilados, procesados y homogeneizados por

\footnotetext{
${ }^{89}$ Desafortunadamente, no es posible realizar el análisis para los años subsiguientes porque el INE interrumpió la estructura del panel en el año 2008, alegando problemas de confidencialidad con respecto a los identificadores de las empresas.

${ }^{90}$ Esta información está disponible públicamente en https://comtrade.un.org/.
} 
Naciones Unidas, a partir de la información provista por las autoridades estadísticas de más de 100 países y regiones. Esta base de datos también ha sido utilizada por muchos trabajos de la literatura de comercio (por ejemplo, Autor et al. (2013, 2014), Acemoglu et al. (2016), Amiti y Khandelwal (2013) y Hummels et al. (2014)). Al fusionar estos datos con la información a nivel firma proveniente de la ENIA, es posible construir una medida anual de penetración de importaciones (PI) de China. Es posible construir esta medida a nivel industria, con una desagregación de 4 dígitos de la clasificación industrial internacional uniforme (CIIU, Rev. 3). La PI China se calcula como el valor total de las importaciones provenientes de China dividido la absorción doméstica:

$$
\operatorname{PIChina~}_{j t}=\frac{M_{j t}^{\text {China }}}{\left[Q_{j t}+M_{j t}-X_{j t}\right]}
$$

Donde $Q_{j t}, M_{j t}$ y $X_{j t}$ representan el valor total de producción, las importaciones y las exportaciones correspondientes a la industria $j$ en el año $t$, respectivamente. ${ }^{91}$

Estos datos también se utilizan con otros fines. Primero, para construir variables instrumentales para PIChina $a_{j}$. La variable instrumental es un promedio simple de la participación de China en las importaciones de un conjunto de países $C$ :

$$
S h_{j t}^{C h i n a}=\frac{1}{C} \sum_{c \in C} \frac{M_{c j t}^{C h i n a}}{M_{c j t}^{M u n d o}}
$$

Donde $M_{c j t}^{\text {China }}$ es el valor total de las importaciones provenientes de China en cada industria-año del país $c$, mientras que $M_{c j t}^{M u n d o}$ es el valor total de las importaciones de la industria $j$ en el año $t$ en el país $c$. Con el objetivo de capturar el shock de oferta inherente a la economía China, este índice (que varía a nivel año-industria) se calcula para un conjunto de países desarrollados que poseen un nivel de desarrollo industrial elevado. Este grupo incluye a los siguientes países de altos ingresos: Australia, Dinamarca, Finlandia, Alemania, Japón, Nueva Zelanda, España y Suiza. ${ }^{92}$

Los datos de COMTRADE también se utilizan para ilustrar (de manera descriptiva)

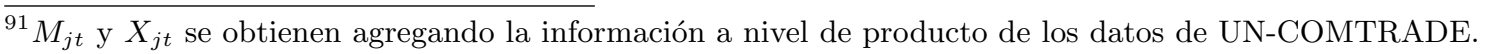
Para ello es necesario utilizar una tabla de conversión entre las clasificaciones del Sistema Armonizado y la Internacional Industrial Uniforme. $Q_{j t}$ se calcula agregado la información de las firmas de una misma industria, a partir de la información contenida en la ENIA.

${ }^{92}$ Este grupo de países es el mismo que utilizan Autor et al. (2014) y Acemoglu et al. (2016). Se evalúa la robustez de los resultados frente a la utilización de grupos de países alternativos (G7, OECD, América Latina y Mercosur) y los resultados se mantienen. También se cuenta con información de la productividad China agregada por industrias, a partir de las estimaciones realizadas por Brandt, van Biesebroeck y Zhang (2012). Desafortunadamente, no es posible utilizar esta información por la imposibilidad de convertir la clasificación ajustada que utilizan estos autores con la clasificación CIIU.
} 
el grado de presión competitiva provocado por la entrada de productos importados desde China (ver Sección 3.3). Para ello, se estima la diferencia de precios de los productos exportados desde China en comparación con sus pares exportados desde otros países de salario bajo, separadamente para distintas industrias de un conjunto representativo de países del mundo que importan estos productos. Siguiendo la práctica estándar en la literatura de comercio internacional, se utiliza el valor unitario (valor sobre cantidad importada) como la variable que aproxima el precio promedio de un producto. ${ }^{93}$

Para aumentar la calidad de los datos y evitar inconsistencias, la muestra utilizada se recorta en algunas dimensiones. Primero, se eliminan aquellas firmas que no cuentan con información completa sobre la utilización de insumos (mano de obra, capital, insumos intermedios) o sobre el valor de la producción. En segundo lugar, se eliminan aquellas empresas que están presentes en un solo año de la muestra y aquellas que dejan de reportar información en un año determinado. Dado que la estimación de la TFP utiliza variables rezagadas como instrumentos es necesario tener información continua sobre producción y utilización insumos (Ackerberg, Caves y Frazer, 2015). Finalmente, se elige trabajar con aquellas industrias que tienen al menos diez firmas diferentes durante el período muestral, en pos de evitar cualquier sesgo derivado de utilizar industrias que no son representativas del sector manufacturero Chileno. ${ }^{94}$ La muestra final representa dos tercios del empleo total en manufacturas y dos tercios del valor total de la producción.

\subsection{Estadísticas descriptivas}

El Cuadro 2 presenta estadísticas descriptivas básicas (media y desvío estándar) para las principales variables de interés. Estas estadísticas se calculan para todas las firmas de la muestra y separadamente para las firmas que están en distintos quintiles de la distribución sectorial de TFP. Los resultados sugieren la existencia de una correlación positiva entre la productividad estimada de la firma y el número total de trabajadores, el salario promedio, la intensidad de uso del capital y la participación en el comercio internacional, en línea con muchos de los hallazgos previos en la literatura (e.g. Bernard, Jensen, Redding y Schott (2007); Verhoogen (2008)). ${ }^{95}$ Notar que existe un considerable

\footnotetext{
${ }^{93}$ Recordar que la idea de utilizar este grupo de países de salario bajo para realizar la comparación de precios es controlar por diferencias de calidad de los productos importados.

${ }^{94}$ Las industrias que tienen menos de 10 firmas representan tan solo el $1 \%$ del empleo total y el $0,25 \%$ del valor total de la producción. Los resultados se mantienen si estas industrias se incluyen en el análisis. Para más detalles, ver la sección de robustez.

${ }^{95}$ La única excepción es que la relación $\mathrm{K} / \mathrm{L}$ no aumenta entre los quintiles uno y dos. Ello se explica fundamentalmente por diferencias en los valores reportados para máquinas y edificios. En el resto de las variables, las firmas que están en los primeros dos quintiles son relativamente similares.
} 
grado de variabilidad en las principales variables de resultado, tanto en las firmas que pertenecen a un mismo quintil como en las firmas que se encuentran en los distintos quintiles de distribución sectorial de TFP.

En promedio, un 7,5\% de las firmas salen del mercado cada año. Como es de esperar, la tasa de salida disminuye cuanto mayor es la TFP de la firma. Mientras que un 10,47\% de las firmas del primer quintil cierran cada año en promedio, esta fracción disminuye a 5,47 \% para aquellas empresas ubicadas en el quintil más alto de la distribución de TFP sectorial. La cantidad promedio de trabajadores en una firma es 76. En promedio, las empresas del quinto quintil son casi diez veces más grandes en términos de trabajadores totales y tienen más de cinco veces el capital por trabajador que aquellas empresas pertenecientes al primer quintil (215 vs. 22 individuos, y 34,630 US\$ vs. 6,860 US\$, respectivamente). El salario promedio que pagan las firmas más productivas es aproximadamente tres veces el salario promedio que pagan las firmas menos productivas. Tan solo un 5,79\% $(9,05 \%)$ de las firmas menos productivas realizan exportaciones (importaciones), mientras que esta fracción se incrementa al 50,5\% (48,3\%) para las firmas ubicadas en el quintil de mayor productividad.

El Cuadro 3 presenta estadísticas descriptivas de la distribución de la penetración de importaciones Chinas (variable endógena) y de la participación promedio de China en las importaciones de los países de altos ingresos (variable instrumental). La PI China promedio a través de todas las industrias durante 1995-2006 es de 4,89\% y presenta un grado de variabilidad considerable (el desvío es 11,76). La PI China alcanza un valor superior al 90\% en la industria de fabricación de juegos y juguetes (CIIU = 3694). Ello significa que 9 de cada 10 dólares de producto de esta industria son importados desde China. Los resultados son robustos a la eliminación de esta industria y a la exlusión de todas aquellas industrias pertenecientes al sector juguetes y otros. Los resultados también se mantienen si se deja fuera de la muestra el $10 \%$ de los valores extremos de PI China (se trabaja con PI China de 0 a $32 \%$ ). Por su parte, la participación promedio de China en las importaciones de los países de altos ingresos es 7,98\%, y también presenta un grado de variabilidad considerable (el desvío es 10,21). 


\section{CUADRO 2}

Estadísticas descriptivas por quintil de productividad

\begin{tabular}{|c|c|c|c|c|c|c|}
\hline & $\begin{array}{l}\mathrm{Q} 1 \\
\end{array}$ & 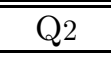 & Q33 & 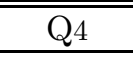 & 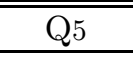 & Todas \\
\hline Tasa de salida (\%) & $\begin{array}{c}10.47 \\
(30.62)\end{array}$ & $\begin{array}{c}7.71 \\
(26.67)\end{array}$ & $\begin{array}{c}6.99 \\
(25.5)\end{array}$ & $\begin{array}{c}6.85 \\
(25.26)\end{array}$ & $\begin{array}{c}5.47 \\
(22.74)\end{array}$ & $\begin{array}{c}7.50 \\
(26.34)\end{array}$ \\
\hline Ingresos & $\begin{array}{c}164 \\
(253)\end{array}$ & $\begin{array}{c}331 \\
(502)\end{array}$ & $\begin{array}{c}668 \\
(1,095)\end{array}$ & $\begin{array}{c}2,221 \\
(7,039)\end{array}$ & $\begin{array}{c}16,928 \\
(76,324)\end{array}$ & $\begin{array}{c}4,061 \\
(34,881)\end{array}$ \\
\hline Trabajadores & $\begin{array}{l}21.96 \\
(29.9)\end{array}$ & $\begin{array}{c}27.05 \\
(30.65)\end{array}$ & $\begin{array}{c}38.40 \\
(38.41)\end{array}$ & $\begin{array}{c}77.63 \\
(137.12)\end{array}$ & $\begin{array}{l}215.36 \\
(273.73)\end{array}$ & $\begin{array}{c}76.07 \\
(156.94)\end{array}$ \\
\hline Salario promedio & $\begin{array}{c}1.78 \\
(1.29)\end{array}$ & $\begin{array}{c}2.05 \\
(1.52)\end{array}$ & $\begin{array}{l}2.38 \\
(1.5)\end{array}$ & $\begin{array}{c}3.10 \\
(4.04)\end{array}$ & $\begin{array}{c}4.23 \\
(3.78)\end{array}$ & $\begin{array}{c}2.71 \\
(2.85)\end{array}$ \\
\hline Ratio K/L & $\begin{array}{c}6.86 \\
(42.42)\end{array}$ & $\begin{array}{c}5.35 \\
(14.11)\end{array}$ & $\begin{array}{c}7.29 \\
(43.58)\end{array}$ & $\begin{array}{c}11.28 \\
(28.47)\end{array}$ & $\begin{array}{c}34.63 \\
(168.85)\end{array}$ & $\begin{array}{c}13.08 \\
(82.22)\end{array}$ \\
\hline Share exporta (\%) & $\begin{array}{c}5.79 \\
(23.36)\end{array}$ & $\begin{array}{c}7.53 \\
(26.39)\end{array}$ & $\begin{array}{c}16.10 \\
(36.75)\end{array}$ & $\begin{array}{c}28.98 \\
(45.37)\end{array}$ & $\begin{array}{c}50.50 \\
(50 .)\end{array}$ & $\begin{array}{c}21.78 \\
(41.27)\end{array}$ \\
\hline Share importa (\%) & $\begin{array}{c}9.05 \\
(28.69)\end{array}$ & $\begin{array}{c}11.81 \\
(32.27)\end{array}$ & $\begin{array}{c}19.03 \\
(39.25)\end{array}$ & $\begin{array}{c}26.80 \\
(44.29)\end{array}$ & $\begin{array}{c}48.29 \\
(49.97)\end{array}$ & $\begin{array}{c}22.99 \\
(42.08)\end{array}$ \\
\hline$N$ & 8,860 & 8,874 & 8,872 & 8,874 & 8,866 & 44,346 \\
\hline
\end{tabular}

Notas. Desvíos estándar en paréntesis. TFP calculada por el método propuesto por Ackerberg, Caves y Frazer (2015) y normalizada por la TFP promedio anual por sector. Sector se define a 2 dígitos de la clasificación ISIC Rev. 3. Quintiles construidos por sector. Salida $=0$ en los años en los que una firma está activa $\mathrm{y}=1$ el último año antes de que la firma cierre (deje el panel). Ingresos por ventas, salarios y ratio K/L medidos en millones de pesos Chilenos del año 1995. Exporta (importa) significa que la firma declara un valor positivo de exportaciones (importaciones). Tipo de cambio promedio de 1995: 396.8 pesos/U.S.\$1. Fuente. Encuesta Nacional Industrial Anual de Chile (INE).

\section{CUADRO 3}

Estadísticas descriptivas PI China

\begin{tabular}{lccccccc}
\hline \hline & Media & DE & P25 & P50 & P75 & Min. & Max. \\
\cline { 2 - 7 } & 4.89 & 11.76 & 0.02 & 0.42 & 3.19 & 0 & 91.86 \\
PI China & & & & & & & \\
$\begin{array}{l}\text { Share China en M } \\
\text { países altos ingresos }\end{array}$ & 7.98 & 10.21 & 1.49 & 3.74 & 10.02 & 0 & 53.77 \\
\hline \hline
\end{tabular}

Notas. Estadísticas descriptivas de la variable independiente y la variable instrumental. La muestra utilizada ( $\mathrm{N}=936)$ se compone de 78 industrias durante 12 años entre 1995-2006. Industrias definidas a 4 dígitos CIIU Rev. 3. La PI China para Chile se mide como el valor total de las importaciones provenientes de China dividido por la absorción doméstica (producción menos exportaciones netas). La participación China $\mathrm{M}$ de países de altos ingresos es el promedio simple de la participación de China en las importaciones totales de los siguientes países: Australia, Dinamarca, Finlandia, Alemania, Japón, Nueva Zelanda, España y Suiza. Fuentes. INE-ENIA y UN-COMTRADE.

\subsection{Estrategia empírica}

Se realizan estimaciones a nivel firma y a nivel industria. La ecuación de regresión principal a nivel firma es la siguiente: 


$$
Y_{i j t}=\beta_{0}+\beta_{1} \text { PIChina }_{j t}+X^{\prime} \beta+\alpha_{i}+\delta_{t}+\varepsilon_{i j t}
$$

Donde $i, j$ y $t$ indexan firmas, industrias y años, respectivamente; $\alpha_{i}$ es un efecto fijo a nivel firma; $\delta_{t}$ es un efecto fijo temporal y $\varepsilon_{i j t}$ representa el término de error del modelo.

Las principales variables de resultado $Y_{i j t}$ son el empleo total de la firma (número de trabajadores), el valor final de los productos vendidos (ingresos por ventas) y la probabilidad de salir del mercado de la firma. ${ }^{96}$ Para construir dicha probabilidad, una observación toma el valor 1 en el año $t$ si la firma cierra en el año siguiente $t+1$, y toma el valor 0 en caso contrario. El coeficiente de interés $\beta_{1}$ es aquel que acompaña a

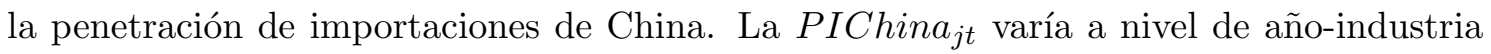
(a 4 dígitos de la CIIU, Rev. 3). Se incluye un amplio conjunto de variables de control a nivel firma (TFP, intensidad de uso del capital, estatus de importador/exportador), la penetración de importaciones provenientes de otros países distintos de China (que se construye análogamente a PIChina $a_{j}$ y por tanto también varía a nivel año-industria). La especificación preferida incluye efectos fijos por año-región y año-sector para controlar por shocks que varían en el tiempo y que afectan a distintas regiones y sectores de manera diferencial. ${ }^{97}$ Estas regresiones explotan la variabilidad en la penetración de importaciones de China a lo largo del tiempo dentro de cada sector (región).

La PI China es potencialmente endógena porque los shocks a la demanda en una industria (e.g. precio de los insumos, crisis macroeconómica) afectan simultáneamente los resultados de una firma (ventas, importaciones, decisiones de contratación y despido), el mercado de trabajo y la demanda de importaciones. Para tratar este problema de endogeneidad, se aplica una estrategia de variables instrumentales que también ha sido utilizada por otros trabajos recientes de la literatura (e.g. Autor et al. (2013, 2014), Acemoglu et al. (2016), Bloom et al. (2015)). La variable PIChina ${ }_{j t}$ se instrumenta con la participación promedio de China en las importaciones de las distintas industrias correspondientes a un grupo de países de altos ingresos: Australia, Dinamarca, Finlandia, Alemania, Japón, Nueva Zelanda, España y Suiza. ${ }^{98}$ El instrumento pretende capturar

\footnotetext{
${ }^{96}$ Los ingresos por ventas y el resto de las variables monetarias se deflactan por un índice de precios a nivel industria obtenido del INE de Chile.

${ }^{97}$ Se construyen 10 sectores definidos de manera amplia, donde cada sector incluye un conjunto de industrias de manufacturas relativamente similares: Alimentos/tabaco (14), Textiles/cueros (10), Maderas/muebles (6), Papeles/impresiones (7), Químicos/petróleo (6), Plásticos/ caucho/vidrio (4), Metales(7), Máquinas/Maq. eléctricas (13), Transporte (3), Juguetes/otros (8).

${ }^{98}$ Este es el mismo grupo de países utilizado por Autor et al. (2013, 2014). Los resultados son robustos a
} 
el shock de oferta explicado por factores inherentes a la economía China (e.g. aumentos genuinos de productividad) que le permitieron ganar participación a lo largo del tiempo en determinadas industrias de distintos países industriales altamente competitivos. La evolución de esta variable se utiliza para predecir la evolución de la PI China en las industrias de Chile.

La correlación no condicional de la primera etapa muestra que el instrumento tiene un fuerte poder predictivo. El coeficiente estimado vale $0.96(0.13)$ y la regresión presenta un R-cuadrado de 0.70 (Figura 5). Luego, la ecuación (5.3) se estima por mínimos cuadrados en dos etapas (MC2E). La primera etapa de la especificación preferida incluye las variables de control a nivel firma, más efectos fijos a nivel firma, año-sector y año-región. El Cuadro 4 presenta los resultados de estimar la primera etapa para las regresiones sin interacción (columna 1), y los coeficientes estimados en la primera etapa para la especificación de efectos heterogéneos (cols. 2 y 3) que se explican en la Sección 6.2. En el primer caso, el coeficiente para la VI (0.79) está precisamente estimado (con un error estándar de 0.17) y la regresión presenta un alto poder predictivo (R-cuadrado de 0.79). En el segundo caso, los coeficientes relevantes también son estadísticamente significativos. Todas las variables superan cómodamente el test de instrumentos débiles. La validez de esta estrategia empírica depende del cumplimiento de los siguientes supuestos de identificación: (i) el crecimiento de las exportaciones de China es exógeno (impulsado por TFP, infraestructura, migración, etc.) y (ii) los shocks a la demanda de una industria no están correlacionados entre Chile y el conjunto de países de altos ingresos. Estos resultados también se presentan gráficamente en la Figura 6. A diferencia del gráfico anterior, en este caso las observaciones se agrupan en (20) segmentos del mismo tamaño para facilitar la interpretación gráfica. Cada punto representa el promedio condicional de la PI China y la VI dentro de cada segmento, y se incluye la predicción lineal de la PI China en la participación promedio. Nuevamente, se advierte el elevado poder predictivo de la primera etapa de la regresión.

utilizar varios grupos alternativos de países, tales como el G7, la OECD, América Latina y el Mercosur. 
FIGURA 5

Correlación no condicional

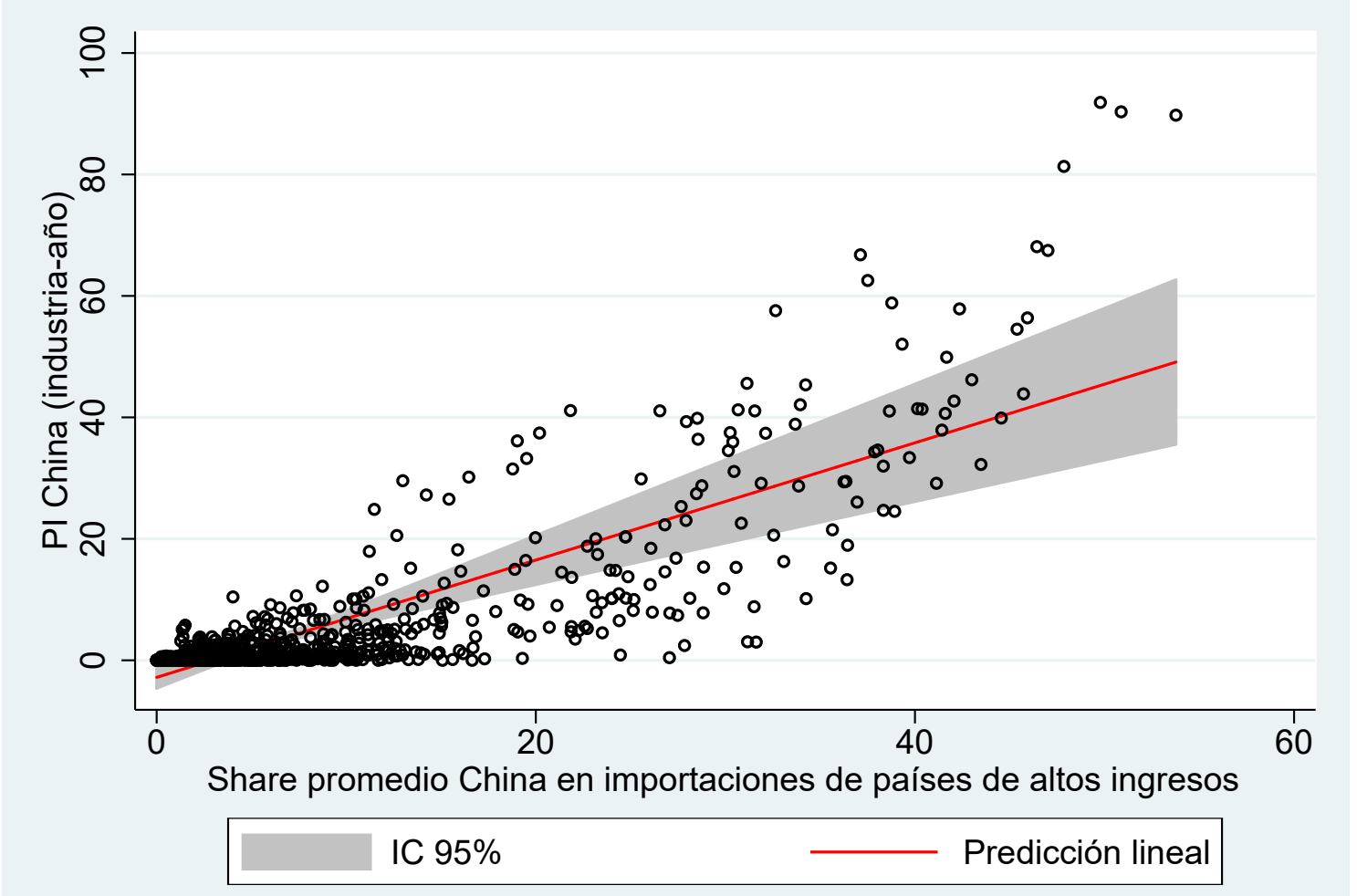

Notas. Cada punto representa una combinación año-industria. Los países de altos ingresos utilizados para construir el promedio de participación China en las importaciones de cada industria son Australia, Dinamarca, Finlandia, Alemania, Japón, Nueva Zelanda, España y Suiza. Este grupo de países es el mismo que utilizan Autor et al. (2013). Los intervalos de confianza al 95\% se construyen a partir de errores estándar robustos clusterizados por sectores a dos dígitos (ISIC Rev. 3). La pendiente de la predicción lineal es .96 con un error estándar de .13, y la regresión tiene un R-cuadrado de .70. Fuentes. ENIA-INE y COMTRADE-UN. 
FIGURA 6

Primera etapa de la regresión

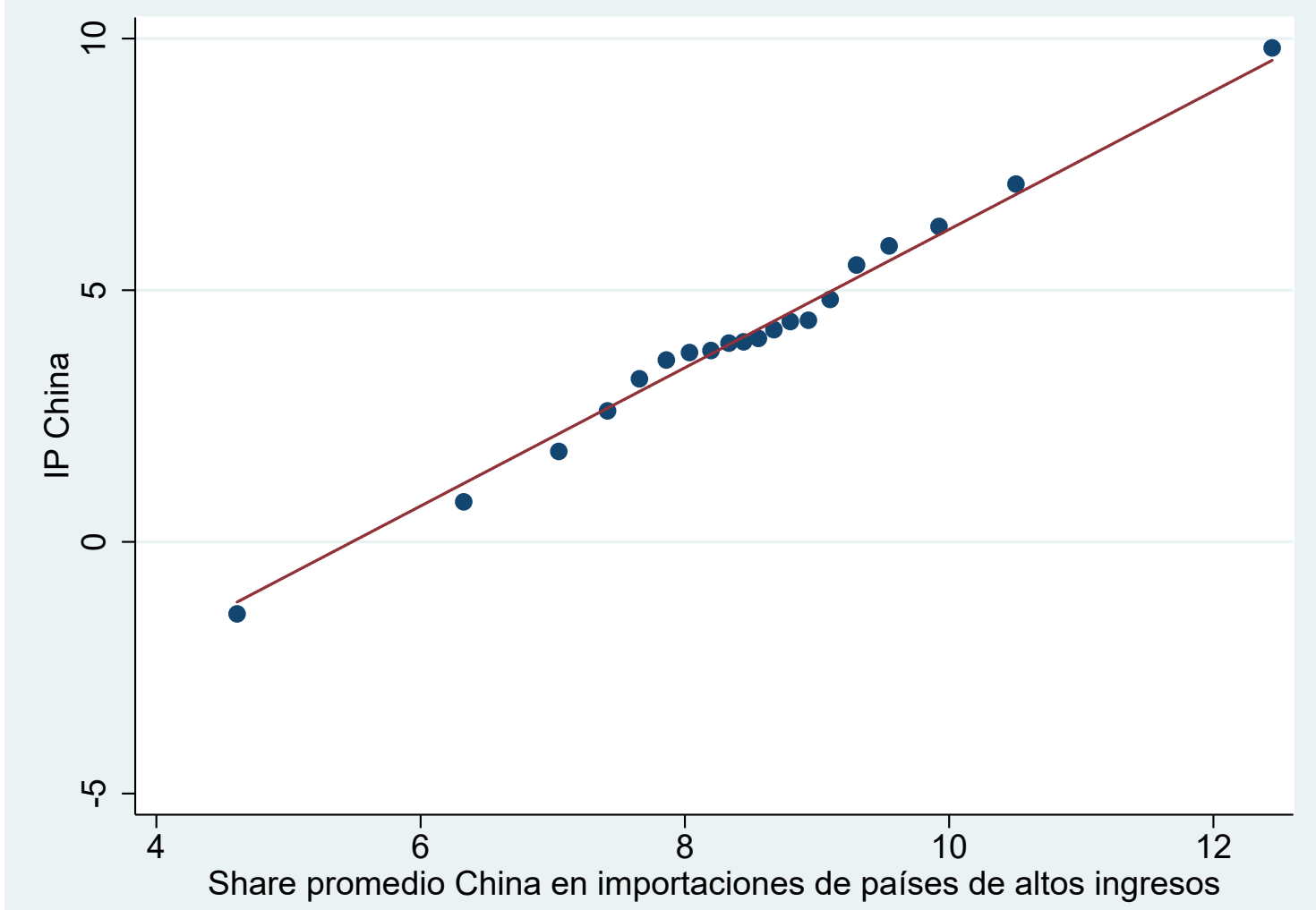

Notas. Primera etapa de la regresión que incluye los siguientes controles: PI de otros países, productividad total de factores, ratio K/L, condición de importador/exportador y efectos fijos a nivel firma y año. Las observaciones se agrupan en (20) segmentos del mismo tamaño para facilitar su interpretación gráfica. Cada punto representa el promedio (condicional) de ambas variables dentro de cada segmento, y se incluye la predicción lineal de la PI China en el share promedio. Fuentes. ENIA-INE y COMTRADE-UN. 


\section{CUADRO 4}

Estimación de la primera etapa

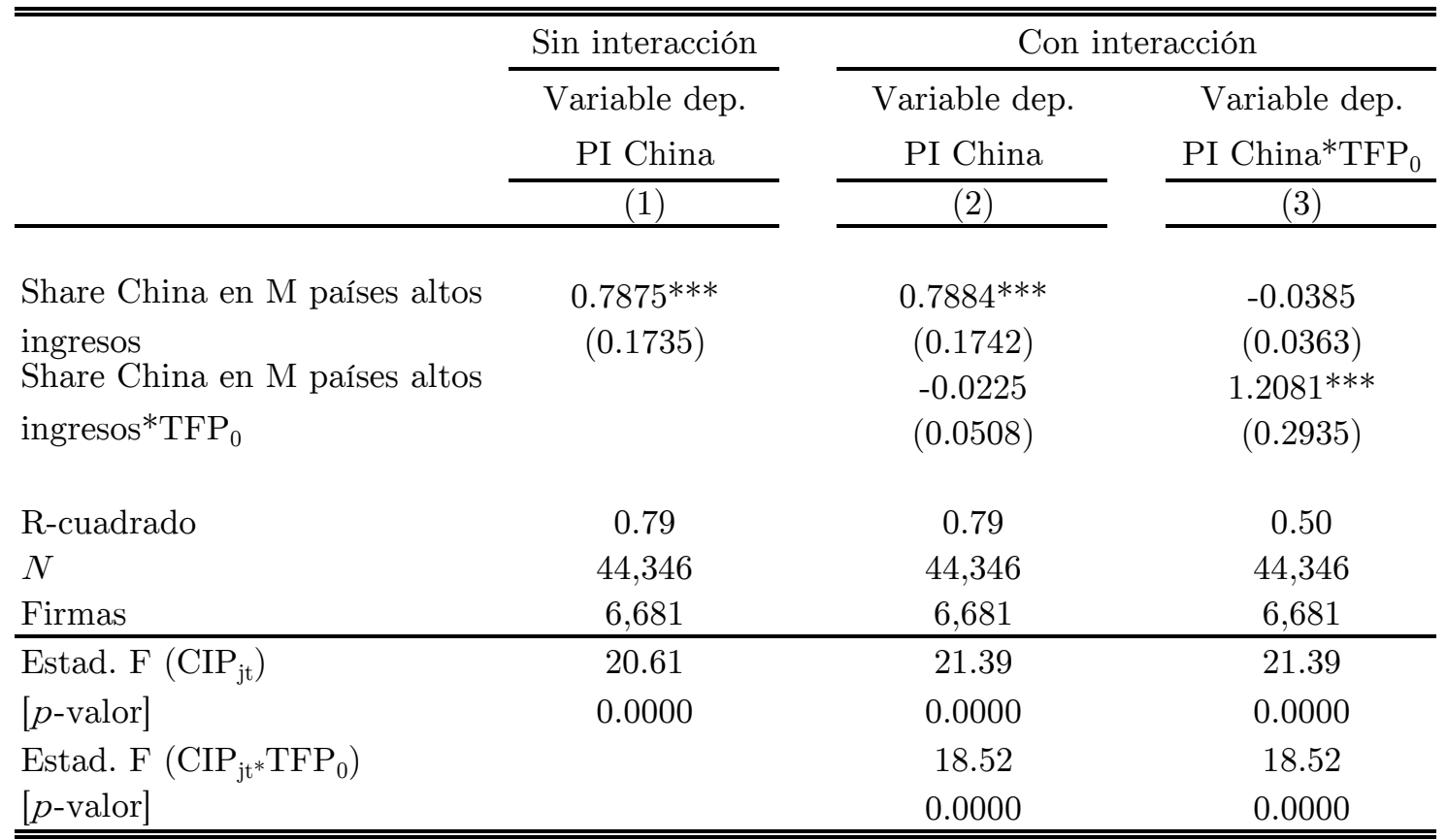

Notas. La PI China se mide como el valor total de las importaciones provenientes de China dividido por la absorción doméstica. Esta variable se instrumenta con la participación promedio de China en las importaciones de un conjunto de países de altos ingresos. Ambas varían a nivel año-industria. Industrias se definen a 4 dígitos de la CIIU Rev. 3. La regresión incluye variables de control a nivel firma (TFP, intensidad de uso de capital, estatus importador/exportador) más efectos fijos por firma, año-sector y año-región. Errores estándar robustos clusterizados por industria. Se presenta el estadístico F de instrumentos débiles de Sanderson-Windmeijer. La TFP se estima siguiendo el método propuesto por Ackerberg, Caves and Frazer (2015). ${ }^{* * *} \mathrm{p}_{\mathrm{i}} 0.01,{ }^{* *} \mathrm{p}_{\mathrm{i}} 0.05,{ }^{*} \mathrm{p}_{\mathrm{i}} 0.1$. Fuentes. ENIA-INE y COMTRADE-UN.

Una potencial amenaza para esta estrategia de identificación se deriva de la posible correlación entre los shocks a la demanda en una industria de Chile y los shocks a la demanda en los países de altos ingresos. En principio, dado que la economía Chilena presenta muchas diferencias con las economías de altos ingresos esta situación es poco probable. Más aún, la especificación preferida incluye efectos fijos sector-año, lo cual vuelve esta situación aún más improbable porque estas regresiones controlan por cualquier shock contemporáneo que afecte tanto a Chile como a los sectores de este grupo de países (por ejemplo, la aparición de una nueva tecnología en el sector de maquinaria eléctrica que disminuye la intensidad de uso del trabajo). También podría pensarse en una situación caracterizada por un shock a los ingresos de los consumidores de todos estos países que afecta simultáneamente la demanda de importaciones provenientes de China. Los efectos fijos temporales capturan aquella heterogeneidad que se distribuye de manera uniforme a través de las distintas industrias. Mientras que los efectos fijos sector-año capturan efectos que se distribuyen uniformemente a través de las industrias que pertenecen a un mismo sector. La única preocupación es la potencial existencia de shocks distribuídos 
de manera desigual a través de las distintas industrias de un mismo sector, que ocurran simultáneamente en Chile y en los países de altos ingresos. Por ejemplo, un shock a la demanda de textiles común a todos los países no sería un problema. En cambio, un shock común específico a la industria de tejidos de artículos de punto y ganchillo violaría uno de los supuestos de identificación. Una vez más, se estima que la probabilidad de ocurrencia de dichos shocks a nivel de industrias finamente desagregadas (4 dígitos del CIIU) que estén correlacionados entre Chile y los países de altos ingresos, es relativamente baja.

El segundo conjunto de regresiones a nivel firma tiene como objetivo capturar la existencia de efectos heterogéneos causados por la penetración de importaciones Chinas en las principales variables de resultado. Recordar que las predicciones derivadas del modelo teórico señalan que las firmas más productivas están en mejores condiciones de soportar este shock competitivo. Esta es la hipótesis que se intenta evaluar. Con este propósito, se incluye la interacción entre la PI China y la productividad de las firmas. Recordar también que la TFP es inobservable y su estimación presenta algunos desafíos importantes. En primer lugar, la elección de los insumos por parte de una firma está correlacionada con su productividad (no observada por el econometrista) lo que genera un problema de endogeneidad (simultaneidad) al utilizar el estimador tradicional de MCO. En segundo lugar, los datos a nivel firma suelen tener un nivel considerable de atrición, porque muchas firmas salen de la muestra a lo largo del tiempo. La decisión de cierre por parte de una firma puede estar correlacionada con su productividad, dado que es probable que las firmas tengan cierto conocimiento de su productividad futura antes de salir del mercado (sesgo de selección). Para estimar una medida de productividad se sigue el método propuesto por Ackerberg, Caves y Frazer (2015) pues representa uno de los avances más recientes en la literatura de estimación de funciones de producción. En la sección 2.2 se describe la idea general de esta literatura y el método propuesto por los autores que se utiliza en este trabajo. El Cuadro A1 del apéndice presenta los resultados de la estimación de la TFP para las firmas Chilenas. Los coeficientes estimados por MCO (en comparación a los que se obtienen mediante la aplicación del método de ACF) a priori presentan el sesgo esperado en función de las predicciones de la teoría, asociadas a la sobreestimación del coeficiente que acompaña al trabajo y a la subestimación del coeficiente que acompaña al capital. Se estiman dos medidas alternativas para la TFP utilizando dos variables proxy distintas en la primera etapa (materiales y energía). Los resultados se mantienen prácticamente inalterados al utilizar cualquiera de estas dos medidas, y también al utilizar una medida simple de productividad laboral (producto por trabajador). 
Una vez estimada la TFP de cada firma, es posible estimar la siguiente ecuación de regresión. Notar que incluye la interacción entre la productividad inicial de las firmas y la penetración de importaciones China:

$$
Y_{i j t}=\beta_{0}+\beta_{1} \text { PIChina }_{j t}+\beta_{2} \text { PIChina }_{j t} * T F P_{i j 0}+X^{\prime} \beta+\alpha_{i}+\delta_{t}+\varepsilon_{i j t}
$$

Donde $T F P_{i j 0}$ se refiere a la TFP estimada de la firma en el año inicial. El resto de la ecuación es igual que la ecuación (5.3). La TFP estimada se normaliza por la TFP promedio del sector-año correspondiente. ${ }^{99}$ La inclusión de la interacción entre la PIChina $_{j t}$ y la TFP inicial pretende capturar la existencia de respuestas heterogéneas a través de firmas con distintos niveles de productividad inicial frente al shock competitivo causado por el crecimiento de las importaciones Chinas en distintas industrias. La decisión de dejar fija la TFP en el valor inicial pretende evitar posibles efectos de confusión derivados de la endogeneidad de la respuesta de la TFP a la evolución de la PIChina ${ }_{j t}$. Otro posible sesgo podría derivar del hecho de que cierta fracción de las empresas comienzan a operar (nacen) en los años que siguen a 1995. La tasa de entrada promedio es de $8,3 \%$. Todos los resultados son robustos a la eliminación de este subconjunto de firmas, y a utilizar la TFP contemporánea en lugar de la TFP del año inicial.

Las regresiones a nivel industria se realizan únicamente con fines motivacionales. Agregar los microdatos de firmas (al nivel de una industria) elimina la posibilidad de controlar por numerosos factores inobservables que no varían en el tiempo (controlados por los efectos fijos a nivel firma) y por aquellos inobservables que sí varían temporalmente al interior de las unidades productivas (variables de control). En primer lugar, se estiman variantes de la siguiente ecuación de regresión:

$$
Y_{j t}=\beta_{0}+\beta_{1} \text { PIChina }_{j t}+\bar{X}^{\prime} \beta+\alpha_{j}+\delta_{t}+\varepsilon_{j t}
$$

Donde $j$ y $t$ indexan industrias y tiempo, respectivamente; $\alpha_{j}$ es un efecto fijo a nivel industria, $\delta_{t}$ es un efecto fijo temporal y $\varepsilon_{j t}$ representa el error de estimación del modelo. Las principales variables de resultado $Y_{j t}$ son el número total de empleados en la industria, los ingresos totales por ventas de productos elaborados y el número total de firmas dentro

\footnotetext{
${ }^{99}$ Esta normalización permite tener en cuenta diferencias relativas de productividad para distintas empresas que pertenecen a un mismo sector en determinado año. Los resultados se mantienen prácticamente inalterados si no se realiza esta normalización, o si se normaliza con distintos niveles de desagregación.
} 
de cada industria $j$ en cada año $t$. Se incluyen como controles la TFP promedio, la intensidad en el uso de capital promedio y la fracción de las empresas que importa/exporta dentro de cada industria. Estas variables se pueden calcular como promedios simples o ponderados. Los resultados son similares con cualquiera de estas opciones. Si se piensa en términos de empleo total, esta especificación captura simultáneamente el efecto neto del crecimiento de la PIChina ${ }_{j t}$ en el empleo total de una industria, originado en variaciones del empleo dentro de cada firma (margen intensivo) y en la apertura/cierre de empresas nuevas/existentes (margen extensivo).

Es importante tener en cuenta que la estrategia de identificación utilizada se sustenta en el efecto diferencial del shock competitivo en firmas que pertenecen a distintas industrias de un mismo sector. Por lo tanto, el estimador utilizado no puede identificar la magnitud de los efectos que son comunes a todas las unidades de análisis (pues estos son absorbidos por los efectos fijos). Notar también que en presencia de variables omitidas (e.g. reasignación de trabajadores desde una firma de una industria expuesta hacia otra firma de una industria no expuesta del mismo sector) se corre el riesgo de que el estimador otorgue una contribución exagerada al shock estudiado. Es importante realizar una interpretación cautelosa de los resultados. La estrategia utilizada tampoco contempla la existencia de efectos de equilibrio general. Por ejemplo, pensar en una empresa que provee insumos o proporciona servicios a otra firma manufacturera que está directamente expuesta a la competencia China. Es probable que parte del shock competitivo también afecte indirectamente la demanda de bienes/servicios de este tipo de empresas. Para evaluar la existencia de estos efectos indirectos es necesario recurrir a microdatos sobre relaciones comerciales entre firmas o a datos agregados sobre relaciones comerciales entre industrias (tipo matriz insumo-producto). También es posible que en las regiones más afectadas se produzca un efecto multiplicador potencialmente negativo en la demanda agregada (a la Keynes). ${ }^{100}$ Tampoco se miden los efectos sobre productividad o costos marginales de la firma derivados de un mayor acceso a insumos intermedios importados desde China, ni el incremento en el excedente del consumidor derivado de importar mayor variedad de productos y/o productos con precios más bajos (ver por ejemplo Caliendo, Dvorkin y Parro (2018)). ${ }^{101}$ También podría suceder que las importaciones Chinas generen una

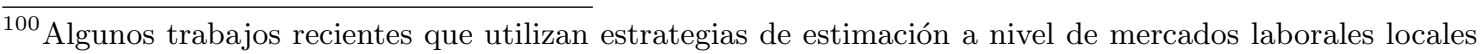
encuentran evidencia a favor de estos efectos (e.g. Autor et al. (2013), Acemoglu et al. (2016) y Dix-Carneiro y Kovak (2017)).

${ }^{101}$ Los autores desarrollan un modelo dinámico de comercio con mercados de trabajo separados espacialmente que presentan distintos niveles de exposición al comercio internacional. Calibran el modelo para 22 sectores, 38 países y 50 estados de EE.UU. Encuentran que el shock comercial en China resultó en una pérdida de 0,8 millones de empleos ( $25 \%$ del declive observado en el empleo de
} 
reducción en el precio de los productos domésticos que compiten en los mismos segmentos de mercado (efectos procompetitivos) que podría generar ganancias adicionales para los consumidores.

manufacturas entre 2000 y 2007), pero en términos agregados existe una ganancia total de bienestar para EE.UU. por comerciar con China (estimada en un $0,35 \%$ del producto) con efectos significativamente heterogéneos a través de los mercados laborales locales debido a fricciones comerciales y migratorias. 


\section{Resultados}

\subsection{Estimación base}

Los Cuadros 5 a 7 presentan los resultados de estimar la ecuación (5.3) para las variables de empleo total de la firma, ventas totales de productos manufacturados y probabilidad de salir del mercado. En la columna (1) de cada tabla se presenta el estimador de MCO, incluyendo efectos fijos a nivel firma, efectos fijos por año y una variable de control asociada a la penetración de importaciones provenientes de otros países distintos de China. ${ }^{102}$ La columna (2) presenta la misma especificación pero estimada por el método de MC2E. En los tres casos, la magnitud del coeficiente estimado para la variable PI China aumenta al utilizar el método de MC2E (en relación al coeficiente estimado por MCO) lo que es consistente con la existencia de una correlación positiva entre los shocks a la demanda de importaciones y los shocks a la demanda de trabajo y ventas de las firmas, que estarían sesgando el estimador de MCO hacia cero.

La columna (3) incluye distintas variables de control a nivel firma (TFP, ratio K/L y estatus de importador/exportador). Todas las variables de control tienen los signos esperados. Los resultados muestran que existe una correlación entre el aumento en la TFP de una firma y (i) una mayor demanda de trabajadores, (ii) mayores ingresos por ventas y (iii) menor probabilidad de salir del mercado. Lo mismo sucede para el estatus de importador y exportador. Las empresas con mayor ratio K/L tienen mayores ingresos, mayor cantidad de trabajadores (esto es así por construcción) y una mayor posibilidad de salir del mercado. Dado que se incluyen efectos fijos a nivel firma, estas regresiones capturan meramente la correlación entre la evolución de dichas variables (al interior de cada firma) a lo largo del tiempo. En este contexto, dado que el trabajo es más móvil que el capital, se espera que las empresas que salen del mercado contraigan sus niveles de empleo antes de abandonar el mercado.

Las columnas (4) y (5) incluyen efectos fijos a nivel región-año y efectos fijos a nivel sector-año que permiten controlar por posibles shocks no observables que varían en el tiempo y afectan a distintas regiones y sectores de manera diferencial. Estas especificaciones explotan la variabilidad en la penetración de importaciones a lo largo del tiempo dentro de cada sector (región). La inclusión de los efectos fijos sector-año en la columna (5) aumenta significativamente la magnitud de los errores estándar. Esto se

\footnotetext{
${ }^{102}$ Esta variable varía a nivel año-industria a 4 dígitos de la CIIU (Rev. 3) y se construye de manera análoga a la penetración de importaciones Chinas, tal como se explica en la Sección 5.1.
} 
explica por el hecho de que la mayor parte de la variabilidad en PI China occure a nivel sectorial. ${ }^{103}$ A pesar de ello, el resto de la variabilidad (de las industrias que pertenecen a un mismo sector a lo largo del tiempo) es suficiente para capturar el efecto causal del shock competitivo en los márgenes de ajuste de las firmas domésticas Chilenas.

Todos los controles adicionales no afectan la significatividad ni el signo de los coeficientes estimados para la PI China. Más aún, la magnitud de los coeficientes estimados presenta poca variabilidad a través de las distintas especificaciones. La única excepción es la columna (7) de la Tabla II. En este caso, la magnitud del coeficiente estimado para PI China se duplica al incluir efectos fijos sector-año. Ello es consistente con shocks temporales a nivel sector que están positivamente correlacionados con los ingresos de las firmas.

Las estimaciones indican que un aumento de 1 p.p. en la penetración de importaciones Chinas, disminuye el empleo total de la firma en un $0,89 \%$, reduce los ingresos totales por ventas en un 1,87\% y aumenta la probabilidad de que una firma salga del mercado en 0,65 p.p.

\footnotetext{
${ }^{103}$ Una simple regresión descriptiva de PIChina ${ }_{j t}$ en dummies de sector-año presenta un $\mathrm{R}$ cuadrado de 0.67 .
} 


\section{CUADRO 5}

Estimación de efectos sobre ingresos

\begin{tabular}{|c|c|c|c|c|c|}
\hline & \multirow{2}{*}{$\begin{array}{c}\mathrm{MCO} \\
(1) \\
\end{array}$} & \multicolumn{4}{|c|}{$\overline{\mathrm{MC} 2 \mathrm{E}}$} \\
\hline & & $(2)$ & $(3)$ & $(4)$ & $(5)$ \\
\hline IP China & $\begin{array}{c}-0.0094^{* * *} \\
(0.0022)\end{array}$ & $\begin{array}{c}-0.0115^{* * *} \\
(0.0042)\end{array}$ & $\begin{array}{c}-0.0093^{* * *} \\
(0.0034)\end{array}$ & $\begin{array}{c}-0.0087^{* * *} \\
(0.0028)\end{array}$ & $\begin{array}{r}-0.0187^{* *} \\
(0.0083)\end{array}$ \\
\hline IP Otros países & $\begin{array}{c}-0.0023^{* *} \\
(0.0010)\end{array}$ & $\begin{array}{c}-0.0023^{* *} \\
(0.0010)\end{array}$ & $\begin{array}{l}-0.0002 \\
(0.0010)\end{array}$ & $\begin{array}{l}-0.0000 \\
(0.0009)\end{array}$ & $\begin{array}{c}0.0001 \\
(0.0008)\end{array}$ \\
\hline $\mathrm{TFP}$ & & & $\begin{array}{c}1.0358^{* * *} \\
(0.0271)\end{array}$ & $\begin{array}{c}1.0350^{* * *} \\
(0.0266)\end{array}$ & $\begin{array}{c}1.0432^{* * *} \\
(0.0260)\end{array}$ \\
\hline $\log ($ ratio K/L $)$ & & & $\begin{array}{c}0.0950^{* * *} \\
(0.0059)\end{array}$ & $\begin{array}{c}0.0944^{* * *} \\
(0.0059)\end{array}$ & $\begin{array}{c}0.0969^{* * *} \\
(0.0055)\end{array}$ \\
\hline Importa & & & $\begin{array}{c}0.0901^{* * *} \\
(0.0107)\end{array}$ & $\begin{array}{c}0.0890^{* * *} \\
(0.0108)\end{array}$ & $\begin{array}{c}0.0878^{* * *} \\
(0.0107)\end{array}$ \\
\hline Exporta & & & $\begin{array}{c}0.1001^{* * *} \\
(0.0150)\end{array}$ & $\begin{array}{c}0.0968^{* * *} \\
(0.0149)\end{array}$ & $\begin{array}{c}0.0896^{* * *} \\
(0.0149)\end{array}$ \\
\hline$N$ & 44,346 & 44,346 & 44,346 & 44,346 & 44,346 \\
\hline Firmas & 6,681 & 6,681 & 6,681 & 6,681 & 6,681 \\
\hline EF Año & SI & SI & SI & SI & SI \\
\hline EF Firma & SI & SI & SI & SI & SI \\
\hline EF Region x Año & - & - & - & SI & SI \\
\hline EF Sector x Año & - & - & - & - & SI \\
\hline
\end{tabular}

Notas. Regresiones del ingreso total (en logaritmos) de la firma en la PI China estimadas por MC2E (cols. 2 a 5). Ingresos por ventas de productos manufacturados se deflactan por un índice de precios a nivel industria elaborado por el INE. La PI China se instrumenta con el promedio de la participación de China en las importaciones de países de altos ingresos. Las industrias se definen a 4 dígitos de la clasificación ISIC Rev. 3. La PI de otros países de mide como el valor total de las importaciones provenientes del resto de los países (distintos de China) dividido por la absorción doméstica. TFP se estima siguiendo el método de Ackerberg, Caves y Frazer (2015). Importa (exporta) significa que las exportaciones (importaciones) son positivas. Las regiones se refieren a la primer división administrativa de Chile (15 regiones). Las Industrias se agrupan en 10 sectores amplios de manufacturas. Errores estándar robustos clusterizados por industrias. ${ }^{* * *} \mathrm{p}<0.01,{ }^{* *} \mathrm{p}<0.05,{ }^{*} \mathrm{p}<0.1$. 


\section{CUADRO 6}

Estimación de efectos sobre empleo

\begin{tabular}{|c|c|c|c|c|c|}
\hline & $\mathrm{MCO}$ & & $\mathrm{MC}$ & & \\
\hline & $(1)$ & $(2)$ & $(3)$ & $(4)$ & $(5)$ \\
\hline IP China & $\begin{array}{c}-0.0071^{* * *} \\
(0.0012)\end{array}$ & $\begin{array}{c}-0.0091^{* * *} \\
(0.0022)\end{array}$ & $\begin{array}{c}-0.0101^{* * *} \\
(0.0024)\end{array}$ & $\begin{array}{c}-0.0084^{* * *} \\
(0.0021)\end{array}$ & $\begin{array}{c}-0.0089^{* *} \\
(0.0042)\end{array}$ \\
\hline IP Otros países & $\begin{array}{l}-0.0005 \\
(0.0006)\end{array}$ & $\begin{array}{l}-0.0005 \\
(0.0006)\end{array}$ & $\begin{array}{l}-0.0001 \\
(0.0006)\end{array}$ & $\begin{array}{c}0.0002 \\
(0.0005)\end{array}$ & $\begin{array}{c}0.0001 \\
(0.0004)\end{array}$ \\
\hline $\mathrm{TFP}$ & & & $\begin{array}{c}0.0837^{* * *} \\
(0.0157)\end{array}$ & $\begin{array}{c}0.0839^{* * *} \\
(0.0155)\end{array}$ & $\begin{array}{c}0.0852^{* * *} \\
(0.0151)\end{array}$ \\
\hline $\log ($ ratio K/L) & & & $\begin{array}{c}-0.0789^{* * *} \\
(0.0102)\end{array}$ & $\begin{array}{c}-0.0844^{* * *} \\
(0.0107)\end{array}$ & $\begin{array}{c}-0.0840^{* * *} \\
(0.0107)\end{array}$ \\
\hline Importa & & & $\begin{array}{c}0.0449^{* * *} \\
(0.0126)\end{array}$ & $\begin{array}{c}0.0431^{* * *} \\
(0.0123)\end{array}$ & $\begin{array}{c}0.0416^{* * *} \\
(0.0118)\end{array}$ \\
\hline Exporta & & & $\begin{array}{c}0.0865^{* * *} \\
(0.0131)\end{array}$ & $\begin{array}{c}0.0844^{* * *} \\
(0.0136)\end{array}$ & $\begin{array}{c}0.0857^{* * *} \\
(0.0136)\end{array}$ \\
\hline$N$ & 44,346 & 44,346 & 44,346 & 44,346 & 44,346 \\
\hline Firmas & 6,681 & 6,681 & 6,681 & 6,681 & 6,681 \\
\hline EF Año & SI & SI & SI & SI & SI \\
\hline EF Firma & SI & SI & SI & SI & SI \\
\hline EF Region x Año & - & - & - & SI & SI \\
\hline EF Sector x Año & - & - & - & - & SI \\
\hline
\end{tabular}

Notas. Regresiones de la cantidad de trabajadores (en logaritmos) de la firma en la PI China estimadas por MC2E (cols. 2 a 5). La PI China se instrumenta con el promedio de la participación de China en las importaciones de países de altos ingresos. Las industrias se definen a 4 dígitos de la clasificación ISIC Rev. 3. La PI de otros países de mide como el valor total de las importaciones provenientes del resto de los países (distintos de China) dividido por la absorción doméstica. TFP se estima siguiendo el método de Ackerberg, Caves y Frazer (2015). Importa (exporta) significa que las exportaciones (importaciones) son positivas. Las regiones se refieren a la primer división administrativa de Chile (15 regiones). Las Industrias se agrupan en 10 sectores amplios de manufacturas. Errores estándar robustos clusterizados por industrias. *** $\mathrm{p}<0.01, * * \mathrm{p}<0.05,{ }^{*} \mathrm{p}<0.1$. 


\section{CUADRO 7}

Estimación de efectos sobre probabilidad de salida

\begin{tabular}{|c|c|c|c|c|c|}
\hline & \multirow{2}{*}{$\begin{array}{c}\mathrm{MCO} \\
(1) \\
\end{array}$} & \multicolumn{4}{|c|}{$\mathrm{MC} 2 \mathrm{E}$} \\
\hline & & (2) & (3) & (4) & (5) \\
\hline IP China & $\begin{array}{c}0.0029^{* * *} \\
(0.0006)\end{array}$ & $\begin{array}{c}0.0043^{* * *} \\
(0.0009)\end{array}$ & $\begin{array}{c}0.0044^{* * *} \\
(0.0009)\end{array}$ & $\begin{array}{c}0.0056^{* * *} \\
(0.0010)\end{array}$ & $\begin{array}{c}0.0065^{* * *} \\
(0.0016)\end{array}$ \\
\hline IP Otros países & $\begin{array}{c}-0.0005^{* * *} \\
(0.0001)\end{array}$ & $\begin{array}{c}-0.0005^{* * *} \\
(0.0001)\end{array}$ & $\begin{array}{c}-0.0006^{* * *} \\
(0.0002)\end{array}$ & $\begin{array}{c}-0.0006^{* * *} \\
(0.0002)\end{array}$ & $\begin{array}{c}-0.0006^{* * *} \\
(0.0002)\end{array}$ \\
\hline TFP & & & $\begin{array}{c}-0.0602^{* * *} \\
(0.0076)\end{array}$ & $\begin{array}{c}-0.0585^{* * *} \\
(0.0075)\end{array}$ & $\begin{array}{c}-0.0586^{* * *} \\
(0.0073)\end{array}$ \\
\hline $\log ($ ratio $K / L)$ & & & $\begin{array}{c}0.0103^{* * *} \\
(0.0034)\end{array}$ & $\begin{array}{c}0.0069^{* *} \\
(0.0030)\end{array}$ & $\begin{array}{c}0.0069^{* *} \\
(0.0031)\end{array}$ \\
\hline Importa & & & $\begin{array}{c}-0.0175^{* *} \\
(0.0072)\end{array}$ & $\begin{array}{c}-0.0186^{* * *} \\
(0.0071)\end{array}$ & $\begin{array}{c}-0.0188^{* * *} \\
(0.0070)\end{array}$ \\
\hline Exporta & & & $\begin{array}{c}-0.0206^{* * *} \\
(0.0073)\end{array}$ & $\begin{array}{c}-0.0212^{* * *} \\
(0.0069)\end{array}$ & $\begin{array}{c}-0.0233^{* * *} \\
(0.0067)\end{array}$ \\
\hline$N$ & 36,766 & 36,766 & 36,766 & 36,766 & 36,766 \\
\hline Firmas & 6,013 & 6,013 & 6,013 & 6,013 & 6,013 \\
\hline$\overline{\text { EF Año }}$ & SI & SI & SI & SI & SI \\
\hline EF Firma & SI & SI & SI & SI & SI \\
\hline EF Region x Año & - & - & - & SI & SI \\
\hline EF Sector x Año & - & - & - & - & SI \\
\hline
\end{tabular}

Notas. Regresiones de la probabilidad de salida en la PI China estimadas por MC2E (cols. 2 a 5). Salida $=0$ en los años en que la firma está activa y $=1$ el último año antes de que la firma cierre (deje el panel). La PI China se instrumenta con el promedio de la participación de China en las importaciones de países de altos ingresos. Las industrias se definen a 4 dígitos de la clasificación ISIC Rev. 3. La PI de otros países de mide como el valor total de las importaciones provenientes del resto de los países (distintos de China) dividido por la absorción doméstica. TFP se estima siguiendo el método de Ackerberg, Caves y Frazer (2015). Importa (exporta) significa que las exportaciones (importaciones) son positivas. Las regiones se refieren a la primer división administrativa de Chile (15 regiones). Las Industrias se agrupan en 10 sectores amplios de manufacturas. Errores estándar robustos clusterizados por industrias. $* * * \mathrm{p}<0.01,{ }^{* *} \mathrm{p}<0.05$, $* \mathrm{p}<0.1$. 


\subsection{Efectos heterogéneos}

El Cuadro 8 presenta los resultados de la estimación de la ecuación (5.4) por el método de MC2E. Las columnas (1-2) corresponden al log del empleo total, las columnas (3-4) corresponden al log de los ingresos totales y las columnas (5-6) a la probabilidad de salir del mercado. Las variables de control son las mismas que se utilizan en la sección anterior. La diferencia entre las columnas pares e impares es que las primeras incluyen además efectos fijos región-año y sector-año. En pos de evaluar la existencia de efectos heterogéneos de la penetración de importaciones Chinas en las variables de interés, la ecuación (4) incluye un término de interacción entre la PI China y la productividad inicial de la firma. Se decide dejar fija la TFP de la firma en el nivel del año inicial para evitar cualquier factor de confusión derivado del impacto que podría tener la PI China en la TFP de las firmas.

Las estimaciones indican que los efectos del crecimiento en la PI China sobre el empleo, los ingresos y la probabilidad de salir del mercado son más pequeños para aquellas firmas que poseen mayor productividad inicial. En los tres casos el coeficiente estimado para el término de interacción presenta el signo opuesto al efecto principal. El efecto marginal del crecimiento en la PI China sobre el empleo/ingresos/salida para una firma ubicada en el percentil 25 de la distribución sectorial inicial de productividad es 2,69/1,66/2,12 mayor que para una firma situada en el percentil 75. Por ejemplo, un aumento de 1 p.p. en la PI China reduce el empleo total de una firma en 1,33\% si la misma está localizada en el percentil 25, mientras que el efecto es de $0,47 \%$ para una firma situada en el percentil 75 .

Las Figuras 7 a 9 grafican la predicción lineal del efecto marginal de la PI China sobre las tres variables de interés junto a los intervalos de confianza al $95 \%$ para firmas ubicadas en diferentes percentiles de la distribución sectorial inicial de TFP. Los errores estándar se estiman por el método Delta. La Figura 7 muestra que el efecto marginal de la PI China sobre el ingreso, no es estadísticamente distinto de cero para una firma ubicada en el séptimo decil de la distribución de TFP. La Figura 8 cuenta una historia similar para el empleo. Notar que ahora los coeficientes están estimados con mayor precisión. Parte de la explicación se relaciona con el hecho de que la distribución de ingresos de las firmas presenta mayor variabilidad y potenciales errores de medición en comparación con el empleo, que suele estar mejor reportado. Para la probabilidad de salida del mercado, se observa que el efecto se vuelve estadísticamente indistinguible de cero para aquellas 
empresas ubicadas en los deciles nueve y diez de la distribución de TFP.

Adicionalmente, se estima la ecuación de regresión principal (especificación preferida que incluye todos los controles, columna 5 de los Cuadros 5,6 y 7 ) separadamente para cada quintil de distribución sectorial de TFP. Los resultados se presentan en las figuras A1, A2 y A3 del apéndice. Estas grafican los coeficientes estimados de la PI China y los intervalos de confianza al 95\% para cada quintil de la distribución sectorial de TFP. Estas estimaciones presentan el mismo patrón que se advierte en las regresiones conjuntas que incluyen el término de interacción con la TFP inicial. Los efectos disminuyen para las firmas que son más productivas en sus sectores de actividad. Los efectos de la PI China en el empleo y en los ingresos por ventas no son estadísticamente significativos para las firmas ubicadas en el quintil de productividad más alto.

Estos resultados pueden interpretarse como antes. El coeficiente estimado de la PI China en empleo/ingresos/salida para una firma situada en el primer quintil de la distribución sectorial de TFP es 1,78/1,44/1,72 veces mayor que el coeficiente estimado para una empresa en el cuarto quintil. ${ }^{104}$ Por ejemplo, un aumento de 1 p.p. en la PI China reduce el empleo de la firma en 1,21\% para una firma del primer quintil, mientras que el efecto es de $0,68 \%$ para una firma del cuarto quintil de productividad.

\footnotetext{
${ }^{104}$ Se prefiere utilizar el cuarto en lugar del quinto quintil porque los coeficientes estimados no son estadísticamente diferentes de cero para el empleo y los ingresos.
} 


\section{CUADRO 8}

Estimación de efectos heterogéneos según productividad

\begin{tabular}{|c|c|c|c|c|c|c|}
\hline & \multicolumn{2}{|c|}{ Log empleo total } & \multicolumn{2}{|c|}{ Log ingreso total } & \multicolumn{2}{|c|}{ Probabilidad salida } \\
\hline & $(1)$ & $(2)$ & $(3)$ & $(4)$ & $(5)$ & $(6)$ \\
\hline IP China & $\begin{array}{c}-0.010^{* * *} \\
(0.002)\end{array}$ & $\begin{array}{c}-0.0090^{* *} \\
(0.0042)\end{array}$ & $\begin{array}{c}-0.010^{* * *} \\
(0.003)\end{array}$ & $\begin{array}{c}-0.0189^{* *} \\
(0.0083)\end{array}$ & $\begin{array}{c}0.0045^{* * *} \\
(0.0010)\end{array}$ & $\begin{array}{c}0.0065^{* * *} \\
(0.0016)\end{array}$ \\
\hline IP China $\mathrm{x} \mathrm{TFP}_{0}$ & $\begin{array}{c}0.013^{* * *} \\
(0.004)\end{array}$ & $\begin{array}{c}0.0126^{* * *} \\
(0.0041)\end{array}$ & $\begin{array}{c}0.015^{* * *} \\
(0.005)\end{array}$ & $\begin{array}{c}0.0138^{* * *} \\
(0.0046)\end{array}$ & $\begin{array}{c}-0.0075^{* * *} \\
(0.0017)\end{array}$ & $\begin{array}{c}-0.0069^{* * *} \\
(0.0016)\end{array}$ \\
\hline IP Otros países & $\begin{array}{l}-0.000 \\
(0.001)\end{array}$ & $\begin{array}{c}0.0001 \\
(0.0004)\end{array}$ & $\begin{array}{l}-0.000 \\
(0.001)\end{array}$ & $\begin{array}{c}0.0001 \\
(0.0008)\end{array}$ & $\begin{array}{c}-0.0006^{* * *} \\
(0.0001)\end{array}$ & $\begin{array}{c}-0.0006^{* * *} \\
(0.0002)\end{array}$ \\
\hline TFP & $\begin{array}{c}0.087^{* * *} \\
(0.016)\end{array}$ & $\begin{array}{c}0.0889^{* * *} \\
(0.0154)\end{array}$ & $\begin{array}{c}1.040^{* * *} \\
(0.027)\end{array}$ & $\begin{array}{c}1.0473^{* * *} \\
(0.0262)\end{array}$ & $\begin{array}{c}-0.0619^{* * *} \\
(0.0075)\end{array}$ & $\begin{array}{c}-0.0602^{* * *} \\
(0.0072)\end{array}$ \\
\hline $\log ($ ratio K/L) & $\begin{array}{c}-0.079^{* * *} \\
(0.010)\end{array}$ & $\begin{array}{c}-0.0842^{* * *} \\
(0.0108)\end{array}$ & $\begin{array}{c}0.095^{* * *} \\
(0.006)\end{array}$ & $\begin{array}{c}0.0968^{* * *} \\
(0.0055)\end{array}$ & $\begin{array}{c}0.0102^{* * *} \\
(0.0035)\end{array}$ & $\begin{array}{c}0.0069^{* *} \\
(0.0032)\end{array}$ \\
\hline Importa & $\begin{array}{c}0.045^{* * *} \\
(0.013)\end{array}$ & $\begin{array}{c}0.0416^{* * *} \\
(0.0118)\end{array}$ & $\begin{array}{c}0.090^{* * *} \\
(0.011)\end{array}$ & $\begin{array}{c}0.0878^{* * *} \\
(0.0103)\end{array}$ & $\begin{array}{c}-0.0176^{* *} \\
(0.0072)\end{array}$ & $\begin{array}{c}-0.0190^{* * *} \\
(0.0070)\end{array}$ \\
\hline Exporta & $\begin{array}{c}0.090^{* * *} \\
(0.013)\end{array}$ & $\begin{array}{c}0.0894^{* * *} \\
(0.0134)\end{array}$ & $\begin{array}{c}0.104^{* * *} \\
(0.015)\end{array}$ & $\begin{array}{c}0.0937^{* * *} \\
(0.0146)\end{array}$ & $\begin{array}{c}-0.0229^{* * *} \\
(0.0077)\end{array}$ & $\begin{array}{c}-0.0255^{* * *} \\
(0.0071)\end{array}$ \\
\hline$N$ & 44,346 & 44,346 & 44,346 & 44,346 & 36,766 & 36,766 \\
\hline Firmas & 6,681 & 6,681 & 6,681 & 6,681 & 6,013 & 6,013 \\
\hline EF Año & SI & SI & SI & SI & SI & SI \\
\hline EF Firma & SI & SI & SI & SI & SI & SI \\
\hline EF Region x Año & - & SI & - & SI & - & SI \\
\hline EF Sector x Año & - & SI & - & SI & - & SI \\
\hline
\end{tabular}

Notas. Regresiones del (log) ingreso total de la firma, el (log) empleo total y la probabilidad de salida en función de la PI China estimadas por MC2E. La PI China y su interacción con la TFP0 (año inicial) se instrumentan con el promedio y la interacción con la TFP0 de la participación de China en las importaciones de países de altos ingresos. Las industrias se definen a 4 dígitos de la clasificación ISIC Rev. 3. La PI de otros países de mide como el valor total de las importaciones provenientes del resto de los países (distintos de China) dividido por la absorción doméstica. TFP se estima siguiendo el método de Ackerberg, Caves y Frazer (2015). Importa (exporta) significa que las exportaciones (importaciones) son positivas. Las regiones se refieren a la primer división administrativa de Chile (15 regiones). Las Industrias se agrupan en 10 sectores amplios de manufacturas. Errores estándar robustos clusterizados por industrias. $\mathrm{p}<0.01, * * \mathrm{p}<0.05, * \mathrm{p}<0.1$. 
FIGURA 7

Predicción lineal: Ingresos

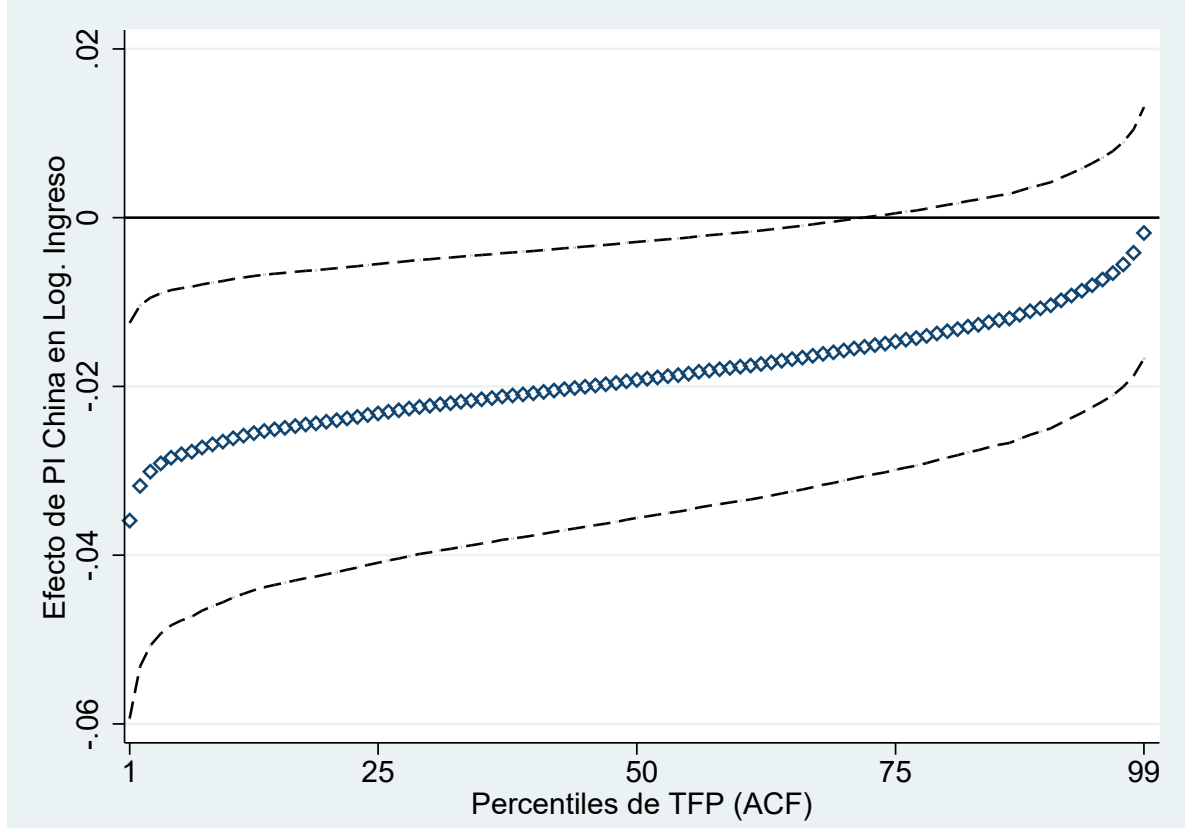

Notas. Predicción lineal del efecto de la PI China sobre el (log) del ingreso para firmas situadas en los distintos percentiles de la distribución sectorial de TFP inicial. Las regresiones incluyen todos los controles (como las especificaciones de las columnas impares del cuadro 8). Intervalos de confianza al 95\% estimados a partir errores estándar robustos estimados por el método Delta.

FIGURA 8

Predicción lineal: Empleo

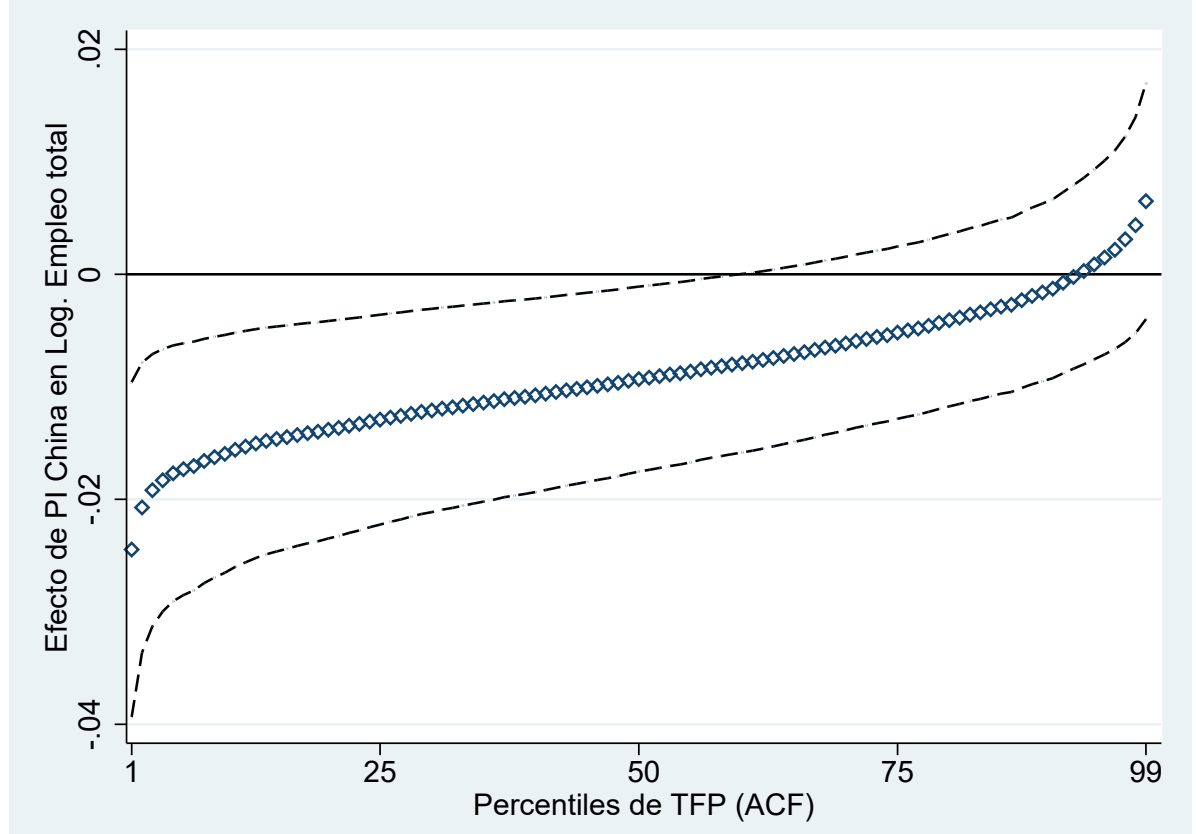

Notas. Predicción lineal del efecto de la PI China sobre el (log) del empleo para firmas situadas en los distintos percentiles de la distribución sectorial de TFP inicial. Las regresiones incluyen todos los controles (como las especificaciones de las columnas impares del cuadro 8). Intervalos de confianza al 95\% estimados a partir errores estándar robustos estimados por el método Delta. 
FIGURA 9

Predicción lineal: Probabilidad de salida

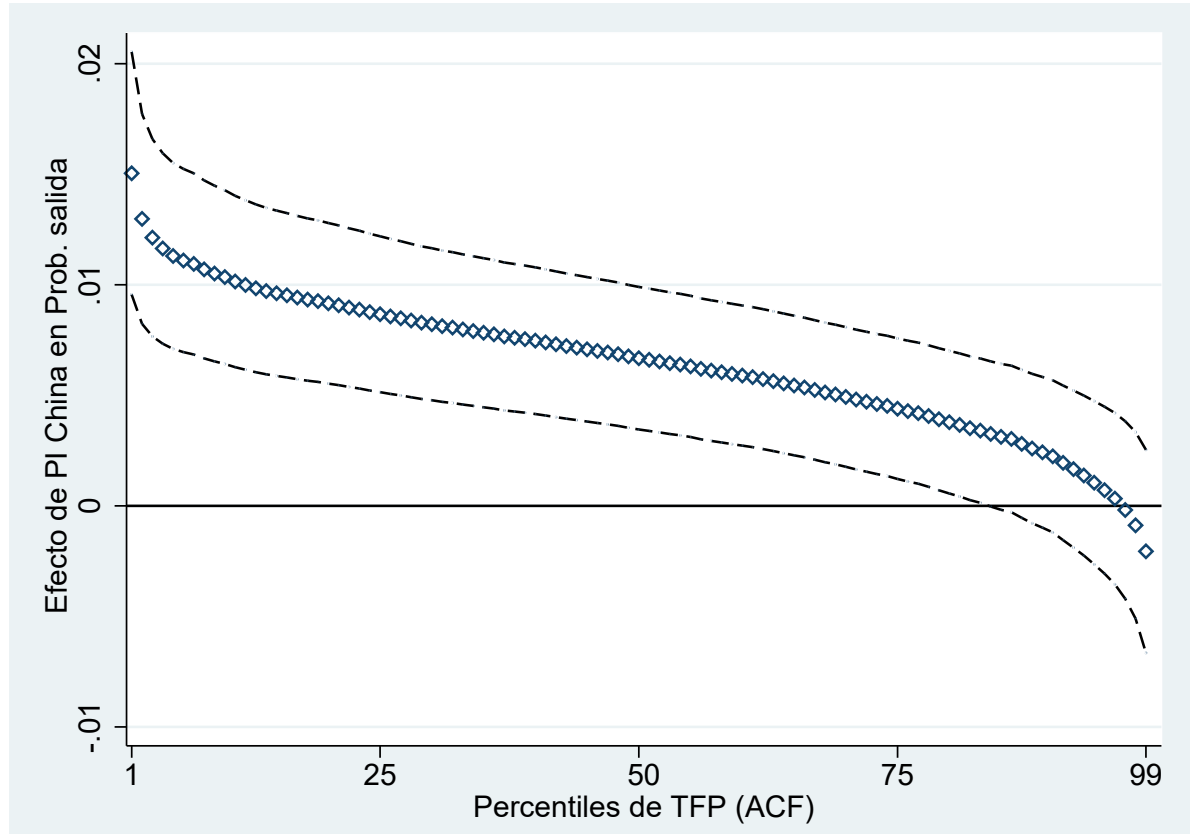

Notas. Predicción lineal del efecto de la PI China sobre la probabilidad de salida para firmas situadas en los distintos percentiles de la distribución sectorial de TFP inicial. Las regresiones incluyen todos los controles (como las especificaciones de las columnas impares del cuadro 8). Intervalos de confianza al $95 \%$ estimados a partir errores estándar robustos estimados por el método Delta. 


\subsection{Magnitud económica}

Para evaluar la magnitud económica de las estimaciones puntuales, se compara el empleo observado en cada firma con un empleo contrafactual, definido como aquel nivel de empleo que la firma hubiese tenido en ausencia del crecimiento en la PI China. El empleo contrafactual $\left(L_{i j t}^{s i m}\right)$ se calcula de la siguiente forma:

$$
L_{i j t}^{s i m}=L_{i j t}\left[1+\left(1-\exp \left(\hat{\beta}_{L} * \Delta C I P_{j t} * R_{I V}^{2}\right)\right)\right]
$$

Donde $\hat{\beta}_{L}$ es el coeficiente estimado por MC2E para la PI China (a partir de la ecuación 3) y $\Delta C I P_{j t}$ es el cambio en la PI China de cada industria a lo largo del tiempo, ajustado por el R-cuadrado parcial de la regresión de la primera etapa en pos de capturar la fracción del aumento en la PI China explicada por el shock de oferta (tal como hacen Autor et al. (2013) y Acemoglu et al. (2016)). En la muestra utilizada, las industrias expuestas (no expuestas) tenían 132.415 (156.508) trabajadores en 1995 y terminaron con 100.581 (197.139) trabajadores en 2006. ${ }^{105} \mathrm{Si}$ bien existen distintos factores que potencialmente explican la divergencia entre las tendencias de crecimiento del empleo total en estos dos grupos de industrias (e.g. cambio tecnológico, cambio en patrones de consumo, etc.), el análisis contrafactual predice que si la PI China no hubiese crecido durante este período, la contracción del empleo total en las industrias expuestas hubiera sido un 30,3\% menor que la observada (Figura 10). Es muy importante tener en cuenta que este ejercicio contrafactual está basado en un análisis de equilibrio parcial, suponiendo que el resto de los factores permanecen constantes.

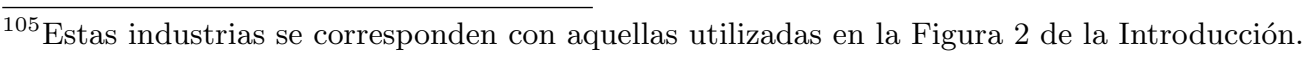


FIGURA 10

Evolución contrafactual del empleo en sectores expuestos

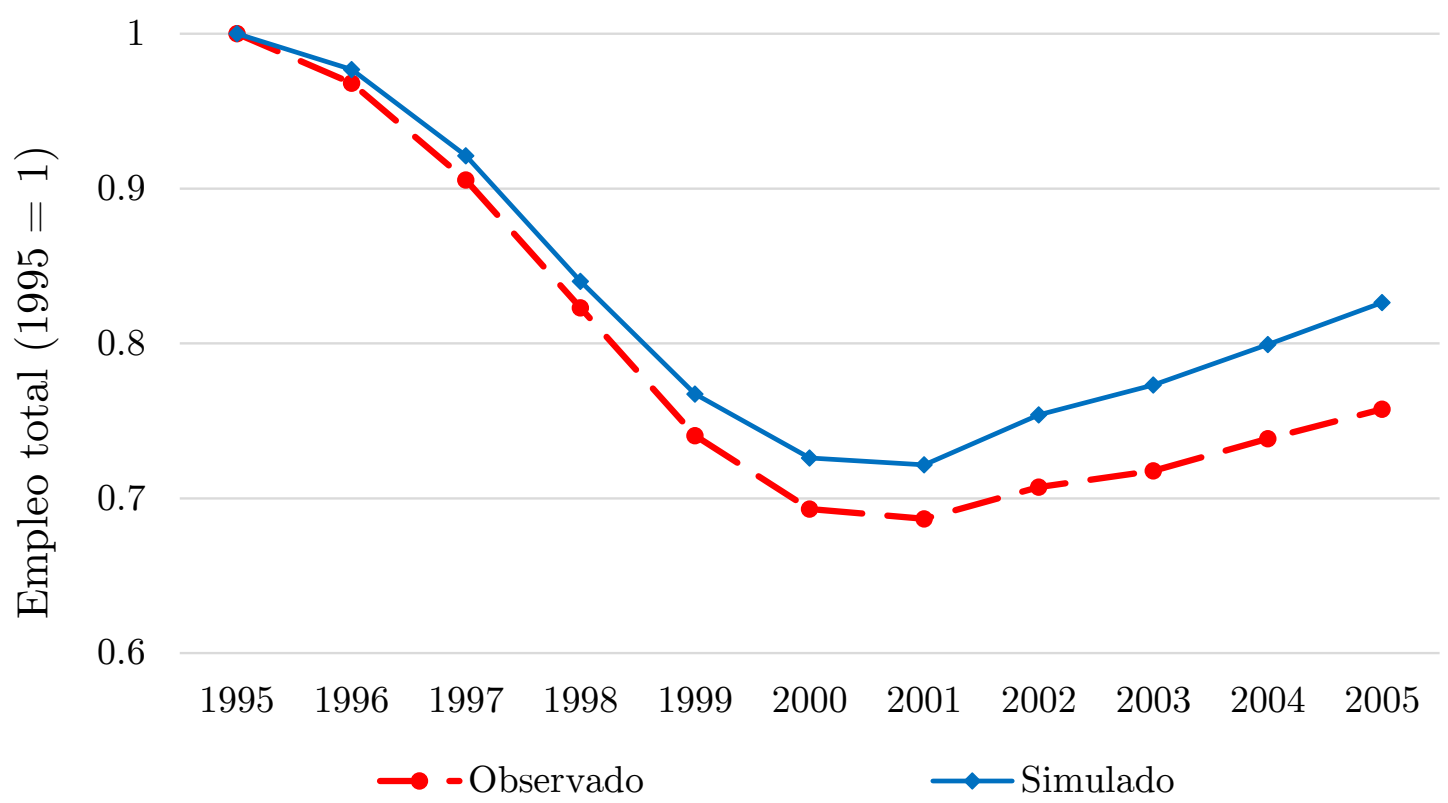

Notas. El empleo contrafactual asume que la PI China se mantiene constante en el valor del año inicial. Las industrias expuestas tienen PI China por encima del percentil 50, que equivale a $0.4 \%$. Cantidad total de trabajadores normalizada a 1 en 1995. 


\subsection{Pruebas de robustez}

Se realizan ejercicios de robustez en distintas dimensiones en pos de evaluar la sensibilidad de los resultados obtenidos. Estos ejercicios aumentan la credibilidad de la estrategia de identificación utilizada y permiten elevar la confianza respecto a la magnitud de los coeficientes puntuales estimados. En todos los casos, se elige la especificación preferida, que incluye todos los controles y combinaciones de efectos fijos. Todos los cuadros se presentan en el apéndice.

En primer lugar, se elimina el 10\% de las observaciones ubicadas en los extremos de la distribución de PI China, empleo, ingresos y ratio K/L, separadamente. Los resultados obtenidos son robustos a eliminar los valores atípicos de la muestra principal (Cuadro A5). Notar que cuando no se tienen en cuenta los valores extremos de PI China (columna 2), la magnitud de los coeficientes estimados aumenta notablemente. Los coeficientes estimados se incrementan un $46 \%, 33 \%$ y $22 \%$ para empleo, ingresos y probabilidad de salida, respectivamente. Al eliminar los valores extremos del resto de las variables, la magnitud de los coeficientes estimados disminuye. Ello ocurre porque el shock competitivo afecta en mayor medida a las firmas más pequeñas y menos productivas.

En segundo lugar, se construyen variables instrumentales alternativas, pero utilizando las importaciones de distintos grupos de países: OECD, G7, América Latina y los países miembros de Mercosur. La construcción de estas variables siguen la misma lógica que en el caso de los países de altos ingresos (ver ecuación (5.2)). Ninguno de los resultados se modifica cuando se instrumenta la PI China con el promedio de importaciones de China en las industrias de estos diferentes grupos de países (Cuadro A6).

En tercer lugar, se estima la ecuación de regresión principal eliminando todas las firmas que pertenecen a cada unos de los 10 grandes sectores económicos separadamente, y los resultados también se mantienen (Cuadro A7).

En cuarto lugar, se incorpora un conjunto de variables de control en la ecuación de regresión principal. Se controla por la participación de los insumos importados en el gasto total de insumos realizado por la firma, ${ }^{106}$ el log del salario promedio pagado por la firma, una variable que vale 1 si los trabajadores de la firma no trabajaron al menos un día en el año por estar de paro laboral, la participación de las exportaciones en las ventas totales de la firma y una variable binaria que vale 1 si la firma tiene participación

\footnotetext{
${ }^{106}$ Recordar por ejemplo la discusión respecto a la utilización de insumos importados por parte de las firmas domésticas (ver Sección 5.3).
} 
de capital extranjera. Todos los resultados se mantienen inalterados (Cuadro A8). Más aún, la magnitud de los coeficientes estimados es muy similar a aquella en la especificación principal.

Los resultados son robustos a utilizar una medida de TFP a nivel firma que no esté normalizada o que sea normalizada por el promedio sectorial en lugar del promedios de las industrias definidas a 2 dígitos de la CIIU. Los resultados también se mantienen si en lugar de utilizar la TFP estimada se utiliza una medida más simple de productividad laboral (ingresos por trabajador).

Finalmente, los resultados también se mantienen si se utiliza la muestra completa en las estimaciones. Recordar que la muestra utilizada contiene 78 de las 111 industrias, que representan aproximadamente dos tercios del empleo total y de los ingresos totales de la industria de manufacturas. Al realizar estas últimas estimaciones se pierden algunas variables de control, como por ejemplo la intensidad de uso del capital o la TFP, porque muchas de estas firmas no cuentan con la información necesaria para construir estas variables. 


\section{Comentarios finales}

Esta parte de la tesis cuantifica el efecto de un shock competitivo en los márgenes de ajuste de corto plazo de las empresas domésticas. Los efectos son heterogéneos, siendo las firmas de menor productividad inicial las que enfrentan los costos de ajuste más grandes. Concretamente, las firmas Chilenas que operan en aquellas industrias más expuestas al crecimiento en la penetración de importaciones Chinas despiden más trabajadores, reducen sus ingresos por ventas de productos elaborados y enfrentan una mayor probabilidad de salir del mercado, en relación a firmas comparables que se encuentran en industrias menos expuestas del mismo sector productivo. Las firmas que presentan mayores niveles de productividad inicial están en mejores condiciones de enfrentar este shock competitivo. Esto es consistente con la idea de que las firmas más productivas pueden escapar a la competencia de países de salario bajo porque elaboran productos de mayor calidad que no compiten directamente con aquellos bienes importados desde estos países.

Estos hallazgos son especialmente relevantes para países en desarrollo que tienen problemas visibles de desempleo estructural, asignación ineficiente de sus factores productivos, una fracción importante de la fuerza laboral empleada en sectores poco competitivos que concentran a muchas empresas de baja productividad, y fricciones en el mercado laboral que dificultan las transiciones laborales.

Esta línea de investigación continúa con un segundo trabajo para Chile, que utiliza una estrategia de identificación similar pero explora los efectos del shock competitivo a nivel trabajador, a partir de microdatos provienentes de la Encuesta de Caracterización Socioeconómica de Chile (CASEN). Los resultados preliminares muestran que el crecimiento de la penetración de importaciones Chinas provocó un aumento en la tasa de informalidad de los trabajadores expuestos, en relación a trabajadores comparables de industrias menos expuestas. En línea con los hallazgos de esta tesis, los efectos son más pronunciados para los individuos empleados en firmas más pequeñas. En un proyecto futuro, es deseable explotar este shock competitivo para estudiar la trayectoria laboral de los trabajadores formales de Argentina, a partir de una base de datos de registro administrativo publicada recientemente por el Ministerio de Trabajo, Empleo y Seguridad Social.

Para finalizar, es muy importante destacar que esta parte de la tesis no mide los efectos de equilibrio general, ni captura potenciales efectos indirectos derivados de las relaciones comerciales entre firmas ubicadas en distintas etapas del eslabón productivo. 
Tampoco se miden las mejoras de productividad y/o reducción de costos derivadas de importar insumos intermedios a precios bajos, ni el aumento en el excedente del consumidor provocado por una potencial reducción en el costo de vida y diversificación de la canasta de consumo. Estos temas también forman parte de la agenda de investigación futura. 


\section{Referencias}

Acemoglu, D. (1998). "Why Do New Techniologies Complement Skills? Directed Technical Change and Wage Inequality," Quarterly Journal of Economics, 113(4): 1055-1089.

Acemoglu, D. (2002). "Technical Change, Inequality, and the Labor Market," Journal of Economic Literature, 15(1): 7-72.

Acemoglu, D. And Autor, D.H. (2010). "Skills, Tasks and Technologies: Implications for Employment and Earnings," Handbook of Labour Economics, 4: 1043-1171.

Acemoglu, D., Autor, D, Dorn, D., Hanson, G. And B. Price (2016). "Import Competition and the Great U.S. Employment Sag of the 2000s," Journal of Labor Economics, 34(1): 141-198.

Acemoglu, D. And P. Restrepo (2017). "The Race Between Machine and Man: Implications of Technology for Growth, Factor Shares and Employment," NBER Working Paper No 22252.

Acemoglu, D. And P. Restrepo (2017). "Robots and Jobs: Evidence from US Labor Markets," NBER Working paper No 23285.

Ackerberg, D., Benkard, C., Berry, S. and A. Pakes (2007). "Econometric Tools for Analyzing Market Outcomes," Handbook of Econometrics, 4171-4276.

Ackerberg, D., Caves, K. and G. Frazer (2015). "Identification Properties of Recent Production Function Estimators," Econometrica, 83(6): 2411-2451.

Aghion, P., Bloom, N., Blundell, R., Griffith, R. And P. Howitt (2005). "Competition and Innovation: an Inverted-U Relationship," Quarterly Journal of Economics, 120(2): 701-728.

Albornoz, F., Calvo Pardo, H., Corcos, G. and E. Ornelas (2012). "Sequential Exporting," Journal of International Economics, 88: 17-31.

Amiti, M. And J. Konings (2007). "Trade Liberalization, Intermediate Inputs, and Productivity: Evidence from Indonesia," American Economic Review, 97(5): 1611-1638.

Amiti, M. And A. Khandelwal (2013). "Import Competition and Quality Upgrading," Review of Economic Studies, 95(2): 476-490.

Amiti, M. And D. Davis (2011). "Trade, Firms, and Wages: Theory and Evidence," Review of Economic Studies, 79: 1-36.

Arkolakis, C., Costinot, A. And A. Rodriguez-Clare (2012). "New Trade Models, Same Old Gains?," American Economic Review, 102(1): 94-130.

Artuç, E., Chaudhuri, A. And J. Mclaren (2010). "Trade shocks and Labor Adjustment: A Structural Empirical Approach," American Economic Review, 100(3): 1008-1045.

AtKin, D. (2016). "Endogenous Skill Acquisition and Export Manufacturing in Mexico," American Economic Review, 106(8): 2046-2085.

Atkin, D., Faber, B. And M. Gonzalez-Navarro (2018). "Retail Globalization and Household Welfare: Evidence from Mexico," Journal of Political Economy, vol 126(1): $1-73$.

Autor, D., Krueger, A. And L. Katz (1998). "Computing Inequality: Have Computers Changed the Labor Market?," Quarterly Journal of Economics, 113(4): 1169-1213.

Autor, F., Levy, A. And J. Murnane (2003). "The Skill Content of Recent Technological Change: An Empirical Exploration," Quarterly Journal of Economics, 
118(4): 1279-1333.

Autor, D., Dorn, D. And G. Hanson (2015). "Untangling Trade and Technology: Evidence from Local Labour Markets," Economic Journal, 584: 621-646.

Autor, D. Dorn (2013). "The Growth of Low Skill Service Jobs and the Polarization of the US Labor Market," American Economic Review, 5(100): 1553-1597.

Autor, D., Dorn, D. And G. Hanson (2013). "The China Syndrome: Local Labor Market Effects of Import Competition in the United States," American Economic Review, 103(6): 2121-2168.

Autor, D., Dorn, D., Hanson, G. And J. Song (2014). "Trade Adjustment: Worker Level Evidence.," Quarterly Journal of Economics, 129(4): 1799-1860.

Aw, B., Chen, X. And M. Roberts (2001). "Firm-Level Evidence on Productivity Differentials and Turnover in Taiwanese Manufacturing," Journal of Development Economics, 66: 51-86.

Becker, G. (1964). "Human Capital: A Theoretical and Empirical Analysis, with Special Reference to Education," University of Illinois at Urbana-Champaign's Academy for Entrepreneurial Leadership Historical Research Reference in Entrepreneurship.

Berman, E., Bound, J. and Z. Griliches (1994). "Changes in the Demand for Skilled Labor within U.S. Manufacturing Industries: Evidence from the Annual Survey of Manufactures," Quarterly Journal of Economics, 109: 365-67.

Berman, E., Bound, J. And S. Machin (1998). "CImplications of Skill-Biased Technological Change: International Evidence," Quarterly Journal of Economics, 113: 1245-1280.

Bernard, A. And B. Jensen, B. (1995). "Exporters, Jobs, and Wages in U.S. Manufacturing, 1976-1987," Brookings Papers on Economic Activity, Microeconomics, $67-119$.

Bernard, A. And B. Jensen, B. (1999). "Exceptional Exporter Performance: Cause, Effect or Both?," Journal of International Economics, 47(1): 1-25.

Bernard, A., Eaton, J., Jensen, B. And S. Kortum (2002). "Plants and Productivity in International Trade," American Economic Review, 93(4): 1268-1290.

Bernard, A., Jensen, B. And P. Schott (2006). "Survival of the Best Fit: Exposure to Low-wage Countries and the Uneven Growth of U.S. Manufacturing Plants," Journal of International Economics, 68(1): 219-237.

Bernard, A., Jensen, B., Redding, S. And P. Schott (2007). "Firms in International Trade," Journal of Economic Perspectives, 21(3): 105-130.

Bernard, A., Redding, S. And P. Schott (2010). "Multiple-Product Firms and Product Switching," American Economic Review, 100: 70-97.

Bernard, A., Redding, S. And P. Schott (2011). "Multi-product Firms and Trade Liberalization," Quarterly Journal of Economics, 126: 1271-1318.

Bloom, N., Draca, M. and J. Van Reenen (2015). "Trade Induced Technical Change? The Impact of Chinese Imports on Innovation, IT, and Productivity," Review of Economic Studies, 83: 87-117.

Brandt, L., Van Biesebroeck, J. And Y. Zhang (2012). "Creative Accounting or Creative Destruction? Firm-level Productivity Growth in Chinese Manufacturing," Journal of Development Economics, 97(2): 339-351.

Broda, C. And D. Weinstein (2006). "Globalization and the Gains from Variety," Quarterly Journal of Economics, 121(2): 541-85.

Broda, C. And J. Romalis (2008). "Inequality and Prices: Does China Benefit the 
Poor in America?," Working Paper.

Bustos, P. (2011). "Trade Liberalization, Exports, and Technology Upgrading: Evidence on the Impact of MERCOSUR on Argentinian Firms," American Economic Review, 101(1): 304-340.

Burstein, A. And J. Vogel (2017). "International Trade, Technology, and the Skill Premium," Journal of Political Economy, 125(5): 1356-1412.

Burstein, A., J. Cravino And J. Vogel (2013) (YYYY). "Importing Skill-Biased Technology," American Economic Journal: Macroeconomics, 5(2): 32-71.

Caliendo, L. And E. Rossi-Hansberg, E., (2012). "The Impact of Trade on Organization and Productivity," Quarterly Journal of Economics, 127(3): 1393-1467.

Caliendo, L., Monte, F., And E. Rossi-Hansberg, E., (2015). "The Anatomy of French Production Hierarchies," Journal of Political Economy, 123(4): 809-852.

Caliendo, L., Monte, F., And E. Rossi-Hansberg, E., (2017). "Exporting and Organizational Change," Working Paper.

Caliendo, L. Mion, G., Opromolla, L. and E. Rossi-Hansberg (2017) (2017). "Productivity and Organization in Portuguese Firms," NBER Working Paper No. 21811.

Caliendo, L., Dvorkin, M. And F. Parro (2018). "Trade and Labor Market Dynamics: General Equilibrium Analysis of the China Trade Shock," NBER Working Paper No. 21149.

Card, D. And T. Lemieux (2001). "Can Falling Supply Explain the Rising Return to College for Younger Men?," Quarterly Journal Economics, 116(2): 705-746.

Card, D., Heining, J. And P. Kline (2013). "Workplace Heterogeneity and the Rise of West German Wage Inequality," Quarterly Journal of Economics, 128(3): 967-1015.

Chen, C. (2017). "Management Quality and Firm Hierarchy in Industry Equilibrium," American Economic Journal: Microeconomics, 9(4): 203-244.

Chiquiar, D. (2008). "Globalization, regional wage differentials and the Stolper-Samuelson Theorem: Evidence from Mexico," Journal of International Economics, 74(1): 70-93.

Clerides, S., Lach, S. And J. Tybout (2000). "Is Learning by Exporting Important? Micro-Dynamic Evidence from Colombia, Mexico, and Morocco," Quarterly Journal of Economics, 113(3): 903-947.

Collard-Wexler, A. And J. De Loecker (2015). "Reallocation and Technology: Evidence from the US Steel Industry," American Economic Review, 105(1): 131-171.

Costinot y Vogel (2010). "Matching and Inequality in the World Economy," Journal of Political Economy, 118(4): 747-786.

Coşar, K., Guner, N. and J. Tybout (2016). "Firm Dynamics, Job Turnover, and Wage Distributions in an Open Economy," American Economic Review, 106(3): 625-663.

Dauth, W., Findeisen, S. And J. Suedekum (2014). "The Rise of the East and the Far East: German Labor Markets and Trade Integration," Journal of the European Economic Association, 12(6): 1643-1675.

Deaton, A. (1989). "Rice Prices and Income Distribution in Thailand: a Non-parametric Analysis," Economic Journal, 99: 1-37.

Deaton, A. And J. Malbauer (1980). "An Almost Ideal Demand System," American Economic Review, 70(3): 312-326.

De Loecker, J. (2007). "Do Exports Generate Higher Productivity? Evidence from 
Slovenia," Journal of International Economics, 73(1): 69-98.

De Loecker, J. (2013). "Detecting Learning by Exporting," American Economic Journal: Microeconomics, 5(3): 1-21.

De Loecker, J., Goldberg, P., Khandelwal, A. and N. Pavcnik (2016) . "Prices, Markups, and Trade Reform," Econometrica, 84: 445-510.

Dhingra, S. (2013). "Trading Away Wide Brands for Cheap Brands," American Economic Review, 103: 2554-2584.

Dhyne, E., Petrin, A., Smeets, V. And F. Warzynski (2017). "Multi Product Firms, Import Competition, and the Evolution of Firm-product Technical Efficiencies," NBER Working Papers 23637.

Dix-Carneiro, R. (2014). "Trade Liberalization and Labor Market Dynamics," Econometrica, 82(3): 825-885.

Dix-Carneiro, R. And B. KovaK (2017). "Trade Liberalization and Regional Dynamics," American Economic Review, 107(10): 2908-2946.

Dollar, D. (1992). "Outward-Oriented Developing Economies Really Do Grow More Rapidly: Evidence from 95 LDCs, 1976-1985," Economic Development and Cultural Change, 40(3): 523-544.

Eaton, J. And S. Kortum (2001). "Technology, Trade, and Growth: A Unified Framework," European Economic Review Papers and Proceedings, 45: 742-755.

Eaton, J. And S. Kortum (2002). "Technology, Geography, and Trade," Econometrica, 70(5): 1741-1779.

Ebenstein, A., Harrison, A., McMillan, M. and S. Phillips (2014). "Estimating the Impact of Trade and Offshoring on American Workers using the Current Population Surveys," Review of Economics and Statistics, 96(4): 581-595.

Eckel, C. Iacovone, L. Javorcik, B. And J. Neary (2015). "Multi-Product Firms at Home and Sway: Cost- versus Quality-Based Competence," Journal of International Economics, 95: 216-232.

Eckel, C. And P. NeARY (2010). "Multi-Product Firms and Flexible Manufacturing in the Global Economy," Review of Economic Studies, 77: 188-217.

EDwards, S. (1993). "Openness, Trade Liberalization, and Growth in Developing Countries," Journal of Economic Literature, 31(3): 1358-1393.

FABer, B. (2014). "Trade Liberalization, the Price of Quality, and Inequality: Evidence from Mexican Store Prices," Working Paper.

Fajgelbaum, P. And A. Khandelwal (2016). "Measuring the Unequal Gains from Trade," Quarterly Journal of Economics, 131(3): 1113-1180.

Feenstra, R. (1994). "New Product Varieties and the Measurement of International Prices," American Economic Review, 84(1): 157-177.

Feenstra, R. And G. Hanson (1996). "Globalization, Outsourcing, and Wage Inequality," American Economic Review, 86(2): 240-245.

Feenstra, R. And G. Hanson (1997). "Foreign Direct Investment and Relative Wages: Evidence from Mexico's Maquiladoras," Journal of International Economics, 42(3-4): 371-393.

Feenstra, R. And G. Hanson (1999). "The Impact of Outsourcing and High-Technology Capital on Wages: Estimates for the United States, 1979-1990," Quarterly Journal of Economics, 114(3): 907-940.

Feenstra, R. And G. Hanson (2003). "Global Production Sharing and Rising 
Inequality: A Survey of Trade and Wages," Handbook of International Trade, 1: 146-85.

Feenstra, R. And D. Weinstein (2017). "Globalization, Markups, and US Welfare," Journal of Political Economy, 125(4): 1040-1074.

Frankel, J. And D. Romer (1999). "Does Trade Cause Growth?," American Economic Review, 89(3): 379-399.

Friedrich, B. (2018). "Trade Shocks, Firm Hierarchies and Wage Inequality," Working paper.

Garicano, L. (2000). "Hierarchies and the Organization of Knowledge in Production," Journal of Political Economy, 108(5): 874-904.

Goldberg, P. AND N. PAVCNIK (2007). "Distributional Effects of Globalization in Developing Countries," Journal of Economic Literature, 16: 39-82.

Goldberg, P. And N. Pavcnik (2005). "Trade, Wages, and the Political Economy of Trade Protection: Evidence From the Colombian Trade Reforms," Journal of International Economics, 66(1): 75-105.

Goldberg, P., Khandelwal, A., Pavcnik, N. And P. Topalova (2010). "Imported Intermediate Inputs and Domestic Product Growth: Evidence from India," Quarterly Journal of Economics, 125(4): 1727-1767.

Grossman, G. And E. Rossi-Hansberg (2008). "Trading Tasks: A Simple Theory of Offshoring," American Economic Review, 98(5): 1978-1997.

Grossman, G. and E. Helpman (1991). "Quality Ladders in the Theory of Growth," Review of Economic Studies, 58(1): 43-61.

Grossman, G. And E. Helpman (1991). Innovation and Growth in the Global Economy, Cambridge, MIT Press.

Grossman, G. And E. Helpman (2007). "Fair Wages and Foreign Sourcing," Working Paper.

Grossman, G. And E. Rossi-Hansberg (2008). "Trading Tasks: A Simple Theory of Offshoring," American Economic Review, 98(5): 1978-1997.

HARrison, A. (1994). "Productivity, Imperfect Competition and Trade Reform," Journal of International Economics, 36: 53-73.

Mclaren, J., Harrison, A. And M. McMillan (2011). "Recent Findings on Trade and Inequality," Annual Reviews of Economics, 3: 261-289.

McLaren, J. (2017). "Globalization and Labor Market Dynamics," Annual Reviews of Economics, 9: 177-200.

Helpman, E., Itskhoki, O. And S. Redding (2010). "Inequality and Unemployment in a Global Economy," Econometrica, 78(4): 1239-1283.

Helpman, E., Itskhoki, O., Muendler, M. and S. Redding (2017). "Trade and Inequality: From Theory to Estimation ," Review of Economic Studies, 84(1): 357-405.

Holmes, T. And T. Schmitz (2010). "Competition and Productivity: A Review of Evidence," Annual Review of Economics, 2: 619-642.

Hsien, C. And R. Ossa (2016). "A Global View of Productivity Growth in China," Journal of International Economics, 102(C): 209-224.

Hsien, C. And P. Klenow (2009). "Misallocation and Manufacturing TFP in China and India,," Quarterly Journal of Economics, 124: 1403-1448.

Hummels, D., Ishit, J. AND K. Yi (2001). "The Nature and Growth of Vertical Specialization in World Trade," Journal of International Economics, 54(1): 75-96. 
Hummels, D., Jørgensen, R., Munch, J. And C. Xiang (2014). "The Wage Effects of Offshoring: Evidence from Danish Matched Worker-Firm Data," American Economic Review, 104(6): 1597-1629.

Katz, L. And D. Autor (1999). "Changes in the Wage Structure and Earnings Inequality," Handbook of Labor Economics, 3A: 1463-1555.

Katz, L. And K. Murphy (1992). "Changes in Relative Wages: Supply and Demand Factors," Quarterly Journal of Economics, 107: 35-78.

Khandelwal, A. (2010). "The Long and Short (of) Quality Ladders," Review of Economic Studies, 77(4): 1450-76.

Kovak, B. (2013). "Regional Efects of Trade Reform: What is the Correct Measure of Liberalization?," American Economic Review, 103(5): 1960-76.

Krishna, P. And P. Mitra (1998). "Trade Liberalization, Market Discipline and Productivity Growth: New Evidence from India," Journal of Development Economics, 56(2): 447-462.

Levinsohn, J. (1993). "Testing the Imports-As-Market-Discipline Hypothesis," Journal of International Economics, 35: 1-22.

Levinsohn, J. (1999). "Employment Responses to International Liberalization in Chile," Journal of International Economics, 47(2): 321-344.

Levinsohn, J. And A. Petrin (2003). "Estimating Production Functions Using Inputs to Control for Unobservables," Review of Economic Studies, 70(2): 317-341.

Lileeva, A. And D. Trefler (2010). "Improved Access to Foreign Markets Raises Plant-level Productivity for Some Plants," Quarterly Journal of Economics, 125(3): 1051-1099.

Lise, J. And J. Robin (2017). "The Macrodynamics of Sorting between Workers and Firms," American Economic Review, 107(4): 1104-1135.

LucAs, R. (1993). "Making a Miracle," Econometrica, 61(2): 251-272.

Machin, M. And J. VAn Reenen (1998). "Technology and Changes in Skill Structure: Evidence from Seven OECD Countries," Quarterly Journal of Economics, 113(4): 1215-1244.

Marschak, J. And J. Andrews (1944). "Random Simultaneous Equations and the Theory of Production," Econometrica, 12: 143-205.

Mayer, T., Melitz, M. and G. Ottaviano, (2014). "Market Size, Competition, and the Product Mix of Exporters," American Economic Review, 104: 495-536.

McLaren, J. (2017). "Globalization and Labor Market Dynamics," Annual Review of Economics, 9: 177-200.

Melitz, M. (2003). "The Impact of Trade on Intra-Industry Reallocations and Aggregate Industry Productivity," Econometrica,, 71(6): 1695-1725.

Melitz, M. And S. Redding (2014). "Missing Gains from Trade?," American Economic Review, 104(5): 317-321.

Muendler, M. (2017). "Trade, Technology, and Prosperity: An Account of Evidence from a Labor-market Perspective," World Trade Organization Staff Working Paper, 1-112.

Mueller, H., Oiumet, P. And E.Simintzi (2017). "Wage Inequality and Firm Growth," American Economic Review: Papers Proceedings, 107(5): 379-383.

Naughton, B. (1996). "China's Emergence and Prospects as a Trading Nation," Brookings Papers on Economic Activity, 2: 273-344. 
NEAL, D. (1995). "Industry-Specific Human Capital: Evidence from Displaced Workers," Journal of Labor Economics, 13(4): 653-177.

Neal, D. And S. Rosen (2000). "Theories of the Distribution of Earnings," Handbook of Income Distribution, Chapter 07, 1: 379-427.

OHNSORGe y TRefler (2007). "Sorting It Out: International Trade with Heterogeneous Workers," Journal of Political Economy, 115(5):868-892.

Olley, S. AND A. PAKes (1996). "The Dynamics of Productivity in the Telecommunications Equipment Industry," Econometrica,, 64(6): 1263-1298.

Ottaviano, G., Peri, G. and G. Wright (2013). "Immigration, Offshoring, and American Jobs," American Economic Review, 103(5): 1925-1959.

PArro (2013). "Capital-Skill Complementarity and the Skill Premium in a Quantitative Model of Trade," American Economic Journal: Macroeconomics, 5(2): 72-117.

PAVCNIK, N. (2002). "Trade Liberalization, Exit, and Productivity Improvements: Evidence from Chilean plants," Review of Economic Studies,, 69(1): 245-276.

Poletaev, M. and C. Robinson (2008). "Human Capital Specificity: Evidence from the Dictionary of Occupational Titles and Displaced Worker Surveys," Journal of Labor Economics, 26(3): 387-420.

Porto, G. (2006). "Using Survey Data to Assess the Distributional Effects of Trade Policy," Journal of International Economics, 70(1): 140-160.

Revenga, A. (1997). "Employment and Wage Effects of Trade Liberalization: The Case of Mexican Manufacturing," Journal of Labor Economics, 15(3): 20-43.

Rosen, S. (1982). "Authority, Control, and the Distribution of Earnings," JOURBell Journal of EconomicsNAL, 13(2): 311-323.

Rodriguez-Clare, A. (2010). "Offshoring in a Ricardian World," American Economic Journal: Macroeconomics, 2(2): 227-258.

Rodriguez, F. And D. Rodrik (2000). "Trade Policy and Economic Growth: A Skeptic's Guide to the Cross-National Evidence," NBER Macroeconomics Annual, 15: 261-338.

RoDrik, D. (2016). "Premature Deindustrialization," Journal of Economic Growth, 21: $1-33$.

Syverson, C. (2011). "What Determines Productivity?," Journal of Economic Literature, 49(2): 326-365.

Song, J., Price, D., Guvenen, F., Bloom, N. And T. von Watcher, (2017). "Firming Up Inequality," RR Quarterly Journal of Economics.

Spanos, G. (2016). "Firm Organization and Productivity Across Locations," RR Journal of Urban Economics.

Topalova, P. (2010). "Factor Immobility and Regional Impacts of Trade Liberalization: Evidence on Poverty from India ," American Economic Journal: Applied Economics, 2(4): $1-41$.

Topel, R. (1991). "Specific Capital, Mobility, and Wages: Wages Rise with Job Seniority," Journal of Political Economy, 99(1): 145-176.

Traiberman, S. (2018). "Occupations and Import Competition," Working Paper.

Trefler, D. (2004). "The Long and Short of the Canada-U.S. Free Trade Agreement," American Economic Review, 94(4): 870-95.

Tybout, J. And M. Westbrook (1995). "Trade Liberalization and the Dimensions 
of Efficiency Change in Mexican Manufacturing Industries," Journal of International Economics, 39: 53-78.

Utar, H. And L. Torres-Ruiz (2013). "International Competition and Industrial Evolution: Evidence from the Impact of Chinese Competition on Mexican Maquiladoras," Journal of Development Economics, 105: 267-287.

UtAR, H. (2018). "Workers Beneath the Floodgates: Impact of Low-Wage Import Competition and Workers' Adjustment," Review of Economics and Statistics, 100(4): 1-17.

Van Biesebroeck (2005). "Exporting Raises Productivity in Sub-Saharan African Manufacturing Firms," Journal of International Economics, 67(2): 373-391.

Verhoogen, E. (2008). "Trade, Quality Upgrading, and Wage Inequality in the Mexican Manufacturing Sector" Quarterly Journal of Economics, 123 (2): 489-530.

Wagner, J. (2007). "Exports and Productivity: A Survey of the Evidence from Firm-level Data," The World Economy, 60-82.

Yeaple, S. (2005). "A Simple Model of Firm Heterogeneity, International Trade, and Wages," Journal of International Economics, 65(1): 1-20.

YI, K. (2003). "Can Vertical Specialization Explain the Growth of World Trade?," Journal of Political Economy, 111(1): 52-102. 


\section{Apéndice}

\subsection{Cuadros}

CUADRO A1

Estimación de productividad

\begin{tabular}{lccc}
\hline \hline & MCO & ACF & ACF \\
& & Proxy $=$ materiales & Proxy = energía \\
\hline Log(trabajo) & $0.181^{* * *}$ & $0.061^{* * *}$ & $0.095^{* * *}$ \\
& $(0.005)$ & $(0.021)$ & $(0.025)$ \\
$\log$ (capital) & $0.068^{* * *}$ & $0.111^{* * *}$ & $0.099^{* * *}$ \\
& $(0.002)$ & $(0.006)$ & $(0.005)$ \\
Log(materiales) & $0.696^{* * *}$ & $0.553^{* * *}$ & $0.583^{* * *}$ \\
& $(0.004)$ & $(0.018)$ & $(0.019)$ \\
Log(energía) & $0.082^{* * *}$ & $0.028^{* * *}$ & $0.032^{* * *}$ \\
& $(0.003)$ & $(0.004)$ & $(0.004)$ \\
$N$ & & & 37,665 \\
R-cuadrado & 44,346 & 37,665 & \\
Firmas & 0.544 & & \\
\hline \hline
\end{tabular}

Notas. Ingresos es el log del total de ventas de productos manufacturados deflactadas con por undice de precios a nivel industria (INE). Trabajo es la cantidad de trabajadores por firma. Capital es la suma de terrenos, edificios, maquinarias y vehículos, deflactado por un índice anual nivel general (Banco Mundial). Materiales incluye materias primas y materiales y se deflacta con un índice de precios a nivel industria (INE). Energía es la electricidad consumida deflactada por un índice de precios de la electricidad (INE). La segunda etapa del método de ACF (cols. 2-3) se estima por MGM, instrumentando al trabajo con su rezago. Errores estándar robustos calculados por bootstrap $(\mathrm{n}=200)$. ${ }^{* * *} \mathrm{p}<0.01,{ }^{* *} \mathrm{p}<0.05,{ }^{*} \mathrm{p}<0.1$. 


\section{CUADRO A2}

Estimación de efectos sobre ingresos a nivel industria

\begin{tabular}{|c|c|c|c|c|c|}
\hline & \multirow{2}{*}{$\begin{array}{c}\mathrm{MCO} \\
(1) \\
\end{array}$} & \multicolumn{4}{|c|}{ MC2E } \\
\hline & & $(2)$ & $(3)$ & $(4)$ & $(5)$ \\
\hline PI China & $\begin{array}{c}-0.029^{* * *} \\
(0.005)\end{array}$ & $\begin{array}{c}-0.020^{* * *} \\
(0.007)\end{array}$ & $\begin{array}{c}-0.019^{* * *} \\
(0.007)\end{array}$ & $\begin{array}{c}-0.017^{* * *} \\
(0.006)\end{array}$ & $\begin{array}{c}-0.016^{* * *} \\
(0.006)\end{array}$ \\
\hline PI Otros países & $\begin{array}{c}-0.010^{* *} \\
(0.004)\end{array}$ & $\begin{array}{c}-0.010^{* *} \\
(0.004)\end{array}$ & $\begin{array}{c}-0.007^{*} \\
(0.004)\end{array}$ & $\begin{array}{c}-0.008^{* *} \\
(0.004)\end{array}$ & $\begin{array}{c}-0.008^{* *} \\
(0.004)\end{array}$ \\
\hline TFP promedio & & & $\begin{array}{c}0.618^{* * *} \\
(0.120)\end{array}$ & $\begin{array}{c}0.611^{* * *} \\
(0.109)\end{array}$ & $\begin{array}{c}0.570^{* * *} \\
(0.112)\end{array}$ \\
\hline Log(ratio K/L) promedic & & & & $\begin{array}{c}0.218^{* * *} \\
(0.065)\end{array}$ & $\begin{array}{c}0.203^{* * *} \\
(0.063)\end{array}$ \\
\hline Share importa & & & & & $\begin{array}{c}0.239 \\
(0.323)\end{array}$ \\
\hline Share exporta & & & & & $\begin{array}{c}0.331 \\
(0.210)\end{array}$ \\
\hline$N$ & 936 & 936 & 936 & 936 & 936 \\
\hline Industrias & 78 & 78 & 78 & 78 & 78 \\
\hline EF Año & SI & SI & SI & SI & SI \\
\hline EF Industria & SI & SI & SI & SI & SI \\
\hline
\end{tabular}

Notas. Regresiones del ingreso total (en logaritmos) de la industria en la PI China estimadas por MC2E. Ingresos por ventas de productos manufacturados se deflactan por un índice de precios a nivel industria elaborado por el INE. La PI China se instrumenta con el promedio de la participación de China en las importaciones de países de altos ingresos. Las industrias se definen a 4 dígitos de la clasificación ISIC Rev. 3. La PI de otros países de mide como el valor total de las importaciones provenientes del resto de los países (distintos de China) dividido por la absorción doméstica. TFP se estima siguiendo el método de Ackerberg, Caves y Frazer (2015). Share importa (exporta) es la proporción de firmas con exportaciones (importaciones) ¿0 en la industria. Las regiones se refieren a la primer división administrativa de Chile (15 regiones). Las Industrias se agrupan en 10 sectores amplios de manufacturas. Errores estándar robustos clusterizados por industrias. ${ }^{* * *} \mathrm{p}<0.01,{ }^{* *} \mathrm{p}<0.05,{ }^{*} \mathrm{p}<0.1$. 


\section{CUADRO A3}

Estimación de efectos sobre empleo a nivel industria

\begin{tabular}{|c|c|c|c|c|c|}
\hline & \multirow{2}{*}{$\begin{array}{c}\mathrm{MCO} \\
(1)\end{array}$} & \multicolumn{4}{|c|}{$\overline{\mathrm{MC} 2 \mathrm{E}}$} \\
\hline & & $(2)$ & $(3)$ & $(4)$ & $(5)$ \\
\hline PI China & $\begin{array}{c}-0.005^{* *} \\
(0.002)\end{array}$ & $\begin{array}{c}-0.006^{* *} \\
(0.003)\end{array}$ & $\begin{array}{c}-0.006^{* *} \\
(0.003)\end{array}$ & $\begin{array}{c}-0.006^{* *} \\
(0.003)\end{array}$ & $\begin{array}{c}-0.005^{*} \\
(0.003)\end{array}$ \\
\hline PI Otros países & $\begin{array}{l}-0.001 \\
(0.001)\end{array}$ & $\begin{array}{l}-0.001 \\
(0.001)\end{array}$ & $\begin{array}{l}-0.000 \\
(0.001)\end{array}$ & $\begin{array}{l}-0.000 \\
(0.001)\end{array}$ & $\begin{array}{l}-0.000 \\
(0.001)\end{array}$ \\
\hline TFP promedio & & & $\begin{array}{c}0.165^{* *} \\
(0.065)\end{array}$ & $\begin{array}{c}0.165^{* *} \\
(0.065)\end{array}$ & $\begin{array}{c}0.097 \\
(0.069)\end{array}$ \\
\hline $\log ($ ratio $\mathrm{K} / \mathrm{L})$ promedic & & & & $\begin{array}{c}0.018 \\
(0.019)\end{array}$ & $\begin{array}{l}-0.008 \\
(0.012)\end{array}$ \\
\hline Share importa & & & & & $\begin{array}{c}0.450^{* * *} \\
(0.121)\end{array}$ \\
\hline Share exporta & & & & & $\begin{array}{c}0.505^{* * *} \\
(0.166)\end{array}$ \\
\hline$N$ & 936 & 936 & 936 & 936 & 936 \\
\hline Industrias & 78 & 78 & 78 & 78 & 78 \\
\hline EF Año & SI & SI & SI & SI & SI \\
\hline EF Industria & SI & SI & SI & SI & SI \\
\hline
\end{tabular}

Notas. Regresiones del empleo total (en logaritmos) de la industria en la PI China estimadas por MC2E. La PI China se instrumenta con el promedio de la participación de China en las importaciones de países de altos ingresos. Las industrias se definen a 4 dígitos de la clasificación ISIC Rev. 3. La PI de otros países de mide como el valor total de las importaciones provenientes del resto de los países (distintos de China) dividido por la absorción doméstica. TFP se estima siguiendo el método de Ackerberg, Caves y Frazer (2015). Share importa (exporta) es la proporción de firmas con exportaciones (importaciones) ¿0 en la industria. Las regiones se refieren a la primer división administrativa de Chile (15 regiones). Las Industrias se agrupan en 10 sectores amplios de manufacturas. Errores estándar robustos clusterizados por industrias. ${ }^{* * *} \mathrm{p}<0.01,{ }^{* *} \mathrm{p}<0.05,{ }^{*} \mathrm{p}<0.1$. 


\section{CUADRO A4}

Estimación de efectos sobre cantidad de firmas a nivel industria

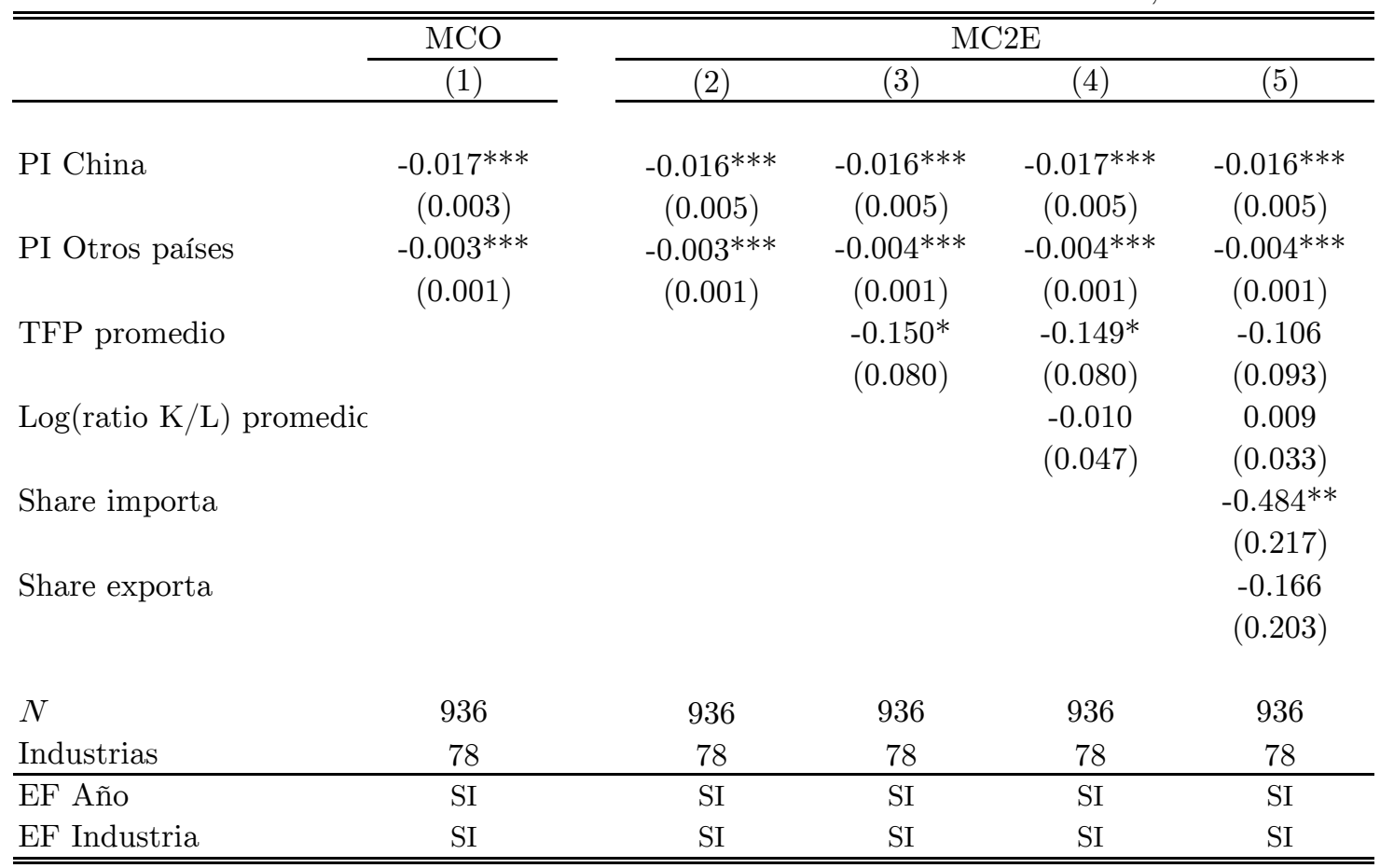

Notas. Regresiones de la cantidad total de firmas (en logaritmos) de la industria en la PI China estimadas por MC2E. La PI China se instrumenta con el promedio de la participación de China en las importaciones de países de altos ingresos. Las industrias se definen a 4 dígitos de la clasificación ISIC Rev. 3. La PI de otros países de mide como el valor total de las importaciones provenientes del resto de los países (distintos de China) dividido por la absorción doméstica. TFP se estima siguiendo el método de Ackerberg, Caves y Frazer (2015). Share importa (exporta) es la proporción de firmas con exportaciones (importaciones) ¿0 en la industria. Las regiones se refieren a la primer división administrativa de Chile (15 regiones). Las Industrias se agrupan en 10 sectores amplios de manufacturas. Errores estándar robustos clusterizados por industrias. $* * * \mathrm{p}<0.01,{ }^{* *} \mathrm{p}<0.05,{ }^{*} \mathrm{p}<0.1$. 


\section{CUADRO A5}

Robustez frente a eliminación de valores extremos

\begin{tabular}{|c|c|c|c|c|c|}
\hline & \multirow[b]{2}{*}{ Todas } & \multicolumn{4}{|c|}{ Eliminando $10 \%$ de valores extremos } \\
\hline & & PI China & Trabajadores & Ingresos & Ratio $\mathrm{K} / \mathrm{L}$ \\
\hline & $(1)$ & $(2)$ & $(3)$ & $(4)$ & $(5)$ \\
\hline \multicolumn{6}{|c|}{ Var. Dependiente: Log (empleo total) } \\
\hline IP China & $\begin{array}{c}-0.0089^{* *} \\
(0.0042)\end{array}$ & $\begin{array}{c}-0.0130 * * \\
(0.0054)\end{array}$ & $\begin{array}{c}-0.0051^{* *} \\
(0.0025)\end{array}$ & $\begin{array}{c}-0.0052^{*} \\
(0.0030)\end{array}$ & $\begin{array}{c}-0.0071^{* *} \\
(0.0035)\end{array}$ \\
\hline$N$ & 44,346 & 35,157 & 39,165 & 39,749 & 39,760 \\
\hline Firmas & 6,681 & 5,861 & 6,098 & 6,126 & 6,195 \\
\hline \multicolumn{6}{|c|}{ Var. Dependiente: Log (ingreso total) } \\
\hline IP China & $\begin{array}{c}-0.0187^{* *} \\
(0.0083)\end{array}$ & $\begin{array}{c}-0.0249 * * * \\
(0.0086)\end{array}$ & $\begin{array}{c}-0.0144^{* *} \\
(0.0067)\end{array}$ & $\begin{array}{c}-0.0119^{*} \\
(0.0062)\end{array}$ & $\begin{array}{c}-0.0160^{* *} \\
(0.0076)\end{array}$ \\
\hline$N$ & 44,346 & 35,157 & 39,165 & 39,749 & 39,760 \\
\hline Firmas & 6,681 & 5,861 & 6,098 & 6,126 & 6,195 \\
\hline \multicolumn{6}{|c|}{ Var. Dependiente: Probabilidad de salida (1996-2005) } \\
\hline IP China & $\begin{array}{c}0.0065^{* * *} \\
(0.0016)\end{array}$ & $\begin{array}{l}0.0079^{*} \\
(0.0041)\end{array}$ & $\begin{array}{c}0.0042^{* *} \\
(0.0018)\end{array}$ & $\begin{array}{c}0.0042^{* * *} \\
(0.0016)\end{array}$ & $\begin{array}{c}0.0055^{* * *} \\
(0.0016)\end{array}$ \\
\hline$N$ & 36,766 & 29,365 & 32,524 & 32,990 & 32,959 \\
\hline Firmas & 6,013 & 5,339 & 5,528 & 5,538 & 5,582 \\
\hline
\end{tabular}

Notas. Regresiones estimadas por el método de MC2E para muestras alternativas que eliminan los valores extremos al $10 \%$ de la distribución de algunas variables relevantes (columnas 2 a 5). La PI China se instrumenta con el promedio de la participación de las importaciones Chinas en el valor importado por año-industria a través de un grupo de países de altos ingresos. Todas las regresiones incluyen efectos fijos a nivel firma, sector-año, región-año y controlan por la penetración de importaciones de otros países, la productividad total de los factores, el ratio capital/trabajo y el estatus de importador/exportador. Por cuestiones de espacio no se reportan los coef. estimados para las variables de control. *** $\mathrm{p}<0.01$, ** $\mathrm{p}<0.05,{ }^{*} \mathrm{p}<0.1$. 


\section{CUADRO A6}

Robustez frente a variables instrumentales alternativas

\begin{tabular}{lcccc}
\hline \hline & Ingreso alto & OECD & Mercosur & América Latina \\
\cline { 2 - 5 } & $(1)$ & $(2)$ & $(3)$ & $(4)$ \\
\hline Var. Dependiente: Log (empleo total) & & & \\
IP China & $-0.0089^{* *}$ & $-0.0073^{* * *}$ & $-0.0047^{* * *}$ & $-0.0046^{* * *}$ \\
& $(0.0042)$ & $(0.0020)$ & $(0.0017)$ & $(0.0016)$ \\
$N$ & 44,346 & 44,346 & 44,346 & 44,346 \\
Firmas & 6,681 & 6,681 & 6,681 & 6,681 \\
\hline Var. Dependiente: Log (ingreso total) & & & \\
IP China & $-0.0187^{* *}$ & $-0.0169^{* *}$ & $-0.0097^{* * *}$ & $-0.0077^{* *}$ \\
& $(0.0083)$ & $(0.0074)$ & $(0.0037)$ & $(0.0033)$ \\
$N$ & 44,346 & 44,346 & 44,346 & 44,346 \\
Firmas & 6,681 & 6,681 & 6,681 & 6,681 \\
\hline Var. Dependiente: Probabilidad de salida (1996-2005) & & \\
IP China & $0.0065^{* * *}$ & $0.0077^{* * *}$ & $0.0046^{* *}$ & $0.0055^{* * *}$ \\
& $(0.0016)$ & $(0.0018)$ & $(0.0018)$ & $(0.0013)$ \\
$N$ & 36,766 & 36,766 & 36,766 & 36,766 \\
Firmas & 6,013 & 6,013 & 6,013 & 6,013 \\
\hline \hline
\end{tabular}

Notas. Regresiones estimadas por el método de MC2E. La PI China se instrumenta con el promedio de la participación de las importaciones Chinas en el valor importado por año-industria a través de distintos grupos de países (columnas). Todas las regresiones incluyen efectos fijos a nivel firma, sector-año, región-año y controlan por la penetración de importaciones de otros países, la productividad total de los factores, el ratio capital/trabajo y el estatus de importador/exportador. Por cuestiones de espacio no se reportan los coef. estimados para las variables de control. ${ }^{* * *} \mathrm{p}<0.01,{ }^{* *} \mathrm{p}<0.05,{ }^{*} \mathrm{p}<0.1$. 


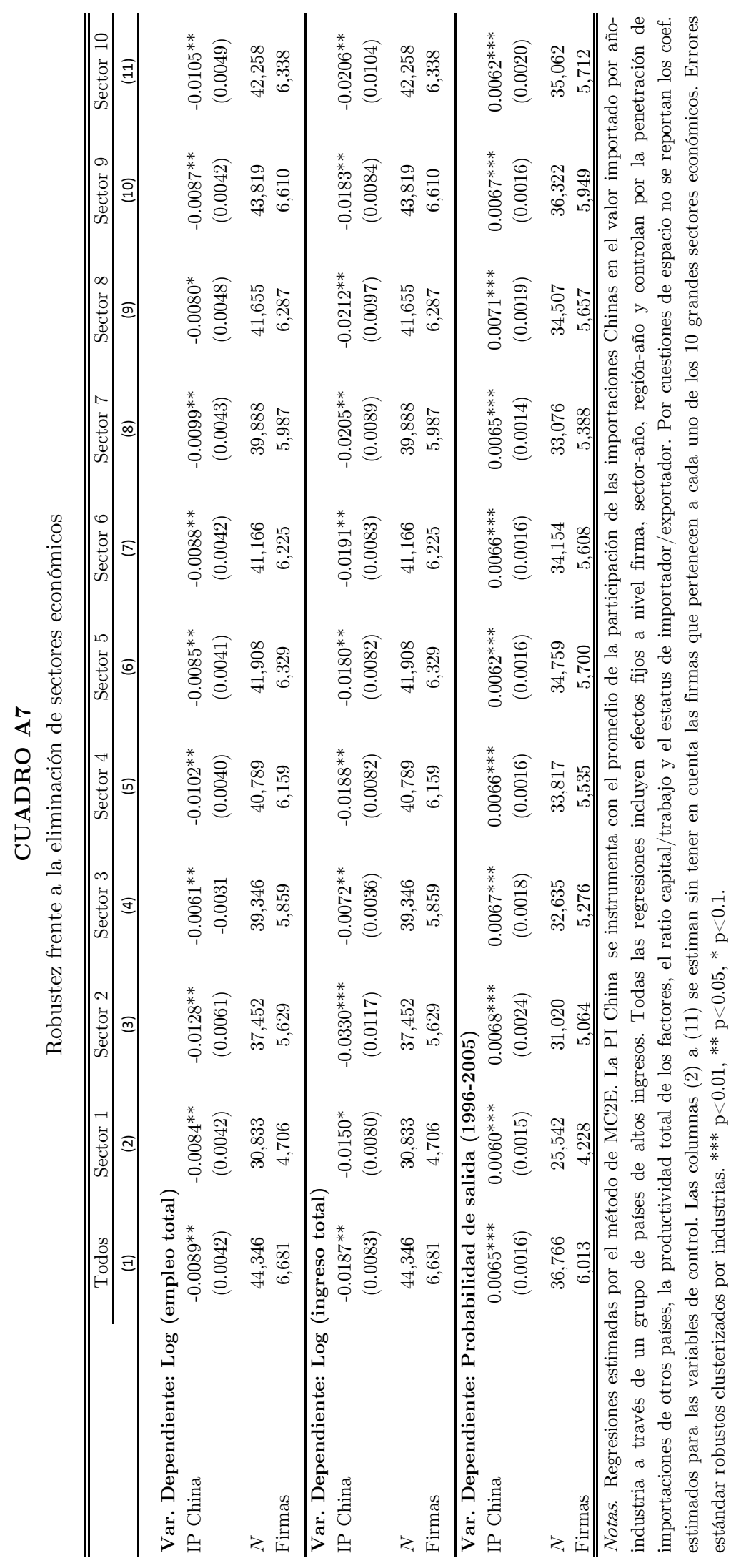




\section{CUADRO A8}

Robustez frente a la incorporación de otras variables de control

\begin{tabular}{|c|c|c|c|}
\hline & $\begin{array}{c}\text { Log ingreso } \\
\text { total } \\
(1) \\
\end{array}$ & $\begin{array}{c}\text { Log empleo } \\
\text { total } \\
(2) \\
\end{array}$ & $\begin{array}{c}\text { Probabilidad } \\
\text { de salida } \\
(3) \\
\end{array}$ \\
\hline IP China & $\begin{array}{c}0.0066^{* * *} \\
(0.0016)\end{array}$ & $\begin{array}{c}-0.0082^{* *} \\
(0.0041)\end{array}$ & $\begin{array}{c}-0.0183^{* *} \\
(0.0083)\end{array}$ \\
\hline IP Otros países & $\begin{array}{c}-0.0006^{* * *} \\
(0.0002)\end{array}$ & $\begin{array}{c}0.0001 \\
(0.0004)\end{array}$ & $\begin{array}{c}0.0001 \\
(0.0008)\end{array}$ \\
\hline TFP & $\begin{array}{c}-0.0576 * * * \\
(0.0072)\end{array}$ & $\begin{array}{c}0.0950^{* * *} \\
(0.0160)\end{array}$ & $\begin{array}{c}1.0440^{* * *} \\
(0.0254)\end{array}$ \\
\hline $\log ($ ratio K/L) & $\begin{array}{c}0.0076^{* *} \\
(0.0031)\end{array}$ & $\begin{array}{c}-0.0791^{* * *} \\
(0.0104)\end{array}$ & $\begin{array}{c}0.0959^{* * *} \\
(0.0054)\end{array}$ \\
\hline Importa & $\begin{array}{l}-0.0152^{*} \\
(0.0078)\end{array}$ & $\begin{array}{c}0.0441^{* * * *} \\
(0.0129)\end{array}$ & $\begin{array}{c}0.0413^{* * *} \\
(0.0158)\end{array}$ \\
\hline Exporta & $\begin{array}{c}-0.0158^{* *} \\
(0.0067)\end{array}$ & $\begin{array}{c}0.0756^{* * *} \\
(0.0125)\end{array}$ & $\begin{array}{c}0.0613^{* * *} \\
(0.0115)\end{array}$ \\
\hline Share mat. Importados & $\begin{array}{l}-0.0272 \\
(0.0336)\end{array}$ & $\begin{array}{c}0.0078 \\
(0.0370)\end{array}$ & $\begin{array}{c}0.4241^{* * *} \\
(0.0661)\end{array}$ \\
\hline Log(salario promedio) & $\begin{array}{c}-0.0132^{* * *} \\
(0.0034)\end{array}$ & $\begin{array}{c}-0.0965^{* * *} \\
(0.0167)\end{array}$ & $\begin{array}{c}0.0284^{* * *} \\
(0.0054)\end{array}$ \\
\hline Paros & $\begin{array}{c}0.0084 \\
(0.0054)\end{array}$ & $\begin{array}{l}-0.0030 \\
(0.0075)\end{array}$ & $\begin{array}{c}-0.0235^{* *} \\
(0.0097)\end{array}$ \\
\hline Participación export. & $\begin{array}{c}-0.0007 * * * \\
(0.0002)\end{array}$ & $\begin{array}{c}0.0012^{* *} \\
(0.0005)\end{array}$ & $\begin{array}{c}0.0028^{* * *} \\
(0.0007)\end{array}$ \\
\hline Extranjera & $\begin{array}{l}-0.0177 \\
(0.0128)\end{array}$ & $\begin{array}{l}-0.0162 \\
(0.0189)\end{array}$ & $\begin{array}{c}0.0268 \\
(0.0168)\end{array}$ \\
\hline $\begin{array}{l}N \\
\text { Firmas }\end{array}$ & $\begin{array}{c}44,346 \\
6,681\end{array}$ & $\begin{array}{c}44,346 \\
6,681\end{array}$ & $\begin{array}{c}36,766 \\
6,013\end{array}$ \\
\hline
\end{tabular}

Notas. Regresiones estimadas por el método de MC2E. La PI China se instrumenta con el promedio de la participación de las importaciones Chinas en el valor importado por año-industria a través de un grupo de países de altos ingresos. Todas las regresiones incluyen efectos fijos a nivel firma, sector-año y región-año. La variable binaria Paros vale 1 si los trabajadores de la firma realizaron un paro laboral al menos un día en el año. Participación exportaciones es el share de las exportaciones en las ventas totales de la firma. La variable binaria Extranjera vale 1 si la firma tiene participación de capital extranjera. ${ }^{* * *} \mathrm{p}<0.01,{ }^{* *}$ $\mathrm{p}<0.05,{ }^{*} \mathrm{p}<0.1$. 


\section{$9.2 \quad$ Figuras}

FIGURA A1

Estimación de efectos sobre ingresos por quintiles de productividad

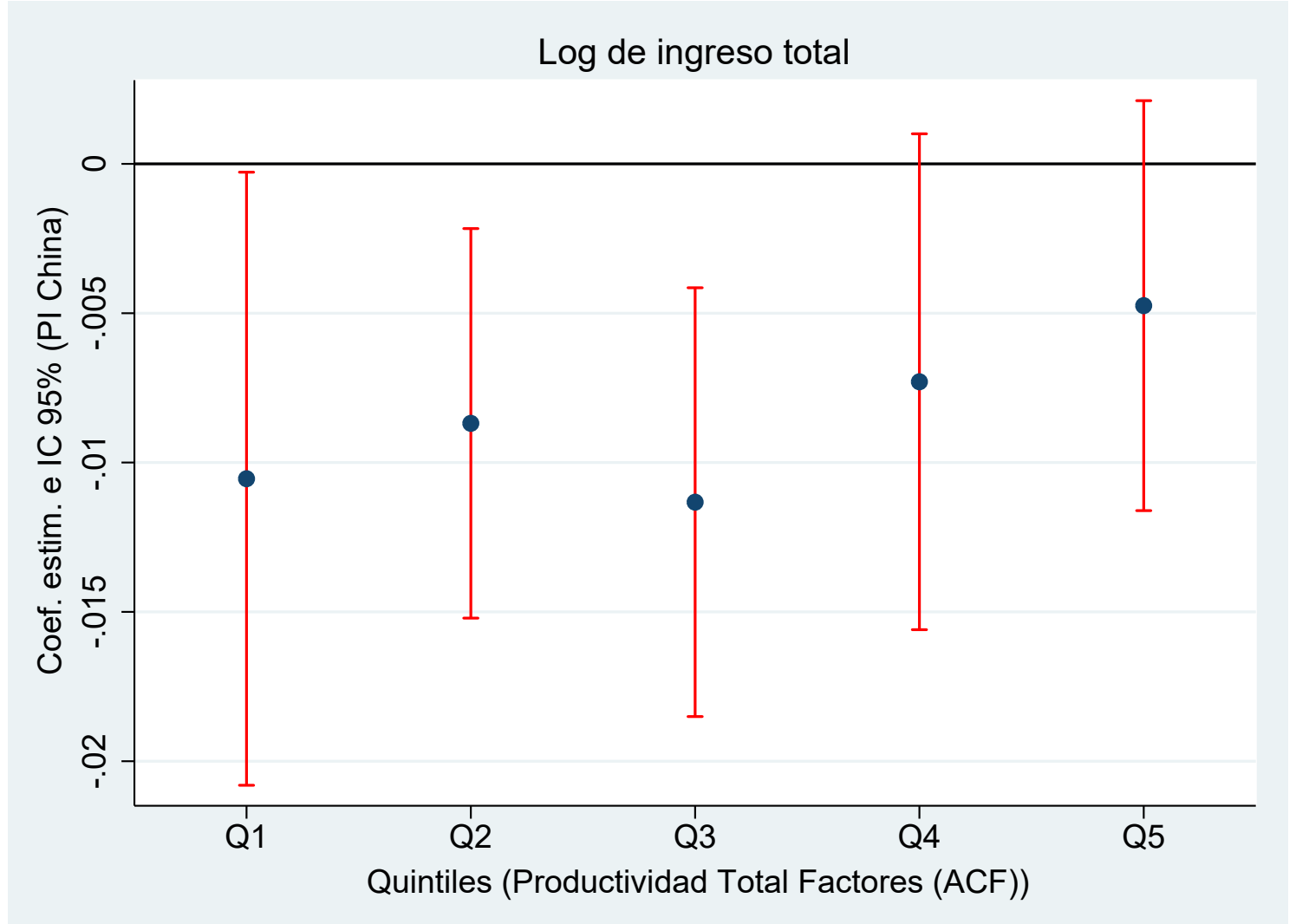

Notas. Coeficientes más IC al $95 \%$ de (cinco) regresiones del (log) ingreso de la firma en la PI China estimadas separadamente por quintiles de productividad. Los quintiles de la distribución de TFP se construyen separadamente para cada sector. Las regresiones incluyen variables de control a nivel firma (TFP, ratio K/L, importa/exporta) y efectos fijos por firma, año-región y año-sector. El vector de controles es el mismo que se utiliza en la columna (5) de los cuadros 5 a 7 . Errores estándar robustos clusterizados por industrias. $* * * \mathrm{p}<0.01, * * \mathrm{p}<0.05, * \mathrm{p}<0.1$. 
FIGURA A2

Estimación de efectos sobre empleo por quintiles de productividad

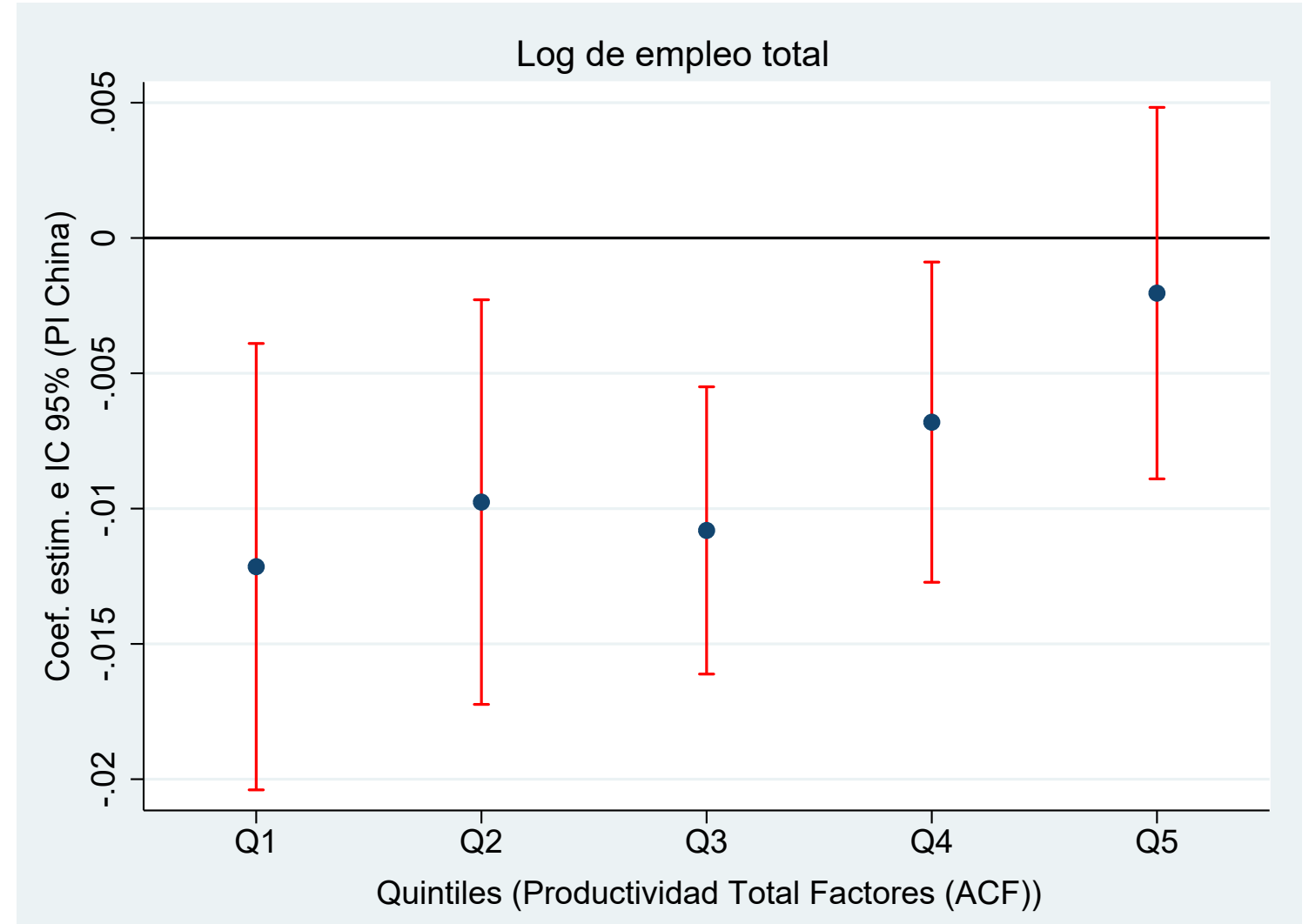

Notas. Coeficientes más IC al 95\% de (cinco) regresiones del (log) empleo de la firma en la PI China estimadas separadamente por quintiles de productividad. Los quintiles de la distribución de TFP se construyen separadamente para cada sector. Las regresiones incluyen variables de control a nivel firma (TFP, ratio K/L, importa/exporta) y efectos fijos por firma, año-región y año-sector. El vector de controles es el mismo que se utiliza en la columna (5) de los cuadros 5 a 7 . Errores estándar robustos clusterizados por industrias. ${ }^{* * *} \mathrm{p}<0.01,{ }^{* *} \mathrm{p}<0.05,{ }^{*} \mathrm{p}<0.1$. 


\section{FIGURA A3}

Estimación de efectos sobre probabilidad de salida por quintiles de productividad

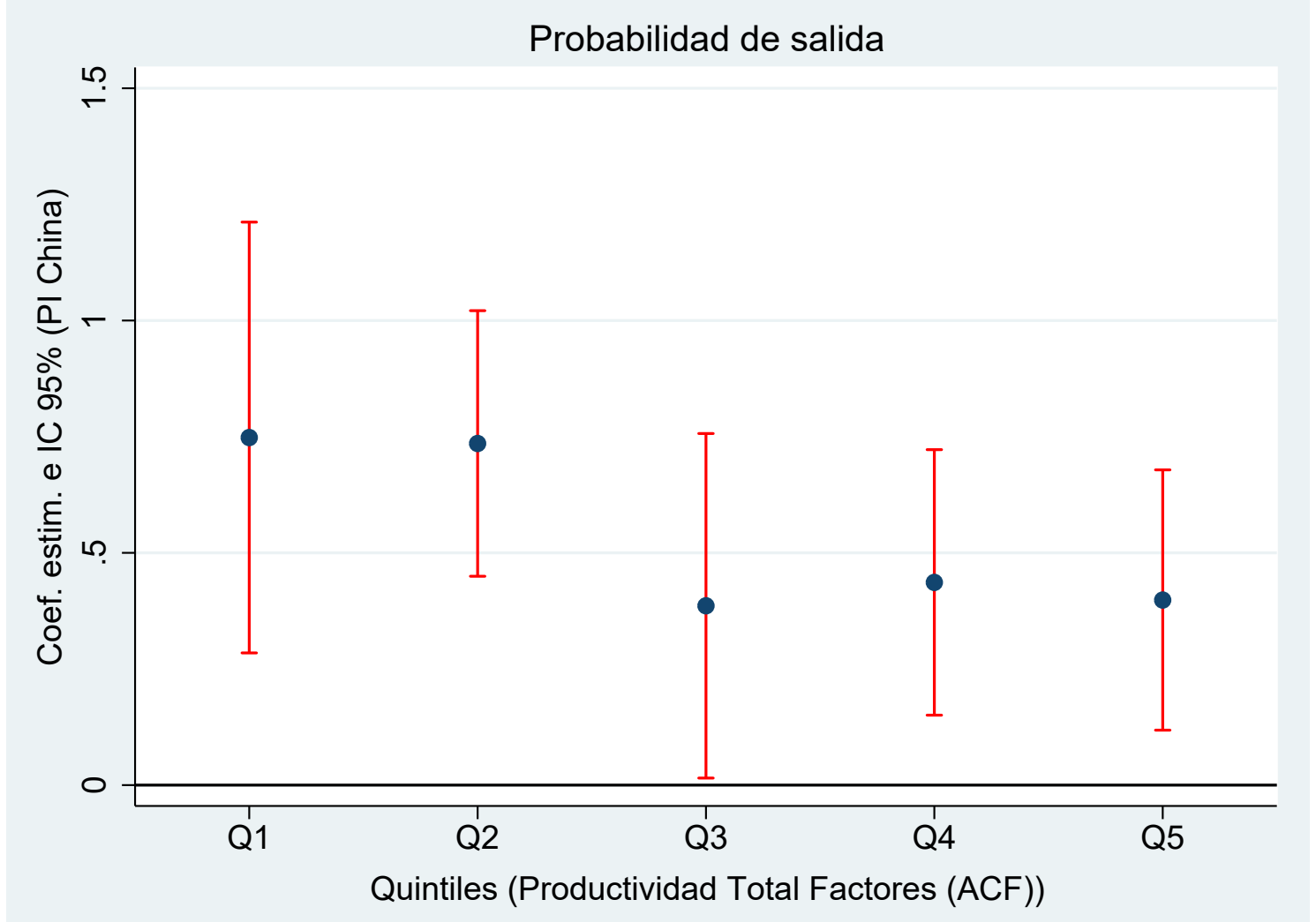

Notas. Coeficientes más IC al 95\% de (cinco) regresiones de la probabilidad de salida en la PI China estimadas separadamente por quintiles de productividad. Los quintiles de la distribución de TFP se construyen separadamente para cada sector. Las regresiones incluyen variables de control a nivel firma (TFP, ratio K/L, importa/exporta) y efectos fijos por firma, año-región y año-sector. El vector de controles es el mismo que se utiliza en la columna (5) de los cuadros 5 a 7 . Errores estándar robustos clusterizados por industrias. $* * * \mathrm{p}<0.01,{ }^{* *} \mathrm{p}<0.05, * \mathrm{p}<0.1$. 